University of Louisville

ThinkIR: The University of Louisville's Institutional Repository

Electronic Theses and Dissertations

$5-2020$

\title{
Electrochemical reduction of carbon dioxide and carbon monoxide for the production of green fuels and chemicals.
}

Jacob M. Strain

University of Louisville

Follow this and additional works at: https://ir.library.louisville.edu/etd

Part of the Analytical Chemistry Commons

\section{Recommended Citation}

Strain, Jacob M., "Electrochemical reduction of carbon dioxide and carbon monoxide for the production of green fuels and chemicals." (2020). Electronic Theses and Dissertations. Paper 3478.

https://doi.org/10.18297/etd/3478

This Doctoral Dissertation is brought to you for free and open access by ThinkIR: The University of Louisville's Institutional Repository. It has been accepted for inclusion in Electronic Theses and Dissertations by an authorized administrator of ThinkIR: The University of Louisville's Institutional Repository. This title appears here courtesy of the author, who has retained all other copyrights. For more information, please contact thinkir@louisville.edu. 
ELECTROCHEMICAL REDUCTION OF CARBON DIOXIDE AND CARBON MONOXIDE FOR THE PRODUCTION OF GREEN FUELS AND CHEMICALS

\author{
By: \\ Jacob M. Strain \\ A Dissertation \\ Submitted to the Faculty of the \\ College of Art and Sciences of the University of Louisville \\ in Partial Fulfillment of the Requirements for the Degree of
}

Doctor of Philosophy in Chemistry

Department of Chemistry

University of Louisville

Louisville, Kentucky

August 2020 
Copyright 2020 by Jacob M. Strain

All rights reserved 

ELECTROCHEMICAL REDUCTION OF CARBON DIOXIDE AND CARBON MONOXIDE FOR THE PRODUCTION OF GREEN FUELS AND CHEMICALS

By

Jacob M. Strain

A Dissertation Approved on

April 21, 2020

by the following Dissertation Committee:

Dissertation Director - Dr. Francis P. Zamborini

Dr. Joshua M. Spurgeon

Dr. Richard Baldwin

Dr. Farshid Ramezanipour 
"Observe constantly that all things take place by change, and accustom thyself to consider that the nature of the universe loves nothing so much as to change the things which are, and to make new things like them."

Marcus Antoninus Aurelius

This dissertation is dedicated to my wife and our baby boy. 


\section{ACKNOWLEDGEMENTS}

The person I would like to thank first and foremost is my advisor, Dr. Josh Spurgeon. His impeccable knowledge and understanding on solar fuels and electrochemistry is the reason why I have accomplished what I have. His attitude in the world of science is one I wish to embody, and I plan to emulate that attitude throughout my career.

I would like to thank Professor Mahendra Sunkara and the rest of the Conn Center for everything they have done.

Professor Francis Zamborini has given me much needed guidance throughout the $\mathrm{PhD}$ program and I am grateful for everything he has done. I would also like to thank my committee members Professor Farshid Ramezanipour and Professor Richard Baldwin.

I would like to especially thank everyone in all the research groups I have had the pleasure to work with including Professor Zamborini's research group, Professor Hemali Rathnayake's past research group at WKU, and the Solar Fuels research group (especially Sudesh Kumari, Saumya Gulati, and Sahar Pishgar). I would also like to show my gratitude towards the many friends and colleagues at University of Louisville: Alex Bates, Dr.

William "Hank" Paxton III, Abdeljaqer Jamhawi, Hamzeh Telfah, Caleb Calvary, Steve Cronin, Ram Hona, and everyone I taught alongside with.

I also would not have made it without the help of the many people from Western Kentucky University: Professor Hemali Rathnayake, Professor Moon-Soo Kim, Dr. Ananthakrishnan Soundaram Jeevarathinam, Dr. Jon Andersland, Professor Kinchel 
Doerner, Professor Di Wu, Professor Shivendra Sahi, Professor Nancy Rice, Professor Sigrid Jacobshagen, Mr. John Sorrell, Professor Chad Snyder, and especially Mr. Mark Clauson who helped me get my first job in a lab at WKU in 2007. All the research opportunities I had the privilege of pursuing at WKU inspired me to pursue my $\mathrm{PhD}$ and laid the groundwork for me to develop into the scientist that I have become.

I would also like to express gratitude to Erin, Brian, Kal, and Jane Crenshaw for helping me when I needed a place to lay my head during hard times. The many conversations I had with Brian and Erin were just what I needed during that time, as well as Kal and Jane's antics.

I would like to thank everyone in my family, especially my late father Michael Strain, my brother Travis Strain and my mother Wynn Strain. For everything they have done for me and put up with to get me to this point, I am eternally grateful.

Finally, I would like to thank the most important person in my life, Bonnie. The best thing that has ever happened to me in my life was meeting you. My journey in life has been beyond significantly enhanced with you by my side. Much of what I have achieved with this dissertation feels like it would not have been possible without you. And, I can simply not wait to see Cade's face! 


\title{
ABSTRACT \\ ELECTROCHEMICAL REDUCTION OF CARBON DIOXIDE AND CARBON MONOXIDE FOR THE PRODUCTION OF GREEN FUELS AND CHEMICALS
}

\author{
Jacob M. Strain
}

April 21, 2020

It has become apparent that closing the carbon cycle on this planet in order to mitigate disastrous consequences of runaway global warming has become one of the most pressing issues of our civilization. One of the ways we need to accomplish this goal is by finding news methods to generate fuels that will be carbon neutral. Renewable fuels and green chemicals will be a major component of closing the carbon cycle and restoring our planet's ecosystem into a sense of balance. A method that can help achieve this goal is the reduction of $\mathrm{CO}_{2}$. If $\mathrm{CO}_{2}$ can be a desirable reactant on a large enough scale to produce fuels and chemicals, many industries will greatly benefit from the implementation of $\mathrm{CO}_{2}$ reduction technologies. This would in turn make removing $\mathrm{CO}_{2}$ from the atmosphere a worthy and realistic endeavor while reducing the concentration of $\mathrm{CO}_{2}$ in the atmosphere. Reducing $\mathrm{CO}_{2}$ concentrations in the atmosphere will help mitigate global warming.

In the following dissertation, several methods are discussed that aid in the development of $\mathrm{CO}_{2}$ electroreduction. The goal of which is to improve the overall efficiency of current $\mathrm{CO}_{2}$ electroreduction technology. The first major effort assesses the contaminants emanating from the membrane component of the $\mathrm{CO}_{2}$ electroreduction 
device, alleviating the issue of spurious product detection. The second effort involves the tuning of product selectivity on oxide-derived copper catalyst by pulsing the bias. The third effort details the pursuit of a stand-alone "artificial leaf" technology for the reduction of carbon monoxide. The electrochemical investigations undertaken in this dissertation discuss in detail the metrics and principles used to accomplish these works. 


\section{TABLE OF CONTENTS}

Page

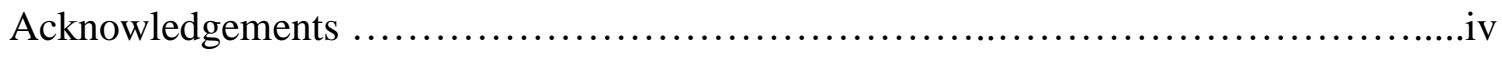

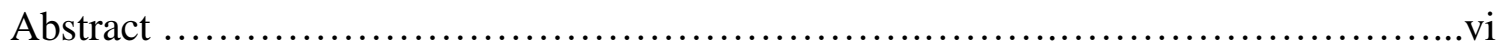

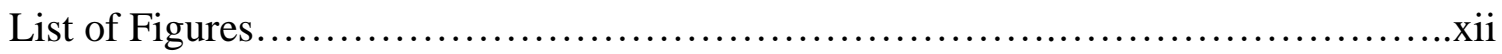

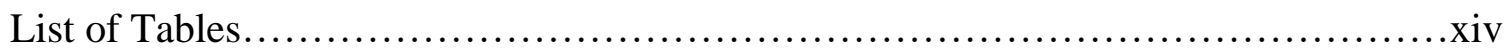

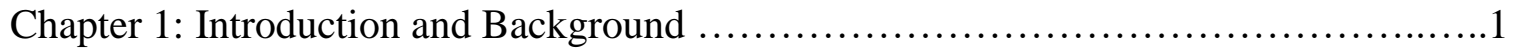

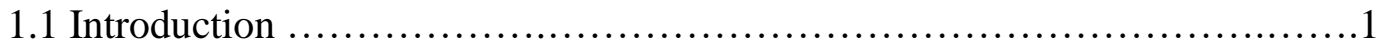

1.2 The Electrochemical Reaction......................................2

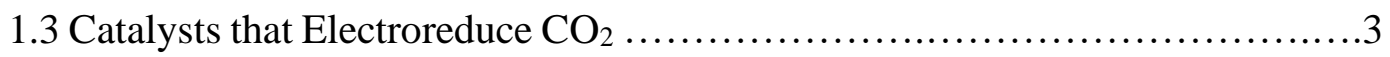

1.4 The Electroreduction of Carbon Monoxide ...............................5

1.5 The Electrochemical Cell...........................................6

1.6 Summary of Accomplishments.................................. 12

Chapter 2: Various Electrochemical Investigations............................. 14

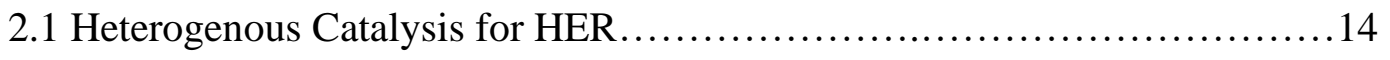

2.2 Homogenous Catalysis for HER ..................................... 19

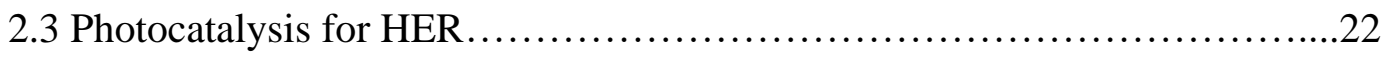

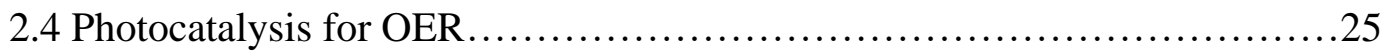

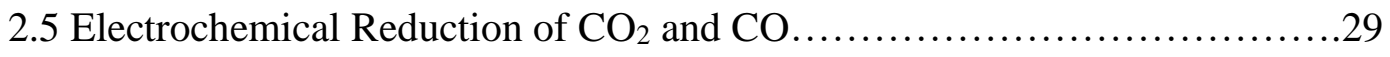

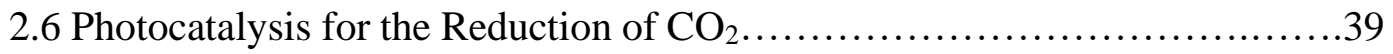


2.7 Isotopic labelling for the Reduction of $\mathrm{CO}_{2}$

Chapter 3: Assessing Contaminants from Ion-Exchange Membranes in the Evaluation of Aqueous Electrochemical Dioxide Reactions ....................................53



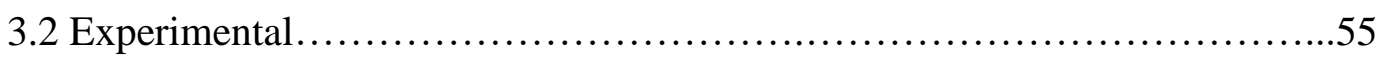

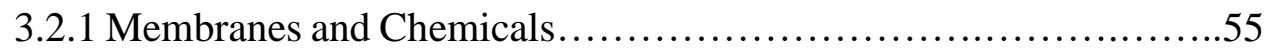

3.2.2 Electrochemical CO Reduction Measurement......................55

3.2.3 Product Detection.............................................56

3.2.4 Membrane Soak............................................57

3.3 Results and Discussion...............................................58

3.3.1 Membrane Contaminants.....................................58

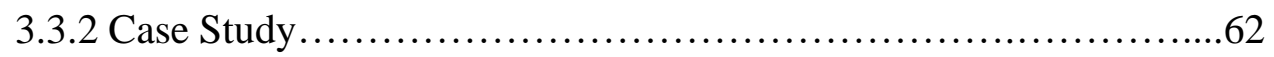

3.3.3 Secondary Confirmation via GC-MS ............................64

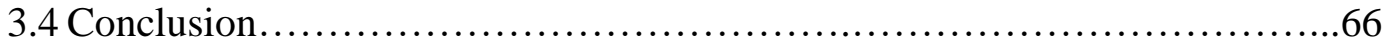

Chapter 4: Pulsed Electrochemical Carbon Monoxide Reduction on Oxide-Derived Copper

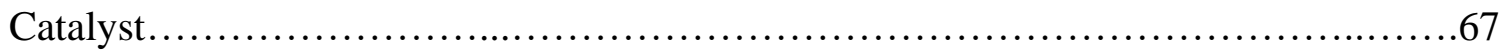

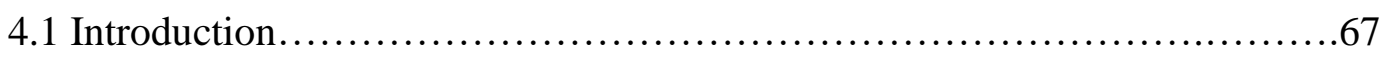

4.2 Results and Discussion..............................................69

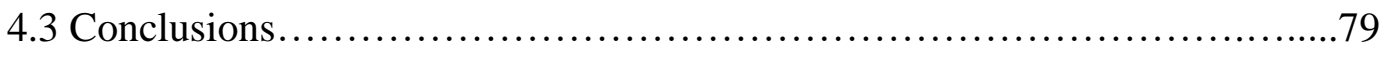

4.4 Experimental Section................................................... 80

4.4.1 Membranes and Chemicals..................................... 80

4.4.2 Electrode Fabrication....................................... 80

4.4.3 Electrochemical Measurements..................................81 
Chapter 5: Unassisted Photoelectrochemical Reduction of Carbon Monoxide with an Oxide-Derived Copper Dark Cathode and Titanium Dioxide $\mathrm{n}^{+} \mathrm{p}-\mathrm{Si}$ Tandem

Photoanode.................................................................. 84

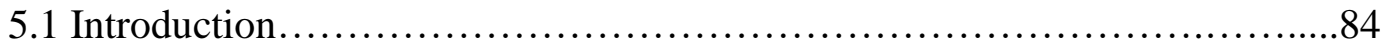

5.2 Experimental Section............................................ 85

5.2.1 Membranes and Chemicals...............................85

5.2.2 Electrode Fabrication........................................86

5.2.2a Tandem Photoanode.............................. 86

5.2.2b OD-Cu Dark Cathode..............................87

5.2.3 Photoelectrochemical Measurements............................88

5.2.4 Product Quantification....................................89

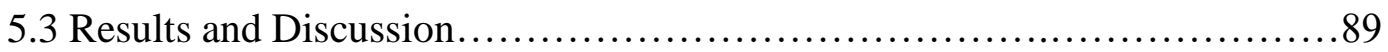

5.4 Conclusions....................................................97

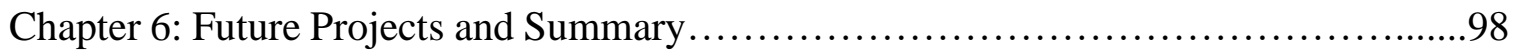

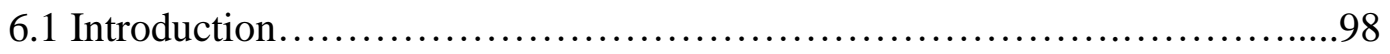

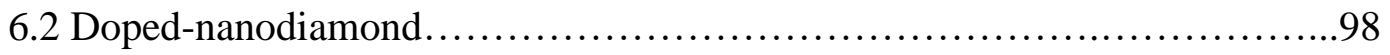

6.3 Bimetallic catalysts........................................... 100

6.4 Differential Photoelectrochemical Mass Spectroscopy.....................101

6.4.1 Introduction............................................. 101

6.4.2 Semiconductor/Cu Photocathode Fabrication....................104

6.4.3 DPEMS Experimental Setup............................... 105 


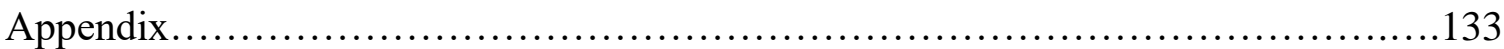

References............................................................. 149

Curriculum Vitae.............................................................. 172 


\section{LIST OF FIGURES}

1.1. Free energy diagram for the reduction of $\mathrm{CO}_{2}$ to $\mathrm{CH}_{4} \ldots \ldots \ldots \ldots \ldots \ldots \ldots \ldots \ldots \ldots \ldots \ldots \ldots \ldots \ldots$

1.2. Proposed reaction pathway for $\mathrm{C}_{2}$ and $\mathrm{C}_{3}$ products..........................

1.3. Experimental setup of the sealed standard three-electrode cell ..................6

2.1. Calibration curve for $\mathrm{H}_{2}$ gas constructed with standard gas mixtures...............17

2.2. Theoretical hydrogen, measured hydrogen, and FE for GC $1-3 \ldots \ldots \ldots \ldots \ldots \ldots . \ldots 18$

2.3. HER FE during the bulk electrolysis of 1 (a), 2 (b), 3 (c), and 4 (d) $\ldots \ldots \ldots \ldots \ldots \ldots . .22$

2.4. Faradaic Efficiency for PEC HER of NiATSM.................................

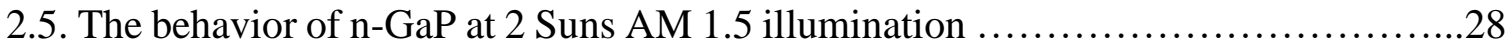

2.6. Characterization of gaseous oxygen in the reactor headspace. $\ldots \ldots \ldots \ldots \ldots \ldots \ldots \ldots \ldots .29$

2.7. XRD data for Ag-NC and OD-Cu catalyst .....................................

2.8. SEM images with insets of Ag-NC catalyst and OD-Cu catalyst...................36

2.9. Double layer capacitance measurements for $\mathrm{Ag}-\mathrm{NC}$ and $\mathrm{OD}-\mathrm{Cu}$ catalysts.............38

2.10. Current density vs. potential (J-E) behavior for Sn-pNW $\ldots \ldots \ldots \ldots \ldots \ldots \ldots \ldots \ldots .44$

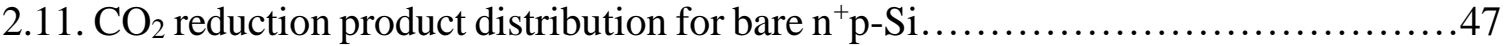

2.12. $\mathrm{CO}_{2}$ reduction product distribution for $\mathrm{n}^{+} \mathrm{p}-\mathrm{Si} / \mathrm{Sn}-\mathrm{pNW} \ldots \ldots \ldots \ldots \ldots \ldots \ldots \ldots \ldots . \ldots . \ldots . \ldots$

2.13. ${ }^{1} \mathrm{H}$ NMR of ${ }^{13} \mathrm{CO}_{2}$ reduction shows ${ }^{13} \mathrm{C}$-labelled formate......................52

3.1. Chemical structures of observed contaminants...............................59

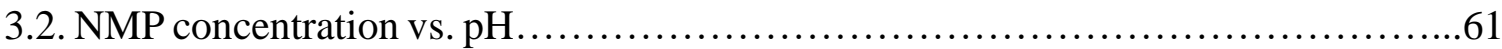




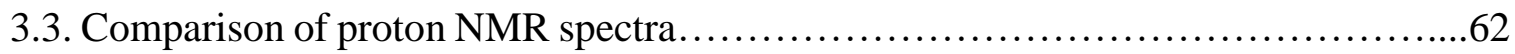

3.4. Characterization of CORR product with AMI-7001 membrane. H-H COSY and

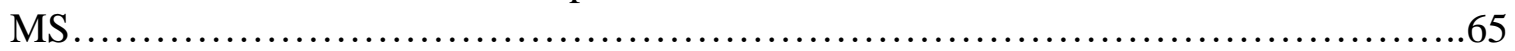

4.1. Product distribution for CORR on OD-Cu.................................... 71

4.2. Proposed reaction pathways for CORR on OD-Cu..............................72

4.3. Pulsed-bias waveform and example pulsed-bias current density response.............74

4.4. Product distribution vs. pulsing time .......................................... 76

5.1. Diagram of photoelectrochemical setup....................................99

5.2. J-V behavior of the PEC setup................................................. 91

5.3. Overlap CVs of OD-Cu and tandem..........................................

5.4. Trial 1: Chronoamperogram and $\mathrm{H}_{2} \mathrm{FE}$ for $19 \mathrm{~h}$ unassisted photoelectrolysis........92

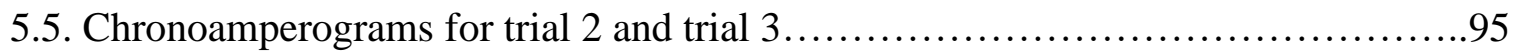

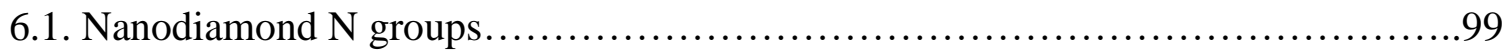

6.2. Cu nanoparticle with high density of grain boundaries..........................102

6.3. Comparison of conventional GC product quantification and DEMS results.........105

6.4. FE for products produced on Sn-porous nanowires................................105

6.5. Schematic of the DPEMS cell.............................................. 108

A.1-7. Membrane Soak NMR Spectra........................................... 135

A.8. Current density vs. potential behavior for OD-Cu.............................. 142

A.9. Production of formate detected with an OD-Cu electrode........................ 142

A.10. SEM images of the OD-Cu surface nanostructure. The scale bar is $500 \mathrm{~nm}$......145

A.11. SEM images of the OD-Cu surface nanostructure. The scale bar is $1 \mu \mathrm{m} . \ldots \ldots \ldots 146$

A.12. SEM images of the OD-Cu surface nanostructure. The scale bar is $10 \mu \mathrm{m} . \ldots \ldots . .146$

A.13. Double-layer capacitance measurements before and after pulsing...............147

A.14. The total charge passed only into the detected CORR products..................148 


\section{LIST OF TABLES}

3.1. The chemical shifts in $\mathrm{ppm}$ to the measured analytes.........................59

3.2. Concentrations of analytes measured in membrane soaks.......................60

3.3. Concentrations of analytes measured for pretreated membranes..................60

5.1. Faradaic Efficiencies and related data for the three trials of unassisted PEC CORR..94

5.2. Solar-to-fuel efficiency data based off of results listed in table 5.1 ................97

6.1. DND catalyst preliminary results ...................................... 100

A.1. Data for CORR on OD-Cu without pulsed-bias........................... 143

A.2. Double-layer capacitance data............................................147

A.3. Product distribution by charge $(\%)$ data................................. 148 


\section{CHAPTER 1}

\section{INTRODUCTION AND BACKGROUND}

\section{$1.1 \quad$ Introduction}

Greenhouse gas emission from anthropogenic sources has steadily increased the concentration of $\mathrm{CO}_{2}$ in the atmosphere and is predicted to continue rising unless large scale mitigation of $\mathrm{CO}_{2}$ emissions takes place. ${ }^{1-4}$ Increased concentrations of $\mathrm{CO}_{2}$ in the atmosphere also disturbs the normal carbon cycle, and allowing it to continue rising is a large-scale test of our understanding of the global ecosystem. ${ }^{5-7}$ Biological plants use $\mathrm{CO}_{2}$ as a fuel source in the process of photosynthesis providing oxygen as a by-product. This natural process is greatly affected by wanton use of fossil fuels and excessive removal of the natural habitats that make up our planet's lungs. ${ }^{8-10}$ Most of the world has agreed that this issue is of existential importance and the goals to mitigate this global warming crisis have been detailed in what is known at the Paris agreement. ${ }^{11-13}$ Many countries and organizations have taken up the responsibility to achieve the goals outlined in the Paris agreement in efforts to mitigate all climate change issues. ${ }^{14-20}$

There have been several research efforts focused on capturing or sequestering $\mathrm{CO}_{2} \cdot{ }^{21-23} \mathrm{CO}_{2}$ conversion and utilization has been massively explored in this past decade. $^{24-35}$ This involves many different strategies including biochemical, ${ }^{36-42}$ radiolysis, ${ }^{43-45}$ thermocatalysis, ${ }^{46-50}$ photocatalysis, ${ }^{51-56}$ electrocatalysis, ${ }^{57-63}$ and photoelectrochemical (PEC). ${ }^{64-67}$ One of the most promising strategies may be the PEC 
strategy due to the possible benefits from the standpoint of overall efficiency. ${ }^{68-76}$ PEC strategies mimic natural photosynthesis (ie. artificial photosynthesis). ${ }^{77-82}$

\subsection{The Electrochemical Reaction}

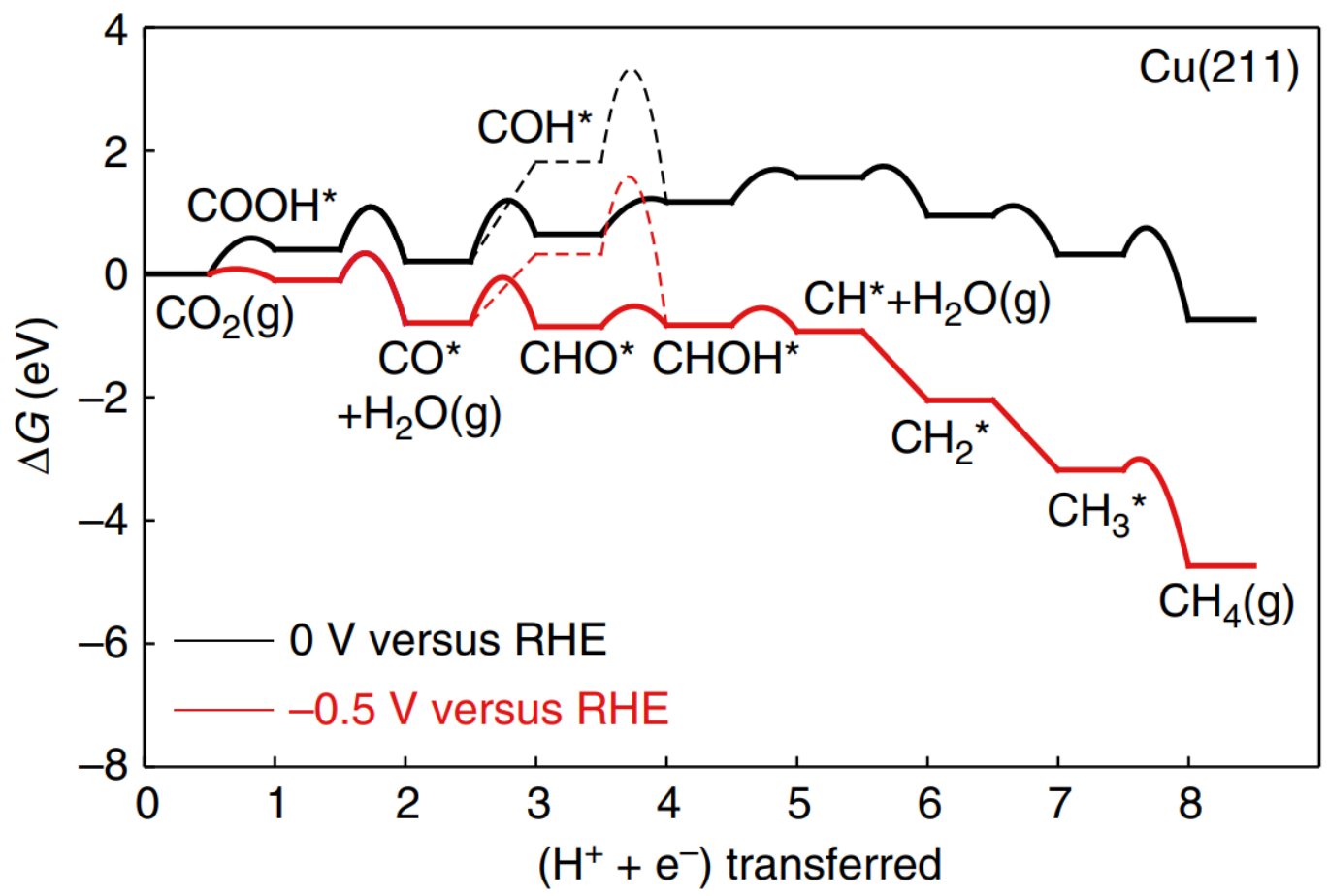

Figure 1.1 Free energy diagram for the reduction of $\mathrm{CO}_{2}$ to $\mathrm{CH} 4$ on $\mathrm{Cu}(211)$ at $0 \mathrm{~V}$ and $-0.5 \mathrm{~V}$ versus RHE. $^{85}$

$\mathrm{CO}_{2}$ is very thermodynamically stable due to its linearity and poor electron affinity. ${ }^{83} \mathrm{CO}_{2}$ is the most oxidized form of carbon and this makes $\mathrm{CO}_{2}$ notoriously hard to reduce. The $\mathrm{C}=\mathrm{O}$ bond has a dissociation energy of $750 \mathrm{~kJ} / \mathrm{mol} .{ }^{84}$ Because of this high bond strength, catalyst methods are required to reduce $\mathrm{CO}_{2}$. Many chemical reactions with $\mathrm{CO}_{2}$ can reduce the molecule but are relatively energetically inefficient in comparison to the room temperature electroreduction with a catalyst. Figure 1.1 contains a free energy diagram of an example of the reduction of $\mathrm{CO}_{2}$ to methane where $\mathrm{Cu}(211)$ serves as the catalyst. The energy path represented in black is representative of the steps that are required to be taken when there is no applied bias ( $0 \mathrm{~V}$ vs. RHE). The red energy path 
represents the steps it takes for the reaction to be completed once applied bias is used (-0.5 V vs RHE). Eight steps are required to get from $\mathrm{CO}_{2}$ to methane. All eight of these protoncoupled electron transfer (PCET) steps each have their own optimal conditions that stabilize each step and its respective intermediate. Because of these specific conditions each step has its own value of Gibb's free energy, causing several reaction steps to be uphill in energy. This concept is known as scaling relations. ${ }^{85}$ The scaling relations of a reaction causes multistep reactions to inherently become more difficult to accomplish in comparison to reactions that only take a couple of steps, like that of $\mathrm{CO}_{2}$ to $\mathrm{CO}$ taking only two PCET steps versus twelve step to get from $\mathrm{CO}_{2}$ to ethanol. Without any applied bias the reaction will not proceed forward if enough reaction steps are uphill in energy. With an applied bias, each of these reaction steps undergoes a drop in the required Gibb's free energy which results in these steps becoming downhill in energy, which then allows the reaction to proceed more efficiently. This is known as an electrochemical reaction instead of a purely chemical reaction. The ability to break the scaling relations to allow these electrochemical reactions to proceed is the main concern for the current research in the field of $\mathrm{CO}_{2}$ reduction to value-added products. Tuning the reaction system to make each step optimal will allow the electrochemical reduction of $\mathrm{CO}_{2}$ to higher order carbon chain products and maybe one day even fuels such as gasoline.

\subsection{Catalysts that Electroreduce $\mathrm{CO}_{2}$}

Many different catalysts allow for the electroreduction of $\mathrm{CO}_{2}$. There are three main categories of metal catalysts that can achieve efficient $\mathrm{CO}_{2}$ electroreduction. The first category of catalysts achieves the production of carbon monoxide (CO) which follows this half-reaction equation: 


$$
\mathrm{CO}_{2}+2\left(\mathrm{H}^{+}+\mathrm{e}^{-}\right) \rightarrow \mathrm{CO}+\mathrm{H}_{2} \mathrm{O}
$$

The main metal catalysts that are known to complete this reaction are $\mathrm{Au}^{86}$ and Ag. ${ }^{87,88}$ The second category of catalyst achieves the production of formic acid (FA) which follows this half-reaction equation:

$$
\mathrm{CO}_{2}+2\left(\mathrm{H}^{+}+\mathrm{e}^{-}\right) \rightarrow \mathrm{HCOOH}
$$

The catalysts known to complete this electrochemical reaction are $\mathrm{Sn}, \mathrm{Bi}, \mathrm{Pb}, \mathrm{In} .{ }^{89}$ The third category belongs to a single metal, $\mathrm{Cu}$. Many different hydrocarbon products are available due to the excellent activity of $\mathrm{Cu}$. These reactions proceed through the general half-reaction:

$$
\mathrm{mCO}_{2}+\mathrm{n}\left(\mathrm{H}^{+}+\mathrm{e}^{-}\right) \rightarrow \mathrm{C}_{\mathrm{x}} \mathrm{H}_{\mathrm{y}} \mathrm{O}_{\mathrm{z}}+\mathrm{oH}_{2} \mathrm{O}
$$

Because $\mathrm{Cu}$ can reduce $\mathrm{CO}_{\underline{\underline{2}}}$ to many different products (Figure 1.2) many more intermediates and therefore more electrochemical steps are required. ${ }^{90,91}$ This presents a challenge for selectivity in the $\mathrm{Cu}$ catalyst systems. Other catalysts that are worth noting

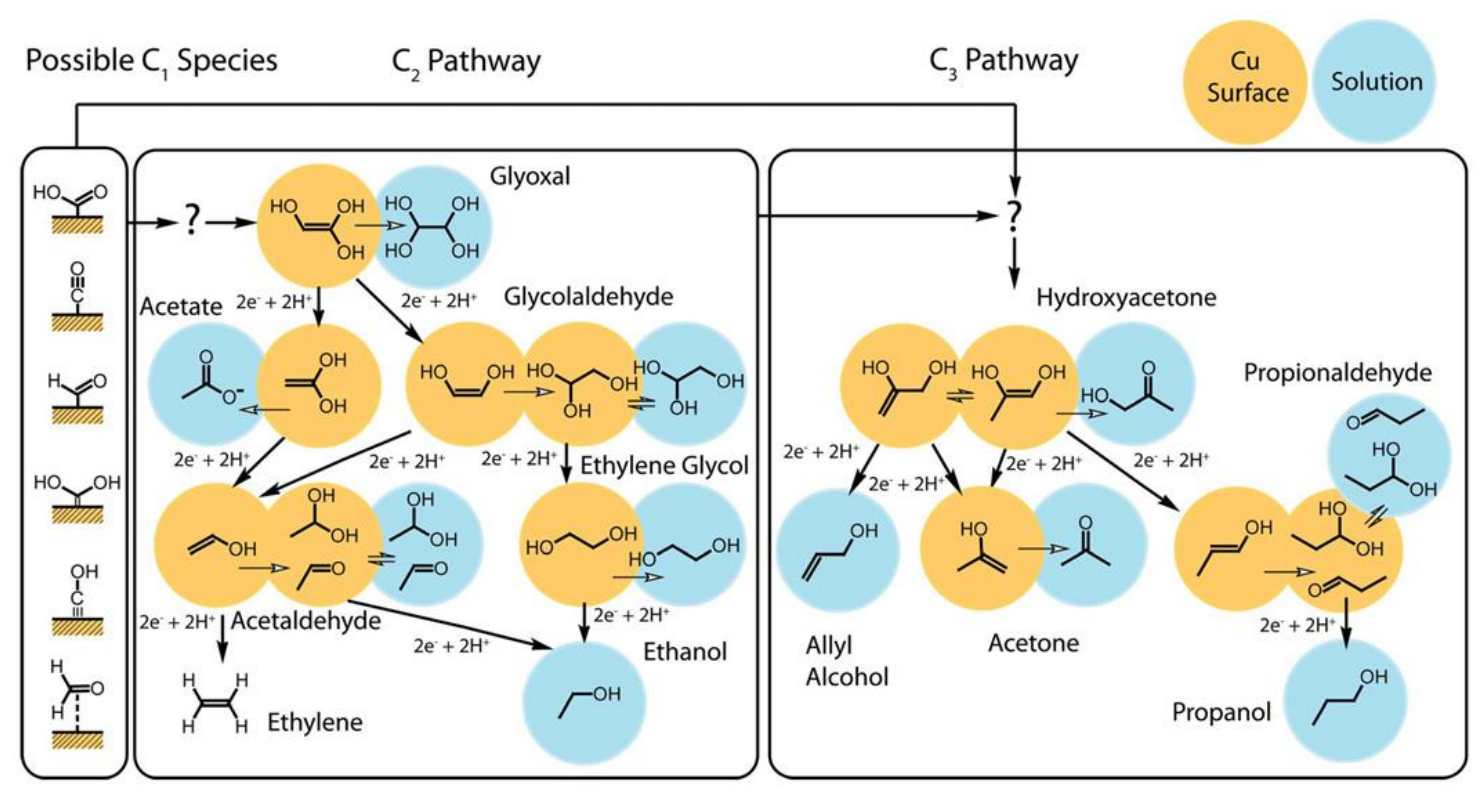

Figure 1.2 Proposed reaction pathway for $\mathrm{C}_{2}$ and $\mathrm{C}_{3}$ products. ${ }^{91}$ 
are $\mathrm{Ni}_{2} \mathrm{P}^{92}$ and $\mathrm{MoS}_{2}{ }^{93}$, which have been shown to produce 2,3-furandiol and $t$-butanol respectively.

\subsection{The Electroreduction of Carbon Monoxide}

There has been a lot of progress on the electroreduction of $\mathrm{CO}_{2}$ to $\mathrm{CO} .^{86,88}$ One remarkable study achieved near $100 \%$ selectivity for CO with the use of ionic liquids. ${ }^{87}$ With this progress in the field of $\mathrm{CO}_{2}$ electroreduction, some research focus has shifted to the intermediate product CO and its electroreduction. ${ }^{94}$ In $2014 \mathrm{Li}$ et al. was able to achieve a high selectivity of over $40 \%$ for ethanol in the CO reduction reaction (CORR) on oxidederived copper (OD-Cu). ${ }^{95}$ This high selectivity for $\mathrm{C}_{2+}$ products is possible due to the high density of grain boundaries inherent in the highly nanostructured catalyst such as ODCu. ${ }^{96}$ This revelation inspired many other research groups that high selectivity for valueadded products from $\mathrm{CO}$ as the main reactant would be a high possibility. Recent work in the Sargent research group has fine-tuned the catalyst to greatly increase the selectivity for $\mathrm{C}_{3}$ products from CORR such as n-propanol. ${ }^{97-99}$ In the Jaramillo group other major accomplishments have been achieved such as understanding the effect $\mathrm{pH}$ has on selectivity for CORR on $\mathrm{Cu},{ }^{94}$ nearly eliminating the competitive hydrogen evolution reaction (HER) with a nanoflower nanostructured $\mathrm{Cu}$ catalyst, ${ }^{100}$ and using that same nanostructure method with bimetallic $\mathrm{CuAg}$ to achieve near $100 \%$ selectivity at very low overpotential for one product: acetaldehyde. ${ }^{101}$ 


\subsection{The Electrochemical Cell}

The fundamental piece of equipment that makes $\mathrm{CO}_{2}$ electroreduction possible is the electrolyzer. The electrolyzer is basically an upgraded electrochemical cell that is specifically engineered to overcome fundamental limits a typical electrochemical cell possesses. In this section the electrochemical cell will be described as well as the limits that the electrochemical cell possesses and the metrics that determine the performance of the cell.

In the typical electrochemical cell, there are at least two electrodes. Between these two electrodes an overall chemical reaction takes place in the cell. This overall chemical reaction is made of two individual half-reactions. Each of these half-reactions involve a reduction or oxidation event where the electrons are supplied or taken away by the



Figure 1.3 Experimental setup of the sealed standard three-electrode cell for reference electrode calibration. Pt foil was used as both the working and counter electrodes, and the electrolyte was saturated with high-purity hydrogen. ${ }^{103}$ 
electrode. The half-reaction one studies occurs at the working electrode (WE). The second electrode is the counter electrode (CE), which in a two-electrode setup functions also as the reference electrode (RE). These two electrodes are connected by a supporting electrolyte which allows the travel of ions between the two electrodes. In a three-electrode setup, a purpose-built RE is used as the third electrode, which can be seen in Figure 1.3. The RE consists of phases having essentially a constant composition that is unperturbed by the overall chemical reaction taking place between the other two electrodes. Since the halfreaction is "standard" at the RE, the behavior of the WE is then always in respect to the RE. This way the behavior of the half-reaction on the WE can be easily compared to other systems. In most of the systems presented in this dissertation, a three-electrode system is used. In this three-electrode system, the CE's potential is driven by the potentiostat to maintain the desired voltage between the WE and RE. The CE typically consists of an electrochemically inert material to act as the opposing cathode or anode of the electrochemical cell. Often, a Pt electrode is used as the CE. This setup allows the measurement of the dependent variable of current during a potentiostatic electrochemical experiment. The reason for this three-electrode setup is to have the ability to report the currents and potentials to an internationally recognized standard via the RE. The RE is designed a certain way to not drive potential in one direction or another and any exchange of charge by the RE is negligible. The $\mathrm{CE}$ responds to the signal from the RE in order to maintain constant voltage conditions at the WE. This way, more information can be extracted about the half-reaction of interest occurring at the WE.

The cell potential is the metric in which the behavior of an electrochemical reaction is judged. The potential describes how much electromotive force it takes to drive current. 
Cell potential, $E$, is measured in volts $(V)$, where $1 V=1 \mathrm{Joule} /$ Coulomb $(\mathrm{J} / \mathrm{C})$. This is the measure of how much energy is required to allow the electrochemical reaction to proceed forward. This cell potential produces a current. Current is the measure of the flow of ions in the electrochemical cell. Current is expressed as $i$ and measured in amperes (A). It is also typically expressed in respect to the geometric area of the electrode in which the electrons flow, which is denoted as current density, $J$. When an electrochemical cell is driven to more negative potential, it is said that reductive conditions are produced at the WE. Vice-versa, when a cell is driven to more positive potential, it is said that oxidative conditions are produced. The production of $i-E$ or $J-E$ curves elucidate the behavior of the half-reactions taking place in the electrochemical cell. These current-potential curves are what is used in most electrochemical investigations, which are used to understand the behavior of an electrochemical system. The measurements of current and potential form the basis for the investigations presented in this dissertation. Knowing where and why electrons go where they go and at how much potential gives us a lot of information on the behavior of an electrochemical system.

The internationally recognized primary reference is the standard hydrogen electrode (SHE), sometimes also called the normal hydrogen electrode (NHE) (technically there is a small difference). SHE/NHE represents referenced potentials independent of the $\mathrm{pH}$ of the electrolyte solution. The real hydrogen electrode (RHE) represents referenced potentials with respect to the $\mathrm{pH}$ of the electrolyte solution.

In the course of common electrochemical investigations, three RE's are typically utilized. ${ }^{102}$ The saturated calomel electrode (SCE) consists of $\mathrm{Hg} / \mathrm{Hg}_{2} \mathrm{Cl}_{2}$, which is suited for acidic solutions. The $\mathrm{Hg} / \mathrm{HgO} \mathrm{RE}$ is typically used for alkaline solutions. The silver- 
silver chloride $(\mathrm{Ag} / \mathrm{AgCl}) \mathrm{RE}$ is the most commonly used $\mathrm{RE}$ works best in neutral solutions and is the primary RE used throughout the work presented in this dissertation. The $\mathrm{Ag} / \mathrm{AgCl} \mathrm{RE}$ consists of a glass tube with a porous glass frit on the end. The tube typically contains a $\mathrm{KCl}$ solution which is in a constant state of equilibrium with a $\mathrm{Ag}$ wire. When this $\mathrm{Ag} / \mathrm{AgCl} \mathrm{RE}$ can maintain its constant phases, the potential of the cell can be adequately referenced. The potential in respect to RHE for these three RE's are calculated according to the Nernst equations in the following fashion:

$$
\begin{gathered}
V_{R H E}=V_{A g / A g C l}+0.210 \mathrm{~V}+0.059 * p H \text { for } 3.0 \mathrm{M} \mathrm{KCl} \\
V_{R H E}=V_{S C E}+0.241 \mathrm{~V}+0.059 * p H \text { for saturated } \mathrm{KCl} \\
V_{R H E}=V_{H g / H g O}+0.165 \mathrm{~V}+0.059 * p H \text { for } 0.1 \mathrm{M} \mathrm{NaOH}
\end{gathered}
$$

where $V_{A g / A g C l}$ is the voltage measured in the experimental cell, $p H$ is the $\mathrm{pH}$ of the electrolyte solution that the RE is in physical contact with. The value of $0.210 / 0.241 / 0.165$ $\mathrm{V}$ comes from the referenced potential versus a $\mathrm{H}_{2}$ saturated $\mathrm{Pt}$ electrode, which in practice can be easily set-up in lab according to Figure 1.3. ${ }^{102}$ This value is sometimes $0.210 \mathrm{~V}$ when a solution of $3 \mathrm{M} \mathrm{KCl}$ is used. The value 0.059 comes from a component of the Nernst equation which is simplified from:

$$
0.059=\frac{2.303 R T}{F}
$$

where $R$ is the molar gas constant $8.31447 \mathrm{~J} \mathrm{~mol}^{-1} \mathrm{~K}^{-1}, T\left({ }^{\circ} \mathrm{C}\right)$ is the temperature which is commonly $25^{\circ} \mathrm{C}$, and $\mathrm{F}$ is Faraday's constant $96,485 \mathrm{C}$.

Since we have this system to report the potential of an electrochemical reaction in a reproducible manner, researchers across the world can collaborate on the study of the same electrochemical system. 
Accurately reporting the potential of a reaction becomes important when referring to the overpotential $(\eta)$ of a reaction. For example, this following half-reaction:

$$
2 \mathrm{CO}_{2}+9 \mathrm{H}_{2} \mathrm{O}+12 \mathrm{e}^{-} \rightarrow \mathrm{C}_{2} \mathrm{H}_{5} \mathrm{OH}+12 \mathrm{OH}^{-} ; E^{o}=+0.09 \mathrm{~V} \text { vs. } \mathrm{RHE}
$$

contains a standard thermodynamic potential $\left(E^{\circ}\right)$ of $+0.09 \mathrm{~V}$ vs. RHE. This term, $E^{\circ}$, refers to the thermodynamic requirements to produce ethanol from $\mathrm{CO}_{2}$. The extra potential beyond $E^{\circ}$ required to reduce $\mathrm{CO} 2$ to ethanol experimentally is referred to as the overpotential. The difference of the operating potential of the electrochemical cell and the standard thermodynamic potential defines the overpotential. Three main processes contribute to this overpotential. These processes are the rates of mass transfer, charge transfer, and the chemical reaction. If an experimental electrochemical reaction takes place at $-1.0 \mathrm{~V}$ vs. RHE and produces ethanol from $\mathrm{CO} 2$, then $1.09 \mathrm{~V}$ of overpotential was said to take place. Many common strategies to improve electroreduction of $\mathrm{CO} 2$ consist of mitigating large overpotentials. One of the main obstacles in the field of $\mathrm{CO}_{2}$ reduction that causes increased overpotential is mass transfer. Once the half-reaction occurs, the reactants at the electrode are depleted and less current is observed. A concentration gradient develops between the region of the electrode surface and the bulk electrolyte. For more current activity to occur, the reactants must travel from the bulk electrolyte to the electrode surface. The rate of this process is defined as the mass transfer overpotential $\left(\eta_{m t}\right)$. For $\mathrm{CO}_{2}$, the solubility in aqueous solutions is $34 \mathrm{mM}$ and for $\mathrm{CO}$ it is approximately $1 \mathrm{mM}$. These solubility limits increase the negative effect of mass transfer which ultimately increases the overpotential. One main strategy of note to overcome this obstacle is optimizing the electrochemical cell through improved engineering of the cell to mitigate this issue. Many different electrolyzer concepts are designed to specifically accomplish this goal. ${ }^{103}$ One of 
the most recent breakthroughs was accomplished by Sargent et al. which accomplished current densities greater than $1 \mathrm{~A} / \mathrm{cm}^{-2}$ for the production of ethylene from $\mathrm{CO}_{2}{ }^{104}$

The current density $(J)$ reported in an electrochemical system refers to how much current was generated at a given potential. This flow of electrons becomes important to track because we want to know where the electrons go when a potential is applied. In most water splitting electrochemical reactions, all the electrons at the cathode find their way into $\mathrm{H}_{2}$ via the following half-reaction:

$$
2 \mathrm{H}^{+}+2 \mathrm{e}^{-} \rightarrow \mathrm{H}_{2}
$$

If there are no other side reactions, it is safe to assume any measured reductive current corresponds to each electron that found its way into each $\mathrm{H}_{2}$ molecule produced. One would say that the reaction current efficiency or faradaic efficiency (FE) is $100 \%$ representing a "perfect" selectivity in the case of the production of hydrogen in water splitting. Now in the case of $\mathrm{CO}_{2}$ reduction, many different products can be produced. The hydrogen evolution reaction (HER) is in constant competition for electrons when there is another reactant that can be reduced. Multiple reductive products are formed, and one cannot assume each produced ampere of current can be implicitly placed. This requires the quantification of the products in an accurate manner via additional methods. The bulk of this dissertation deals with this issue. The combination of different product quantification methods such as gas chromatography (GC) and nuclear magnetic resonance spectroscopy (NMR) allows the quantification of the possible reductive products and allows the tracking of FE in different electrochemical conditions. If a reaction contains a high FE for a certain product, one can say that the selectivity for that type of product is 
high. One important issue in the field of $\mathrm{CO}_{2}$ reduction is finding ways to mitigate this issue concerning the selectivity of the electrochemical reaction.

The three metrics overpotential, current density, and Faradaic efficiency are the primary measurables that describe the performance of an electrochemical system. These metrics are consistently described throughout the entire dissertation.

\subsection{Summary of Accomplishments}

The following sections describes the summary of accomplishments this dissertation details. In chapter two, several works are described where the author contributed a necessary but small component in a collaborative effort to study the following types of systems: heterogenous HER, homogenous HER, photoelectrochemical HER, photoelectrochemical OER, electrochemical $\mathrm{CO}_{2}$ and $\mathrm{CO}$ reduction, photocatalytic $\mathrm{CO}_{2}$ reduction, and non-aqueous $\mathrm{CO}_{2}$ reduction. Each of these co-authored works describes an important concept related to the context described in the previous section. In chapter three the work titled "Assessing Contaminants from Ion-Exchange Membranes in the Evaluation of Aqueous Electrochemical Dioxide Reduction" is presented where the author describes the importance of correctly identifying the reduction products of a $\mathrm{CO}$ reduction system. The author identified a potential source of contaminant species emanating from a component of the typical electrolyzer used in this field and was able to correctly identify the contaminate despite the challenging levels of concentrations of products and the contaminant in the $\mathrm{CO}$ reduction system. The work highlights the importance of accurate product identification methods. In chapter four the work titled "Pulsed Electrochemical Carbon Monoxide Reduction on Oxide-Derived Catalyst" is presented where the author 
describes a previously unstudied reaction for the reduction of $\mathrm{CO}$. The electrochemical cell is pulsed at different frequencies, which has been done in several works before but only for $\mathrm{CO}_{2}$ reduction. The author was able to discover that when the electrochemical cell is pulsed under $\mathrm{CO}$ reduction conditions that selectivity for the products can be controlled via shorter pulses of cathodic potential. This work represents a newly discovered control method over the selectivity of an electrochemical reaction. In chapter five the currently ongoing project which is titled, "Unassisted Photoelectrochemical Reduction of Carbon Monoxide with a Tandem Oxide-Derived Copper Dark Cathode and Titanium Dioxide $\mathrm{n}^{+} \mathrm{p}$-Si Photoanode" is described. This project is currently stalled due to the COVID-19 pandemic and to the extent to which the project has been pursued will be described. This project takes advantage of the low overpotential achieved for $\mathrm{CO}$ reduction to $\mathrm{C}_{2}$ products on oxide-derived copper catalyst and the tandem photoanode structures made in our lab which have high photovoltage capabilities to create a device possible of achieving unassisted photoreduction of $\mathrm{CO}$ to $\mathrm{C}_{2}$ products. In chapter six the ongoing side projects the author has worked on will be described and future goals of those projects will be explained. 


\section{CHAPTER 2}

\section{VARIOUS ELECTROCHEMICAL INVESTIGATIONS}

The following sections contain examples of key methods from assisted projects which bore co-authored publications in collaborative efforts. Each section contains a brief motivation for the work, relevant details, the results acquired by the author, and relevant details that made the results possible. These sections are organized by examples of different types of electrochemical investigations: Heterogenous Catalysis for HER, Homogenous Catalysis for HER, Photocatalysis for HER, Photocatalysis for OER, Electrochemical Reduction of $\mathrm{CO}_{2}$ and $\mathrm{CO}$, Photocatalysis of $\mathrm{CO}_{2}$, and Isotopic Labelling for $\mathrm{CO}_{2}$ Reduction.

\subsection{Heterogenous Catalysis for HER}

There is consensus that most homogeneous molecular electrocatalysts generate reactive metal hydride intermediates during HER. ${ }^{105-109}$ Several of these electrocatalysts display low overpotential, high turnover frequencies, and faradaic efficiencies in excess of $90 \% .{ }^{106,110}$ Noncovalent modification of electrode surfaces with catalysts has been studied for various applications. ${ }^{111-114}$ There is an emerging interest in the modification of electrode surfaces with small-molecule HER catalysts. ${ }^{115-121}$ Most notably, Fontecave and co-workers developed multiwalled carbon nanotube $\left[\mathrm{Ni}\left(\mathrm{P}^{\mathrm{Ph}}{ }_{2} \mathrm{~N}_{2}\right)_{2}\right]$ modified electrodes that display high catalytic activity at low overpotential. ${ }^{122}$ It has been reported that the translation of activity and mechanism of a rhenium thiolate HER catalyst from solution to 
Scheme 2.1 Synthesis and Labeling Scheme of Complexes 1-3<smiles>[R2]N([R2])C(=S)N([R])N=C(C)C(C)=NN([R2])C(=S)N([R])[Y13]</smiles>



\begin{tabular}{lcll} 
ligand & complex & $\mathrm{R}_{1}$ & $\mathrm{R}_{2}$ \\
\hline $\mathrm{H}_{2} \mathrm{~L}_{1}$ & $\mathbf{1}$ & $\mathrm{CH}_{3}$ & $\mathrm{H}$ \\
$\mathrm{H}_{2} \mathrm{~L}_{2}$ & $\mathbf{2}$ & $\mathrm{CH}_{3}$ & $\mathrm{CH}_{3}$ \\
$\mathrm{H}_{2} \mathrm{~L}_{3}$ & $\mathbf{3}$ & $\mathrm{CH}_{2} \mathrm{CF}_{3}$ & $\mathrm{H}$
\end{tabular}

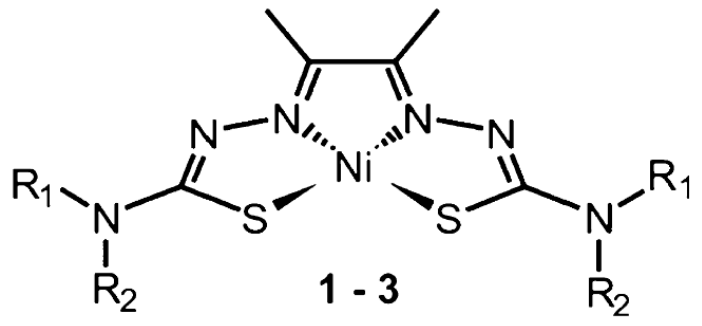

modified electrodes. ${ }^{123}$ Other examples of heterogeneous molecular catalysts for HER include Co complexes of (dmgBF2)2 with carbon black on Nafion-coated glassy carbon ${ }^{120}$ and cobaloxime-modified electrodes ${ }^{115,120}$ as well as cobalt porphyrin, ${ }^{117,118,124}$ metal phthalocyanine, ${ }^{125-128}$ and an organometallic complex incorporated in a Nafion film. ${ }^{129}$ However, these complexes either require high overpotentials and/or are unstable over prolonged electrolysis, reducing their practical use as HER catalysts.

A 4 mg sample of a given complex $(1,2$, or 3 , Scheme 2.1$)$ was dispersed in $1 \mathrm{~mL}$ of acetonitrile (VWR, ACS grade, dried using an MB-SPS from MBRAUN) using a vortex mixer (Vortex Genie 2, Scientific Industries). A $12.5 \mu \mathrm{L}$ aliquot of a 10\% aqueous Nafion solution was added to the resulting ink. The dispersion was further homogenized via ultrasonication (Cole-Parmer ultrasonic bath) for $2 \mathrm{~h}$. After sonication, $10 \mu \mathrm{L}$ of the resulting dispersion was dropped onto a GCE (E4TQ ChangeDisk, Pine Research), rotating at $50 \mathrm{rpm}$, affixed to a rotator (MSR Rotator, Pine Research). The rotation speed was subsequently increased to $300 \mathrm{rpm}$, and this speed was maintained until the film was dried. Evaluation of the materials' activities for HER was carried out in a three-electrode glass 
electrochemical cell (RDE/RRDE Cell Without Water Jacket, Pine Research) with $0.5 \mathrm{M}$ $\mathrm{H}_{2} \mathrm{SO}_{4}$ (VWR, ACS grade) in twice-deionized Millipore water $(18.2 \Omega \mathrm{cm}$ ). A graphite rod (Pine Research), in a protective fritted glass tube (Pine Research), was used as the counter electrode. $\mathrm{Ag} / \mathrm{AgCl}(1 \mathrm{M} \mathrm{KCl}, \mathrm{CH}$ Instruments) was used as the reference electrode. Measured potentials were calibrated versus RHE after experiments were conducted (to prevent platinum contamination) by measuring the potential difference between a pristine platinum electrode (Standard Platinum Counter Electrode, Pine Research) and the reference electrode in $\mathrm{H}_{2}$-saturated $\mathrm{H}_{2} \mathrm{SO}_{4}$. High-purity $\mathrm{H}_{2}$ and $\mathrm{N}_{2}$ gases used throughout these experiments were provided by Welders Supply, Louisville, KY. For determination of the faradaic efficiencies, produced $\mathrm{H}_{2}$ gas was measured by gas chromatography (GC; SRI 6810) via online automatic injection ( $1 \mathrm{~mL}$ sample) and a thermal conductivity detector. Nitrogen (99.99\%, Specialty Gases) was used as the carrier gas to enable accurate $\mathrm{H}_{2}$ quantification. The gas was injected every $15 \mathrm{~min}$, and each measured value for the faradaic efficiency was representative of the past 15 min of electrolysis. In the bulk electrolysis cell itself, nitrogen was diffused into the electrolyte at 10 standard cubic centimeters per minute $(\mathrm{sccm})$ regulated by a mass flow controller (MKS Instruments, Inc.).

The calculation for the faradaic efficiency of hydrogen gas is accomplished via the following equations.

moles of gas $=\left(1 \mathrm{~atm} *\left(\frac{100 * \mathrm{ppm}}{1000000}\right) * 0.001 \mathrm{~L}\right) /\left(0.08205 \frac{\mathrm{K} * \mathrm{~atm}}{\mathrm{~mol} * \mathrm{~K}} * 298.15 \mathrm{~K}\right)$ 
Where ppm represents the amount of molecules of gas per volume according to the ideal gas law. This concentration is measured against a calibration curve (Fig 2.1) made with a

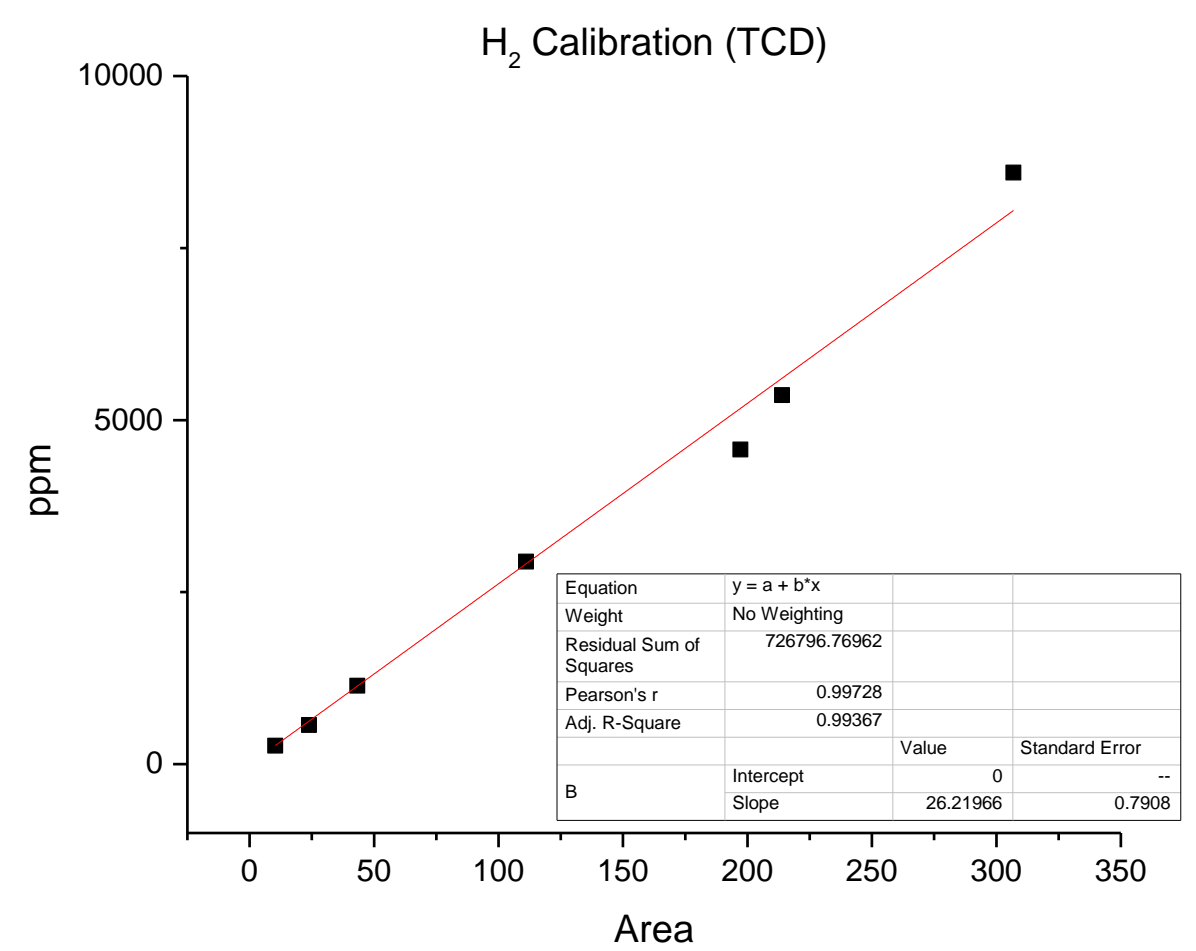

Figure 2.1 Calibration curve for $\mathrm{H}_{2}$ gas constructed with standard gas mixtures.

standard mixture of $1 \%$ hydrogen gas (Restek). The following calibration curve represents a thorough standardization of hydrogen by mixing the calibration gas with nitrogen at varying flow rates to attain different peak areas representing specific concentrations of hydrogen. Typically, only one concentration is needed to adequately calibrate for the gas to be analyzed and the TCD response only drifts by less than a percent per month of steady GC use.

$$
\text { Faradaic Effeciency }=\frac{100 *\left(\frac{2 \text { moles } e}{\text { Moles gas }}\right) * \text { moles of gas }}{\text { Current } A * \frac{96485 \mathrm{C}}{\text { moles } e} * 1 \mathrm{~cm}^{3}\left(\frac{60 \mathrm{sec}}{10 \mathrm{sccm}}\right)}
$$


faradaic efficiency is then calculated from the mole of gas product, the number of electrons used to make the product, the flow rate, the current applied to the electrochemical cell and Faraday's constant.

The potentiostat was operated in galvanostatic mode at a constant current density of $10 \mathrm{~mA} \mathrm{~cm}{ }^{-2}$ during faradaic efficiency measurements. In order to maintain an airtight seal, the GCE was not rotated. Instead, a magnetic stirrer was rotated at $360 \mathrm{rpm}$ underneath the GCE to remove $\mathrm{H}_{2}$ bubbles from the electrode surface. Theoretical $\mathrm{H}_{2}$ was determined



Figure 2.2 Plot of theoretical hydrogen, measured hydrogen, and Faradaic efficiencies for GC $1-3$ after cycling to peak activity. 
by counting the coulombs of charge that passed, and measured $\mathrm{H}_{2}$ was determined via GC. The faradaic efficiencies were determined by comparing these values.

Theoretical $\mathrm{H}_{2}$ is calculated from the coulombs of charge passed during the experiment. Measured $\mathrm{H}_{2}$ was detected via gas chromatography. The faradaic efficiency was calculated by comparing these two values. GC $1-3$ were evaluated after 300, 200, and 300 cycles respectively.

The results expressed in Fig 2.2 indicate that all three complexes studied exhibited a steady HER performance of near 100\% FE over the course of a ninety-minute period. The implications of these results indicate that the deposition method described earlier can provide a high performing heterogenous catalyst system.

\subsection{Homogenous Catalysis for HER}

Recently, Grapperhaus et al. ${ }^{130-132}$ and others ${ }^{105}, 133,134$ explored the use of bis(thiosemicarbazone) (BTSC) ligands, such as diacetyl-bis(N4-methyl-3thiosemicarbazone) ( $\left.\mathrm{H}_{2} \mathrm{ATSM}\right){ }^{135}$ in the design of HER electrocatalysts. The BTSC ligands are non-innocent and can participate as a site of protonation and/or reduction leading to ligand-assisted metal-centered, ligand-centered, and metal-assisted ligandcentered HER pathways. ${ }^{130}$ The specific mechanism depends on the identity of the metal. Straistari et al. reported HER activity with a NiBTSC complex containing $p$-anisidine groups that was proposed, based on quantum chemical calculations, to involve ligandbased reduction and protonation followed by formation of a $\mathrm{Ni}^{\mathrm{IIII}}$-hydride. ${ }^{105}$ Recently, Grapperhaus et al. reported similar HER activity for the NiATSM compound and further evaluated the proposed mechanism including location of a transition state confirming the participation of the putative Ni-hydride in the hydrogen evolving step. ${ }^{132}$ Ni-hydrides are 
well known to participate in HER in natural occurring hydrogenases ${ }^{136-140}$ and synthetic small molecule catalysts. ${ }^{141-144}$ Of the latter, the most well-known is the family of bisdiphosphane complexes pioneered by DuBois and Bullock. ${ }^{145}$ The incorporation of pendant amines in these complexes provides a second coordination sphere that facilitates proton transfer and enhances HER activity. ${ }^{146}$ Likewise, the "Hangman" metalloporphyrin catalysts developed by the Nocera group employ a flyover carboxylate to position a proton source proximal to the metal-hydride. ${ }^{147}$ An alternate second coordination sphere strategy explored by the Yang group introduces charge sites through encapsulation of non-redox active cations (i.e. $\mathrm{Na}^{+}, \mathrm{K}^{+}, \mathrm{Ca}^{2+}$ ) to lower the reduction potential of the catalyst without decreasing its basicity. ${ }^{148}$

In this work, the above-mentioned concepts to NiATSM derivatives were applied by incorporating pendant diamines on the BTSC framework (Scheme 2.2). The diamine moiety introduces a second-coordination sphere that could participate as a proton relay during HER. Since the pendant amine may be protonated under acid saturating conditions during catalysis, they could also introduce charge sites that may affect the overpotential. To decouple the proton relay and charge effects, we have prepared the methylated derivatives to introduce a fix charge at a non-basic site for comparison.

The CPC data were collected using a two-chambered glass electrolysis cell. The working compartment was fitted with a glassy carbon working electrode and $\mathrm{Ag} / \mathrm{Ag}+$ reference electrode. The auxiliary compartment was fitted with a platinum wire counter electrode. The cell was washed and dried in an oven overnight before conducting the experiments. In a typical experiment, the working compartment was loaded with $0.3 \mathrm{mM}$ catalyst, $\mathrm{CH}_{3} \mathrm{COOH}$ at saturation conditions, and $0.1 \mathrm{M} \mathrm{Bu}_{4} \mathrm{NPF}_{6}$ in $\mathrm{MeCN}$ solution. The 
Scheme 2.2. Synthesis of the methylated complexes $\mathbf{2}$ and $\mathbf{4}$ from corresponding free base complexes $\mathbf{1}$ and $\mathbf{3}$.

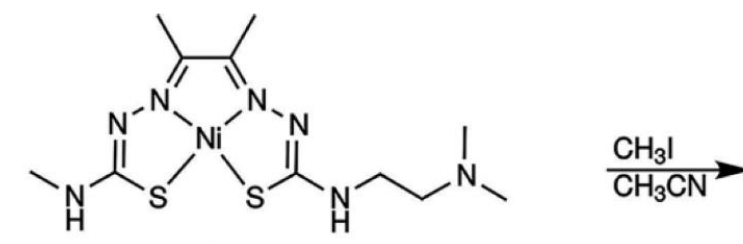

1
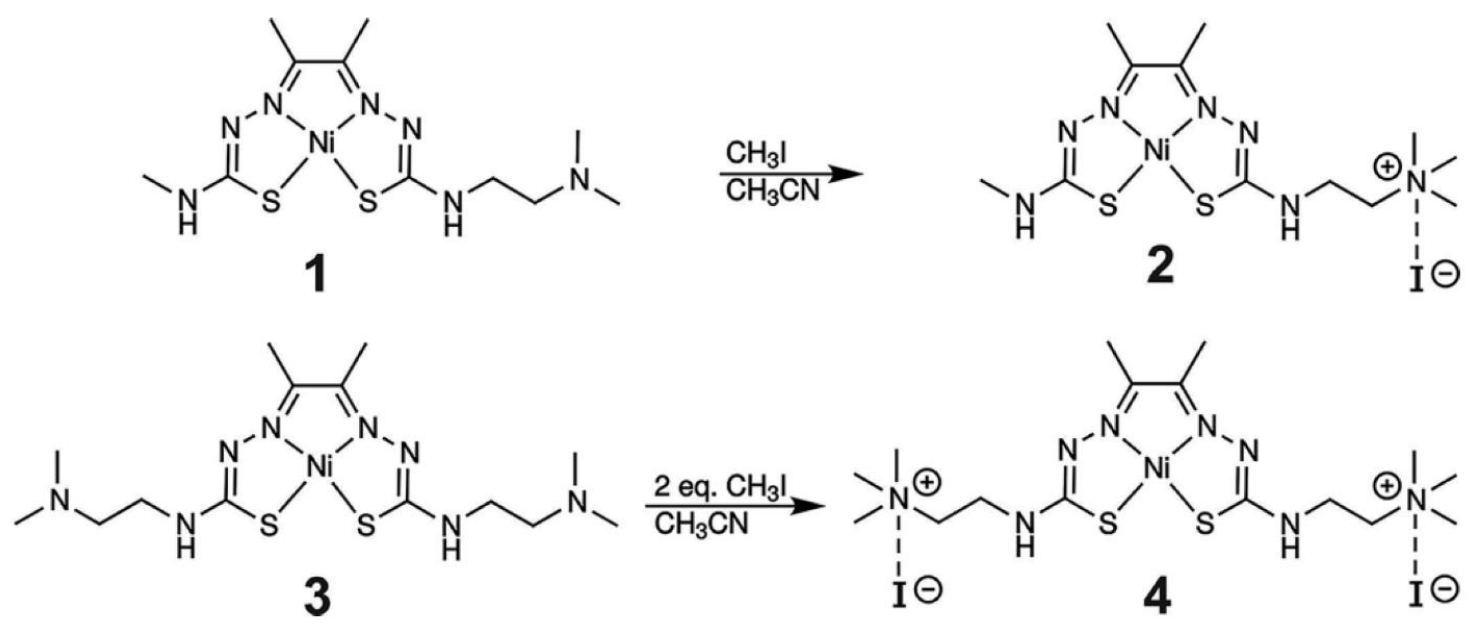

auxiliary compartment was filled with a $0.1 \mathrm{M} \mathrm{Bu} \mathrm{NPFF}_{6} / \mathrm{MeCN}$ solution. Before electrolysis, both compartments were sparged with nitrogen for 15 minutes and then stirred throughout bulk electrolysis experiment. Data were collected at a constant applied potential equal to the potential required for $i_{\text {cat }} / 2$ in the $\mathrm{CV}$ studies. A control (blank) CPC study was conducted and subtracted from experimental results. Hydrogen gas was measured by gas chromatography (GC, SRI 6810) via online automatic injection (1 $\mathrm{mL}$ sample) and a thermal conductivity detector (TCD). Nitrogen $(99.99 \%$, Specialty Gases) was used as the carrier gas to enable accurate hydrogen quantification. The gas was injected every 15 minutes and each measured value for faradaic efficiency is representative of the past 15 minutes of electrolysis. In the bulk electrolysis cell itself nitrogen was diffused into the electrolyte at $10 \mathrm{sccm}$ regulated by a mass flow controller (MKS Instruments, Inc.). The electrochemical cell was set up identically as described for all other homogeneous electrochemical experiments except joints were sealed with vacuum grease and a nitrogen outlet line was run from the cell to the GC apparatus. In order to maintain an air-tight seal, the GCE was not rotated. Instead, a magnetic stir was rotated at 360 RPM underneath the GCE to remove hydrogen bubbles from the electrode surface. Theoretical $\mathrm{H}_{2}$ was 

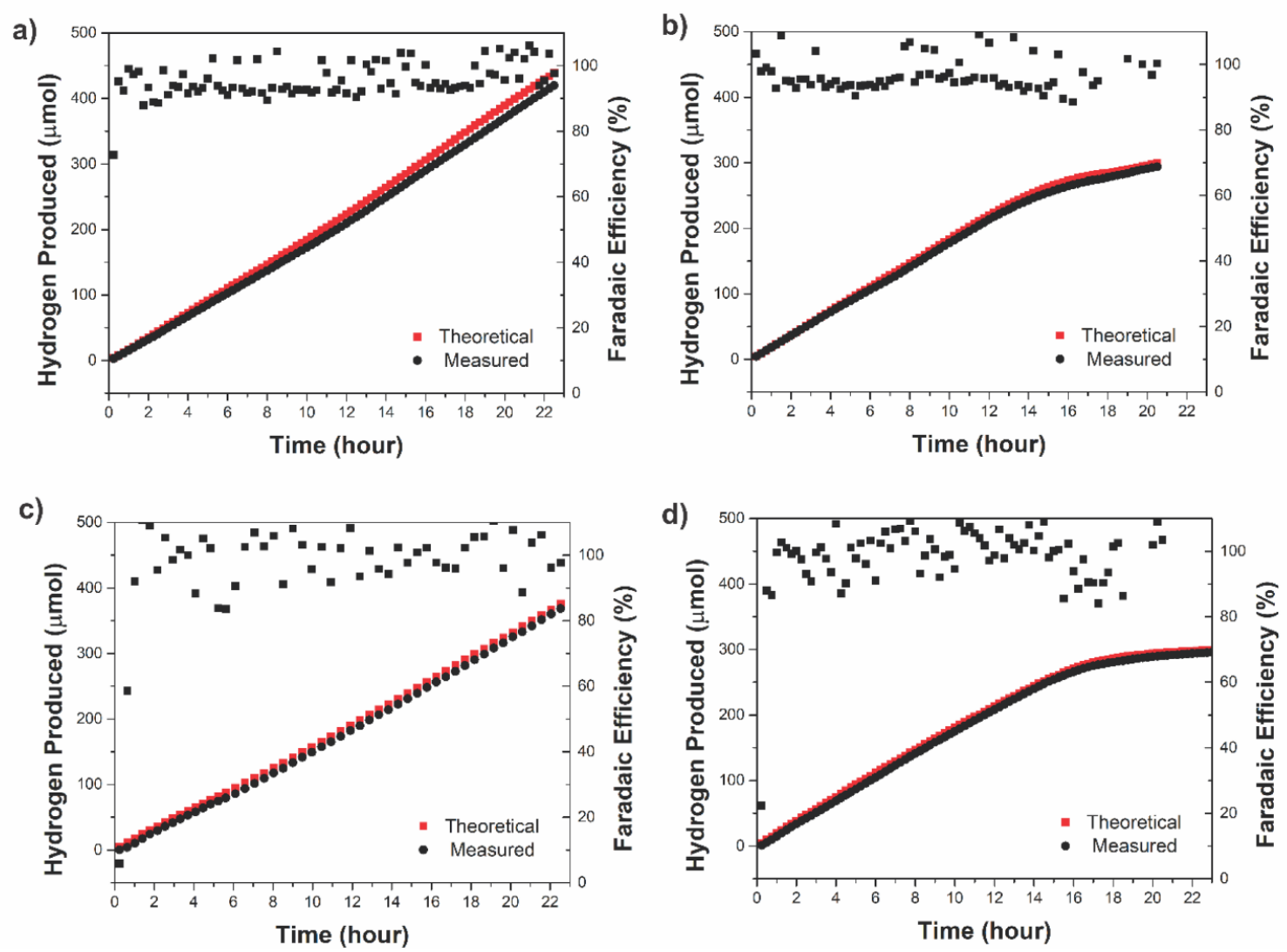

Figure 2.3. Faradaic efficiency of the hydrogen produced during the bulk electrolysis of $\mathbf{1}$ (a), 2 (b), $\mathbf{3}$ (c), and 4 (d) detected by gas chromatography. The potential was held at $-1.4 \mathrm{~V}$ vs $\mathrm{Ag} / \mathrm{Ag}+$.

determined by counting the coulombs of charge passed, and measured $\mathrm{H}_{2}$ was determined via GC. The faradaic efficiencies were determined by comparing these values. Each of these complexes exhibited faradaic efficiencies of approximately $100 \%$. The charged complexes (2 and 4) declined in HER activity after approximately 13 hours of electrolysis but maintained near $100 \% \mathrm{FE}$.

\subsection{Photocatalysis for HER}

There have been a number of studies to leverage molecular HER catalysts for solar $\mathrm{H}_{2}$ generation by incorporating these structures onto the surface of semiconductor 
photocathodes. ${ }^{149-151}$ In many cases, the catalyst was immobilized on the semiconductor surface via covalent linking strategies for direct charge transfer between the electrode and catalyst. ${ }^{151-153}$ Covalent attachment is often necessary to prevent catalyst delamination or dissolution in aqueous media but adds processing complexity as well as charge-transfer resistance at the interface. Ideally then, a molecular catalyst could be durably coupled to a photoelectrode with low overpotential in aqueous solution at low or high $\mathrm{pH}$ where electrolysis efficiency is maximized. NiATSM co-catalyst with CdS nanorods was recently reported for light-driven hydrogen evolution using monochromatic illumination with a sacrificial species at moderate $\mathrm{pH}$ values. ${ }^{154}$ Herein we report the characterization of the NiATSM catalyst under conditions for practical solar hydrogen generation. Simple catalyst attachment methods were used with $\mathrm{p}$-Si photocathodes in $\mathrm{pH} 0$ aqueous electrolyte to yield robust photoelectrochemical energy-conversion behavior that clearly outperforms an equivalent loading of Ni metal catalyst. Two different types of Si substrate were used in this work.

Degenerately doped $n^{+}-\operatorname{Si}(100)$ (doped with As to a resistivity of $0.001-0.005 \Omega$ $\mathrm{cm}$, University Wafer) substrates were used to measure the dark electrocatalytic behavior of the Si semiconductor surface as well as the Si-supported NiATSM electrocatalyst behavior. Photoactive substrates for illuminated hydrogen evolution consisted of $\mathrm{p}-\mathrm{Si}(100)$ (doped with B to $1-10 \Omega \mathrm{cm}$, University Wafer). Before attaching the NiATSM cocatalyst, the Si native oxide layer was removed with a > $10 \mathrm{~s}$ dip in $10 \% \mathrm{HF}$. To load the catalyst on the electrodes, a $2.0 \mathrm{mM}$ solution of NiATSM in acetonitrile was dropcast on the $\mathrm{Si}$ surface to a consistent loading of $\sim 60 \mathrm{nmol} \mathrm{cm}{ }^{-2}$, followed by $1 \mathrm{~min}$ in a vacuum oven at $70{ }^{\circ} \mathrm{C}$. For Nafion-bound NiATSM, each $20 \mathrm{~mL}$ of $2 \mathrm{mM}$ solution also contained $25 \mu \mathrm{L}$ of 
$5 \%$ aqueous Nafion solution (Beantown Chemical) and was further heated in air at $60{ }^{\circ} \mathrm{C}$ for $1 \mathrm{~min}$. Hydrogen quantification and faradaic efficiency determination were measured under potentiostatic conditions at $-0.2 \mathrm{~V}$ vs. RHE using gas chromatography (GC, SRI 8610). For this measurement, $\mathrm{H}_{2}$ was not bubbled but instead nitrogen $(99.99 \%$, Specialty Gases) was used as the carrier gas to enable accurate hydrogen quantification. The gas outlet from the catholyte was connected to the GC, which used an automatic valve injection (1 $\mathrm{mL}$ sample) and a thermal conductivity detector (TCD). faradaic efficiency was calculated by determining the charge required to produce the measured $\mathrm{H}_{2}$ concentration and dividing by the total charge passed in the electrolysis during the gas collection period. However, by casting the NiATSM layer in a dilute Nafion solution as a cation-exchanging binder, the extended current density vs. time performance became steady at $\sim 22 \mathrm{~mA} \mathrm{~cm}{ }^{-2}$ at $-0.2 \mathrm{~V}$ vs. $\mathrm{RHE}$ over the measured period $\mathrm{H}_{2}$ faradaic efficiency by gas chromatography displayed almost total direction of the charge to HER.

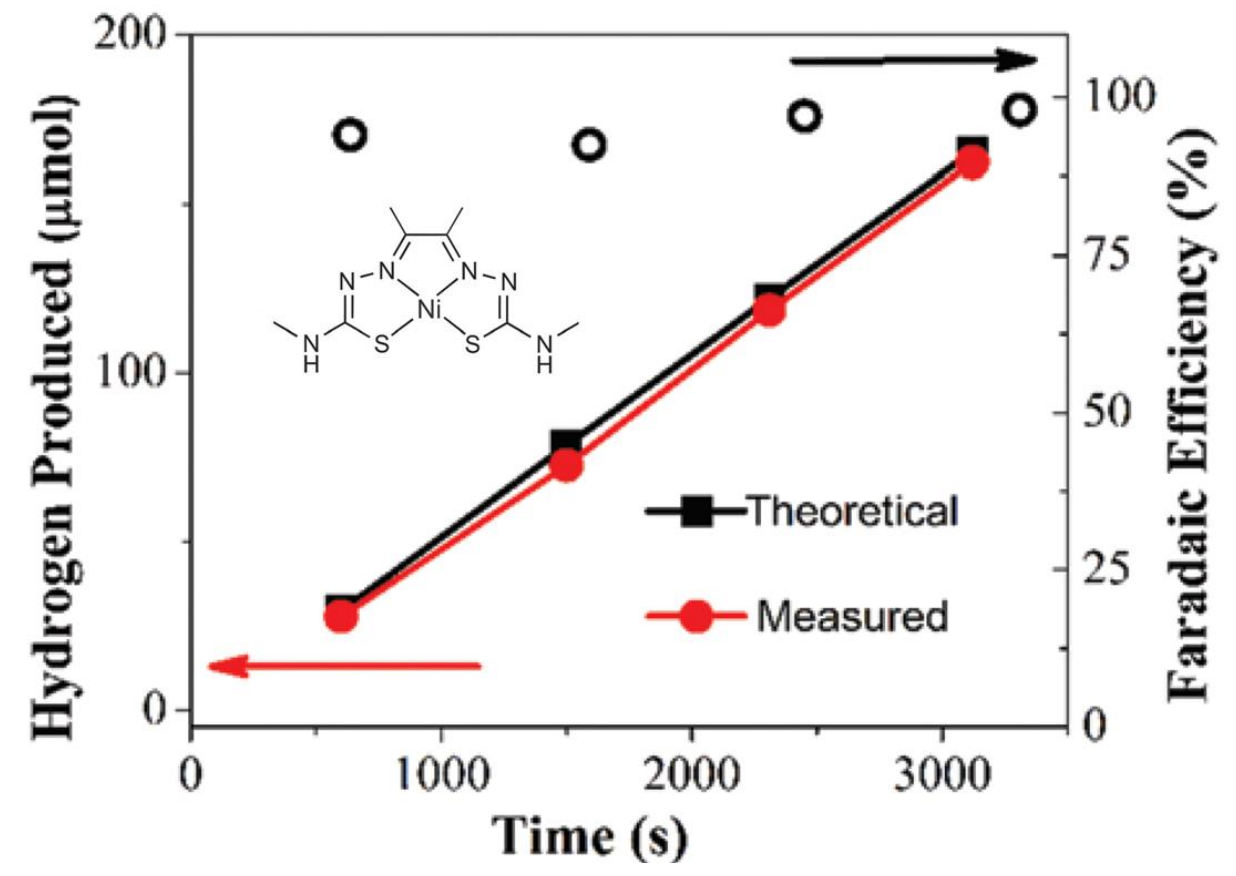

Figure 2.4 Faradaic Efficiency for PEC HER of NiATSM. 


\subsection{Photocatalysis for OER}

Photoelectrolysis of water to oxygen and hydrogen fuel is a promising large-scale solution to store intermittent solar energy in a dense and portable form. ${ }^{155}$ Photoelectrochemical (PEC) water-splitting, or artificial photosynthesis, research strives to develop a semiconductor photoelectrode with both high efficiency and long-term stability. For high efficiency, room-temperature water-splitting requires $\sim 1.6 \mathrm{~V}$ or more $(1.23 \mathrm{~V}$ plus anodic and cathodic activation overpotentials) of photovoltage at the highest possible photocurrent, which has led to most designs featuring a two-semiconductor tandem approach. ${ }^{156,157}$ For the wider bandgap top subcell material, III-V semiconductors have been produced with exceptional light absorption and charge-transport properties and are among the few types of materials that can meet the photovoltage and photocurrent requirements. The highest efficiency PEC systems to date have thus leveraged III-V photoactive materials. ${ }^{156,158,159}$ Gallium phosphide is one such material that has been successfully made into efficient photoanodes, ${ }^{160-164}$ although its indirect bandgap of 2.26 $\mathrm{eV}$ is slightly higher than the ideal top cell for a two-cell tandem combination. ${ }^{157}$ Ternary alloys, however, can tune the bandgap by varying the composition, with materials such as $\mathrm{GaSb}_{\mathrm{x}} \mathrm{P}_{1-\mathrm{x}}$ recently showing promise as a photoanode material. ${ }^{165,}{ }^{166}$ Unfortunately, III-V semiconductors including $\mathrm{GaP}$ are not stable in aqueous electrolyte at the anodic potentials necessary for water oxidation. Instead, the redox potential for the thermodynamically favored semiconductor anodic oxidation reaction (i.e., the self-oxidation potential) is negative of the oxygen evolution reaction potential, and thus these materials anodically

photocorrode or photopassivate. ${ }^{167,168}$ In recent years, researchers have successfully employed thin protective layers to stabilize corrosion-prone semiconductors, with a 
method like atomic layer deposition (ALD) enabling uniform conformal coverage of a surface with a chemically robust material at thicknesses that still permit efficient interfacial charge-transfer. ${ }^{169-174} \mathrm{ALD} \mathrm{TiO}_{2}$ on n-GaP significantly improved the stability for water oxidation in alkaline media for many hours. ${ }^{161,162}$ However, even a single pinhole can lead to corrosion, undercutting of the protective layer, and eventual device failure. Thus, there remains a significant need in the solar fuels field to investigate semiconductor degradation and mitigation strategies.

The following study on GaP photocorrosion includes an important story about investigating the direction of charge (calculation of FE). The mechanism for GaP photocorrosion is not $100 \%$ confirmed and this investigation sheds light on the probable chemical equation that describes GaP's photocorrosion reaction.

With data for the dissolved Ga concentration vs. time and corresponding cumulative charge passed, the faradaic efficiency for the GaP oxidation reaction can be calculated. However, the calculation assumes a known and constant number of electrons transferred, n, to fully decompose one molecule of GaP. Several studies for GaP in acid have assumed a value of 6 charge carriers required to oxidize one GaP unit. ${ }^{175,176}$ This value appears to have been derived from a colorimetric measurement which assumed no side reactions, in a batch-method approach which would not capture transient behavior. ${ }^{177}$ The proposed anodic half-reaction is:

$$
\mathrm{GaP}+3 \mathrm{H}_{2} \mathrm{O} \rightarrow \mathrm{Ga}^{3+}+\mathrm{H}_{3} \mathrm{PO}_{3}+3 \mathrm{H}^{+}+6 \mathrm{e}^{-}
$$

However, the same study reported that only 3 charge-carriers were required to oxidize GaP in alkaline conditions. ${ }^{177}$ Similarly, a more recent computational study proposed that the 
most energetically favorable route to $\mathrm{GaP}$ oxidation in acid would require 3 charge-carriers per GaP unit, in which the anodic half-reaction would be: ${ }^{168}$

$$
2 \mathrm{GaP}+3 \mathrm{H}_{2} \mathrm{O} \rightarrow \mathrm{Ga}_{2} \mathrm{O}_{3}+2 \mathrm{P}+6 \mathrm{H}^{+}+6 \mathrm{e}^{-}
$$

For $\mathrm{GaP}$ in the zinc blende lattice, the dissolution mechanism is understood to occur through step edges at the surface where both $\mathrm{Ga}$ and $\mathrm{P}$ atoms are in contact with solution. ${ }^{177}$ In acid, $\mathrm{H}_{3} \mathrm{O}^{+}$is proposed to bridge to the unpaired electron of the surface $\mathrm{P}$ atom. In this case, three bonds have to be split for the dissolution of one GaP molecule. If both atoms are electrochemically dissolved, then six charges are required, following reaction (Eq. 2.4.1). Alternatively, if three charges per GaP molecule are passed electrochemically, one electron of each bond remains at the $\mathrm{P}$ atom, leaving neutral phosphorous which subsequently dissolves by a non-electrochemical step. Thus, the calculated GaP oxidation faradaic efficiency is plotted in Fig. 2.5 using either $n=3$ or $n=6$, and assuming the $\mathrm{Ga}_{2} \mathrm{O}_{3}$ fully dissolves. These results were performed via in-situ UV-Vis spectroscopy.

A value of $n=6$ for the corrosion reaction resulted in faradaic efficiencies greater than $100 \%$ at shorter times, and therefore this cannot be the dominant reaction pathway for the initial stage of etching on illuminated n-GaP. Instead, we attribute the initial behavior to the $\mathrm{n}=3$ route being dominant in the early stages of etching, though a combination of reaction mechanisms is possible. At longer times, the $\mathrm{n}-\mathrm{GaP}$ oxidation faradaic efficiency approached a value of $\sim 40 \%$ for $n=3, \sim 80 \%$ for $n=6$. Measuring $\mathrm{O}_{2}$ in the gaseous headspace by GC for illuminated n-GaP resulted in faradaic efficiency values for OER of 5-20\%, averaged over $2 \mathrm{~h}$ (Fig. 2.6b). If the $\mathrm{n}=6$ corrosion route is dominant at longer times, this value for OER represents most of the balance of charge. Some portion of the 
charge may also be assigned to undissolved or incomplete oxidation of the semiconductor surface.

Oxygen concentration calibration was performed with a three-electrode setup using a Pt mesh working electrode, a Pt mesh counter electrode and a $\mathrm{Ag} / \mathrm{AgCl}$ reference
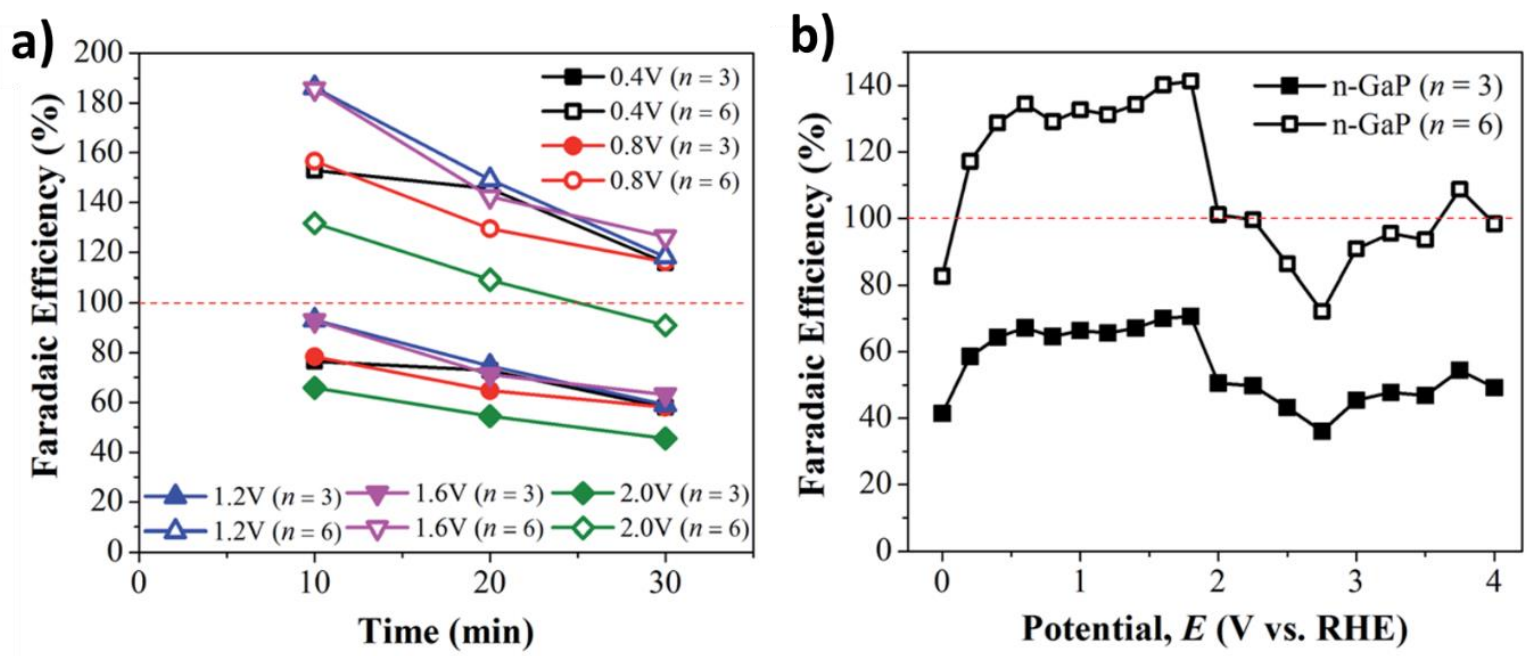

Figure 2.5 The behavior of $\mathrm{n}-\mathrm{GaP}$ at 2 Suns AM 1.5 illumination (a) at various applied potentials vs. time, and (b) at $30 \mathrm{~min}$ vs. applied potential.

electrode in a four-neck flask containing $1 \mathrm{M} \mathrm{H}_{2} \mathrm{SO}_{4}$. The counter electrode was separated from the rest of the cell with a glass frit to avoid hydrogen gas from mixing into the exhaust of the dynamic sampling loop of the gas chromatograph, and to prevent oxygen reduction at the cathode. $\mathrm{N}_{2}$ carrier gas was bubbled through the electrolyte at $10 \mathrm{sccm}$, and the gas outlet stream was sampled in a $1 \mathrm{~mL}$ sampling loop. The GC was an SRI 6810C Gas Mix \#3 configuration. Oxygen was detected by a thermal conductivity detector (TCD). The calibration was performed using chronopotentiometry at $0,1,2,3,4,5,6$, and $7 \mathrm{~mA}$ with at least 6 measurements for each current level (Fig. 2.6a). OER on n-GaP was performed in a similar fashion with the $\mathrm{n}-\mathrm{GaP}$ as the working electrode and the position calibrated for 2 suns intensity. OER faradaic efficiency was determined at a no bias (no sun) condition as well as $0.7,1.2,1.7$, and $2.2 \mathrm{~V}$ vs. RHE (Fig. 2.6b). No oxygen beyond the baseline 
value was detected at the no bias condition. Each faradaic efficiency value measured consisted of an average of 6 oxygen measurements conducted sequentially over $\sim 2 \mathrm{~h}$.
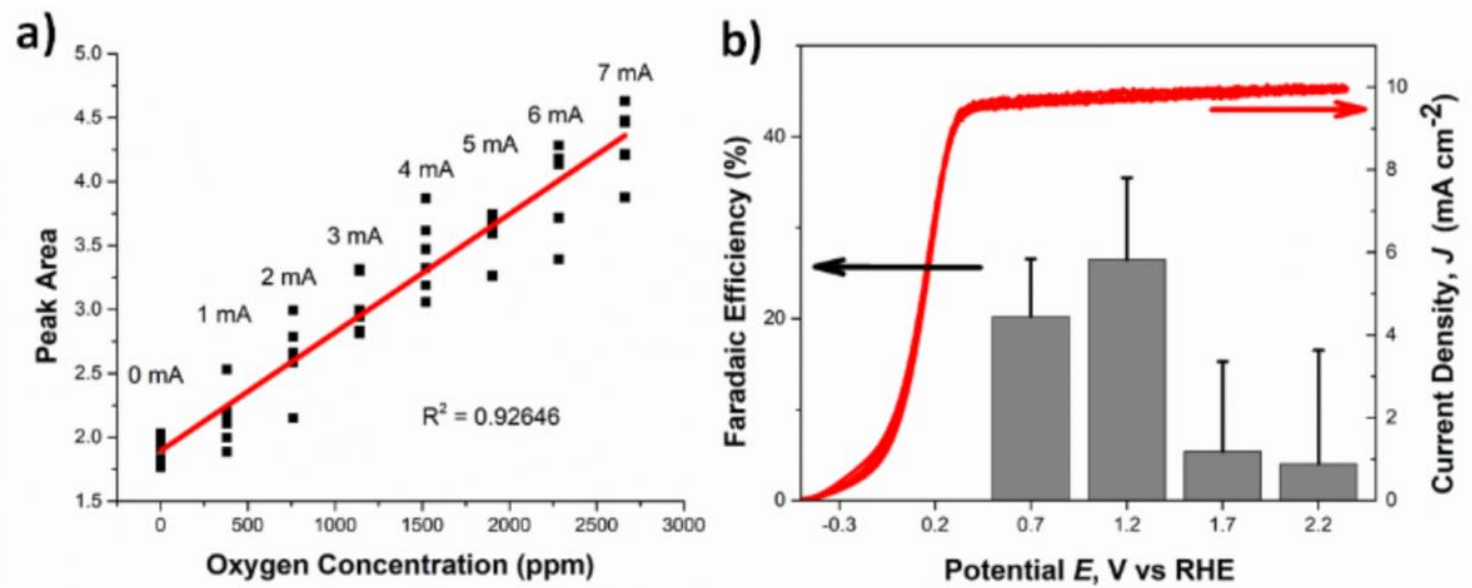

Figure 2.6 Characterization of gaseous oxygen in the reactor headspace. (a) $\mathrm{O}_{2}$ calibration curve produced with a Pt anode for water-splitting. (b) Calculated faradaic efficiency for OER (grey, left scale) vs. potential based on measured $\mathrm{O}_{2}$ concentration and the charge passed, and corresponding n-GaP current density (red, right scale) vs. potential. Bare $\mathrm{n}-\mathrm{GaP}$ was measured in $1 \mathrm{M} \mathrm{H}_{2} \mathrm{SO}_{4}$ under 2 Suns AM1.5 illumination.

\subsection{Electrochemical Reduction of $\mathrm{CO}_{2}$ and $\mathrm{CO}$}

Unlike the hydrogen evolution reaction (HER), many different products are possible in the carbon dioxide reduction reaction $\left(\mathrm{CO}_{2} \mathrm{RR}\right)$ coupled with the oxidation of water. ${ }^{178-180}$ Most metallic electrocatalysts only yield $\mathrm{C}_{1}$ products, ${ }^{179,} 181,182$ but copper surfaces are capable of directing significant faradaic current to $\mathrm{C}-\mathrm{C}$ bond forming reactions and producing $\mathrm{C}_{2}$ and $\mathrm{C}_{3}$ products. ${ }^{91,183-186}$ While there has been success at achieving high yields of $\mathrm{CO}^{187-190}$ and formate ${ }^{191-197}$ in a single-step $\mathrm{CO}_{2}$ reduction process, more energydense fuel products such as ethanol have been difficult to produce with high faradaic efficiency and reproducibility. ${ }^{91,183,}{ }^{185}$ Several efforts to develop electrocatalysts for a direct conversion of $\mathrm{CO}_{2}$ to $\mathrm{C}_{2} \mathrm{H}_{5} \mathrm{OH}$ have shown reasonable faradaic efficiencies but generally required high overpotentials. ${ }^{198-204}$ The $\mathrm{CO}_{2} \mathrm{RR}$ activity of single crystal planes 
of $\mathrm{Cu}$ have been reported with distinctly different activity to polycrystalline $\mathrm{Cu}$, with a faradaic efficiency for $\mathrm{C}_{2} \mathrm{H}_{5} \mathrm{OH}$ as high as $29.9 \%$ for $\mathrm{Cu}(310)$, albeit with a high overpotential of $>1 \mathrm{~V} \cdot{ }^{200} \mathrm{Cu}$ surface orientations have also been observed to restructure under electrolysis conditions, ${ }^{205}$ adding uncertainty to the stability of a $\mathrm{Cu}$ single crystal catalyst. Additionally, oxide-derived $\mathrm{Cu}$ electrodes with varied oxide layer thicknesses led to $\mathrm{C}_{2} \mathrm{H}_{5} \mathrm{OH}$ faradaic efficiencies up to $16.4 \%$, but again with an overpotential of $\sim 1 \mathrm{~V} .^{203}$ A recent report even claims $\mathrm{C}_{2} \mathrm{H}_{5} \mathrm{OH}$ faradaic efficiency up to $63 \%$ on $\mathrm{Cu}$ nanoparticles on graphene, but in a narrow potential range with cathodic overpotential upwards of $1.3 \mathrm{~V} .{ }^{204}$ The myriad of possible reaction pathways on the way to $\mathrm{C}_{2}$ and $\mathrm{C}_{3}$ compounds underscores the difficulty of achieving high product selectivity in a single reaction step. ${ }^{91}$ Theory and DFT calculations which have provided $\mathrm{CO}_{2} \mathrm{RR}$ mechanistic insight suggest that the optimal catalytic surface for driving a specific reaction pathway is one in which the free energy change of the reaction is achieved in thermochemically equivalent elementary steps. ${ }^{186}$ However, changing the surface binding energy to tune the free energy of one elementary step has a concomitant effect on the free energy of the other elementary steps. Breaking this scaling relation is thus a major challenge to optimize electrocatalysis for $\mathrm{CO}_{2} \mathrm{RR}$ products such as $\mathrm{C}_{2} \mathrm{H}_{5} \mathrm{OH}$ and may be exceptionally difficult for one electrocatalyst in a single-step electrolysis. ${ }^{206}$ Therefore, the field of electrolytic $\mathrm{CO}_{2}$ reduction would benefit greatly from the development of approaches and systems to optimize the selectivity and overpotential of heterogeneous catalysts to more complex, desirable fuel products. One approach to directing $\mathrm{CO}_{2}$ reduction toward a more energy-dense product is to break down the complex electron transfer reaction into multiple reaction steps with fewer electron transfers and relatively stable products. In this type of cascade catalysis, the products of 
the first reaction become the reactants of the second reaction, and so on, allowing for the design of multiple catalysts to minimize the energy barrier of each intermediate reaction on the way to the ultimately desired product. The advantages of cascade catalysis to improve product yield have been demonstrated in a "one-pot synthesis" for homogeneous catalysis of $\mathrm{CO}_{2}$ to $\mathrm{CH}_{3} \mathrm{OH}$, using three different catalysts simultaneously to promote the conversion. ${ }^{207} \mathrm{~A}$ major difficulty with the one-pot cascade is finding compatible catalysts that operate effectively under the same reaction conditions and are not poisoned by any of the intermediates. Alternatively, an assembly line cascade system with stepwise reactors can be used with varying conditions tailored to optimize the kinetic rate and selectivity at each stage. The major advantage of an assembly line cascade is versatility and modularity. Each individual reaction can be operated with the optimal choice of catalyst, temperature, applied bias, etc., to maximize yield and minimize overpotential. While $\mathrm{CO}_{2}$ conversion via heterogeneous cascade catalysis has been reported for thermochemical synthesis, ${ }^{208}$ reports for electrochemical $\mathrm{CO}_{2}$ reduction are lacking. This versatile systems engineering approach could provide a framework to improve the selectivity of $\mathrm{CO}_{2}$ electroreduction to higher order products. This $\mathrm{CO}_{2} \mathrm{RR}$ cascade system demonstrated an overall $\mathrm{FE}$ of $11.0 \%$ for ethanol at an averaged applied potential of $-0.52 \mathrm{~V}$ vs. RHE. The overall cathode halfreaction for ethanol formation is ${ }^{202}$ :

$$
2 \mathrm{CO}_{2}+9 \mathrm{H}_{2} \mathrm{O}+12 \mathrm{e}^{-} \rightarrow \mathrm{C}_{2} \mathrm{H}_{5} \mathrm{OH}+12 \mathrm{OH}^{-} ; E^{o}=+0.09 \mathrm{~V} \text { vs. RHE }
$$

Ethanol production was pursued by splitting this reaction into two distinct electrochemical steps. For the assembly cascade approach, the intermediate product should be a stable species that is readily separated from the first electrolyte. CO, which has routinely been 
demonstrated at high faradaic efficiencies from $\mathrm{CO} 2$ electroreduction, was targeted as the stable intermediate product

from the first stage $\mathrm{e}^{209}$ :

$$
\mathrm{CO}_{2}+\mathrm{H}_{2} \mathrm{O}+2 \mathrm{e}^{-} \rightarrow \mathrm{CO}+2 \mathrm{OH}^{-} ; E^{o}=-0.10 \mathrm{~V} \text { vs. } \mathrm{RHE}
$$

The low solubility of $\mathrm{CO}$ also makes it an easily separated intermediate product for passing to the second-stage electrolyzer, although it also presents a challenge to achieving subsequent high current density for $\mathrm{CO}$ reduction. Among numerous electrocatalytic systems which have shown high selectivity for $\mathrm{CO}$ formation, etched $\mathrm{Ag}$ nanocoral (AgNC) films have achieved $>95 \%$ faradaic efficiency at only $-0.5 \mathrm{~V}$ vs. RHE in aqueous media with promising stability. ${ }^{210}$ Furthermore, oxide-derived nanocrystalline $\mathrm{Cu}$ (OD-Cu) catalysts have reduced $\mathrm{CO}$ to $\mathrm{C}_{2} \mathrm{H}_{5} \mathrm{OH}$ at $\sim 43 \%$ faradaic efficiency at only $-0.3 \mathrm{~V}$ vs. RHE following the reaction ${ }^{211}$ :

$$
2 \mathrm{CO}+7 \mathrm{H}_{2} \mathrm{O}+8 \mathrm{e}^{-} \rightarrow \mathrm{CH}_{3} \mathrm{CH}_{2} \mathrm{OH}+8 \mathrm{OH}^{-} ; E^{o}=+0.18 \mathrm{~V} \text { vs. RHE }
$$

These catalytic systems were leveraged to demonstrate the cascade approach as a rational strategy for targeting high faradaic efficiency of a complex product at a low overall overpotential.

Ag-NC foil was used as the $\mathrm{CO}_{2} \mathrm{RR}$ catalyst for the first-stage electrolysis cell, along with an OD-Cu foil electrode for the second-stage electrolysis cell. The Ag-NC was prepared from a Ag foil (99.999\% pure, Alfa Aesar) by first producing a AgCl surface by electrochemical oxidation at $+0.3 \mathrm{~V}$ vs. $\mathrm{Ag} / \mathrm{AgCl}$ in $0.1 \mathrm{M} \mathrm{KCl}$ electrolyte for $12 \mathrm{~h}$. Subsequently, the foil was reduced to nanocoral structure by applying a potential of $-1.2 \mathrm{~V}$ vs. $\mathrm{Ag} / \mathrm{AgCl}$ in the same electrolyte for $30 \mathrm{~min}^{210}$ The $\mathrm{OD}-\mathrm{Cu}$ electrode was fabricated from a $\mathrm{Cu}$ foil $(99.98 \%$ pure, Alfa Aesar) which was cleaned with a $1 \mathrm{M} \mathrm{HCl}$ soak for 2 
min, then rinsed with isopropyl alcohol and water. The $\mathrm{Cu}$ foil was then dried with $\mathrm{N}_{2}$ gas ( $99.99 \%$ pure) and then heated at $500{ }^{\circ} \mathrm{C}$ for $1 \mathrm{~h}$ under atmospheric air. Following thermal oxidation, the foil was cooled gradually to room temperature over $\sim 1 \mathrm{~h}$ to prevent delamination of the oxide layer. The thermally oxidized $\mathrm{Cu}$ foil was electrochemically reduced at $-0.6 \mathrm{~V}$ vs. RHE in $0.1 \mathrm{M} \mathrm{KOH}$ solution for $45 \mathrm{~min}$. After the reduction process, fresh electrolyte was added to the cell prior to $\mathrm{CO}$ reduction. ${ }^{211}$

$\mathrm{CO}_{2}(99.99 \%$, Specialty Gases) was flowed at $20 \mathrm{sccm}$ with a mass flow controller (MKS Instruments, Inc.) through a custom absorption column filled with $0.1 \mathrm{M} \mathrm{KHCO}_{3}$ in $18 \mathrm{M} \Omega-\mathrm{cm}$ water in a random packing of $1 \mathrm{~mm}$ diameter glass beads. The liquid electrolyte was cycled with a peristaltic pump through the column and the cathode section of the first electrolyzer at a rate of $80 \mathrm{~mL} \mathrm{~min}^{-1}$. The flowrates were chosen to provide near saturation of $\mathrm{CO}_{2}$ in the electrolyte at the column outlet and to avoid transferring gaseous $\mathrm{CO}_{2}$ bubbles to the first-stage electrolyzer. From the cathode (Ag-NC) of the first electrolysis cell, the electrolyte flowed into a separate chamber for an extended residence time, permitting the effective separation of product $\mathrm{CO}$ and $\mathrm{H}_{2}$ bubbles from the liquid, with the electrolyte recycled back to the inlet of the $\mathrm{CO}_{2}$ absorption column. The gaseous product output from the separation chamber of the first-stage electrolyzer was directed to the second-stage electrolyzer through a porous glass frit bubbler positioned at the bottom of the $0.1 \mathrm{M} \mathrm{KOH}$ catholyte to promote gas dissolution and mass transfer to the OD-Cu cathode. There was no pump in between the electrolyzer stages, with the evolution of gases in the first stage being the driver for gaseous flow. To avoid interruption of the development of steady state conditions in the second-stage electrolyzer, gaseous products from the first-stage 
electrolyzer were not sampled by GC during cascade operation but were analyzed thoroughly in independent measurements.

The first-stage electrolyzer was a custom-designed two compartment polycarbonate cell with a large Ag-NC working electrode geometric surface area $\left(\sim 11 \mathrm{~cm}^{2}\right)$, a Pt mesh counter electrode, and a $\mathrm{Ag} / \mathrm{AgCl}(3 \mathrm{M} \mathrm{KCl})$ reference electrode. An anion exchange membrane (Selemion AMV) separated the Ag-NC cathode and reference from the Pt anode with $0.1 \mathrm{M} \mathrm{KHCO}_{3}(\mathrm{pH}$ 6.8) electrolyte in both chambers. The second-stage electrolysis cell was a similar two-compartment polycarbonate cell designed to maximize catalyst area relative to the electrolyte volume, enabling higher sensitivity for liquid product detection. ${ }^{193,212}$ An OD-Cu foil working electrode of $\sim 5 \mathrm{~cm}^{2}$ geometric surface area was used along with a $\mathrm{Ag} / \mathrm{AgCl}(3 \mathrm{M} \mathrm{KCl})$ reference electrode in the cathode compartment and a Pt mesh counter electrode in the anode compartment. The same Selemion anion exchange material was used as a membrane but with $0.1 \mathrm{M} \mathrm{KOH}$ electrolyte, in accord with the reported optimum electrolyte for CO reduction. ${ }^{211}$ Electrochemical measurements were performed with either one (for an individual electrolyzer) or two (for the two-step cascade) Biologic SP-200 potentiostats. Potentiostatic electrochemical impedance spectroscopy measurements were performed before every experiment to determine the uncompensated cell resistance, $R_{u}$, and the potentiostat subsequently compensated for $85 \%$ of $R_{u}$ in each cell during electrolysis. Potentials were converted to the reversible hydrogen electrode (RHE) utilizing the Nernst equation according to $\mathrm{V}_{\mathrm{RHE}}=\mathrm{V}_{\mathrm{Ag} / \mathrm{AgCl}}+0.210 \mathrm{~V}+$ $0.059 * \mathrm{pH}_{\mathrm{soln}}{ }^{213}$

Gaseous products were measured by gas chromatography (GC, SRI 8610) and liquid products were measured with nuclear magnetic resonance (NMR, Bruker $400 \mathrm{MHz}$ ) 
spectroscopy. Both the liquid and gas phase product concentrations were determined using calibrations from known standards. The gas phase products were injected into the GC via automatic valve injection (1 mL sample) with a thermal conductivity detector (TCD) and a flame ionization detector (FID). Nitrogen (99.99\% Specialty Gases) was utilized as a carrier gas to permit accurate hydrogen quantification. For potentiostatic measurements, an injection to the $\mathrm{GC}$ was made after 5 min and then after each subsequent $30 \mathrm{~min}$. Liquid samples for ${ }^{1} \mathrm{H}$ NMR spectroscopy were taken periodically throughout the experiment and at the end of each experiment. Samples were prepared by mixing $\mathrm{D}_{2} \mathrm{O}$ and electrolyte aliquots in a 1:1 vol ratio. Dimethyl sulfoxide (DMSO) was added at a known low concentration for internal calibration. faradaic efficiency was calculated for the potentiostatic measurements by determining the charge required to produce the measured product concentration and dividing by the total charge passed during the time the sample underwent electrolysis. For the two-stage cascade experiments, the faradaic efficiency of ethanol was defined from $\mathrm{CO}_{2}$ to $\mathrm{C}_{2} \mathrm{H}_{5} \mathrm{OH}$ across the entire system, as the charge required
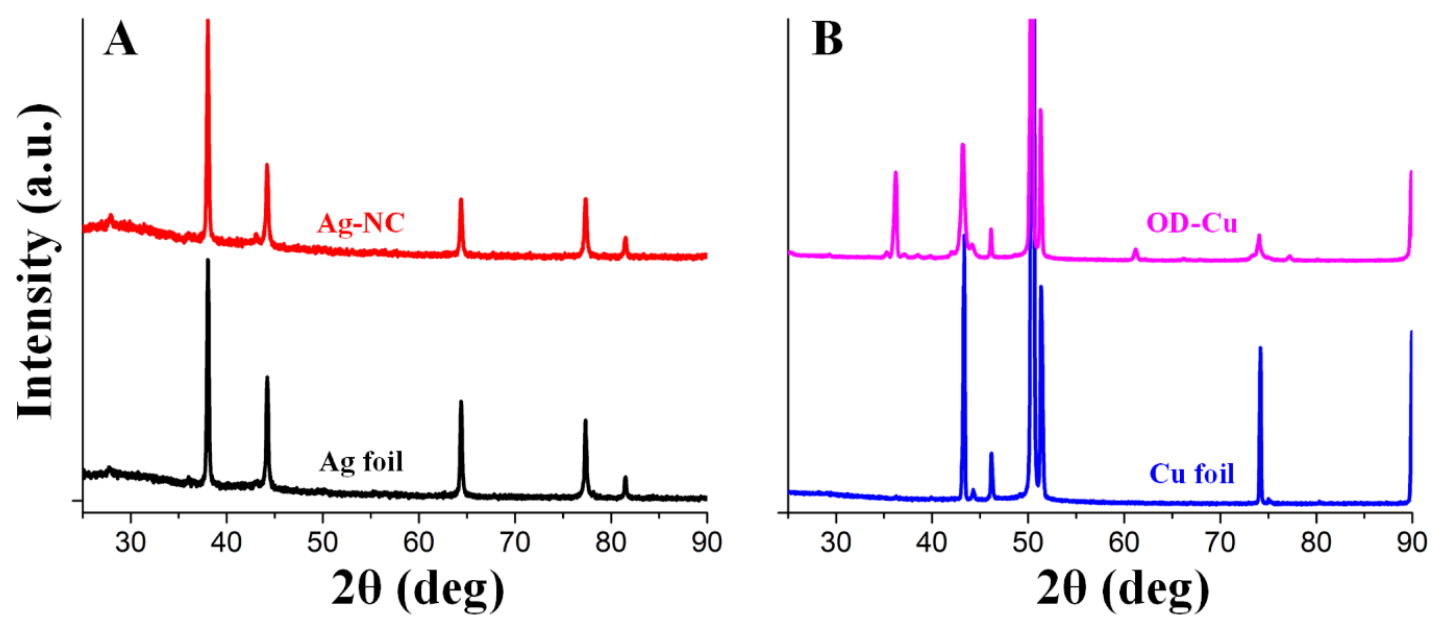

Figure 2.7 XRD data for (A) Ag-NC catalyst (red) compared to unaltered polycrystalline Ag foil (black) and (B) OD-Cu (magenta) compared to unaltered polycrystalline $\mathrm{Cu}$ foil (blue). 


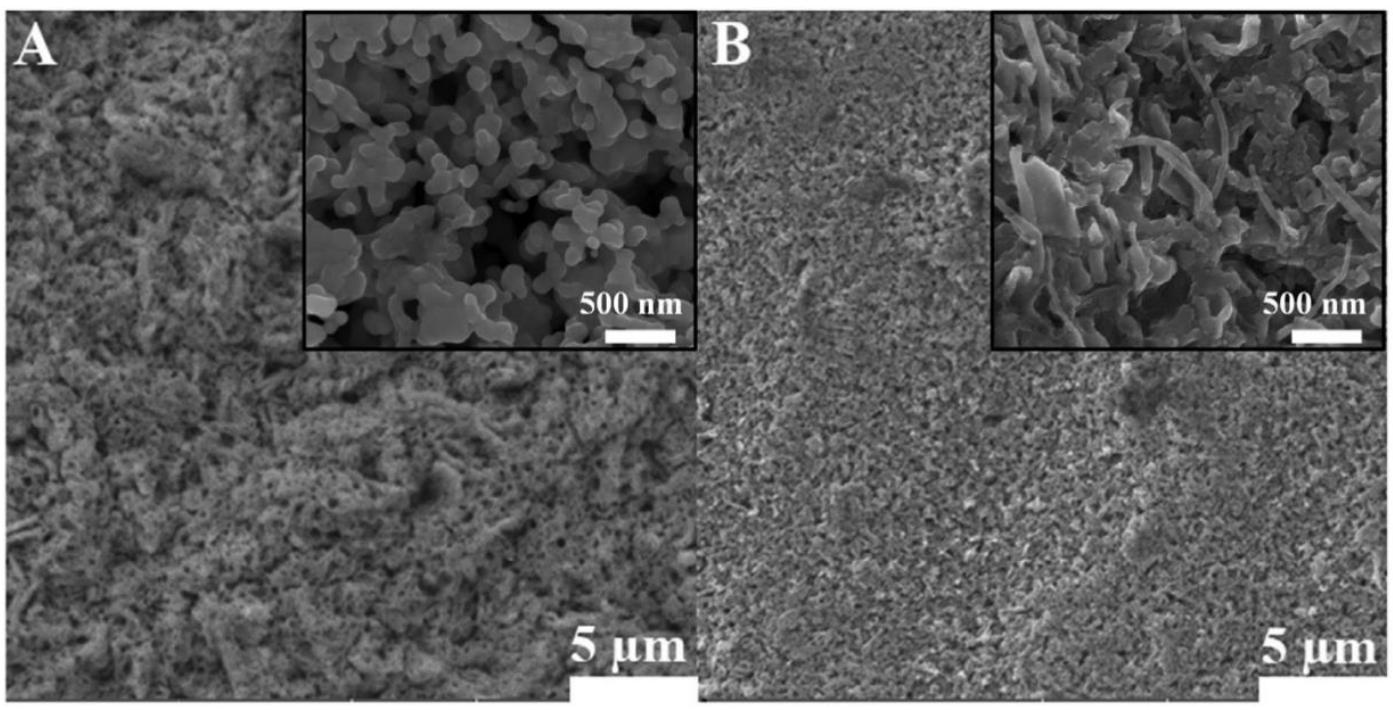

Figure 2.8. SEM images with insets of (A) the Ag-NC catalyst and (B) OD-Cu catalyst.

to produce the measured $\mathrm{C}_{2} \mathrm{H}_{5} \mathrm{OH}$ from $\mathrm{CO}_{2}\left(12 \mathrm{~mol} \mathrm{e}\right.$ required per mol $\left.\mathrm{C}_{2} \mathrm{H}_{5} \mathrm{OH}\right)$ divided by the sum of the charge passed in both electrolysis cells.

A Bruker D8 powder X-ray diffraction (XRD) system was used for crystal structure and phase analysis using non-monochromated $\mathrm{Cu}-\mathrm{K} \alpha$ radiation produced by an $\mathrm{X}$-ray tube operated at $40 \mathrm{kV}$ and $40 \mathrm{~mA}$. The sample XRD patterns were scanned between $20-90^{\circ}$ at a scan speed of 4 seconds per step with a step size of $0.02^{\circ}$ (Figure 2.7). SEM of the catalysts were also obtained (Figure 2.8).

The roughness of the electrodes was determined by measuring the electrochemically active surface area in comparison to the flat geometrically projected surface area of the electrodes, in accordance with the method used to benchmark heterogeneous catalysts (Figure 2.9). ${ }^{214}$ The electrochemical double-layer capacitance of the sample was measured by taking a scan-rate dependent measurement across a narrow range of potential in a non-faradaic region of the $J-E$ curve. The double layer capacitance, $C_{D L}$, can be extracted from the slope of the resulting current vs. scan rate behavior. The electrochemically active surface area roughness factor, ECSA, can then be found by: 


$$
E C S A=\frac{C_{D L}}{C_{S}}
$$

where $C_{S}$ is the specific capacitance of the sample or the capacitance of an atomically smooth planar surface of the material per unit area under identical electrolyte conditions. For $\mathrm{Cu}$ in alkaline liable reference was found for specific capacitance, so a polished $\mathrm{Ag}$ foil was measured instead, in the roughness factor of Ag-NC.electrolyte, the specific capacitance was taken as $29 \mu \mathrm{F} \mathrm{cm}^{-2} \cdot{ }^{215}$ For Ag in neutral electrolyte, no reliable reference was found for specific capacitance, so a polished Ag foil was measured instead, which will result in a lower limit estimate for the roughness factor of Ag-NC. 

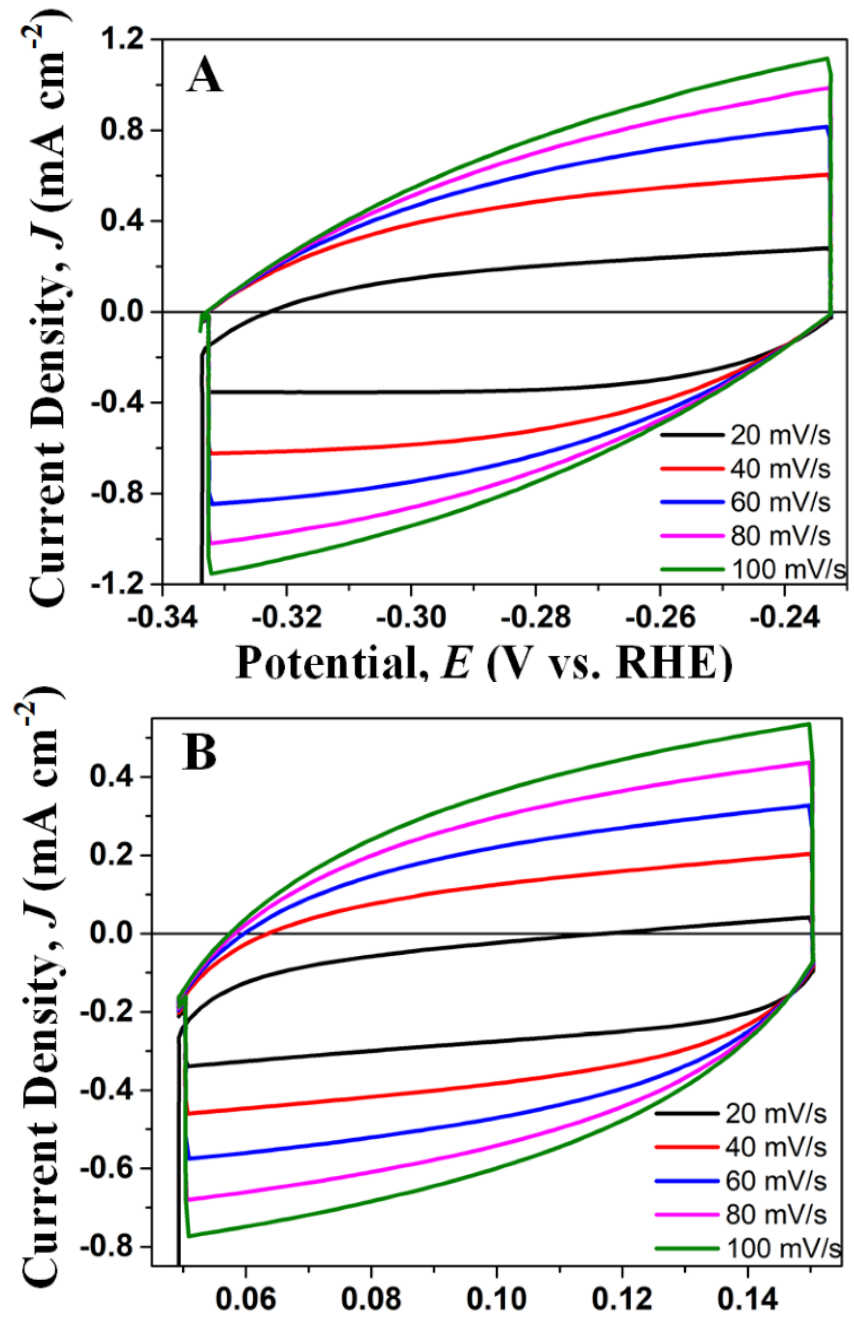

Potential, $E$ (V vs. RHE)

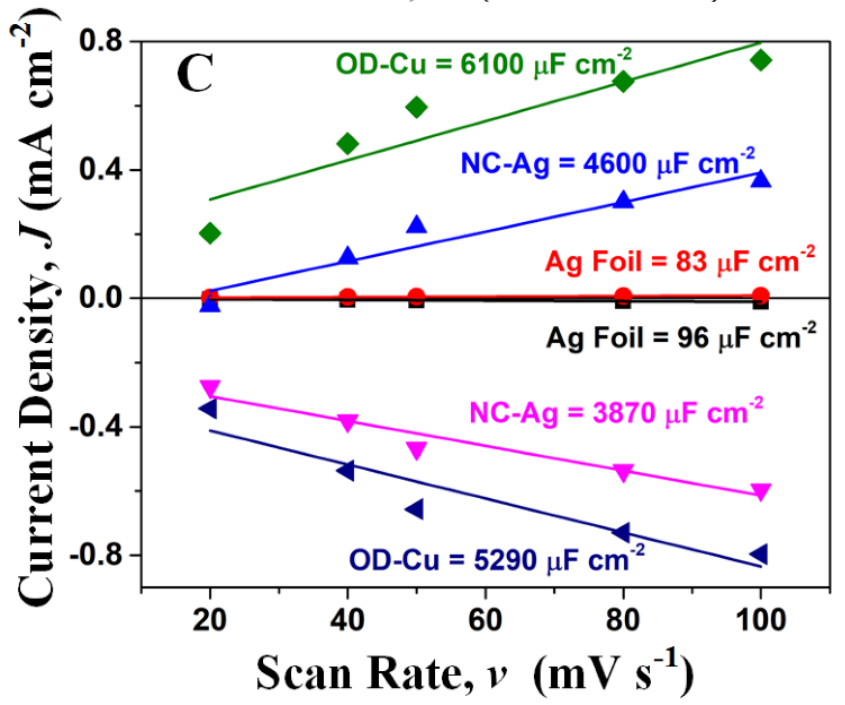

Figure 2.9. Double layer capacitance measurements for the determination of roughness factor based on electrochemically active surface area. Scan-rate dependent behavior for (A) Ag-NC and (B) OD$\mathrm{Cu}$ catalysts, and (C) cathodic and anodic charging currents as a function of scan rate for both catalysts and a polished Ag foil reference. 


\subsection{Photocatalysis for the Reduction of $\mathrm{CO}_{2}$}

Although other liquid products such as ethanol have been produced through $\mathrm{CO}_{2}$ electroreduction at low to moderate faradaic efficiency, ${ }^{199,200,202}$ much greater selectivity has been achieved for formic acid. ${ }^{179} \mathrm{Sn}$ and $\mathrm{SnO}_{\mathrm{x}}$ foils and nanostructures in particular have been prevalent electrocatalysts for the high faradaic efficiency formation of HCOOH. ${ }^{193,216-218}$ The benefits of $\mathrm{HCOOH}$ include stability and low volatility, and it is competitive with current state-of-the-art $\mathrm{H}_{2}$ storage methods with a viable volumetric capacity of $53.4 \mathrm{~g} \mathrm{H}_{2} / \mathrm{L}$ at ambient temperature and pressure. ${ }^{219,}{ }^{220} \mathrm{HCOOH}$ can also be consumed as a fuel in direct formic acid fuel cells. Moreover, the high market value of $\mathrm{HCOOH}$ per $\mathrm{CO}_{2}$ consumed makes it one of the most economically practical products for the initial establishment of an industrial electrochemical $\mathrm{CO}_{2}$ reduction process. ${ }^{221}$

In recent years, an increasing effort has been directed towards the realization of solar fuels through photoelectrochemical $\mathrm{CO}_{2}$ reduction. ${ }^{178,222}$ For photoelectrochemical $\mathrm{HCOOH}$ formation in particular, numerous studies have used photoanode materials to drive a separate $\mathrm{CO}_{2}$ reduction electrocatalyst at the cathode, ${ }^{223-228}$ and some have used photocathodes with a co-catalyst. ${ }^{229-234}$ With a sophisticated tandem III-V photoanode in combination with a noble metal Pd cathode, up

to $10 \%$ solar-energy-conversion to formic acid has been achieved. ${ }^{235}$ The equilibrium potential for the reduction of $\mathrm{CO}_{2}$ to formic acid is close to that for hydrogen evolution, ${ }^{178}$ and thus high efficiencies should be achievable with two-junction tandem photoelectrodes similar to that modeled for unassisted water-splitting. ${ }^{157} \mathrm{Si}$, as a well-developed, low-cost semiconductor with a band gap of $1.12 \mathrm{eV}$, is a prominent candidate for a bottom subcell photocathode in such a tandem. Photocathodes of $\mathrm{p}$-Si integrated with $\mathrm{Cu}$ and $\mathrm{Ag}$ catalysts 
have previously been demonstrated to provide light-enhanced $\mathrm{CO}_{2}$ reduction, with the resulting faradaic efficiencies and product distribution offset by the Si photovoltage but otherwise largely unchanged. ${ }^{236}$

Recently, we reported electrochemically reduced porous $\mathrm{SnO}_{\mathrm{x}}$ nanowire ( $\mathrm{Sn}-\mathrm{pNW}$ ) catalysts produced by a highly scalable plasma synthesis. ${ }^{193}$ An acid etching step during the catalyst processing was observed to introduce the nanoporosity as well as an increase in crystalline grain boundaries, which resulted in notably enhanced $\mathrm{CO}_{2}$ reduction current density and faradaic efficiency for $\mathrm{HCOOH}$. The enhanced activity was much greater than could be attributed to increased surface area in the Sn-pNWs alone, and the improved performance was credited to the introduction of more effective active sites at the grain boundaries. Herein we have incorporated these catalysts on $\mathrm{Si}$ photocathodes for the photoelectrochemical conversion of $\mathrm{CO}_{2}$ to $\mathrm{HCOOH}$ at high selectivity.

The synthesis of Sn-pNW catalysts has been described in detail previously. ${ }^{193,} 237$ Briefly, a solvo-plasma synthesis method was used in which bulk $\mathrm{SnO}_{2}$ powder was mixed with $\mathrm{KOH}$ in a 3:1 weight ratio and exposed to an atmospheric plasma of Ar and air at 1 $\mathrm{kW}$ for $2 \mathrm{~min}$. This process resulted in a potassium-rich $(\sim 7 \%) \mathrm{SnO}_{2}$ nanowire (Sn-NW) form which was separated from the larger particles by centrifugation. The as-synthesized Sn-NWs were then immersed in $0.1 \mathrm{M} \mathrm{HCl}$ for $1 \mathrm{~h}$ to etch the potassium-rich nanowires. The acid-etch removed most of the $\mathrm{K}$ atoms and produced the porous $\mathrm{SnO}_{2}$ nanowires ( $\mathrm{Sn}$ pNWs) with a high density of grain boundaries. ${ }^{193}$ The Sn-pNWs were subsequently calcined in air at $500{ }^{\circ} \mathrm{C}$ for $7 \mathrm{~h}$. Three types of electrode substrate were used throughout the work. Fluorine-doped tin oxide (FTO) coated glass (TEC 15, Hartford Glass Company, Inc.) substrates were used to measure the electrocatalyst properties by itself. Degenerately 
doped $\mathrm{n}^{+} \mathrm{p}-\mathrm{Si}(100)$ (doped with As to a resistivity of $0.001-0.005 \Omega \mathrm{cm}$, University Wafer) substrates were used to measure the dark electrocatalytic behavior of the Si semiconductor surface as well as the Si-supported Sn-pNW electrocatalyst behavior. Photoactive substrates consisted of a buried-junction $\mathrm{n}^{+} \mathrm{p}-\mathrm{Si}$ wafer $(\mathrm{p}-\mathrm{Si}(100)$ doped with $\mathrm{B}$ to $1-10 \mathrm{U}$ $\mathrm{cm}$, University Wafer, with $\mathrm{n}^{+}$emitter layer from $\mathrm{P}$ thermal diffusion to a junction depth of $\sim 200 \mathrm{~nm}$ following an established procedure ${ }^{238}$ ). Before drop-casting Sn-pNW catalysts on Si substrates, the Si native oxide layer was removed with a $10 \mathrm{~s}$ dip in $10 \% \mathrm{HF}$. To load catalyst on the electrodes, $5 \mathrm{mg}$ of $\mathrm{Sn}$-pNWs were sonicated in $1 \mathrm{~mL}$ of isopropanol, and then drop-cast onto the substrate in three separate intervals (with $15 \mathrm{~min}$ in between for drying) to an approximate loading of $\sim 2 \mathrm{mg} \mathrm{cm}^{-2}$, followed by $2 \mathrm{~h}$ on a hot plate at $70{ }^{\circ} \mathrm{C}$. An ohmic back contact to Si substrates was made using Ga/In eutectic (Alfa Aesar).

Current density vs. potential $(J-E)$ photoelectrochemical energy conversion behavior for all electrodes was measured in $\mathrm{CO}_{2}$-saturated $0.1 \mathrm{M} \mathrm{KHCO}_{3}(\mathrm{pH} 6.8$, made with $18 \mathrm{M} \Omega \mathrm{cm} \mathrm{H}_{2} \mathrm{O}$ ) under stirring with active bubbling of $\mathrm{CO}_{2}(99.99 \%$, Specialty Gases) at a flow rate of $10 \mathrm{sccm}$ at room temperature. The FTO or Si electrode served as a working electrode with a $\mathrm{Ag} / \mathrm{AgCl}$ (saturated $\mathrm{KCl}$ ) reference electrode ( $\mathrm{CH}$ Instruments, Inc.) along with a Pt gauze counter electrode separated from the main cell compartment by an anion exchange membrane (Selemion AMV) in a glass cell with a flat quartz window for illumination. Before each measurement with a Si electrode, the native oxide was removed with a $10 \mathrm{~s}$ dip in $10 \% \mathrm{HF}$. A potentiostat (Bio-Logic SP-200) with electrochemical impedance spectroscopy (EIS) was used for all measurements. Potentiostatic EIS measurements were performed before every experiment to determine the uncompensated solution resistance, $\mathrm{R}_{\mathrm{u}}$, and the potentiostat subsequently compensated for $85 \%$ of $\mathrm{R}_{\mathrm{u}}$ 
during electrolysis. The results are reported versus the reversible hydrogen electrode (RHE) scale according to $V_{R H E}=V_{A g / A g C l}+0.197 \mathrm{~V}+0.059 * \mathrm{pH}$. Simulated sunlight at an intensity of $100 \mathrm{~mW} \mathrm{~cm} \mathrm{~cm}^{-2}$ at normal incidence to the working electrode was generated with a 300 W Xe lamp (Newport 6258) coupled with an AM1.5 global filter (Newport 81094) and calibrated in the electrolyte with a Si photodiode (Thorlabs FDS100-CAL).

$\mathrm{CO}_{2}$ reduction products were measured by gas chromatography (GC, SRI 8610) for gaseous products and by nuclear magnetic resonance (NMR, Bruker $400 \mathrm{MHz}$ ) spectroscopy for liquid products. Both instruments were calibrated with standard gases or liquid solutions. The gas outlet from the catholyte was connected to the GC which used an automatic valve injection (1 mL sample) and a thermal conductivity detector (TCD) and flame ionization detector (FID). Nitrogen (99.99\%, Specialty Gases) was used as the carrier gas to enable accurate hydrogen quantification. For potentiostatic conditions at each measured potential, the gas was injected after 5 min and again twice at 18 min intervals. For ${ }^{1} \mathrm{H}$ NMR spectroscopy analysis of the liquid phase, samples were prepared by mixing $\mathrm{D}_{2} \mathrm{O}$ and electrolyte aliquots in a 1:1 volume ratio. Dimethyl sulfoxide (DMSO) was added at a known low concentration for internal calibration. faradaic efficiency for each product was calculated by determining the charge required to produce the measured product concentration and dividing by the total charge passed during the potentiostatic electrolysis measurement.

The photoelectrochemical $\mathrm{CO}_{2}$ reduction current density vs. potential $(J-E)$ behavior of the electrodes are shown in Fig. 2.10. The dark electrocatalytic performance of Sn-pNWs in the absence of substrate effects from the Si semiconductor was first established on flat FTO/glass substrates. Blank FTO is a kinetically poor surface for the 
reaction, while the addition of $\mathrm{Sn}-\mathrm{pNW}$ led to $-10 \mathrm{~mA} \mathrm{~cm} \mathrm{~cm}^{-2}$ at $-1.0 \mathrm{~V}$ vs. RHE. At the chosen catalyst loading, this performance was comparable to that previously reported on structured porous carbon gas diffusion layer substrates, which was competitive with many other reported $\mathrm{Sn}$-based $\mathrm{CO}_{2}$ reduction catalysts. ${ }^{193}$

For Si electrodes, degenerately doped $\mathrm{n}^{+}-\mathrm{Si}$ substrates were used to measure the dark electrocatalytic properties owing to their metallic character and abundance of majority-carrier electrons available for driving reduction under cathodic conditions. In contrast, for a buried-junction $\mathrm{n}^{+} \mathrm{p}-\mathrm{Si}$ or a photoelectrochemical liquid junction to $\mathrm{p}-\mathrm{Si}$, reverse bias conditions for the resulting diode behavior in the dark prevent the flow of electrons across the interface and prohibit the measurement of exponentially increasing current density characteristic of electrocatalytic Butler-Volmer kinetics. ${ }^{213}, 238-240$ The degenerate $\mathrm{n}^{+}-\mathrm{Si}$ substrates were thus used to capture this dark kinetic behavior of the $\mathrm{Si}$ surface to enable the photogenerated performance of the buried-junction electrodes to be compared to the dark Si cathodic overpotential behavior. For all Si electrodes, the surface was chemically etched prior to measurement to prevent the $\sim 1-2 \mathrm{~nm}$ native oxide from impeding charge transfer across the $\mathrm{Si} /$ water or $\mathrm{Si} / \mathrm{Sn}$-pNW interface. In the dark, bare $\mathrm{n}^{+}-$ Si electrodes exhibited a cathodic current onset at $-0.75 \mathrm{~V}$ vs. RHE and reached $10 \mathrm{~mA} \mathrm{~cm}^{-}$ 2 at $-1.30 \mathrm{~V}$ vs. RHE. With the addition of Sn-pNW co-catalyst, the cathodic current onset increased to $-0.42 \mathrm{~V}$ vs. RHE and reached $10 \mathrm{~mA} \mathrm{~cm}^{-2}$ at $-0.98 \mathrm{~V}$ vs. RHE, a decrease of $\sim 320 \mathrm{mV}$ in overpotential compared to the bare Si. However, the resulting linear ohmic character of the J-E curve for dark $\mathrm{n}^{+}-\mathrm{Si} / \mathrm{Sn}-\mathrm{pNW}$ s indicates an appreciable increase in series resistance, which we attribute to the interfacial series resistance from the contiguous 
Sn-pNW layer. If it was directly contacting a p-Si photocathode, this unbroken layer of SnpNWs would establish the barrier height at the $\mathrm{Sn} / \mathrm{Si}$ interface and restrict the achievable photovoltage in a liquid-junction photoelectrochemical cell. ${ }^{238,241}$ By using a buriedjunction $\mathrm{n}^{+} \mathrm{p}-\mathrm{Si}$ photoelectrode instead, the $\mathrm{Si}$ homojunction can maintain maximum
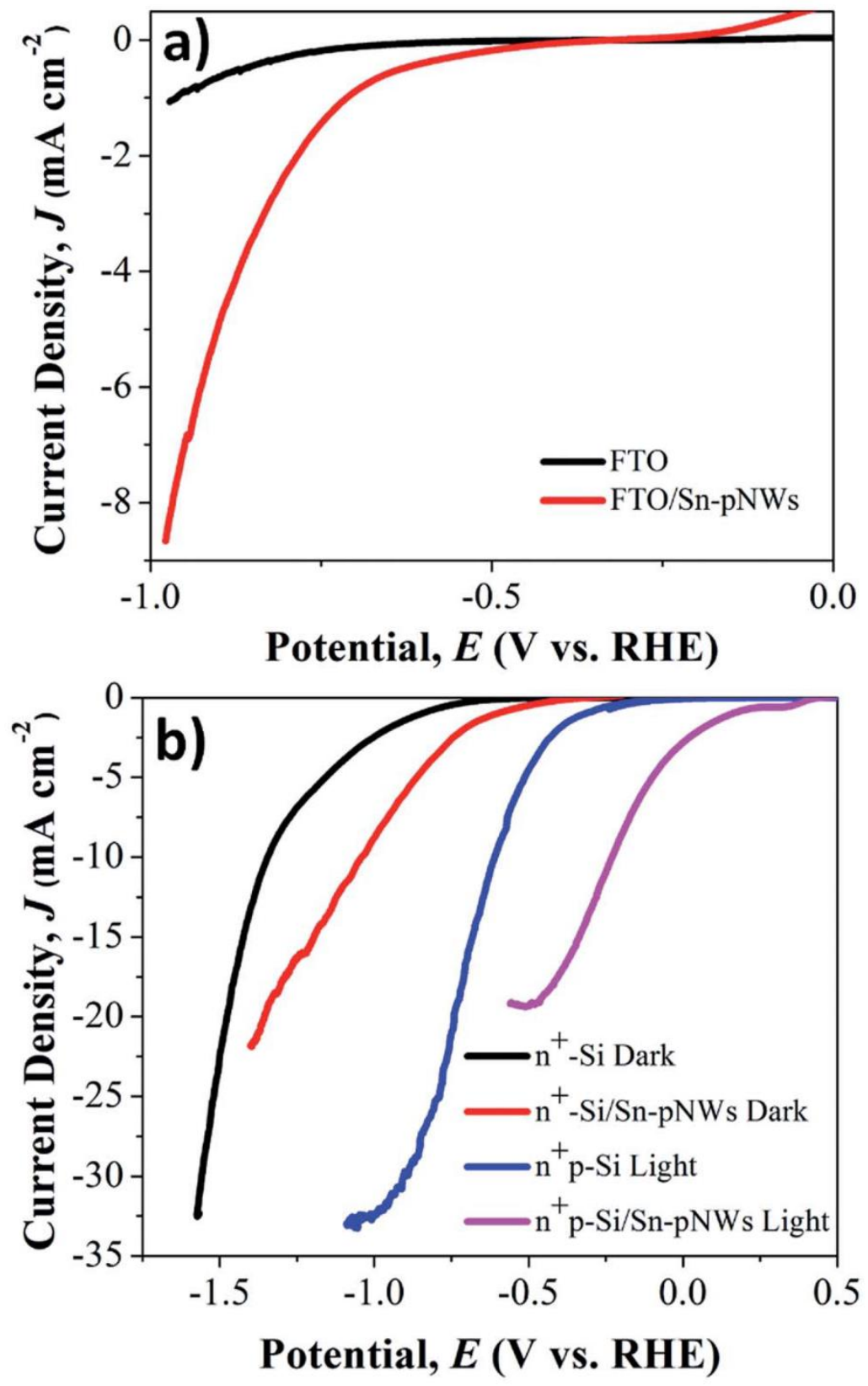

Figure 2.10 Current density vs. potential $(J-E)$ behavior for electrodes in $\mathrm{CO}_{2}$-saturated $0.1 \mathrm{M} \mathrm{KHCO}_{3}$. (a) Dark electrocatalytic behavior for FTO/glass with and without Sn-pNW catalyst. (b) Dark electrocatalytic behavior for degenerate $n^{+}-S i$ with and without $\mathrm{Sn}-\mathrm{pNW}$ catalyst and illuminated 1 Sun AM 1.5 behavior for buried-junction $n^{+}$p-Si photocathodes with and without Sn-pNW catalyst. 
photovoltage with minimal recombination at the junction interface. ${ }^{216,242}$ Charge transfer resistance at the $\mathrm{Si} / \mathrm{Sn}$-pNW interface may also contribute to the increased ohmic overpotential. However, the $\mathrm{SnO}_{2}$ conduction band edge is significantly lower (i.e., more positive) than the Si conduction band edge, ${ }^{168}$ which should promote photoexcited electron transfer to the co-catalyst for photoelectrochemical $\mathrm{CO}_{2}$ reduction. The bare buriedjunction $\mathrm{n}^{+} \mathrm{p}$-Si photoelectrode under 1 Sun AM 1.5 illumination showed the expected behavior relative to the bare $\mathrm{n}^{+}-\mathrm{Si}$. Illuminated bare $\mathrm{n}^{+} \mathrm{p}-\mathrm{Si}$ exhibited an onset for cathodic current at $-0.15 \mathrm{~V}$ vs. RHE, achieving $10 \mathrm{~mA} \mathrm{~cm} \mathrm{~cm}^{-2}$ at $-0.64 \mathrm{~V}$ vs. RHE, and reaching a lightlimited current density of $-33.0 \mathrm{~mA} \mathrm{~cm}{ }^{-2}$. Coating the $\mathrm{n}^{+} \mathrm{p}-\mathrm{Si}$ with Sn-pNW co-catalyst, the onset potential shifted to $-0.32 \mathrm{~V}$ vs. RHE and exhibited $10 \mathrm{~mA} \mathrm{~cm}^{-2}$ at $-0.25 \mathrm{~V}$ vs. RHE. The illuminated $\mathrm{n}^{+} \mathrm{p}-\mathrm{Si} / \mathrm{SnpNWs}$ photoelectrodes displayed a reduced light-limited current density $\left(-19.5 \mathrm{~mA} \mathrm{~cm}{ }^{-2}\right)$ relative to the bare photoelectrodes due to parasitic light absorption within the Sn-pNW co-catalyst layer. The reduced photocurrent was consistent with the measured catalyst layer transmittance which averaged $\sim 60 \%$ at wavelengths above the Si bandgap. The $\mathrm{n}^{+} \mathrm{p}-\mathrm{Si} / \mathrm{Sn}$-pNWs electrode also maintained $>90 \%$ of its photocurrent after $>3 \mathrm{~h}$ of operation. On illuminated buried junction $\mathrm{n}^{+} \mathrm{p}-\mathrm{Si}$ photoelectrodes at $10 \mathrm{~mA}$ $\mathrm{cm}^{-2}$, the Sn-pNW catalyst thus decreased the overpotential by $\sim 390 \mathrm{mV}$. Moreover, the positive shift in potential at $10 \mathrm{~mA} \mathrm{~cm}{ }^{-2}$ from dark Si electrocatalytic behavior to the illuminated performance reflects a 1-Sun generated photovoltage of $\sim 660 \mathrm{mV}$ for the $\mathrm{n}^{+} \mathrm{p}$ $\mathrm{Si}$. This is a high photovoltage for $\mathrm{Si}$, indicating a quality junction and low overall recombination. For Sn-pNW catalyzed electrodes, the light-driven positive shift in potential at $10 \mathrm{~mA} \mathrm{~cm}{ }^{-2}$ was even greater at $730 \mathrm{mV}$. This shift is perhaps too large to attribute to a buried-junction Si photovoltage alone, and we attribute the remainder to a 
slightly better catalyst interface with less series resistance compared to the dark $\mathrm{n}^{+}-\mathrm{Si} / \mathrm{Sn}$ pNW electrode.

The faradaic efficiencies for $\mathrm{CO}_{2}$ reduction products measured at the cathode are shown in Fig. 2.12 for $\mathrm{n}^{+} \mathrm{p}-\mathrm{Si} / \mathrm{Sn}$-pNWs under 1-Sun illumination and in the dark. The only products observed at these conditions by $\mathrm{GC}$ were $\mathrm{H}_{2}$ and $\mathrm{CO}$, and the only liquid product observed by NMR was HCOOH. At low applied potential (>-0.4 V vs. RHE) in the dark on $\mathrm{FTO}, \mathrm{H}_{2}$ was the dominant product with $>95 \%$ faradaic efficiency. However, the selectivity for formic acid increased greatly at more cathodic potentials, reaching as high as $65.9 \%$ at $-0.8 \mathrm{~V}$ vs. RHE, consistent with previously reported results on porous carbon electrodes. ${ }^{193}$ The CO faradaic efficiency for FTO/Sn-pNWs at this potential was limited to $9.2 \%$. The same trend in product distribution was observed under illumination on $\mathrm{n}^{+} \mathrm{p}-$ $\mathrm{Si} / \mathrm{Sn}$-pNWs with $\mathrm{H}_{2}$ being the sole product detected at potentials >-0.1 V vs. RHE, while the peak $\mathrm{HCOOH}$ faradaic efficiency was $59.2 \%$ at $-0.4 \mathrm{~V}$ vs. RHE with a corresponding $\mathrm{CO}$ faradaic efficiency of $11.4 \%$. Although the light-driven positive potential shift was less than observed in the $J-E$ curves, the overpotential for peak formic acid selectivity decreased by at least $400 \mathrm{mV}$. The energy of the incident light was thus converted to assist in the reduction of $\mathrm{CO}_{2}$ to a useful liquid product as $\mathrm{HCOOH}$. Without the Sn-pNW catalyst, $n^{+} \mathrm{p}-\mathrm{Si}$ electrodes produced primarily $\mathrm{H}_{2}$ with $<10 \%$ faradaic efficiency for $\mathrm{CO}$ (Fig. 2.11). 


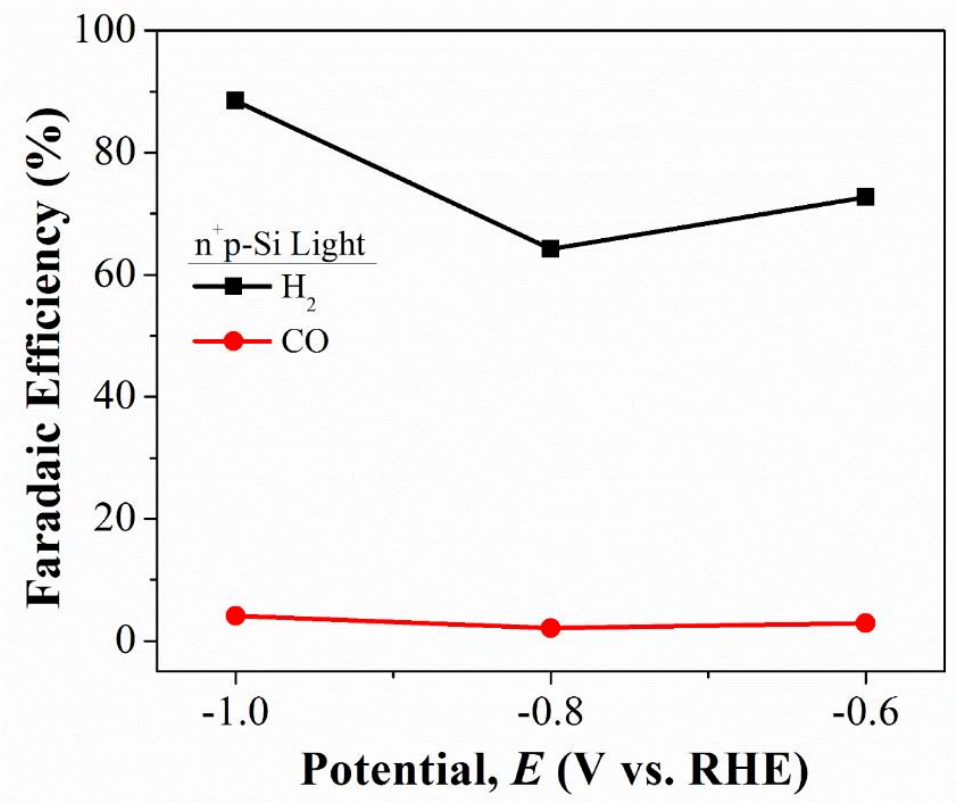

Figure 2.11 $\mathrm{CO}_{2}$ reduction product distribution in $\mathrm{CO}_{2}$-saturated $0.1 \mathrm{M} \mathrm{KHCO}_{3}$. Faradaic efficiency vs. potential for bare $\mathrm{n}^{+} \mathrm{p}-\mathrm{Si}$ under 1 Sun AM 1.5 illumination.

The partial current density of each product is displayed in Fig. 2.12 for illuminated $\mathrm{n}^{+} \mathrm{p}-$ Si/Sn-pNW photoelectrodes. The partial current density of formic acid, $J_{\mathrm{HCOOH}}$, achieved $10.0 \mathrm{~mA} \mathrm{~cm}^{-2}$ at $-0.4 \mathrm{~V}$ vs. RHE, increasing only slightly at more negative potentials as the photoelectrode reached its light-limited current density. For dark FTO/Sn-pNWs at - $0.8 \mathrm{~V}$ vs. RHE, the potential measured for peak $\mathrm{HCOOH}$ faradaic efficiency, $J_{\mathrm{HCOOH}}$ was only $1.64 \mathrm{~mA} \mathrm{~cm}^{-2}$. Only some of the best literature $\mathrm{Sn}$ based catalysts have reported $J_{\mathrm{HCOOH}}=$ $10 \mathrm{~mA} \mathrm{~cm}^{-2}$. For instance, $\mathrm{SnO}_{\mathrm{x}}$ on graphene was reported to produce $J_{\mathrm{HCOOH}} \sim 10 \mathrm{~mA} \mathrm{~cm}-$ ${ }^{2}$ at $-1.15 \mathrm{~V}$ vs. RHE. ${ }^{218}$ Hierarchical mesoporous $\mathrm{SnO}_{2}$ nanosheets on carbon cloth are among the highest current density formic-acid-selective $\mathrm{CO}_{2}$ electroreduction systems reported to date, but they required a cathodic potential of at least $-0.8 \mathrm{~V}$ vs. RHE to achieve $J_{\mathrm{HCOOH}}=10 \mathrm{~mA} \mathrm{~cm}{ }^{-2} .{ }^{243}$ Thus a solar driven $J_{\mathrm{HCOOH}} \sim 10 \mathrm{~mA} \mathrm{~cm}^{-2}$ at $-0.4 \mathrm{~V}$ vs. RHE makes this Si photoelectrode quite competitive for Sn-catalyzed $\mathrm{HCOOH}$ electrosynthesis from $\mathrm{CO}_{2}$. 


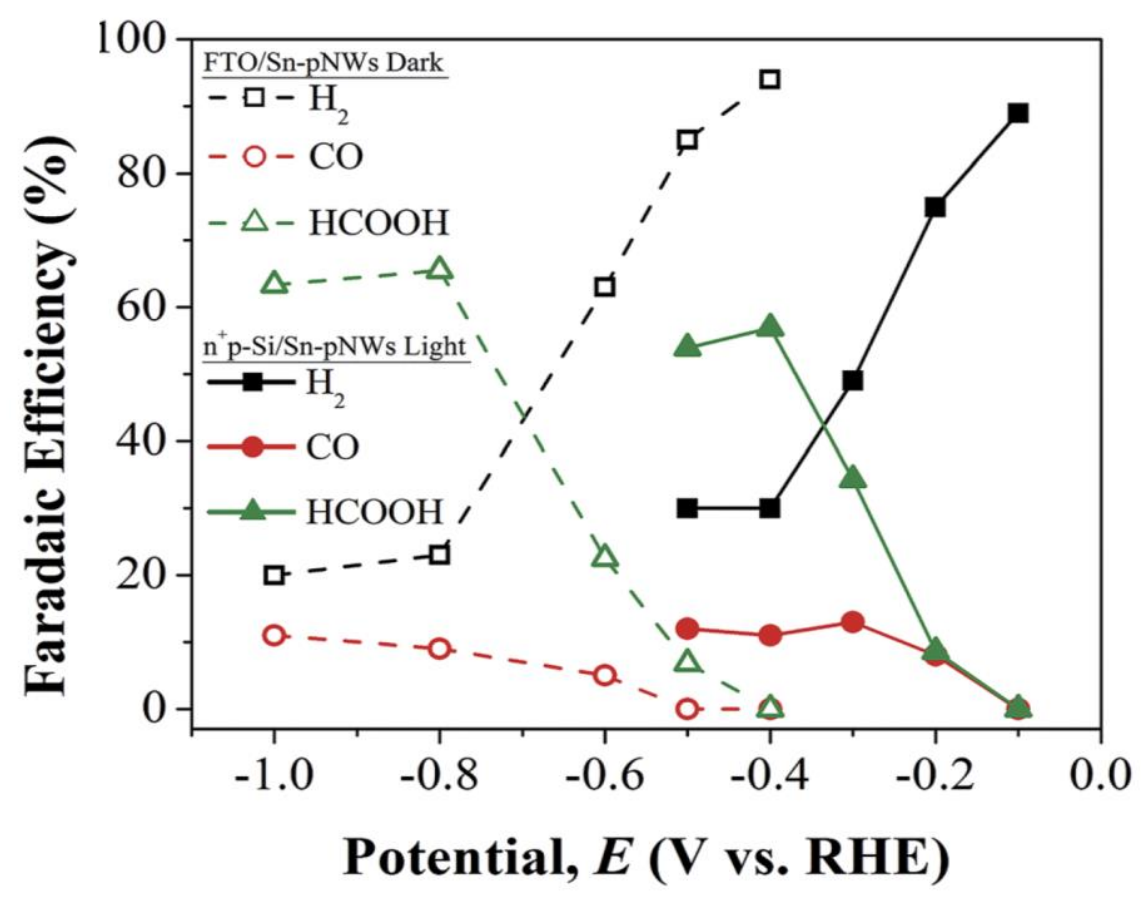

Figure 2.12 $\mathrm{CO}_{2}$ reduction product distribution in $\mathrm{CO}_{2}$-saturated $0.1 \mathrm{M} \mathrm{KHCO}$. Faradaic efficiency for $\mathrm{H}_{2}$ (squares), $\mathrm{CO}$ (circles), and $\mathrm{HCOOH}$ (triangles) for FTO/Sn-pNWs in the dark (dashed lines, open markers) and for $n^{+}$p-Si/Sn-pNWs under 1 Sun AM1.5 illumination (solid lines, filled markers).

To estimate the system efficiency for the photoelectrochemical energy-conversion behavior of the illuminated $\mathrm{n}^{+} \mathrm{p}-\mathrm{Si} / \mathrm{Sn}-\mathrm{pNW}$ photoelectrode for $\mathrm{CO}_{2}$ reduction, a photoassisted electrolysis system efficiency, $\eta_{P A E}$, was calculated by: ${ }^{244}$

$$
\eta_{P A E}=\frac{P_{f, o}}{P_{S}+P_{e, i}}
$$

where $P_{f, o}$ is the output power density contained in the chemical fuel produced, $P_{s}$ is the incident illumination power density, and $P_{e, i}$ is the input electrical power density. Considering the energy stored in the multiple products of this system $\left(\mathrm{H}_{2}, \mathrm{CO}, \mathrm{HCOOH}\right)$ :

$$
\eta_{P A E}=\frac{J_{f, o}\left(\varepsilon_{\mathrm{H}_{2}} E_{f, \mathrm{H}_{2}}+\varepsilon_{\mathrm{CO}} E_{f, \mathrm{CO}}+\varepsilon_{\mathrm{HCOOH}} E_{f, \mathrm{HCOOH}}\right.}{P_{S}+J_{o p} V_{e, i}}
$$

where $J_{o p}$ is the operating current density at the potential under evaluation, $\varepsilon_{i}$ represents the faradaic efficiency of each respective product, $E_{f, i}$ is the potential difference corresponding to the Gibbs free-energy difference between the two half-reactions for the fuels being 
produced at the cathode and for water oxidation at the anode, and $V_{e, i}$ is the input voltage required to drive the electrolysis at the operating current density of interest. $V_{e, i}$ is the total applied bias to the system, and thus represents the voltage required in a two-electrode electrolysis measurement. However, by separately measuring the $J-E$ behavior of the $\mathrm{Pt}$ gauze anode in the cell, the corresponding anodic overpotential at $J_{o p}$ can be accounted for to estimate $V_{e, i}{ }^{244} \mathrm{In}$ the current system for $\mathrm{n}^{+} \mathrm{p}-\mathrm{Si} / \mathrm{Sn}-\mathrm{pNW}$ under illumination at $-0.4 \mathrm{~V}$ vs. RHE, $V_{e, i}$ was estimated to be $\sim 2.03 \mathrm{~V}$. Using literature values for the cathodic halfreaction potentials for each product, ${ }^{209}$ we determined the total $\eta_{P A E} \sim 17.4 \%$. For the formic acid product alone $\eta_{P A E, \mathrm{HCOOH}} \sim 11.0 \%$. Though informative, photo-assisted electrolysis efficiency should not be compared directly with solar-to-fuel efficiency in the absence of electrical bias since electricity-to-fuel efficiency is typically much higher than solar-energy conversion efficiency. ${ }^{244}$ To produce $\mathrm{HCOOH}$ with the $\mathrm{n}^{+} \mathrm{p}-\mathrm{Si} / \mathrm{Sn}$-pNWs photocathode from sunlight unassisted by electrical bias, extra series-connected solar cells or a tandem combination

with complementary bandgap subcells would be required to achieve the necessary additional photovoltage.

\subsection{Isotopic Labelling for the Reduction of $\mathrm{CO}_{2}$}

The two-electron reduction of $\mathrm{CO}_{2}$ in the presence of a proton donor typically yields $\mathrm{HCO}_{2}{ }^{-}$or carbon monoxide $(\mathrm{CO})$ through common pathways that dictate the product 
Scheme 3 (A) Catalytic pathway for the reduction of $\mathrm{CO}_{2}$ to $\mathrm{HCO}_{2}{ }^{-}$by $\mathrm{Zn}(\mathrm{DMTH})$. The proton of the catalytic methanol is shown in red. The hydride $\left(\mathrm{H}^{-}\right)$, which can be chemical or electrochemical, is shown in green. All noncoordinating lone-pair electrons are shown. (B) Representation of $\mathrm{Zn}(\mathrm{DMTH})$ highlighting the frustrated Lewis pair-like interaction between the noncoordinating Lewis base (blue) and Lewis acid (red). Formal charges are shown in green. (C) Addition of methanol to $\mathrm{Zn}(\mathrm{DMTH})$ via metal-ligand cooperativity.

A

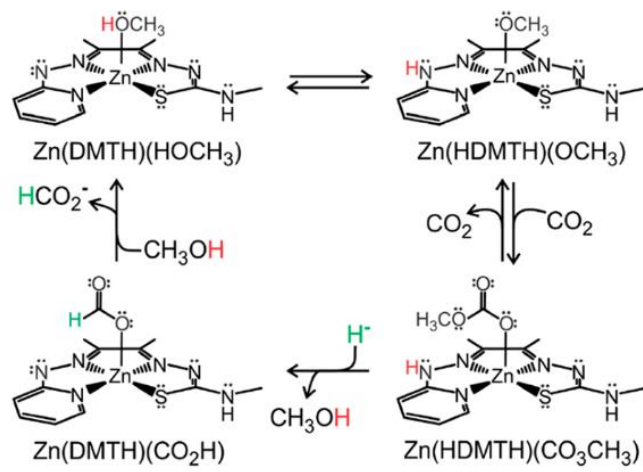

B

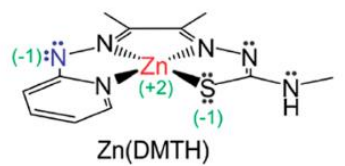

C

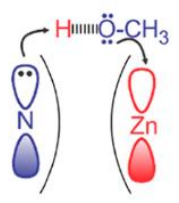

distribution. ${ }^{245}$ A significant limitation of these pathways is the requirement for reduction prior to $\mathrm{CO}_{2}$ binding, which limits their ability to fix $\mathrm{CO}_{2}$ at low pressure. To date, no catalyst following these pathways can utilize $\mathrm{CO}_{2}$ from air or 3-13\% streams commonly found in power plant exhaust. ${ }^{246}$ Recently, two catalysts that bind substrate prior to reduction have been reported, demonstrating the potential of alternate mechanistic approaches to improve catalytic activity. Protonation of fac- $\mathrm{Mn}\left(\left[(\mathrm{MeO})_{2} \mathrm{Ph}\right]_{2}\right.$ bpy) $\left.(\mathrm{CO})_{3}\left(\mathrm{CH}_{3} \mathrm{CN}\right)\right)-(\mathrm{OTf}) \quad\left(\left[(\mathrm{MeO})_{2} \mathrm{Ph}\right]_{2}\right.$ bpy $)=6,6^{\prime}$-bis(2,6-dimethoxyphenyl)-2,2'bipyridine, OTf $=$ triflate) prior to reduction lowers the overpotential for $\mathrm{CO}_{2}$ reduction to CO by $450 \mathrm{mV}^{247}$ relative to that of $\operatorname{Re}(\mathrm{bpy})(\mathrm{CO})_{3}(\mathrm{X})$ (bpy $=2,2^{\prime}$-bipyridine, $\mathrm{X}=$ halide). The $\operatorname{Re}($ bpy $)(\mathrm{CO})_{3}(\mathrm{X})$ derivative developed by Ishitani and co-workers, where $\mathrm{X}$ is a deprotonated triethanolamine, facilitates $\mathrm{CO}_{2}$ binding from air without prior reduction. ${ }^{248}$ Similar complexes with $\mathrm{Ru}^{249}$ and $\mathrm{Mn}^{250}$ also sequester low levels of $\mathrm{CO}_{2}$, but only the $\mathrm{Re}$ derivative has been reported to catalytically reduce $\mathrm{CO}_{2} \cdot{ }^{251}$ The Ishitani catalyst underscores the necessity to bind $\mathrm{CO}_{2}$ first in order to reduce $\mathrm{CO}_{2}$ at low concentrations. Previously, Ito reported $\mathrm{CO}_{2}$ fixation that yielded zinc-alkylcarbonate complexes $\mathrm{Zn}$ $\mathrm{CO}_{3} \mathrm{R}$ ) from air with alcohol solutions of $\mathrm{N} 4$ macrocycles, such as $\mathrm{Me}_{4}[14] \mathrm{aneN} 4$, 
containing $\mathrm{Zn}(\mathrm{II})$ and base. ${ }^{252}$ Building upon these ideas, Grapperhaus et al. developed $\mathrm{Zn}(\mathrm{DMTH}) \quad(\mathrm{DMTH}=$ diacetyl-2-(4-methyl-3-thiosemicarbazonate)-3-(2pyridinehydrazonato)) as a sustainable catalyst for the reduction of $\mathrm{CO}_{2}$ to formate from air.

To confirm that $\mathrm{HCO}_{2}{ }^{-}$is derived from $\mathrm{CO}_{2}$, isotopic labeling studies with ${ }^{13} \mathrm{CO}_{2}$ were conducted. The resulting experiment showed a doublet centered at $8.44 \mathrm{ppm}(J=139$ $\mathrm{Hz}$ ) for $\mathrm{H}^{13} \mathrm{CO}_{2}^{-}$and a singlet at $8.44 \mathrm{ppm}$ for $\mathrm{H}^{12} \mathrm{CO}_{2}^{-}$(Figure 2.13). ${ }^{253}$ The singlet intensity for $\mathrm{H}^{12} \mathrm{CO}_{2}^{-}$is attributed to $\mathrm{CO}_{2}$ generated by oxidation of solvent at the anode. Remarkably, when the reaction was repeated using air pumped into solution from the surroundings in place of a $\mathrm{CO}_{2}$ stream, reduction to $\mathrm{HCO}_{2}{ }^{-}$was observed with a total of 4 turnovers. The optimal faradaic efficiency is $15.8 \%$ based on total charge consumed and 47.6\% for background corrected charge. To our knowledge, this is the first reported electrocatalytic reduction of $\mathrm{CO}_{2}$ to $\mathrm{HCO}_{2}{ }^{-}$from air. For isotopic labeling studies, a $5 \mathrm{~L}$ tank of ${ }^{13} \mathrm{CO}_{2}$ was purchased from Cambridge Isotopes. This tank was connected with Swagelok fittings and a regulator to the airtight electrochemical cell containing $0.1 \mathrm{M}$ $\mathrm{NBu}_{4} \mathrm{PF}_{6}$ and $1.0 \mathrm{mM} \mathrm{Zn}(\mathrm{DMTH})$ in methanol. This cell contained a working glassy carbon and a $\mathrm{Ag} / \mathrm{AgCl}$ reference. The flow rate was adjusted to $10.0 \mathrm{cc} / \mathrm{min}$, and the cell was purged with the ${ }^{13} \mathrm{CO}_{2}$ for $15 \mathrm{~min}$. Then, $8.3 \mathrm{mM}$ acetic acid was added to the solution and it was stirred. The counter compartment containing $0.1 \mathrm{M} \mathrm{NBu}_{4} \mathrm{PF}_{6}$ in methanol and a platinum mesh electrode was placed as close to the working cell as possible. The solution was held at $-2.30 \mathrm{~V}$ vs $\mathrm{Fc} / \mathrm{Fc}^{+}$for $2 \mathrm{~h}$ using a Biologic SP200. A $500 \mu \mathrm{L}$ aliquot of this solution was removed and added to $100 \mu \mathrm{L}$ of DMSO- $\mathrm{d}_{6}$, and a ${ }^{1} \mathrm{H}$ NMR spectrum was recorded. 
$\mathrm{Zn}(\mathrm{DMTH})$ catalyzes the sequestration, activation, and reduction of $\mathrm{CO}_{2}$ to $\mathrm{HCO}_{2}^{-}$ on its own or in tandem with a hydride source. Notably, Zn(DMTH) maintains its activity at low pressure in the presence of oxygen and water allowing for direct capture and reduction of $\mathrm{CO}_{2}$ from air. This system was able to achieve 18.7-24.1\% $\mathrm{FE}$ for $\mathrm{HCO}_{2}^{-}$at 1 atm $\mathrm{CO}_{2}$ streams and 14.3-15.8\% $\mathrm{FE}$ for $\mathrm{HCO}_{2}^{-}$under air streams $\left(<1000 \mathrm{ppm} \mathrm{CO}_{2}\right)$. The unprecedented activity of $\mathrm{Zn}(\mathrm{DMTH})$ results from the inclusion of a FLP-like interaction for $\mathrm{CO}_{2}$ fixation in a redox-active ligand framework that facilitates $\mathrm{CO}_{2}$ reduction at a nonredox active $\mathrm{Zn}(\mathrm{II})$. Further, $\mathrm{Zn}(\mathrm{DMTH})$ is a stable catalyst that incorporates a sustainable earth-abundant metal in an oxygen- and water tolerant complex that can be synthesized from inexpensive chemical reagents. Our ligand-centric approach that combines features to fix and reduce $\mathrm{CO}_{2}$ at a single redox nonactive metal site is different from all other $\mathrm{CO}_{2}$ reduction catalysts and provides a new strategy to mitigate global $\mathrm{CO}_{2}$ levels.
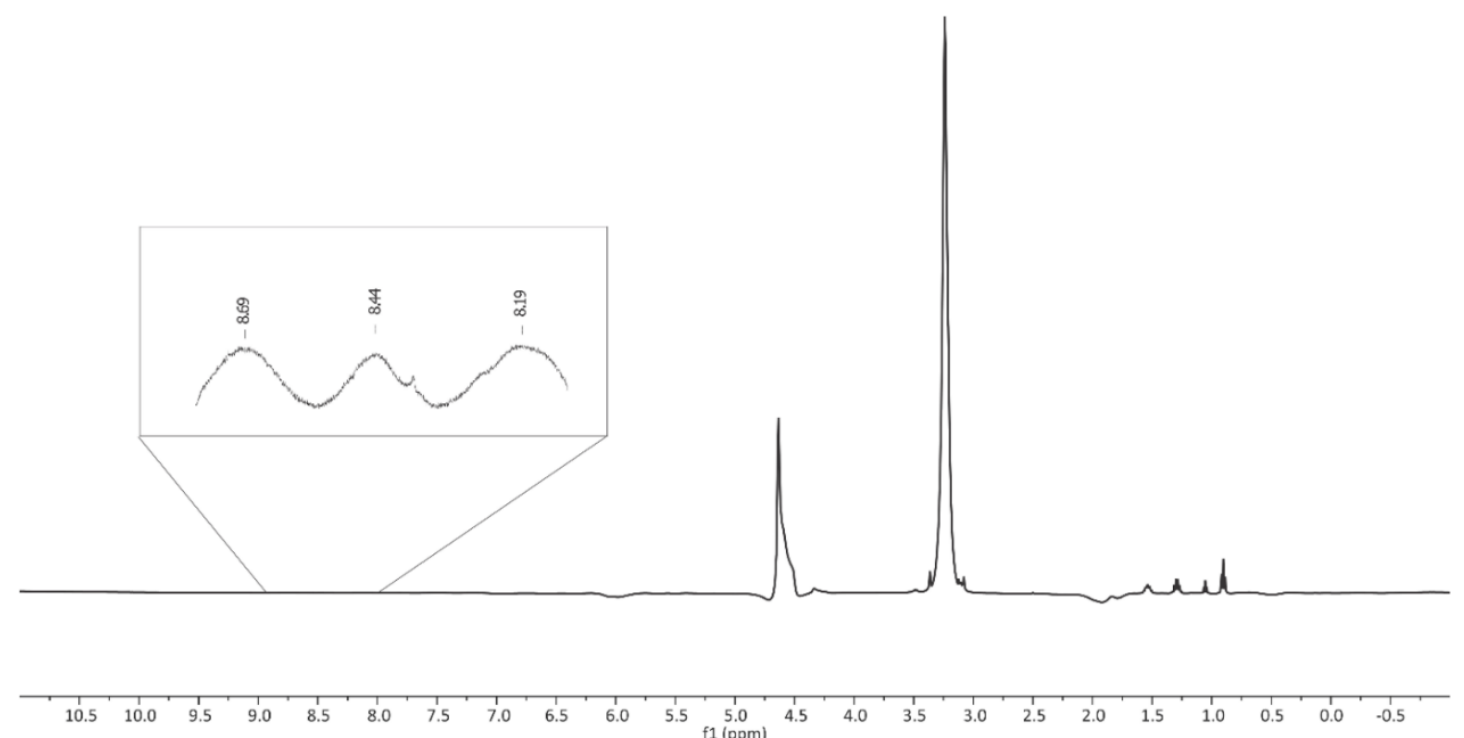

Figure 2.13 ${ }^{1} \mathrm{H}$ NMR of ${ }^{13} \mathrm{CO}_{2}$ reduction shows characteristic splitting of ${ }^{13} \mathrm{C}$-labelled formate $(8.44$ ppm). $J_{C-H}=138.75 \mathrm{~Hz}(500 \mathrm{MHz})$. 


\section{CHAPTER 3}

\section{ASSESSING CONTAMINANTS FROM ION-EXCHANGE MEMBRANES IN THE EVALUATION OF AQUEOUS ELECTROCHEMICAL DIOXIDE REDUCTION}

\subsection{Introduction}

The electrosynthesis of fuels and feedstock chemicals using $\mathrm{CO}_{2}$ and water as precursors has been widely recognized as a vital step toward a carbon-emission-free economy. ${ }^{254,255}$ Electrochemical $\mathrm{CO}_{2}$ reduction to $\mathrm{CO}$ has reached selectivity nearing $100 \%$ faradaic efficiency (FE) and has achieved high current densities on both $\mathrm{Au}$ and $\mathrm{Ag}$ catalysts. $^{256,257} \mathrm{CO}_{2}$ reduction to formic acid has been demonstrated with $94 \% \mathrm{FE}$ and high current density. ${ }^{258}$ Ethylene electrosynthesis from $\mathrm{CO}_{2}$ on $\mathrm{Cu}$ has achieved $70 \% \mathrm{FE}$ and $473 \mathrm{~mA} \mathrm{~cm}^{-2}{ }^{259}$ These advances and others suggest commercial promise for the electrochemical $\mathrm{CO}_{2}$ reduction reaction $\left(\mathrm{CO}_{2} \mathrm{RR}\right)$. Motivated by these results and guided by technoeconomic analyses $260,261, \mathrm{CO}_{2} \mathrm{RR}$ researchers are seeking to develop new catalysts and electrolysis strategies to selectively produce more complex, multicarbon products with greater value to enable $\mathrm{CO}_{2}$ electroreduction to gain a competitive foothold in the chemical industry.

As many as sixteen different products have been reported for $\mathrm{CO}_{2} \mathrm{RR}$ on $\mathrm{Cu}$, highlighting the myriad possible reaction pathways for hydrocarbon and oxygenate production with $\mathrm{C}-\mathrm{C}$ bond formation. ${ }^{91}$ To move towards greater multicarbon product selectivity, researchers are striving to design catalysts that break the scaling relations, which limit the degree to which the free energies of intermediates for a specific pathway 
can be optimized. ${ }^{206}$ Cascade electrolysis strategies have also been pursued ${ }^{262,263}$, leading to significant work in the direct $\mathrm{CO}$ reduction reaction (CORR). ${ }^{211,264} \mathrm{CO}$ reduction on $\mathrm{Cu}$ has attained high rates with a flow cell design achieving $91 \% \mathrm{FE}$ for $\mathrm{C}_{2+}$ products with a current density of $630 \mathrm{~mA} \mathrm{~cm}{ }^{-2} \cdot{ }^{265}$ Recently n-propanol production from CORR on $\mathrm{Cu}$ reached $23 \% \mathrm{FE}$ at $11 \mathrm{~mA} \mathrm{~cm}{ }^{-2}$, the present state-of-the-art for $\mathrm{C}_{3}$ product selectivity. ${ }^{97}$ Even $\mathrm{C}_{4}$ products have recently been reported. With $\mathrm{MoS}_{2}$ catalyst, t-butanol was discovered to be a $\mathrm{CO}_{2} \mathrm{RR}$ product at low rates. ${ }^{93} \mathrm{On} \mathrm{Ni}_{2} \mathrm{P}, 71 \% \mathrm{FE}$ to 2,3-furandiol was reported at strikingly low overpotential, although it only reached $22.25 \mu \mathrm{A} \mathrm{cm}{ }^{-2} .{ }^{92}$

In the expanding pursuit of multicarbon products from $\mathrm{CO}_{2} \mathrm{RR}$, even minor products are of interest. However, particularly at low electrolysis currents, the detection sensitivity becomes more challenging and the possible influence of contaminants is more significant. One potential source of contaminants is from the ion-exchange membrane commonly employed in electrolysis cells to separate the anode and cathode half-reactions. These membranes may still contain an appreciable amount of solvents or preservatives used in their fabrication and processing. As researchers become increasingly proficient at designing catalysts and electrochemical systems for $\mathrm{CO}_{2} \mathrm{RR}$ to complex multicarbon products, it is vital to eliminate sources of error which could contribute to spurious product identification. Herein we highlight the importance of appropriate membrane choice, pretreatment, and proper control experiments to ensure accurate product identification. 


\subsection{Experimental}

\subsubsection{Membranes and chemicals}

All reagents were used as received, including $\mathrm{KHCO}_{3}$ (ACS grade, $99.7-100 \%$, Alfa Aesar) and $\mathrm{KOH}$ (Reagent grade, Amresco). Membrane materials were purchased commercially, including Nafion-115 and Nafion-117 (Chemours), AMI-7001 and CMI7000 (Membranes International), Selemion (AGC Engineering Co., Ltd.), Sustainion (Dioxide Materials), and FumaSep FAPQ-375-PP (FuMA-Tech).

\subsubsection{Electrochemical CO reduction measurement}

Oxide-derived copper (OD-Cu) electrodes were prepared from $\mathrm{Cu}$ foil $(0.127 \mathrm{~mm}$ thick, 99.9\%, Alfa Aesar) following the procedure described by Li et al. ${ }^{211}$ The $\mathrm{Cu}$ foil was sonicated for 30 minutes in acetone and isopropanol for cleaning and then electropolished in $85 \%$ phosphoric acid (Macron Fine Chemicals) at $2 \mathrm{~V}$ applied bias vs. a secondary $\mathrm{Cu}$ foil for 5 min under vigorous stirring. Both sides of the foil were electropolished. The foil was then profusely rinsed in $18 \mathrm{M} \Omega-\mathrm{cm}$ water and dried under nitrogen. The $\mathrm{Cu}$ foil was subsequently placed in a muffle furnace under ambient air for thermal oxidation with a 1.5 $\mathrm{h}$ ramp up to $500{ }^{\circ} \mathrm{C}, 12 \mathrm{~h}$ at $500{ }^{\circ} \mathrm{C}$, and then a $10 \mathrm{~h}$ ramp down to room temperature. The $\mathrm{CuO}_{\mathrm{x}}$ foil was then placed in the electrochemical cell with $\sim 3 \mathrm{~cm}^{2}$ exposed to the $0.1 \mathrm{M}$ $\mathrm{KOH}$ electrolyte and reduced at $-0.5 \mathrm{~V}$ vs. RHE for 45-60 min until the current density reached a steady state current for $5 \mathrm{~min}$ at $\leq 5 \mathrm{~mA} \mathrm{~cm}^{-2}$. The electrochemical cell was made of polycarbonate plates and set up for a three-electrode experiment with the OD-Cu foil as the working electrode, platinum mesh as the counter electrode separated from the cathode compartment by the membrane, a $\mathrm{Ag} / \mathrm{AgCl}(\mathrm{CH}$ Instruments, Inc) in $3.0 \mathrm{M} \mathrm{KCl}$ as the 
reference electrode. ${ }^{212}$ Potentials were calculated from the equation $V_{R H E}=V_{A g / A g C l}+$ $0.210+0.059 * \mathrm{pH}$. The $\mathrm{pH}$ of the $0.1 \mathrm{M} \mathrm{KOH}$ electrolyte was 13 . The catholyte was then flushed and replaced with fresh $0.1 \mathrm{M} \mathrm{KOH}$ with a catholyte volume of $7.5 \mathrm{~mL}$, which had been purified using Chelex (100 sodium form, Sigma) ion-exchange resin.

Prior to CORR measurements, the electrolyte was bubbled with CO $(99.99 \%$, Specialty Gases) at $20 \mathrm{sccm}$ for $20 \mathrm{~min}$ and potentiostatic electrochemical impedence spectroscopy (PEIS) was conducted to measure the uncompensated cell resistance. Typical resistances for the cell were $11-14 \Omega$. The potentiostat (Biologic SP-200) was then set to compensate for $85 \%$ of the uncompensated resistance during the electrochemical CORR experiment, which was conducted with a steady $\mathrm{CO}$ flow rate of $20 \mathrm{sccm}$ through a bubbler in the catholyte at the base of the OD-Cu electrode. The example CORR electrolysis demonstrated herein was measured at $-0.3 \mathrm{~V}$ vs. RHE for 60 min using a pretreated AMI7001 membrane.

\subsubsection{Product detection}

CO reduction products were measured by gas chromatography (GC, SRI 8610) and nuclear magnetic resonance (NMR) for the gas and liquid products, respectively. Both instruments were calibrated with standard gases or liquid solutions. The liquid products were collected at $0 \mathrm{~min}$ and $60 \mathrm{~min}$ for each electrolysis experiment. A $400 \mu \mathrm{L}$ aliquot of the catholyte was mixed with $100 \mu \mathrm{L}$ of $\mathrm{D}_{2} \mathrm{O}$ that contained $\sim 100 \mathrm{ppm}$ dimethyl sulfoxide (DMSO, ACS grade, Amresco). The peak area of the internal standard of DMSO was compared to the peak area of each liquid product in ${ }^{1} \mathrm{H}-\mathrm{NMR}$ using a Varian $700 \mathrm{MHz}$ cold-probe. The ${ }^{1} \mathrm{H}-\mathrm{NMR}$ and H-H COSY spectra were obtained on a Varian $700 \mathrm{MHz}$ 
cold probe spectrometer. The proton 1D spectra were conducted with a water saturated method with a $5 \mathrm{~s}$ presaturation delay, $4 \mathrm{~s}$ acquisition time, $2 \mathrm{~s}$ relaxation delay, $45^{\circ}$ pulse angle, and 16 scans. The H-H COSY spectra was conducted with a relaxation delay of 1.2 s, an acquisition time of $0.183 \mathrm{~s}, 64$ scans, and 256 increments. Gas-chromatography mass spectrometry (GC-MS) was performed on an Agilent 7820A GC with a quadrupole mass spectrometer (Agilent Technologies 5975 MSD). Data analysis was performed with Agilent Chemstation and the species referenced to the NIST08 library. ${ }^{257}$ The GC-MS instrument was comprised of a 7820 A GC system and 5975 series MSD using He as a carrier gas at a flow rate of $1 \mathrm{~mL} \mathrm{~min}^{-1}$. The oven temperature was set to $50{ }^{\circ} \mathrm{C}$ and then ramped at a rate of $20{ }^{\circ} \mathrm{C}$ to $250{ }^{\circ} \mathrm{C}$ over $10 \mathrm{~min}$. The column used was an Agilent $\mathrm{J} \& \mathrm{~W}$ HP- $5 \mathrm{~ms}$ with a length of $30 \mathrm{~m}$, a $250 \mu \mathrm{m}$ inner diameter and a $0.25 \mu \mathrm{m}$ thickness.

\subsubsection{Membrane soak}

Several ionomer membranes common for electrolysis experiments were analyzed for contaminants, and one example case study was explored to demonstrate how the membrane residue can lead to the misidentification of electroreduction products. A selection of common commercially available ion-exchange membranes was tested. The group of anion-exchange membranes included: Selemion AMV (ammoniumfunctionalized polystyrene blend with poly(vinyl chloride) ${ }^{266}$ ), Sustainion (imidazoliumfunctionalized polystyrene ${ }^{267}$ ), FumaSep FAPQ-375-PP (polypropylene-reinforced fluorinated anion-exchange copolymer ${ }^{268}$ ), and AMI-7001 (quaternary-ammoniumfunctionalized polystyrene ${ }^{269}$ ). The group of cation-exchange membranes included: CMI7000 (sulfonic-acid-functionalized polystyrene ${ }^{269}$ ), Nafion-117 (sulfonic-acid- 
functionalized polytetrafluoroethylene ${ }^{270}$ ), and Nafion-115. In each case, $1 \mathrm{~cm}^{2}$ of the membrane material as received was immersed in $10 \mathrm{~mL}$ of an aqueous solution of either $0.1 \mathrm{M} \mathrm{KHCO}_{3}$ or $0.1 \mathrm{M} \mathrm{KOH}$ for two hours. These are the two most common electrolytes used for $\mathrm{CO}_{2} \mathrm{RR}$ and $\mathrm{CORR}$, respectively. Aliquots of the solution were then analyzed by nuclear magnetic resonance (NMR) spectroscopy (see Appendix), following the technique used by Kuhl, et al. ${ }^{91}$

\subsection{Results and discussion}

\subsubsection{Membrane contaminants}

NMR has been a favored method of liquid product detection by $\mathrm{CO}_{2} \mathrm{RR}$ researchers. The analyte species were identified by the chemical shifts listed in Table 3.1. Several contaminants were detected from these membranes (Fig. 3.1, Table 3.2), including stearic acid, N-methyl-2-pyrrolidinone (NMP), n-propanol, acetone, methanol, ethylene glycol, and polyethylene glycol (PEG). NMR spectra for each membrane soak are shown in Figs. A.1-7. Stearic acid was observed in small quantities in every measurement, including blank electrolyte control measurements. We attribute this to the role of stearic acid as a precursor in the synthesis of polypropylene, which was a component in the tubes used for these experiments. ${ }^{271}$ Although stearic acid was thus excluded from the subsequent table of 
a)<smiles>CN1CCCC1=O</smiles>

b)<smiles>CCCO</smiles>

$\mathrm{N}$-methyl-2-pyrrolidinone (NMP)

d)<smiles>CC(C)=O</smiles>
acetone e)<smiles>CO</smiles>
methanol n-propanol

)<smiles>O=CO</smiles>
ethylene glycol c)<smiles>CCCC(=O)O</smiles>
stearic acid

g)<smiles>OCCCO</smiles>

polyethylene glycol (PEG) h)<smiles>O=C(O)CCCO</smiles>

gamma-hydroxybutyric acid (GHB) i)<smiles>O=C(O)CCC(=O)O</smiles>

succinic acid

Figure 3.1. Chemical structures of observed contaminants (a-g) and misinterpreted hypothetical products $(\mathrm{h}-\mathrm{i})$.

membrane contaminants, its appearance further highlights the importance of control experiments in avoiding false product detection. Polypropylene is also used in some membranes (e.g., FumaSep FAPQ-375-PP).

For the untreated membranes, some materials displayed nearly negligible contaminants, while others had a contaminant at levels that could lead to product misinterpretation. Selemion AMV, Nafion-117, and Nafion-115 contained only trace levels of the common solvents methanol, propanol, and acetone. However, Sustainion had high levels of ethylene glycol and FumaSep FAPQ-375-PP had high levels of PEG. AMI-7001 and CMI-7000 both had high levels of NMP, which is a casting and modifying solvent used in some membrane fabrication. ${ }^{272}$ Without proper controls, these contaminants could

Table 3.1

The chemical shifts in ppm assigned to the measured analytes.

\begin{tabular}{lllllll}
\hline Analyte & Propanol & NMP & Acetone & Methanol & Ethylene Glycol & PEG \\
\hline$\delta(\mathrm{ppm})$ & 0.78 & 1.87 & 2.06 & 3.20 & 3.52 & 3.60 \\
\hline
\end{tabular}


Table 3.2

Concentrations (ppm) of analytes measured in membrane soaks for untreated membranes. $\mathrm{KHCO}_{3}$ and $\mathrm{KOH}$ were both $0.1 \mathrm{M}$.

\begin{tabular}{|c|c|c|c|c|c|c|c|c|c|c|c|c|}
\hline \multirow[b]{2}{*}{ Membrane } & \multicolumn{2}{|c|}{ Propanol } & \multicolumn{2}{|l|}{ NMP } & \multicolumn{2}{|l|}{ Acetone } & \multicolumn{2}{|c|}{ Methanol } & \multicolumn{2}{|c|}{ Ethylene Glycol } & \multicolumn{2}{|l|}{ PEG } \\
\hline & $\mathrm{KHCO}_{3}$ & $\mathrm{KOH}$ & $\mathrm{KHCO}_{3}$ & $\mathrm{KOH}$ & $\mathrm{KHCO}_{3}$ & $\mathrm{KOH}$ & $\mathrm{KHCO}_{3}$ & $\mathrm{KOH}$ & $\mathrm{KHCO}_{3}$ & $\mathrm{KOH}$ & $\mathrm{KHCO}_{3}$ & $\mathrm{KOH}$ \\
\hline Selemion AMV & - & - & - & - & 0.68 & - & 1.36 & - & - & - & - & - \\
\hline Sustainion & - & - & - & - & 0.90 & - & 0.41 & - & 268 & 169 & - & - \\
\hline FumaSep FAPQ-375-PP & - & - & - & - & 0.07 & - & 0.07 & - & - & - & 51.6 & 12.62 \\
\hline AMI-7001 & - & - & 428 & 379 & - & 6.77 & - & - & - & - & - & - \\
\hline CMI-7000 & - & - & 307 & 167 & - & 11.34 & - & - & - & - & - & - \\
\hline Nafion-117 & - & - & - & - & - & - & 0.51 & - & 0.52 & - & - & - \\
\hline Nafion-115 & 0.52 & - & - & - & 0.15 & - & 0.11 & - & 0.02 & - & - & - \\
\hline
\end{tabular}

easily be misidentified as products of $\mathrm{CO}_{2} \mathrm{RR} / \mathrm{CORR}$. Or in the case of NMP, an unsuspecting researcher not expecting to find $\mathrm{N}$-containing products could misinterpret the spectroscopy results.

Some of these membrane manufacturers specify pretreatment conditioning that should be applied before use. Sustainion, as received was stored in a solution of $10 \%$ ethylene glycol, so this contaminant is not surprising for the untreated membrane. Upon pretreatment by soaking in $1 \mathrm{M} \mathrm{KOH}$ for $24 \mathrm{~h}$, however, the ethylene glycol concentration fell below the NMR detection limit (Table 3.3). The pretreatment step is thus critical prior to using Sustainion in $\mathrm{CO}_{2} \mathrm{RR} / \mathrm{CORR}$ research for multicarbon products. FumaSep FAPQ375-PP, in contrast, is sold ready to use without pretreatment. The lack of pretreatment makes the observed PEG contaminant more problematic. However, the FumaSep manufacturer does recommend an ideal electrolyte $\mathrm{pH}<4$, unlike the neutral and alkaline conditions tested here. Lastly, AMI-7001 and CMI-7000, which are analogous anionexchange and cation-exchange membranes, respectively, from the same manufacturer (Membranes International), both have a recommended pretreatment consisting of a 12 hour soak in the application electrolyte. After this pretreatment, the detected NMP Table 3.3

Concentrations (ppm) of analytes measured for Sustainion, AMI-7001, and CMI-7000 after pretreatment. $\mathrm{KHCO}_{3}$ and $\mathrm{KOH}$ were both $0.1 \mathrm{M}$.

\begin{tabular}{|c|c|c|c|c|c|c|c|c|c|c|c|c|}
\hline \multirow[b]{2}{*}{ Membrane } & \multicolumn{2}{|c|}{ Propanol } & \multicolumn{2}{|l|}{ NMP } & \multicolumn{2}{|l|}{ Acetone } & \multicolumn{2}{|c|}{ Methanol } & \multicolumn{2}{|c|}{ Ethylene Glycol } & \multicolumn{2}{|l|}{ PEG } \\
\hline & $\mathrm{KHCO}_{3}$ & $\mathrm{KOH}$ & $\mathrm{KHCO}_{3}$ & $\mathrm{KOH}$ & $\mathrm{KHCO}_{3}$ & $\mathrm{KOH}$ & $\mathrm{KHCO}_{3}$ & $\mathrm{KOH}$ & $\mathrm{KHCO}_{3}$ & $\mathrm{KOH}$ & $\mathrm{KHCO}_{3}$ & $\mathrm{KOH}$ \\
\hline Sustainion & - & - & - & - & - & - & - & - & - & - & - & - \\
\hline AMI-7001 & - & 0.23 & 53.14 & 12.44 & - & 9.89 & - & - & - & - & - & - \\
\hline CMI-7000 & - & - & 28.75 & 17.41 & 0.11 & 0.07 & - & - & - & - & - & - \\
\hline
\end{tabular}


concentration was reduced by approximately an order of magnitude. However, the observed NMP contaminant for AMI-7001 was still 53.14 and 12.44 ppm for $0.1 \mathrm{M} \mathrm{KHCO}_{3}$ and $0.1 \mathrm{M} \mathrm{KOH}$, respectively (Table 3.3). This is an appreciable concentration for a $\mathrm{C}_{4}$ species which could cause a significant error in $\mathrm{CO}_{2} \mathrm{RR} / \mathrm{CORR}$ product quantification if misinterpreted. The anion-exchange form, AMI-7001, is the more commonly employed membrane of the two for $\mathrm{CO}_{2} \mathrm{RR} / \mathrm{CORR}$ studies. The untreated NMP concentration for AMI-7001 showed significant variability, especially at moderate $\mathrm{pH}$ values, as evidenced by large error bars at $\mathrm{pH}$ 7-11 (Fig. 3.2). NMP concentrations were measured ranging from $<200$ to even over $1000 \mathrm{ppm}$ at $\mathrm{pH} 9-10$. This variability may be partially attributable to solvent residue nonuniformity and edge effects across large area membrane rolls that were randomly sampled for testing. The pretreated membrane, however, did not show a

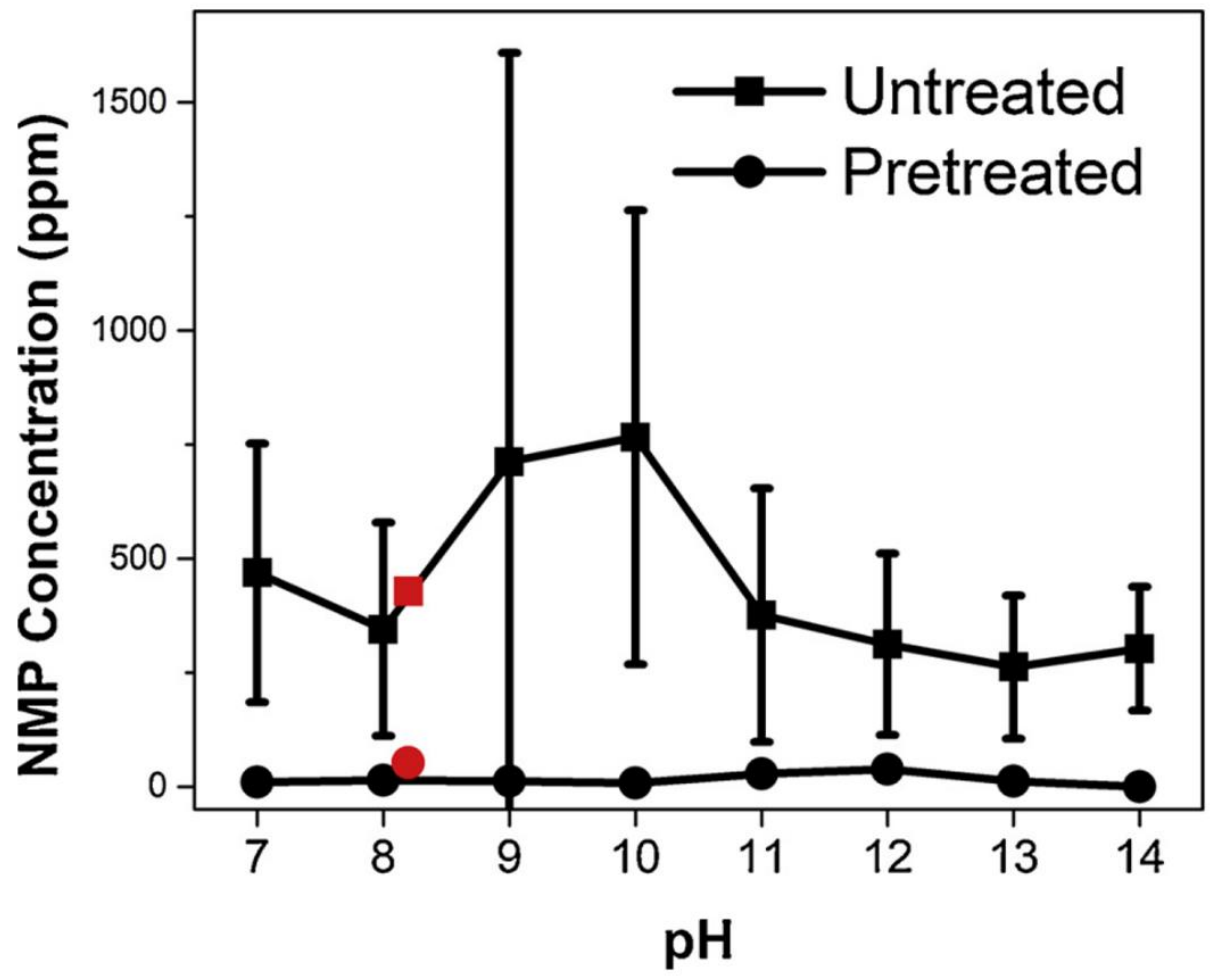

Figure 3.2. NMP concentration vs. $\mathrm{pH}$ for the soaking of AMI-7001 in KOH, with pH adjusted by $\mathrm{H}_{2} \mathrm{SO}_{4}$. The soaks in $0.1 \mathrm{M} \mathrm{KHCO}_{3}$ are shown with red markers. 
$\mathrm{pH}-$ dependence to the contaminant level, with a steady NMP concentration from $10-53$ ppm.

\subsubsection{Case study}

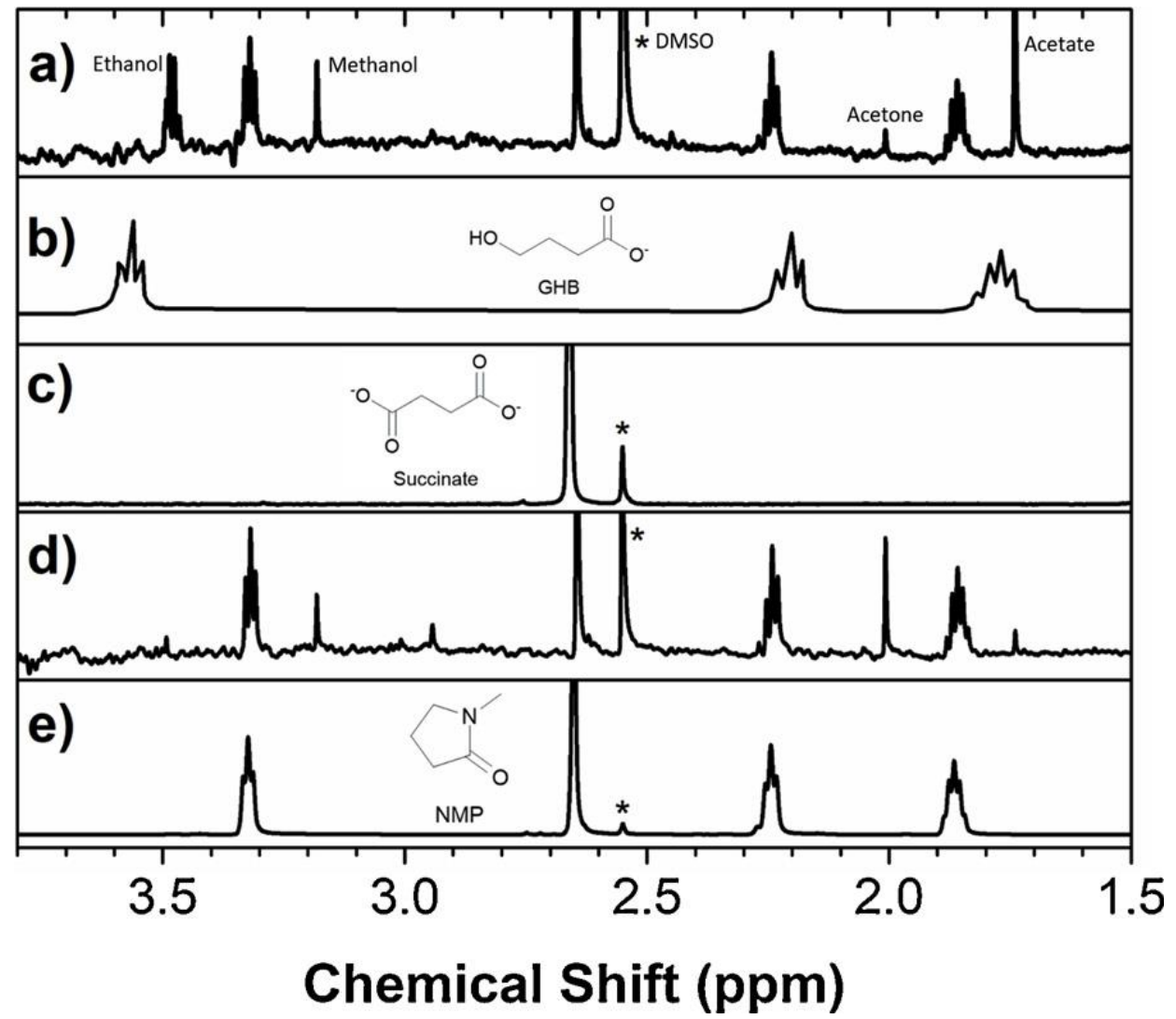

Figure 3.3. Comparison of proton NMR spectra $(700 \mathrm{MHz})$ for (a) an experimental sample from $\mathrm{CO}$ electroreduction at $-0.3 \mathrm{~V}$ vs. RHE in $0.1 \mathrm{M} \mathrm{KOH}$ on OD-Cu, (b) a literature result for GHB at $\mathrm{pH} 8,{ }^{273}$ (c) a succinic acid standard, (d) an aliquot from the AMI-7001 membrane soak, and (e) an NMP standard.

To illustrate the detrimental effect of the membrane contaminants on product identification, a case study for $\mathrm{CO}$ reduction on oxide-derived $\mathrm{Cu}(\mathrm{OD}-\mathrm{Cu})$ catalyst in $0.1 \mathrm{M}$ $\mathrm{KOH}$ with an AMI-7001 membrane was investigated. OD-Cu reaches a peak faradaic efficiency for ethanol at $-0.3 \mathrm{~V}$ vs. RHE under these conditions. ${ }^{211}$ For a $60 \mathrm{~min}$ potentiostatic electrolysis at $-0.3 \mathrm{~V}$ vs. RHE in CO- bubbled electrolyte, the resulting NMR spectra of the catholyte is shown in Fig. 3.3a. Peaks in chemical shift were observed at $\delta=$ 
$2.55 \mathrm{ppm}$, corresponding to the dimethyl sulfoxide (DMSO) used as an internal standard (see Appendix), as well as at $\delta=1.71$ and $3.45 \mathrm{ppm}$, corresponding to substantial levels of the expected acetate and ethanol products, respectively. Four additional peaks were observed at $\delta=3.30,2.65,2.22$, and $1.87 \mathrm{ppm}$. The splitting pattern of three of the peaks denoted a possible chain of three methylenes. The fourth peak at $\delta=2.65 \mathrm{ppm}$ however was a singlet and initially difficult to interpret. The triple methylene fragment chemical shifts could possibly be attributed to a $\mathrm{C}_{3}$ carbon chain with alcohol and carboxylate end groups. This molecule would then be $\gamma$-hydroxybutyrate (GHB) (Fig. 3.1h). This interpretation can be supported by a literature example of the proton NMR of GHB (Fig. $3.3 b)^{273}$ showing very similar chemical shifts, albeit the peak corresponding to the methylene adjacent to the alcohol group was reported at modestly higher chemical shift ( $\delta$ $=3.59 \mathrm{ppm})$ compared to the relevant peak from the CO reduction sample $(\delta=3.30 \mathrm{ppm}$, Fig. 3.3a). However, the solution $\mathrm{pH}$ is known to influence this NMR peak for GHB, leading to a decreased chemical shift under more basic conditions. ${ }^{273,}{ }^{274}$ With the CO reduction electrolyte at $\mathrm{pH} 13$ compared to the reported GHB sample at $\mathrm{pH} 8$, the deviation in this peak could be attributed to this effect. Further identification was pursued by $2 \mathrm{D}$ proton-proton correlation spectroscopy (H-H COSY), and two cross-peaks representing links between the triple methylene chain chemical shifts confirmed the observation of this $\mathrm{C}_{3}$ fragment (Fig. 3.4a). These observed cross-peaks also resemble a 2D H-H COSY spectrum of GHB, further supporting this identification. ${ }^{275}$ For the unknown singlet peak at $\delta=2.65 \mathrm{ppm}$, a similar chemical shift was reported in the literature for another $\mathrm{C}_{4}$ species, succinic acid (Fig. 3.1i). ${ }^{276}$ A measured proton NMR spectrum for a standard of succinic acid confirmed the presence of a strong singlet peak at $\delta \sim 2.65$ ppm (Fig. 3.3c). 
Thus, a CORR researcher relying solely on NMR for liquid product identification and unaware of the presence of possible membrane contaminants could reasonably conclude that the $\mathrm{CO}$ reduction had produced the $\mathrm{C}_{4}$ species $\mathrm{GHB}$ and succinic acid.

\subsubsection{Secondary confirmation via GC-MS}

However, expanding the catholyte characterization methods to include gaschromatography mass-spectrometry (GC-MS) provides additional insight. The mass-tocharge ratio $(\mathrm{m} / \mathrm{z})$ data for the $\mathrm{GC}$ peak corresponding to the experimental $\mathrm{C}_{4}$ species is shown in Fig. 3.4b, along with the mass spectrum for a NIST reference of NMP. The NIST08 library confirmed the experimental $\mathrm{C}_{4}$ mass spectrum to be NMP with $>95 \%$ probability. Because NMP is a nitrogen-containing cyclic compound, it is clearly not a product resulting directly from $\mathrm{CO}$ reduction in water, but instead is attributed to membrane contamination. Indeed, a proton NMR spectrum of the aliquot from AMI-7001 membrane soaking (Fig. 3.3d) shows the same four peaks analyzed above and naively assigned to GHB and succinic acid. An NMR spectrum for a standard solution of NMP further clarifies these peak assignments (Fig. 3.3e). Note that for the experimental conditions of this example, $\sim 1.24 \mathrm{~mA} \mathrm{~cm}^{-2}$ at $-0.3 \mathrm{~V}$ vs. RHE for $60 \mathrm{~min}$ in $7.0 \mathrm{~mL}$ of electrolyte, the highest pretreated AMI-7001 concentration of 53.14 ppm NMP (Table 3.3) would be calculated to correspond to a faradaic efficiency of $6.26 \%$ GHB and $8.34 \%$ succinic acid following the incorrect NMR interpretation. Thus, for multicarbon products requiring numerous electrons per molecule to produce, it is particularly important to eliminate spurious product detection due to contaminants from membranes and other sources. 

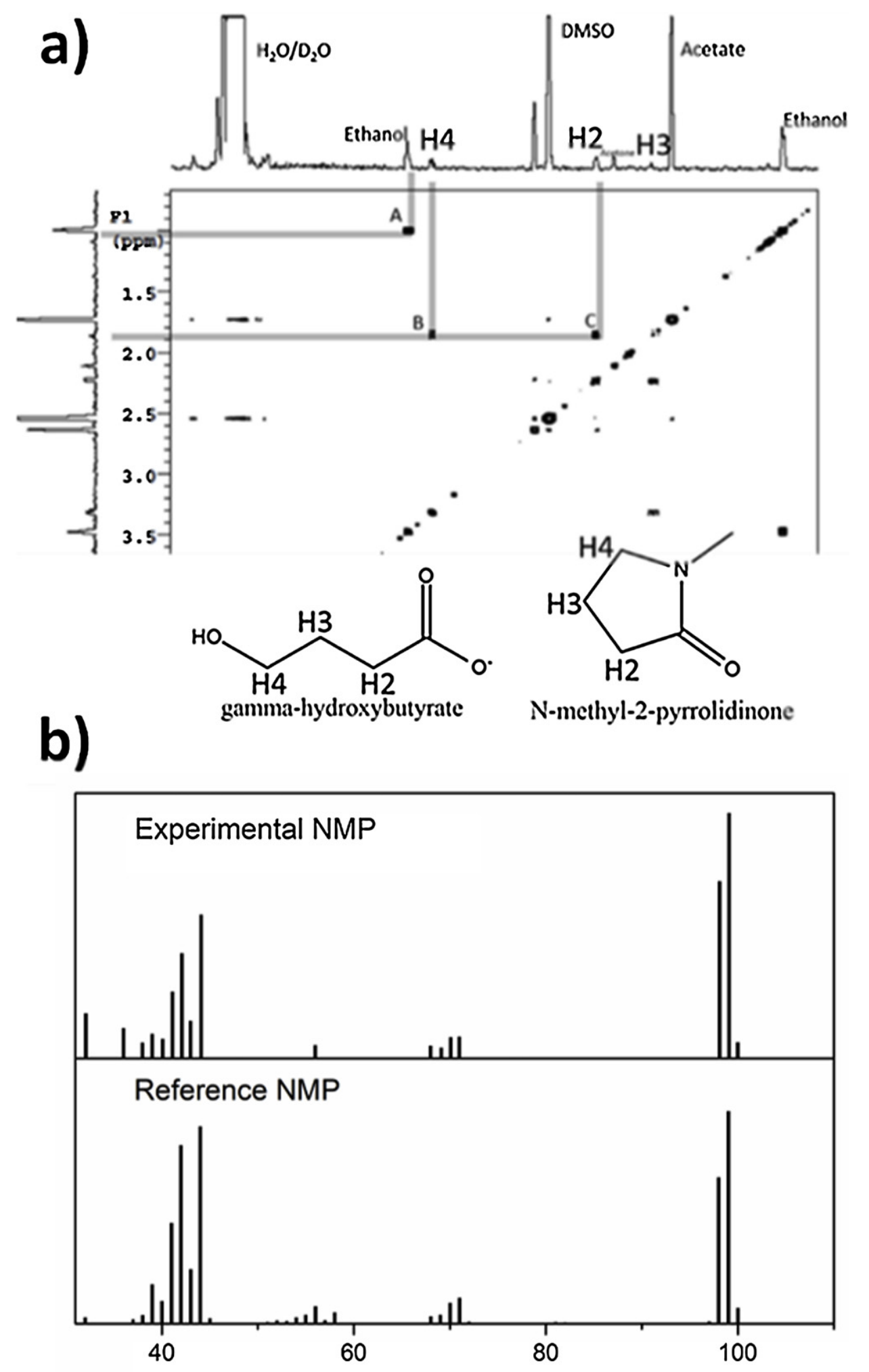

Figure 3.4. Characterization of CORR product with AMI-7001 membrane. (a) 2D H-H COSY spectrum $(700 \mathrm{MHz})$ demonstrating the interpretation of cross-peaks $\mathrm{B}$ and $\mathrm{C}$ to the misidentification of GHB. Cross-peak A is for ethanol. The 1D spectra on the top axis contains assignments to the analytes' proton groups (HX). (b) GC-MS mass-to-charge ratio $(\mathrm{m} / \mathrm{z})$ data for the experimental CORR product (top) compared to a reference NMP standard (bottom). 


\subsection{Conclusion}

With the intensifying effort being directed towards electrochemical reduction as a route to synthesize increasingly more complex, multicarbon products, it is important to eliminate sources of error which could result in the spurious detection of novel products and skew faradaic efficiency calculations. As shown herein, many of the commonly employed membrane materials for aqueous $\mathrm{CO}_{2} / \mathrm{CO}$ reduction result in significant contaminant levels in the electrolyte, especially if used as received without pretreatment. Even after pretreatment, non-negligible contaminant concentrations are possible which can lead to spurious product identification. Thus, especially for cases claiming novel multicarbon products, it is necessary to eliminate sources of contamination and to verify the products with more than NMR spectroscopy alone. 


\section{CHAPTER 4}

\section{PULSED ELECTROCHEMICAL CARBON MONOXIDE REDUCTION ON OXIDE- DERIVED COPPER CATALYST}

\subsection{Introduction}

Developing viable routes to convert waste $\mathrm{CO}_{2}$ to value-added chemicals is receiving increasing interest as a strategy to decrease greenhouse gas emissions. ${ }^{277}$ Several technoeconomic analyses have indicated that with sufficient performance improvements, several products could be commercially produced through electrochemical $\mathrm{CO}_{2}$ reduction. ${ }^{278,279}$ Copper is one of the few catalysts that has shown high activity for producing hydrocarbons and oxygenates through the carbon dioxide reduction reaction $\left(\mathrm{CO}_{2} \mathrm{RR}\right) .{ }^{91}$ Oxide-derived copper $(\mathrm{OD}-\mathrm{Cu})$, wherein an oxidized $\mathrm{Cu}$ surface is subsequently electrochemically reduced, possesses a high electrochemically active surface area with a high density of grain boundaries, which has led to increased activity compared to planar $\mathrm{Cu} .{ }^{194,}{ }^{280}$ However, designing catalysts for very high $\mathrm{CO}_{2} \mathrm{RR}$ selectivity to a single product is hindered by the scaling relations which limit the degree to which the binding energy can be simultaneously optimized for the various intermediate reactions in a multi-step reaction. ${ }^{281}$ For a simple single-carbon product like $\mathrm{CO}$, several other catalysts have 
been able to achieve near $100 \%$ faradaic efficiency (FE) from $\mathrm{CO}_{2}$ at high current density ${ }^{87}$

Thus, a promising approach to mitigate the limitations of the $\mathrm{CO}_{2} \mathrm{RR}$ scaling relations is the further direct electrochemical reduction of $\mathrm{CO}$ in a second electrocatalytic system. Cascade electrolysis systems have been demonstrated by first reducing $\mathrm{CO}_{2}$ to $\mathrm{CO}$ with $\mathrm{Au}$ or $\mathrm{Ag}$, then subsequently flowing the $\mathrm{CO}$ to a second electrolyzer or catalyst for a more selective secondary reduction. ${ }^{282,283}$ With $\mathrm{OD}-\mathrm{Cu}$, for instance, the grain boundary active sites promote adjacent $\mathrm{CO}$ binding and subsequent $\mathrm{C}-\mathrm{C}$ bond formation, leading to higher $\mathrm{FE}$ for $\mathrm{C} 2$ products like ethanol and acetate compared to conventional $\mathrm{Cu}$ for the electrochemical $\mathrm{CO}$ reduction reaction (CORR). ${ }^{11}$ This approach has motivated significant recent study of $\mathrm{CO}$ reduction, ${ }^{12,13}$ which has yielded advancements like $>90 \% \mathrm{FE}$ for CORR at a partial current density of over $600 \mathrm{~mA} \mathrm{~cm}^{-2}$, enabled by $\mathrm{CO}$ gas flow-through electrolyzer designs. ${ }^{265}$

Beyond modifications to the catalyst, the reaction branching pathway can also be tuned by affecting the dynamics at the electrochemical interface by pulsing the applied bias to the electrolyzer. This approach manipulates a complex interplay between the pulsing frequency and vertex potentials with the balance between reaction kinetics and mass transfer as well as the charging and discharging of the electrode double-layer capacitance. ${ }^{284}$ For potential pulses in the multi-second time range, improved $\mathrm{CO}_{2}$ mass transport to the electrode during the rest pulse enabled modestly enhanced $\mathrm{FE}$ for $\mathrm{CH}_{4}$ and $\mathrm{C}_{2}$ products. ${ }^{285-287}$ In the sub-200 ms pulse time range, the charging/discharging of the electrode capacitance favored $\mathrm{CO}_{2} \mathrm{RR}$ 
intermediate desorption and resulted in tunable and selective syngas $\left(\mathrm{H}_{2}+\mathrm{CO}\right)$ formation. ${ }^{284}$ Pulsed-bias $\mathrm{CO}_{2} \mathrm{RR}$ activity was also shown to depend strongly on the electrode geometric surface area, with the differences attributed to induction time and the rate of double-layer charging. ${ }^{288}$ Pulsed-bias electrolysis has further been demonstrated to have the added benefit of mitigating catalyst poisoning from contaminants or byproducts by repeated reduction/oxidation of the electrode interface to release or convert the undesired adsorbed species. ${ }^{289,290}$ Despite the increasing interest in electrochemical $\mathrm{CO}$ reduction, however, few if any reports exist on the ability of pulsed-bias conditions to direct the selectivity of CORR. Herein, we have investigated the effects of variable electrolysis parameters on the product distribution for reducing $\mathrm{CO}$ with a highly nanostructured OD-Cu catalyst surface.

\subsection{Results and Discussion}

First the behavior of OD-Cu for CORR under potentiostatic conditions without pulsed bias was established (see Experimental). After in situ reduction of the OD-Cu, current density vs. potential $(J-E)$ behavior was measured to confirm the near absence of the peak corresponding to copper oxide reduction (Fig. A.8). Fig. 4.1 shows the CORR product FEs and overall current density as determined at the end of a $60 \mathrm{~min}$ electrolysis. The results are the average of three redundant measurements at each potential. The product FE values

(Table A.1) are consistent with other reports for potentiostatic CORR on OD-Cu. ${ }^{100,} 291$ Minimum $\mathrm{H}_{2}$ production was observed at $-0.30 \mathrm{~V}$ vs. RHE, with a $\mathrm{FE}$ of $44.1 \%$. Peak $\mathrm{C}_{2+}$ 
product formation occurred at $-0.35 \mathrm{~V}$ vs. RHE, with FEs of $19.7 \%$ and $4.6 \%$ for ethanol and acetate, respectively, as well as trace propanol with a FE of $0.35 \%$. At $-0.40 \mathrm{~V}$ vs. RHE, the gaseous $\mathrm{C}_{2}$ products ethylene and ethane were detected at a combined FE of 8.0\%. At -0.25 and $-0.30 \mathrm{~V}$ vs. RHE, the total FE to measured products was significantly below $100 \%$, and we attribute the balance to continued restructuring and reduction of the electrode as well as unquantified acetaldehyde. Acetaldehyde, which is known to be an intermediate product on the way to ethanol formation ${ }^{291}$ is highly volatile. Although the low concentration makes it difficult to quantify by GC with the dynamic flow mode used herein, a static-headspace method has permitted quantification by others. ${ }^{291}$ It was recently reported that acetaldehyde is a major product $(\sim 60 \% \mathrm{FE})$ at low overpotentials on nanoflower $\mathrm{Cu},{ }^{100}$ making this a likely source for much of the missing charge in Fig. 4.1. Furthermore, a moderate drop in current density occurred during the 60 min electrolysis (Fig. A.8), most likely due to a partial loss of the $\mathrm{Cu}$ wire mesh-like nanostructures over time as has been seen in other OD-Cu studies. ${ }^{194,292}$

A small amount of formate, $\mathrm{HCOO}^{-},(<1.7 \% \mathrm{FE})$ is reported in Fig. 4.1 as an electrochemical CORR product on OD-Cu. The presence of formate as a product is noteworthy because other groups have reported that it may arise via a non-electrochemical route in CORR, perhaps as a hydration product. ${ }^{292}$ Some formate is clearly generated through a non-electrochemical route, as it has been demonstrated to form under CORR conditions at open-circuit voltage (OCV) with a Cu electrode. ${ }^{100}$ We performed additional control experiments to further elucidate the behavior of $\mathrm{HCOO}^{-}$production on $\mathrm{OD}-\mathrm{Cu}$ for 


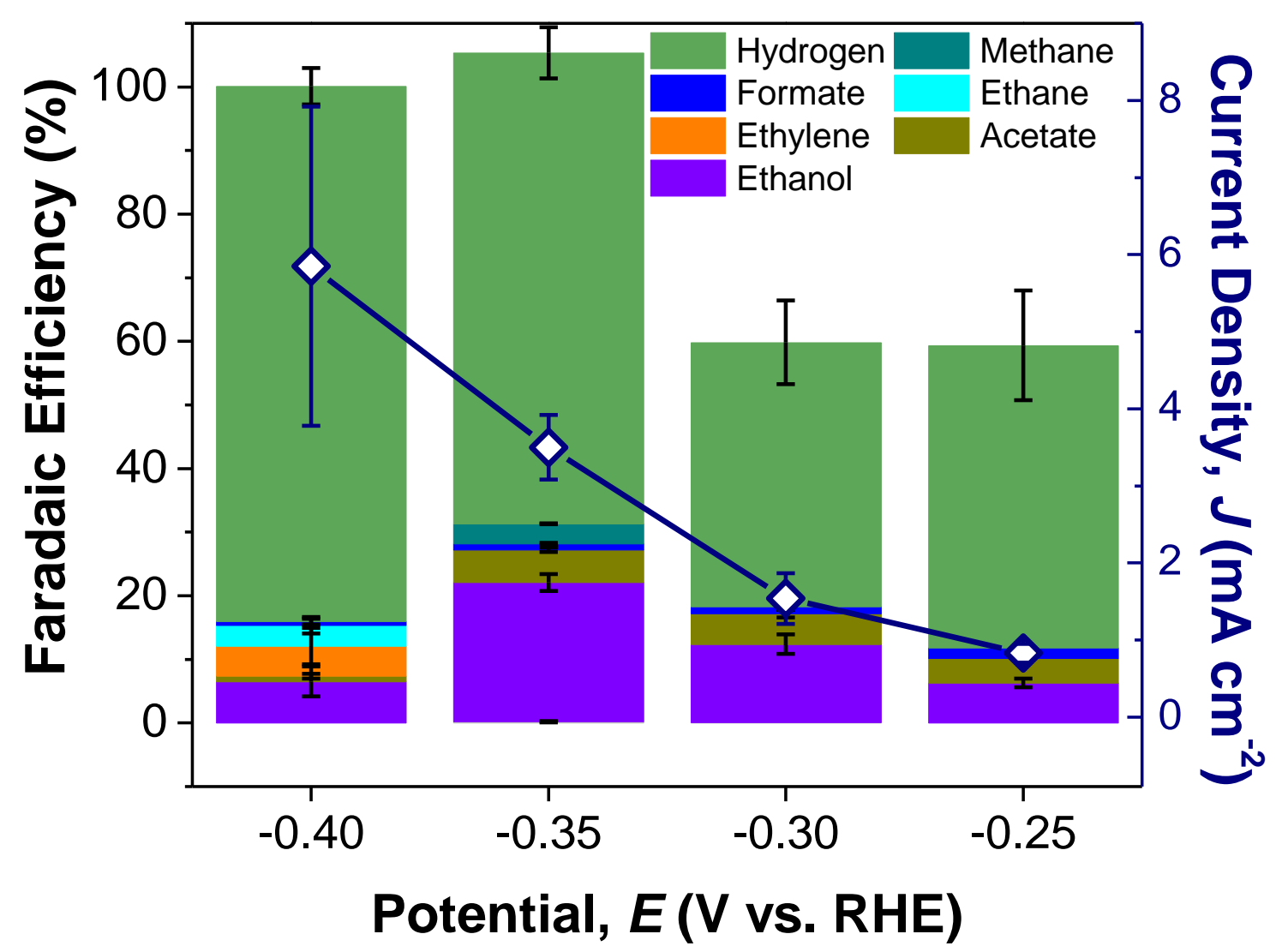

Fig. 4.1. Product distribution for CORR on OD-Cu in CO-saturated aqueous $0.1 \mathrm{M} \mathrm{KOH}$. Overall current density (diamonds) is the value after $60 \mathrm{~min}$. Values are the average of three measurements at each potential.

CORR. Figure A.9 shows the total formate production rate on $\mathrm{OD}-\mathrm{Cu}$ at relevant potentials, including where no faradaic current passed, as well as the formate produced in the absence of an electrode. Only $0.09 \mu \mathrm{mol}$ of $\mathrm{HCOO}^{-}$was detected without the OD-Cu catalyst, which increased to $0.95 \mu \mathrm{mol}$ for OD-Cu at $0 \mathrm{~V}$ vs. RHE and reached as high as $3.99 \mu \mathrm{mol}$ at $-0.35 \mathrm{~V}$ vs. RHE.

While some formate is likely produced through a non-electrochemical CO hydration, this route alone cannot explain the observed potential-dependence of $\mathrm{HCOO}^{-}$concentration. Instead, it is proposed that electrochemically generated $\mathrm{OH}^{-}$ from alkaline hydrogen evolution at higher localized concentration in the vicinity of surface-adsorbed $\mathrm{CO}$ on the electrode accelerates the rate of $\mathrm{CO}$ hydration to 


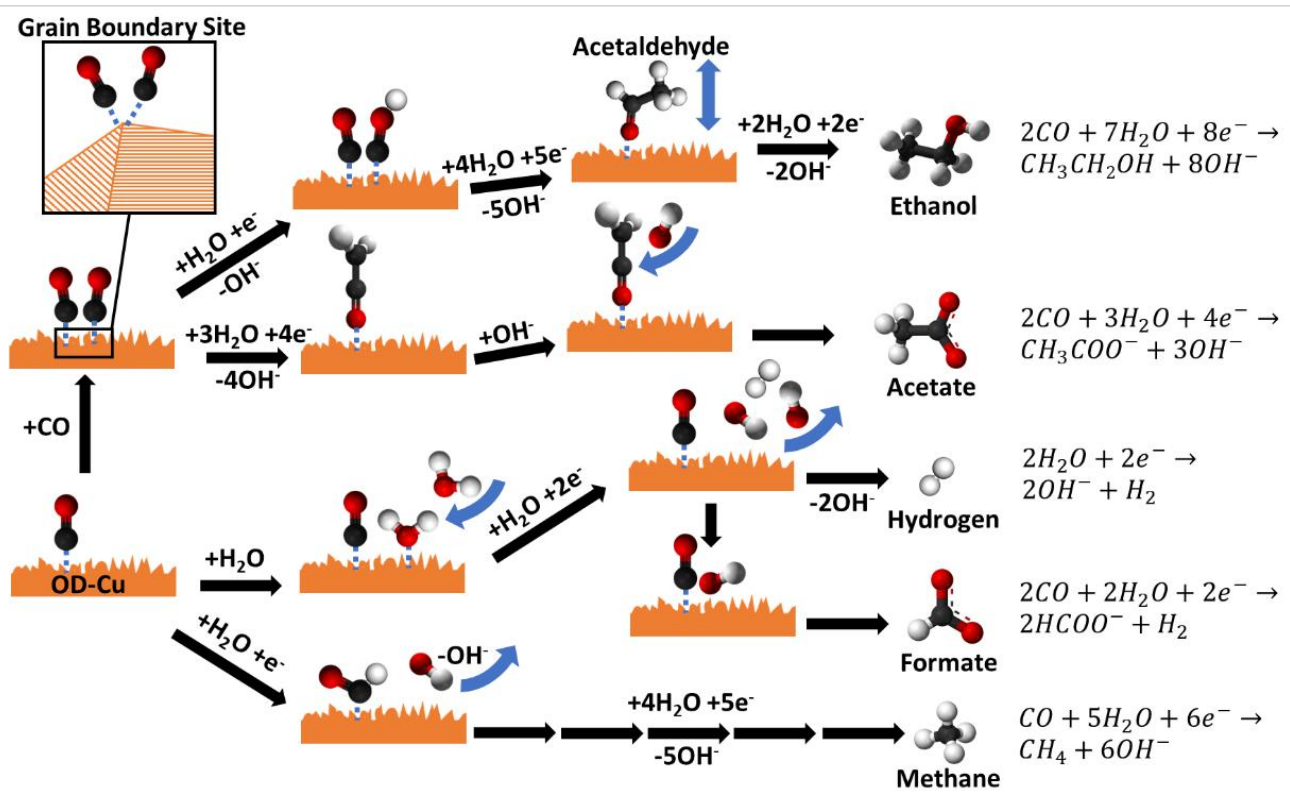

Fig. 4.2. Proposed reaction pathways for CORR on OD-Cu in $0.1 \mathrm{M} \mathrm{KOH}$ to the observed products. $\mathrm{Cu}$ grain boundaries promote adjacent $\mathrm{CO}$ binding and subsequent $\mathrm{C}-\mathrm{C}$ bond formation. Acetaldehyde is a readily desorbed intermediate species on the reduction pathway to ethanol. ${ }^{291}$ Acetate formation is believed to proceed through hydroxide attack of a surface-bound ketene. ${ }^{260}$

formate (see Appendix). Faradaic efficiency for formate by an indirect electrochemical route was therefore determined by subtracting the baseline molar production of $\mathrm{HCOO}^{-}$in the $0.1 \mathrm{M} \mathrm{KOH}$ electrolyte with an $\mathrm{OD}-\mathrm{Cu}$ electrode at open-circuit from the value measured at a given applied bias. Variation in the $\mathrm{HCOO}^{-}$production under pulsed-bias conditions was even more pronounced, further indicating that a purely non-electrochemical route was not sufficient to explain the generation of formate. The formate production route, along with the proposed reaction pathways and cathodic half-reactions for the other products for alkaline CORR on OD-Cu are shown schematically in Figure 4.2.

For the pulsed-bias CORR experiments, the main parameter investigated for its effect on the product distribution was the pulse frequency. A square-wave pulse between a cathodic potential, $E_{c}$, at $-0.35 \mathrm{~V}$ vs. RHE and a rest potential, $E_{r}$, at $0 \mathrm{~V}$ vs. RHE was used consistently throughout the study (Fig. 4.3a). The $E_{c}$ value was selected as the potential 
for maximum CORR FE, including to $\mathrm{C}_{2}$ products (Fig. 4.1). At the $E_{r}$ potential, no steadystate faradaic current passes, which allows time for $\mathrm{CO}$ diffusion without promoting the local oxidation of the CORR products that might occur at more anodic potentials. Pulsedbias CO measurements applied the potential square wave for $60 \mathrm{~min}$, of which only half that time was spent at the active $E_{c}$ reductive condition. After switching potentials, a transient current decayed over $\sim 1 \mathrm{~s}$ before reaching a pseudo-steady-state current within the pulse. An example pulsed-bias current density vs. time profile is shown in Fig. 4.3b. Within each pulse, the current is a combination of non-faradaic capacitive charging current and the faradaic currents directing charge to CORR, the hydrogen evolution reaction (HER), and $\mathrm{Cu}$ reduction/oxidation. It is difficult to determine an unequivocal and quantifiable deconvolution of the faradaic and non-faradaic components of the charge passed. Although double-layer capacitive charging can be fit with an RC circuit exponential fit, the underlying baseline faradaic current is likely not constant and thus difficult to accurately quantify. Thus, rather than calculate FEs in pulsed-bias conditions, the selectivity in these experiments is reported as the product distribution by charge. Moreover, OD-Cu morphology after pulsing was investigated by SEM and capacitance measurements (Figs. A.10-12, Table A.2). With no clear trend in surface roughness observed with pulsing times, we attribute the variations in product distribution to the dynamic interfacial electrochemistry rather than changes in the catalyst.

Pulsing times varied from $10 \mathrm{~ms}$ to $50 \mathrm{~s}$, covering the wide range of pulse frequencies reported in previous pulsed-bias studies on $\mathrm{Cu}$ for $\mathrm{CO}_{2} \mathrm{RR} .{ }^{284-290}$ Figure 4.4 shows the resulting product distributions measured at each pulse time along with the total measured charge required to produce all the detected products (Table S3). 
Each of the values are the average of three individual measurements. The total measured charge was determined by calculating the required charge to produce all the measured products from $\mathrm{CO}$ and $\mathrm{H}_{2} \mathrm{O}$ reactants.

With increasingly longer pulses, the product distribution would be predicted to asymptote towards the values observed for non-pulsed continuous electrolysis as steady-state conditions increasingly dominate each pulse. ${ }^{284}$ However, the observed CORR products for $50 \mathrm{~s}$ pulse times deviated appreciably from the values measured for continuous electrolysis (Fig. 4.4a). In particular, a lower fraction of ethanol and acetate was observed for long pulse times relative to the no-pulse condition. A control experiment was therefore conducted with a 30 min continuous electrolysis followed by 30 min at OCV with continued CO bubbling (i.e., a $1800 \mathrm{~s}$ pulse). The $1800 \mathrm{~s}$ pulse product distribution was consistent with the values measured for $50 \mathrm{~s}$ pulse times and also had notably lower fractions of ethanol and acetate compared to the no-pulse condition. We therefore attribute the reduced measured fraction of these liquid $\mathrm{C}_{2}$ products to changes occurring during the rest periods of the pulsed
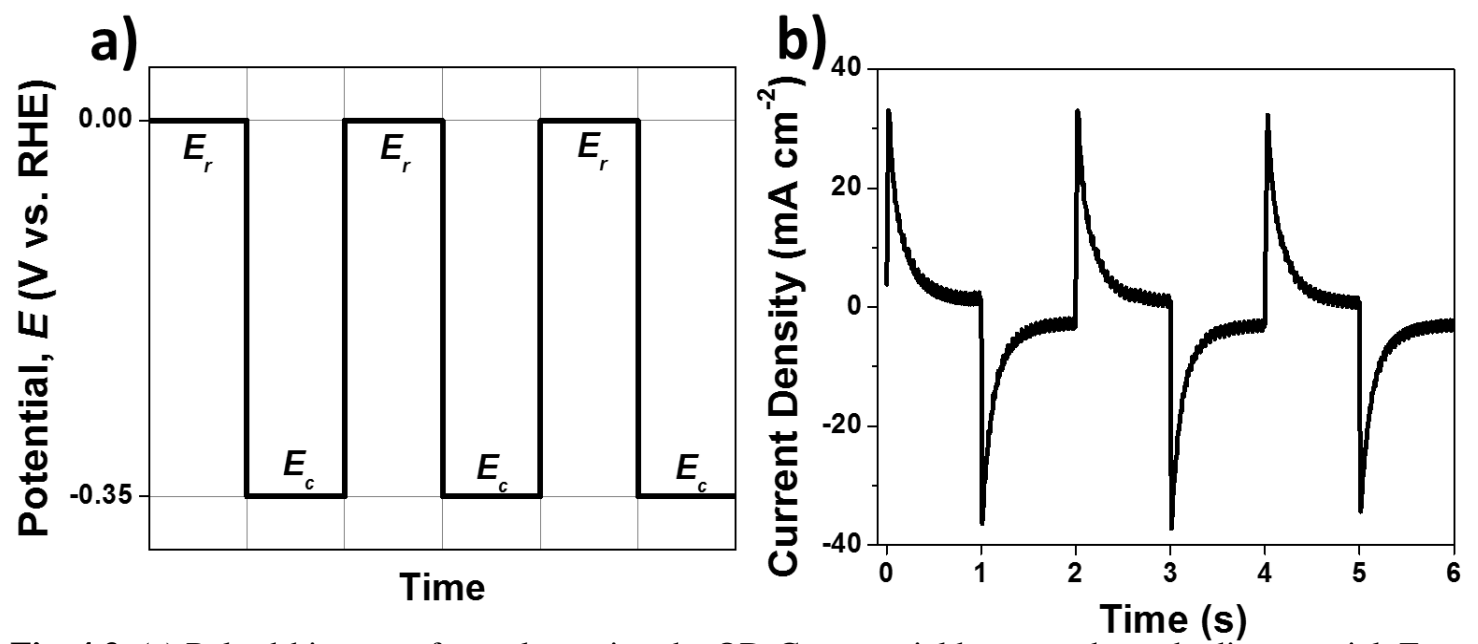

Fig. 4.3. (a) Pulsed-bias waveform alternating the OD-Cu potential between the cathodic potential, $E_{c}$, at $-0.35 \mathrm{~V}$ vs. RHE and a rest potential, $\mathrm{E}_{\mathrm{r}}$, at $0 \mathrm{~V}$ vs. RHE. (b) Example pulsed-bias current density response for $1 \mathrm{~s}$ pulse times. 
electrolysis. Gaseous $\mathrm{CH}_{4}$ and $\mathrm{H}_{2}$ products, however, were observed in similar amounts. The discrepancy between the observed liquid products for long pulses and non-pulsed electrolysis is likely attributable to the volatility of ethanol and acetate, leading to the gradual vaporization of these products into the output $\mathrm{CO}$ stream at concentrations below the GC detection limit in the continuous dynamic flow mode used herein. Because the NMR liquid product quantification measures the accumulated product at the end of the experiment, the time spent under active $\mathrm{CO}$ bubbling at the rest potential for pulsed-bias conditions reduces the observed fraction of volatile liquid products relative to a continuous electrolysis. The reported product distribution by charge for ethanol and acetate under pulsed-bias is therefore a lower limit, and the actual fraction of $\mathrm{C}_{2}$ species produced is assumed to be higher. However, precisely accounting for the volatile product with a static-headspace method is challenging for CORR due to the low solubility of $\mathrm{CO}$, which makes steady-state reduction difficult in the absence of active $\mathrm{CO}$ bubbling.

For non-pulsed CORR electrolysis at $-0.35 \mathrm{~V}$ vs. RHE, the faradaic efficiency for $\mathrm{H}_{2}$ was $68.2 \%$, and the total FE for CORR was $28.8 \%$ (Fig. 4.1, Table A.1). Accounting for faradaic current to undetected products, this is equivalent to a product distribution by charge of $70.3 \%$ for HER and $29.7 \%$ for CORR (Fig. 4.4a, Table A.2). Vaporization of volatile liquid products during the rest period accounted for a decrease in the charge fraction of CORR, with a product distribution by charge for CORR of $13 \%$ for the 1800 s pulse time, and corresponding increase in HER to 87\%. The HER charge fraction increased to as high as $92.4 \%$ at $25 \mathrm{~s}$ pulses, then decreased with decreasing pulse times to $29.3 \%$ for $10 \mathrm{~ms}$ pulses (Fig. $4.4 \mathrm{a}$, Table 

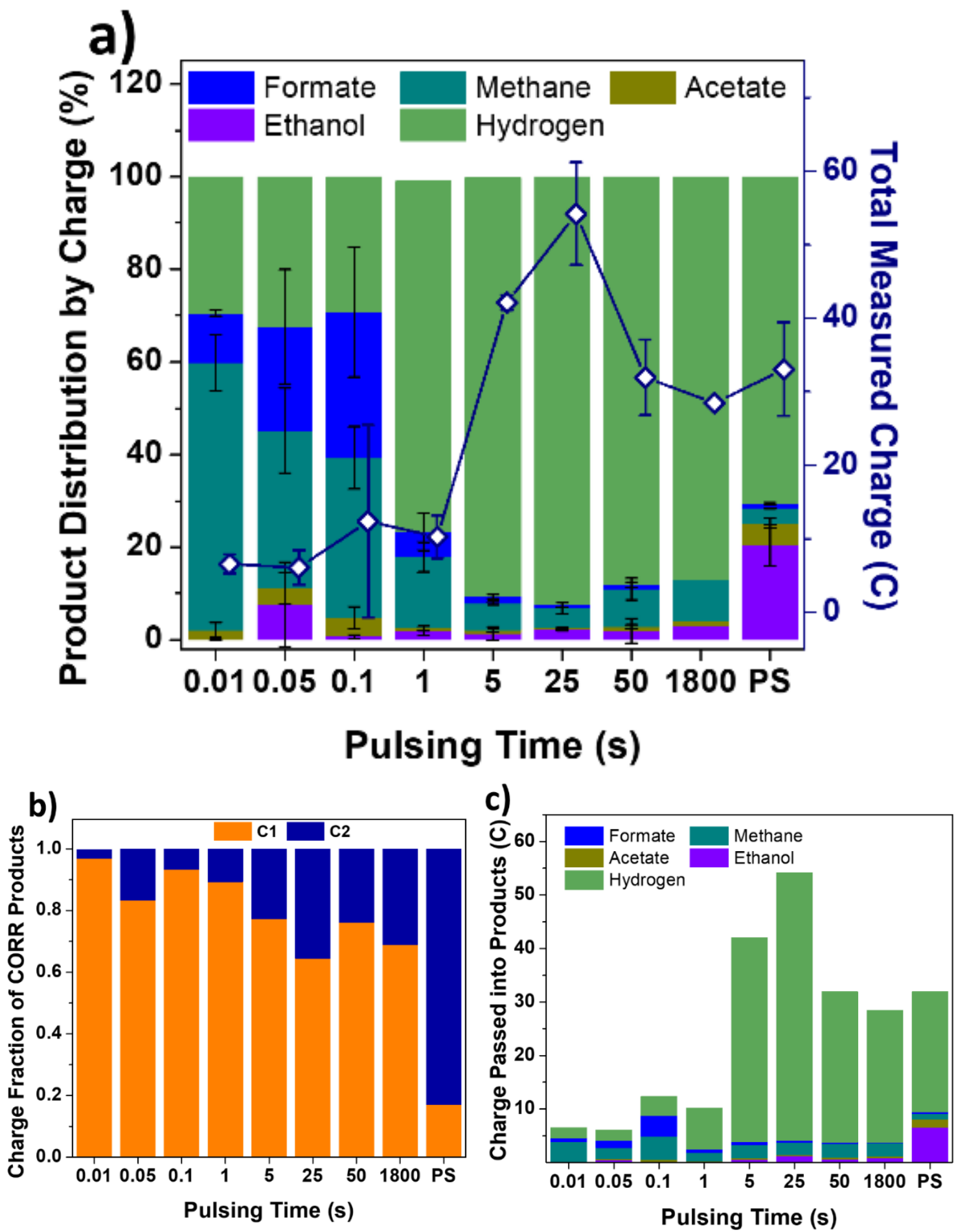

Fig. 4.4. (a) Product distribution vs. pulsing time along with the corresponding total measured charge (white diamonds, right axis) attributed to the detected products, and (b) the fraction of CORR products which are either one- or two-carbon species. (c) The total charge attributable to each detected product. The "PS" condition refers to a potentiostatic measurement at $-0.35 \mathrm{~V}$ vs. RHE for $60 \mathrm{~min}$. 
A.2). CORR became the dominant reaction over HER at $100 \mathrm{~ms}$ and shorter pulses, accounting for $\sim 70 \%$ of the charge, although the total charge was lower in this pulse frequency range. While the partial charge for CORR products increased from $4.1 \mathrm{C}$ at $25 \mathrm{~s}$ pulses to as high as $8.8 \mathrm{C}$ at $100 \mathrm{~ms}$ pulses, the partial charge for HER decreased from 50.1 C to $3.6 \mathrm{C}$ between the same conditions, respectively (Fig. 4.4c). Thus, the decrease in the total measured charge at shorter pulses can primarily be attributed to a decrease in the rate of HER. Interestingly, this finding is the reverse trend of the results observed in our previous pulsed-bias work on $\mathrm{CO}_{2} \mathrm{RR}$ on $\mathrm{Cu}$ in neutral aqueous $\mathrm{KHCO}_{3}$, in which the rate of $\mathrm{H}_{2}$ formation increased with shorter millisecond pulses. ${ }^{284}$ In that work, an increase in HER relative to $\mathrm{CO}_{2} \mathrm{RR}$ at short pulse times was attributed to the constantly changing electric field due to double layer charging/discharging leading to desorption of the $\mathrm{CO}_{2}$ reduction intermediates and subsequent promotion of HER. In the present case, $\mathrm{CO}$ binding and reduction is instead competing with alkaline HER, in which water-splitting occurs through a $\mathrm{OH}^{-}$ intermediate rather than a $\mathrm{H}^{+}$. We thus speculate that the non-faradaic current from charging/discharging which dominates short pulses in the ms regime could have a different effect on the binding energy and species adsorption which acts to inhibit HER in this situation. In addition, a less reductive potential (-0.35 V vs. RHE) was used for CORR in the present work compared to the potential (-1.0 V vs. RHE) applied for $\mathrm{CO}_{2} \mathrm{RR}$ in the previous study, leaving less driving force for HER to overcome competing effects in the present study. ${ }^{284}$

Besides changing the relative rates of HER to CORR, pulsing frequency also influenced the charge distribution of carbonaceous products. For pulsed-bias 
electrolysis, a general trend was observed in which shorter pulses corresponded to a lower charge fraction of the CORR products being directed towards $\mathrm{C}_{2}$ species (Fig. 4.4b). Only minor variation was observed in the CORR product distribution for pulse times $>5 \mathrm{~s}$, which can be attributed to the majority of the active $E_{c}$ period being in pseudo-steady-state for pulses of this duration. For pulses $\leq 1 \mathrm{~s}$, however, more significant variation in the CORR product distribution occurred (Fig. 4.4a). The charge fraction of $\mathrm{C}_{2}$ products was notably lower in the sub-second pulse range, reaching as low as 3.0\% of the CORR products for $10 \mathrm{~ms}$ pulse times (Fig. 4.4b). While some pulsed-bias $\mathrm{CO}_{2} \mathrm{RR}$ studies have reported notable enhancements in selectivity toward $\mathrm{C}_{2}$ products at pulses in the $1-5 \mathrm{~s}$ range, ${ }^{285-287}$ pulsing at $100 \mathrm{~ms}$ and below decreased $\mathrm{C}_{2}$ product formation. ${ }^{284}$ The short pulse time CORR results herein are consistent with previous reports in which the non-faradaic component is dominant at sub-second pulse times and the continuously changing interfacial energetics affect species adsorption and prevent the pseudo-steady-state needed to promote adjacent adsorbed $\mathrm{CO}^{*}$ species capable of $\mathrm{C}-\mathrm{C}$ bond formation to $\mathrm{C}_{2}$ products.

Furthermore, with the decreased HER and $\mathrm{C}_{2}$ production at sub-second pulse times, the production of $\mathrm{C}_{1}$ methane and formate species increased as a result. The partial charge for $\mathrm{C}_{1}$ products varied from $2.6 \mathrm{C}$ ( $0.4 \mathrm{C}$ to formate, $2.2 \mathrm{C}$ to methane) at $25 \mathrm{~s}$ pulses to $8.2 \mathrm{C}$ ( $3.9 \mathrm{C}$ to formate, $4.3 \mathrm{C}$ to methane) at $0.1 \mathrm{~s}$ pulses (Fig. $4.4 \mathrm{c}$, Fig. A.14). If the strong component of non-faradaic current throughout the short pulse times inhibits HER and C-C bond formation, reduction of the single adsorbed $\mathrm{CO}$ becomes the preferred route. Full reduction and protonation of the $\mathrm{CO}$ leads to 
$\mathrm{CH}_{4} \cdot{ }^{23}$ As mentioned above, some formate is produced through a nonelectrochemical hydration step, but the potential dependence of the formate concentration indicates an electrochemical pathway exists as well (Fig. A.9). Increased formate production at short pulses is consistent with the favored reduction of a single adsorbed $\mathrm{CO}$, as near-surface $\mathrm{OH}^{-}$reacts with the $\mathrm{CO}$ to make formate (see Appendix). At longer active cathodic pulse times, these reaction rates compete with diffusion of $\mathrm{CO}$ from the bulk to the electrode, permitting greater HER relative to CORR.

\subsection{Conclusions}

Herein, a pulsed-bias technique on a nanostructured $\mathrm{Cu}$ surface was investigated using the pulse time as a parameter for affecting the CORR selectivity. The 50\% duty cycle used for pulsed-bias conditions resulted in appreciable loss of the volatile $\mathrm{C}_{2}$ liquid products to the gas phase relative to a continuous process. Using pulses from $0.01-50 \mathrm{~s}$, the selectivity to CORR was significantly enhanced at sub-second pulse times mainly due to a decrease in the rate of the competing HER, which is a different behavior than previously observed for $\mathrm{CO}_{2}$ reduction in neutral electrolyte. Additionally, the shorter pulses greatly enhanced the direction of charge to $C_{1}$ relative to $C_{2}$ products, reaching a ratio as high as $97: 3$ at $10 \mathrm{~ms}$ pulse times. Consequently, sub-second pulse conditions had significantly higher fractions of the total charge resulting in the production of methane and formate. Further study with variable duty cycle and applied potential $E_{c}$ during the cathodic pulse may yield additional conditions for controlling the selectivity of CORR on Cu. Pulsed-bias 
studies such as these are a promising way to achieve an additional systems-level control over the electroreduction reaction as a way to complement the design of catalyst materials for high selectivity.

\subsection{Experimental Section}

\subsubsection{Membranes and Chemicals}

All reagents were used as received, except for $\mathrm{KOH}$ (reagent grade, Amresco) which was purified using the $\mathrm{K}$ form of Chelex 100 (received as the Na form, SigmaAldrich). All electrolyte solutions were prepared in $18 \mathrm{M} \Omega-\mathrm{cm}$ water. The anion exchange membrane used in the electrochemical cell was $100 \mu \mathrm{m}$ thick Selemion (AGC Engineering Co., Ltd.), pretreated by soaking in a bath of $1 \mathrm{M} \mathrm{KOH}$ for over 24 hours to ensure there were negligible membrane contaminants in the electrolyte. ${ }^{24}$

\subsubsection{Electrode Fabrication}

Oxide-derived copper (OD-Cu) electrodes were prepared from $\mathrm{Cu}$ foil (0.127 mm thick, 99.9\%, Alfa Aesar) following a published method. ${ }^{5,11}$ The Cu foil was sonicated for $30 \mathrm{~min}$ in acetone and isopropanol for cleaning and then electropolished in $85 \%$ phosphoric acid (Macron Fine Chemicals) at $2.0 \mathrm{~V}$ vs. a secondary $\mathrm{Cu}$ foil for $5 \mathrm{~min}$ under vigorous stirring. Both sides of the foil were electropolished. The foil was then rinsed in $18 \mathrm{M} \Omega-\mathrm{cm}$ water and dried under nitrogen. The $\mathrm{Cu}$ foil was subsequently placed in a muffle furnace under ambient air for thermal oxidation with a $1.5 \mathrm{~h}$ ramp up to $500{ }^{\circ} \mathrm{C}, 12 \mathrm{~h}$ at $500{ }^{\circ} \mathrm{C}$, and then a $10 \mathrm{~h}$ ramp down to room temperature. The $\mathrm{CuO}_{\mathrm{x}}$ foil was then placed in the 
electrochemical cell with $\sim 3 \mathrm{~cm}^{2}$ exposed to the $0.1 \mathrm{M} \mathrm{KOH}$ electrolyte and reduced at $-0.5 \mathrm{~V}$ vs. RHE for $45-60$ min until the current density reached a steady-state value for $5 \mathrm{~min}$ at $\leq 5 \mathrm{~mA} \mathrm{~cm}$. Previous XPS and XRD characterization has demonstrated a surface of $\mathrm{Cu}$ (II) present as $\mathrm{Cu}_{2} \mathrm{O}$ after thermal oxidation, converting to primarily $\mathrm{Cu}(0)$ after the electrochemical reduction step, with the return of a thin oxide layer and $\mathrm{Cu}(\mathrm{II})$ and $\mathrm{Cu}(\mathrm{I})$ due to residual anodic surface oxidation during pulsed-bias operation. ${ }^{5,15}$

\subsubsection{Electrochemical Measurements}

Electrochemical CO reduction experiments were performed with a BioLogic SP-200 potentiostat. The electrochemical cell was made of polycarbonate plates and set up for a three-electrode experiment with the OD-Cu foil as the working electrode, Pt mesh as the counter electrode separated from the cathode compartment by the membrane, and a $\mathrm{Ag} / \mathrm{AgCl}(\mathrm{CH}$ Instruments, Inc.) in $3.0 \mathrm{M} \mathrm{KCl}$ as the reference electrode. ${ }^{15}$ Potentials were calculated from the equation $V_{R H E}=V_{A g / A g C l}+0.210+$ $0.059 * \mathrm{pH}$. The $\mathrm{pH}$ of the $0.1 \mathrm{M} \mathrm{KOH}$ electrolyte was 13 . Following electrochemical reduction of the OD-Cu, the catholyte was flushed and replaced with fresh $0.1 \mathrm{M}$ $\mathrm{KOH}$ with a catholyte volume of $7.5 \mathrm{~mL}$. Prior to CORR measurements, the electrolyte in both the cathode and anode chambers was bubbled with CO (99.99\%, Specialty Gases) at $10 \mathrm{sccm}$ for $20 \mathrm{~min}$ and potentiostatic electrochemical impedance spectroscopy (PEIS) was then used to measure the uncompensated cell resistance. Typical resistances for the cell ranged from $15-28 \Omega$. The potentiostat was then set to compensate for $85 \%$ of the uncompensated resistance during the 
electrochemical CORR experiment, which was conducted with a steady CO flow rate of $10 \mathrm{sccm}$ through a bubbler with $4-5 \mu \mathrm{m}$ pores in the catholyte at the base of the OD-Cu electrode. Electrochemical surface area (ECSA) measurements were performed to obtain the double-layer capacitance values of the OD-Cu electrodes before and after pulsed-bias electrolysis. ${ }^{25}$ A cyclic voltammogram was produced at potentials without faradaic current $(0.02$ to $0.26 \mathrm{~V}$ vs. RHE) and the non-faradaic current was plotted versus the scan rate to calculate the double-layer capacitance. The scan rates were $10,20,40,60$, and $80 \mathrm{mV} \mathrm{s}^{-1}$. The roughness factor was estimated by dividing the calculated $\mathrm{OD}-\mathrm{Cu}$ electrode capacitance by the approximate capacitance of atomically smooth $\mathrm{Cu}(29 \mu \mathrm{F}){ }^{6}$

\subsubsection{Product Analysis}

$\mathrm{CO}$ reduction products were measured by gas chromatography (GC, SRI 8610) and nuclear magnetic resonance (NMR) spectroscopy for the gas and liquid products, respectively. Both instruments were calibrated with standard gases or liquid solutions. The concentration of gaseous products was measured at 15, 30, 45, and $60 \mathrm{~min}$. The liquid products were collected at $0 \mathrm{~min}$ and $60 \mathrm{~min}$ for each electrolysis experiment. The moles of each liquid product were determined by taking the difference between the final and initial concentrations. A $400 \mu \mathrm{L}$ aliquot of the catholyte was mixed with $100 \mu \mathrm{L}$ of $\mathrm{D}_{2} \mathrm{O}$ that contained $\sim 100 \mathrm{ppm}$ dimethyl sulfoxide (DMSO, ACS grade, Amresco). The peak area of the DMSO internal standard was compared to the peak area of each liquid product in ${ }^{1} \mathrm{H}-\mathrm{NMR}$ using a Varian $700 \mathrm{MHz}$ cold-probe while using a water peak suppression technique. For 
non-pulsed experiments, the faradaic efficiency was determined directly by comparing the charge required to produce the measured products to the total charge passed as measured by the potentiostat. Because of the constantly shifting convolution of faradaic and transient non-faradaic (i.e., double-layer capacitive charging) currents during pulsed-bias conditions, it is not straightforward to calculate faradaic efficiency for pulsed-bias experiments. Instead, for pulsed-bias experiments the selectivity was based on the product distribution by charge, which was calculated by comparing the charge required to produce a given product relative to the charge required to produce all the measured products. Thus, the product distribution by charge is the same as faradaic efficiency except that it does not account for charge passed which did not result in a detected product.

\subsubsection{Catalyst Characterization}

A scanning electron microscope (FEI NOVA nano-SEM 600) was used to image the surface morphology of the $\mathrm{Cu}$ foil. A Bruker D8 powder X-ray diffraction (XRD) system was used for crystal structure and phase analysis using nonmonochromated $\mathrm{Cu}-\mathrm{K} \alpha$ radiation produced by an $\mathrm{X}$-ray tube operated at $40 \mathrm{kV}$ and $40 \mathrm{~mA}$. The sample XRD patterns were scanned between $30-80^{\circ}$ at a scan speed of 4 s per step with a step size of $0.02^{\circ}$. 


\section{CHAPTER 5}

\section{UNASSISTED PHOTOELECTROCHEMICAL REDUCTION OF CARBON MONOXIDE WITH AN OXIDE-DERIVED COPPER DARK CATHODEAND TITANIUM DIOXIDE N ${ }^{+}$P-SILICON TANDEM PHOTOANODE}

\subsection{Introduction}

The photoelectrochemical (PEC) carbon dioxide reduction reaction $\left(\mathrm{CO}_{2} \mathrm{RR}\right)$ has been pursued with several different strategies. ${ }^{293-301}$ Many of these strategies employ the combinatory effort of bias and photobias to achieve production of $\mathrm{CO}_{2} \mathrm{RR}$ products. ${ }^{302}$ One such effort utilizes $\mathrm{Cu}_{2} \mathrm{O}$ dark cathode directly wired to a $\mathrm{TiO}_{2}$ photoanode to perform $\mathrm{PEC}$ $\mathrm{CO}_{2} \mathrm{RR}^{303}$ In this study, $\mathrm{Cu}_{2} \mathrm{O}$ remains stable for 3 hours while maintaining $90 \%$ selectivity. The $\mathrm{Cu}_{2} \mathrm{O}$ dark cathode achieved a selectivity of $92.65 \%$ for carbonaceous products at $+0.75 \mathrm{~V}$ vs RHE. Many efforts for PEC systems have the goal of developing an "artificial leaf" device where no external bias is applied. ${ }^{304}$ One such study recently achieved this for $\mathrm{CO}_{2} \mathrm{RR}$. Syngas was produced bias-free from $\mathrm{CO}_{2}$ via integrating a molecular cobalt catalyst with a perovskite- $\mathrm{BiVO}_{4}$ tandem photoanode, an "artificial leaf". ${ }^{305}$ They achieved a solar-to-CO efficiency of $0.02 \%$. In a gas-diffusion electrode (GDE) electrolyzer a solar-to-CO efficiency of $19 \%$ was achieved. ${ }^{302}$

Many electrochemical $\mathrm{CO}_{2} \mathrm{RR}$ systems have been shown to produce $\mathrm{CO}$ at near $100 \%$ selectivity. ${ }^{87}$ Because of this achievement, several cascade style reaction designs have been pursued where the generated $\mathrm{CO}$ is allowed to reach a secondary catalytic site 
in order for optimal CO reduction reaction (CORR) conditions to be optimized. ${ }^{263,306}$ The study of the CORR has greatly expanded since it was shown that CO can be reduced with high selectivity to carbonaceous products. ${ }^{95,264,307}$ Studies have shown this is a promising route through modelling ${ }^{308}$ and technoeconomic analysis. ${ }^{261}$ As of yet there has not been a study on PEC CORR, let alone unassisted PEC CORR. Herein we present for the first time PEC CORR with no assistance from bias, but only photoinduced current. This is possible because many recent reports have shown that CORR can be achieved from very low overpotentials. ${ }^{100,101}$ When these low overpotentials are combined with a tandem photoanode capable of a high enough photovoltage, enough current can then drive the CORR. A CORR artificial leaf system has yet to be reported in the literature.

\subsection{Experimental}

\subsubsection{Membranes and Materials}

All reagents were used as received, except for $\mathrm{KOH}$ (reagent grade, Amresco) which was purified using the K form of Chelex 100 (received as the Na form, SigmaAldrich). All electrolyte solutions were prepared in $18 \mathrm{M} \Omega-\mathrm{cm}$ water. The anion exchange membrane used in the electrochemical cell was $100 \mu \mathrm{m}$ thick Selemion (AGC Engineering Co., Ltd.), pretreated by soaking in a bath of $1 \mathrm{M} \mathrm{KOH}$ for over 24 hours to ensure there were negligible membrane contaminants in the electrolyte. $^{309}$ 


\subsubsection{Electrode Fabrication}

\subsection{2a Tandem Photoanode}

p+Emitter Layer- A boron doped $\mathrm{p}^{+}$emitter $^{310,311}$ layer was formed on the $\mathrm{n}-\mathrm{Si}(2 \mathrm{~cm} \mathrm{x}$ 1cm wafer) by using a solid-source BN dopant wafer (Saint Gobain-BN-975). The silicon wafers were kept alternatively between the dopant wafers in a ceramic boat at $950 \mathrm{C}$ for 4 minutes under $\mathrm{N}_{2}$ flow (200 sccm for a 1-inch diameter tube). The boat was taken out slowly (in $1 \mathrm{~min}$ ) to remove the dopant wafers while the temperature in the furnace ramped down to $750{ }^{\circ} \mathrm{C}$. Each wafer was etched in BHF for $30 \mathrm{~s}$ to remove any excess un-reacted dopant glass and then loaded again at $750{ }^{\circ} \mathrm{C}$ under $\mathrm{O}_{2}$ flow $(100 \mathrm{sccm})$ for 30 min to grow a low temperature oxide (LTO). The LTO step oxidizes the Si-B layer and a thin layer of Si below to prevent propagation of crystal defects during subsequent drive cycle. The wafers were then taken out and etched again in 10\% HF for 1 min.

FTO Deposition- The $\mathrm{p}^{+} \mathrm{n}$ Si wafers were etched with $10 \% \mathrm{HF}$ for $30 \mathrm{~s}$ and then placed on a hotplate preheated at $400 \mathrm{C}$. Fluorinated tin oxide(FTO) was deposited using a plastic spray bottle that created a fine mist of the precursor when pressed. ${ }^{312,313}$ The solution consisted of $0.015 \mathrm{M}$ Ammonium fluoride solution in DI water and 0.5 M Butyltin Trichloride solution in 200 proof ethanol. The spray solution was made by mixing $97 \%$ by volume of the Butyltin trichloride (Sigma-Aldrich) solution and 3\% by volume of the ammonium fluoride solution. 30 cycles of spraying were done with 2-3 sprays per cycle. The wafers were rotated after 15 cycles during the deposition to ensure conformal coverage of FTO.

$\mathrm{TiO}_{2}$ growth- Rutile $\mathrm{TiO}_{2}$ nanorod structures were grown on $\mathrm{p}^{+} \mathrm{n}$ Si/FTO wafer using a hydrothermal method. ${ }^{312}$ An aqueous solution of $0.05 \mathrm{M}$ titanium n-butoxide and $6 \mathrm{M} \mathrm{HCl}$ 
was prepared and poured into a PTFE cell. The FTO coated $\mathrm{p}^{+} \mathrm{n}$ Si wafers were then placed in, at an angle supported by the cell wall. The cell was then placed within a hydrothermal autoclave reactor and subsequently in a muffle furnace preheated to $200{ }^{\circ} \mathrm{C}$ for $4 \mathrm{~h}$. The reactor is taken out and cooled under running water for $15 \mathrm{~min}$. The $\mathrm{TiO}_{2}$ coated wafers were then taken out of the PTFE cell, washed with DI water and annealed at $450{ }^{\circ} \mathrm{C}$ for 30 min in air.

Electrode for PEC measurement- After the $\mathrm{p}^{+} \mathrm{n}-\mathrm{Si} / \mathrm{FTO} / \mathrm{TiO}_{2}$ tandem semiconductor wafers were prepared they were cleaved from the edges to eliminate shunting. Ga-In (99.99\%Alfa-Aesar) eutectic was scratched with a diamond scribe on the exposed n-Si side of the wafer to make an ohmic contact. This side was then attached to a $\mathrm{Cu}-\mathrm{Sn}$ wire with Ag paint (SPI-05001-AB). The active area on the $\mathrm{TiO}_{2}$ grown side was defined with epoxy (Loctite Hysol 9640) and the entire electrode was sealed to a glass tube using epoxy.

\subsection{2b OD-Cu Dark Cathode}

The fabrication method used to make OD-Cu is detailed in previous reports. ${ }^{95,309}$ Specifically, OD-Cu electrodes were prepared from $\mathrm{Cu}$ foil $(0.127 \mathrm{~mm}$ thick, $99.9 \%$, Alfa Aesar). The $\mathrm{Cu}$ foil was sonicated for $30 \mathrm{~min}$ in acetone and isopropanol for cleaning and then electropolished in $85 \%$ phosphoric acid (Macron Fine Chemicals) at $2.0 \mathrm{~V}$ vs. a secondary $\mathrm{Cu}$ foil for $5 \mathrm{~min}$ under vigorous stirring. Both sides of the foil were electropolished. The foil was then rinsed in $18 \mathrm{M} \Omega-\mathrm{cm}$ water and dried under nitrogen. The $\mathrm{Cu}$ foil was subsequently placed in a muffle furnace under ambient air for thermal oxidation with a $1.5 \mathrm{~h}$ ramp up to $500{ }^{\circ} \mathrm{C}, 12 \mathrm{~h}$ at $500{ }^{\circ} \mathrm{C}$, and then a $10 \mathrm{~h}$ ramp down to

room temperature. The $\mathrm{CuO}_{\mathrm{x}}$ foil was then placed in the electrochemical cell with $\sim 1 \mathrm{~cm}^{2}$ 
exposed to the $0.1 \mathrm{M} \mathrm{KOH}$ electrolyte and reduced at $-0.5 \mathrm{~V}$ vs. RHE for 45-60 min until the current density reached a steady-state value for $5 \mathrm{~min}$ at $\leq 5 \mathrm{~mA} \mathrm{~cm}{ }^{-2}$.

\subsubsection{Photoelectrochemical Measurements}

Electrochemical CO reduction experiments were performed with a BioLogic SP200 potentiostat. The electrochemical cell was made of PTFE plates and the design was adopted from Corson et al. ${ }^{314}$ Simulated sunlight at an intensity of $100 \mathrm{~mW} \mathrm{~cm}{ }^{-2}$ at normal incidence to the working electrode was generated with a $300 \mathrm{~W}$ Xe lamp (Newport 6258) coupled with an AM1.5 global filter (Newport 81094) and calibrated in the electrolyte with a Si photodiode (Thorlabs FDS100-CAL). For electrode fabrication of the OD-Cu and $J$ $V$ behavior where OD-Cu was the WE, a three-electrode experiment with the OD-Cu foil as the WE, Pt mesh as the CE separated from the cathode compartment by the membrane, and a $\mathrm{Ag} / \mathrm{AgCl}(\mathrm{CH}$ Instruments, Inc.) in $3.0 \mathrm{M} \mathrm{KCl}$ as the $\mathrm{RE}$, which was placed in the catholyte compartment. ${ }^{15}$ For $J-V$ behavior measured for the tandem electrode as the WE in a three-electrode set-up, the OD-Cu was used as the $\mathrm{CE}$ and a $\mathrm{Ag} / \mathrm{AgCl} \mathrm{RE}$ was placed in the anolyte compartment. Each individual three-electrode $J$-V experiment was $i R$ corrected immediately before scans were started. For two-electrode experiments $(J-V$ behavior and long-term electrolyses) the photoanode was the WE and the OD-Cu was the RE. Potentials were calculated from the equation $V_{R H E}=V_{A g / A g C l}+0.210+0.059 * \mathrm{pH}$. The $\mathrm{pH}$ of the $0.1 \mathrm{M} \mathrm{KOH}$ electrolyte was 13 . Following electrochemical reduction of the OD$\mathrm{Cu}$, the catholyte was flushed and replaced with fresh $0.1 \mathrm{M} \mathrm{KOH}$ with a catholyte volume of $3.5 \mathrm{~mL}$. Prior to CORR measurements, the electrolyte in the cathode chamber was bubbled with CO (99.99\%, Specialty Gases) at $5 \mathrm{sccm}$ for $20 \mathrm{~min}$ and potentiostatic 
electrochemical impedance spectroscopy (PEIS) was then used to measure the uncompensated cell resistance for the three-electrode measurements. Typical resistances for the cell ranged from $30-50 \Omega$. The potentiostat was then set to compensate for $85 \%$ of the uncompensated resistance during the electrochemical CORR experiment, which was conducted with a steady CO flow rate of $5 \mathrm{sccm}$ through a bubbler with $4-5 \mu \mathrm{m}$ pores in the catholyte at the base of the OD-Cu electrode.

\subsubsection{Product Quantification}

CO reduction products were measured by gas chromatography (GC, SRI 8610) and nuclear magnetic resonance (NMR) spectroscopy for the gas and liquid products, respectively. Both instruments were calibrated with standard gases or liquid solutions. The concentration of gaseous products was measured every $15 \mathrm{~min}$. The liquid products were collected at $0 \mathrm{~min}$ and the end time-point for each electrolysis experiment. The moles of each liquid product were determined by taking the difference between the final and initial concentrations. A $400 \mu \mathrm{L}$ aliquot of the catholyte was mixed with $100 \mu \mathrm{L}$ of $\mathrm{D}_{2} \mathrm{O}$ that contained $~ 100$ ppm dimethyl sulfoxide (DMSO, ACS grade, Amresco). The peak area of the DMSO internal standard was compared to the peak area of each liquid product in ${ }^{1} \mathrm{H}$ NMR using a Varian $700 \mathrm{MHz}$ cold-probe while using a water peak suppression technique.

\subsection{Results and Discussion}

The photoelectrochemical cell used to accomplish unassisted PEC CORR was based off the design built by Corson et al. The difference between that PEC cell and the one used here is that the incident light is allowed to hit the photoanode as opposed to a 
photocathode. The top port of the anolyte chamber is enlarged to allow to ease the switching of electrodes between specific PEC cell set-ups (i.e. the calibration $\mathrm{Si}$ photodiode, a Pt mesh CE, and the photoanode). The PEC cell set-up used for the long term unassisted photoelectrolysis experiments is denoted in Figure 5.1. The photoanode generates a photocurrent in which alkaline OER occurs following the half-reaction:

$$
4 \mathrm{OH}^{-} \rightarrow \mathrm{O}_{2}+4 \mathrm{e}^{-}+2 \mathrm{H}_{2} \mathrm{O}, E^{\circ}=1.23 \mathrm{~V} \text { vs. } \mathrm{RHE}
$$

The electrons photogenerated make their way to the OD-Cu dark cathode where the electrons reduce $\mathrm{CO}$ into hydrocarbon products, 1-propanol, acetate, and ethanol, in the half-reactions: ${ }^{95}$

$$
3 \mathrm{CO}+12 \mathrm{e}^{-}+11 \mathrm{H}_{2} \mathrm{O} \rightarrow \mathrm{C}_{3} \mathrm{H}_{7} \mathrm{OH}+12 \mathrm{OH}^{-}, E^{\circ}=0.36 \text { vs. RHE }
$$

$$
2 \mathrm{CO}+4 \mathrm{e}^{-}+3 \mathrm{H}_{2} \mathrm{O} \rightarrow \mathrm{C}_{2} \mathrm{H}_{3} \mathrm{O}_{2}^{-}+3 \mathrm{OH}^{-}, E^{\circ}=0.50 \text { vs. RHE }
$$

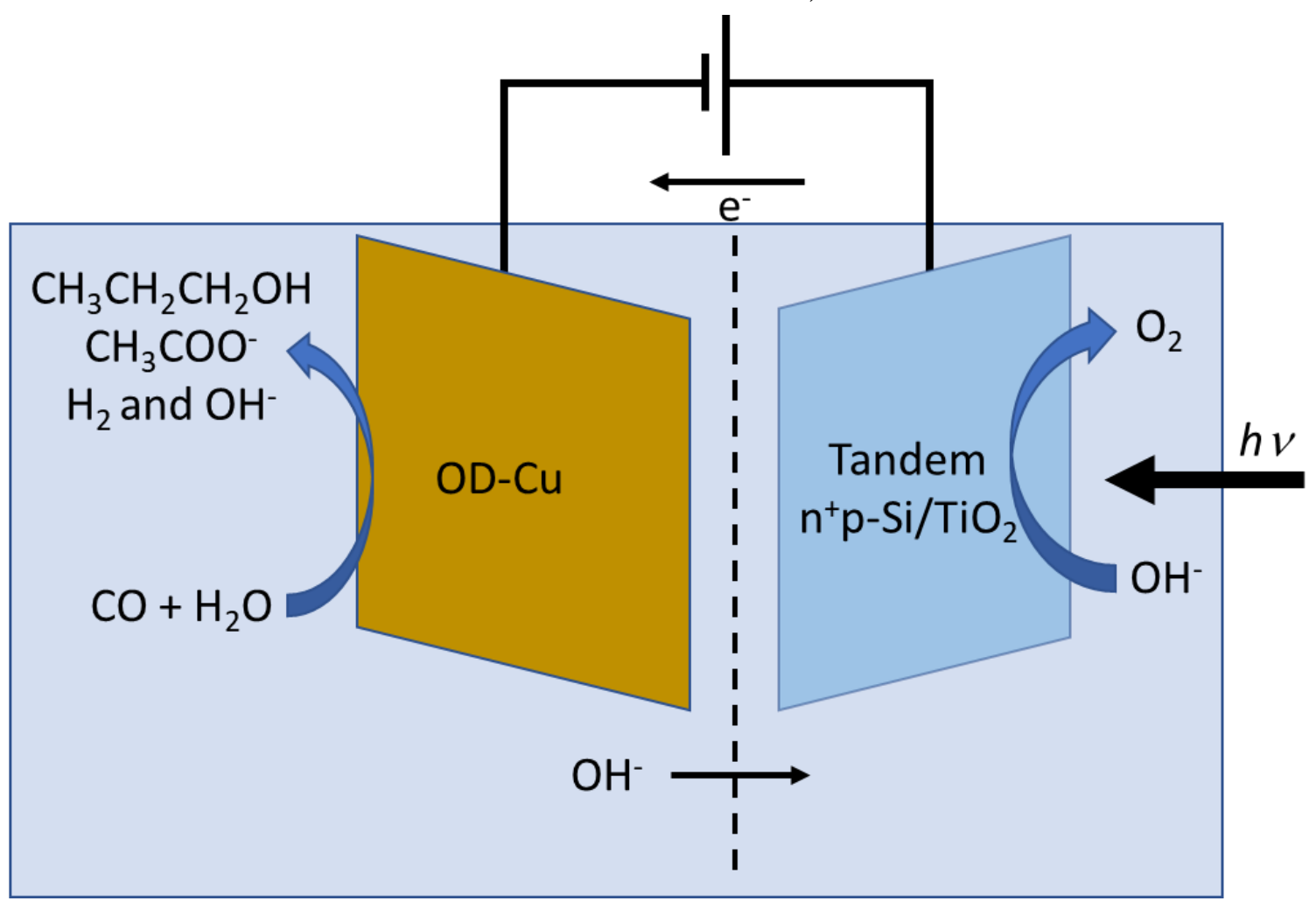

Figure 5.1 Diagram of photoelectrochemical setup. 


$$
2 \mathrm{CO}+8 \mathrm{e}^{-}+7 \mathrm{H}_{2} \mathrm{O} \rightarrow \mathrm{C}_{2} \mathrm{H}_{5} \mathrm{OH}+8 \mathrm{OH}^{-}, E^{\circ}=0.18 \text { vs. } \mathrm{RHE}
$$

1-propanol's $E^{\circ}$ was calculated using an estimation method adopted by Calvinho et al. ${ }^{92}$

These half-reactions that produce hydrocarbon products are in competition with HER:

$$
2 \mathrm{H}_{2} \mathrm{O}+2 \mathrm{e}^{-} \rightarrow \mathrm{H}_{2}+2 \mathrm{OH}^{-}
$$
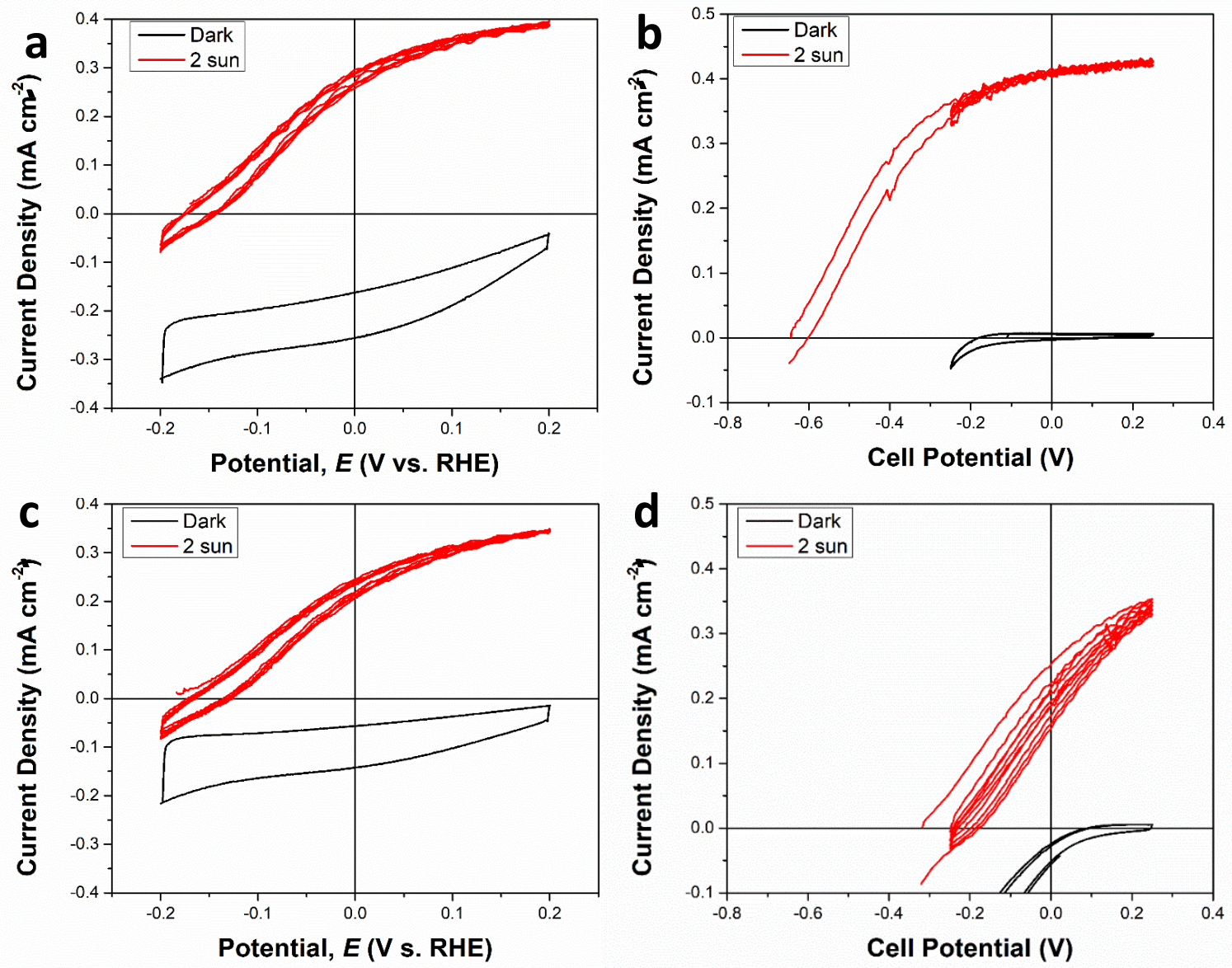

Figure 5.2 J-V behavior of the PEC setup. Three-electrode setup before (a) and after $20 \mathrm{~h}$ of electrolysis (c). Two-electrode before (b) and after $20 \mathrm{~h}$ of electrolysis (d). Black curves represent the dark current and red curves represent the photocurrent.

Three trials were so far successfully complete. The first trial began at 1 sun but needed to be increased to two suns which concluded at $19 \mathrm{~h}$, the second trial was done at two suns for $20 \mathrm{~h}$, and the third trial was done at five suns for $4 \mathrm{~h}$. The $J$ - $V$ behavior of the PEC set-up before and after $20 \mathrm{~h}$ of electrolysis is displayed in Figure 5.2 from the 


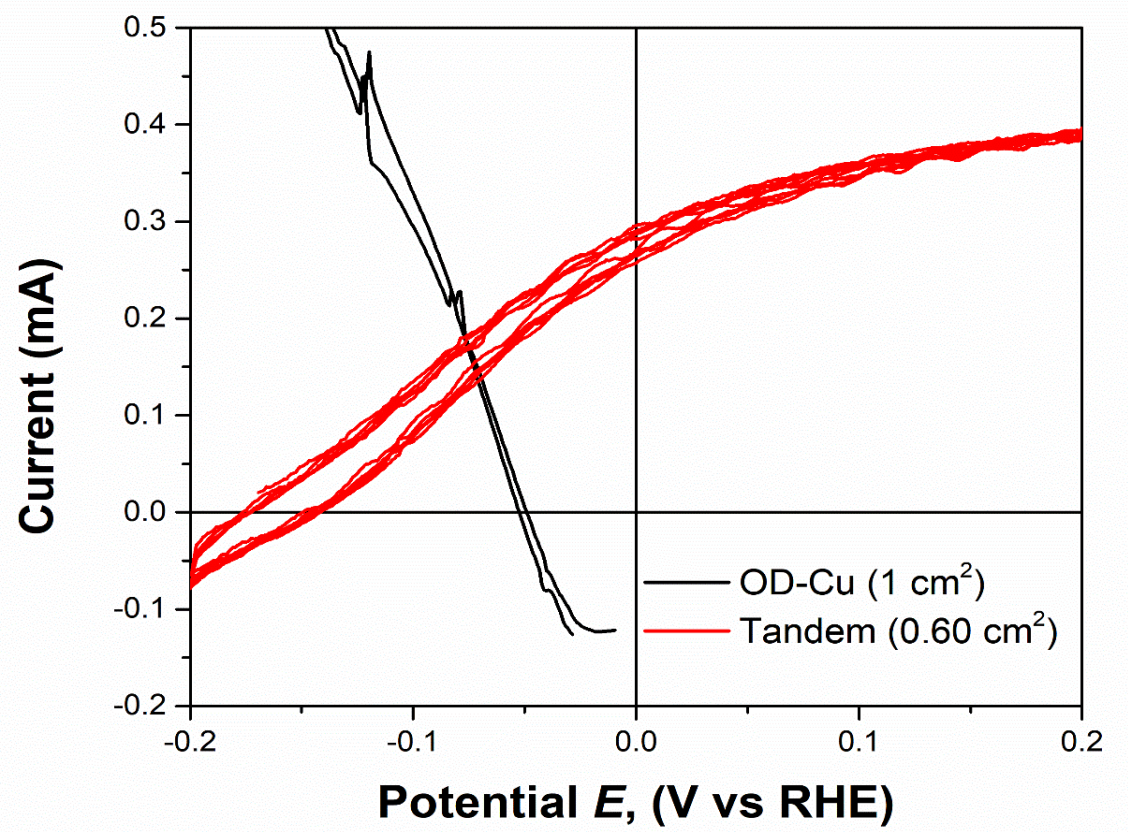

Figure 5.3 Overlap CVs of OD-Cu (black) and tandem (red).

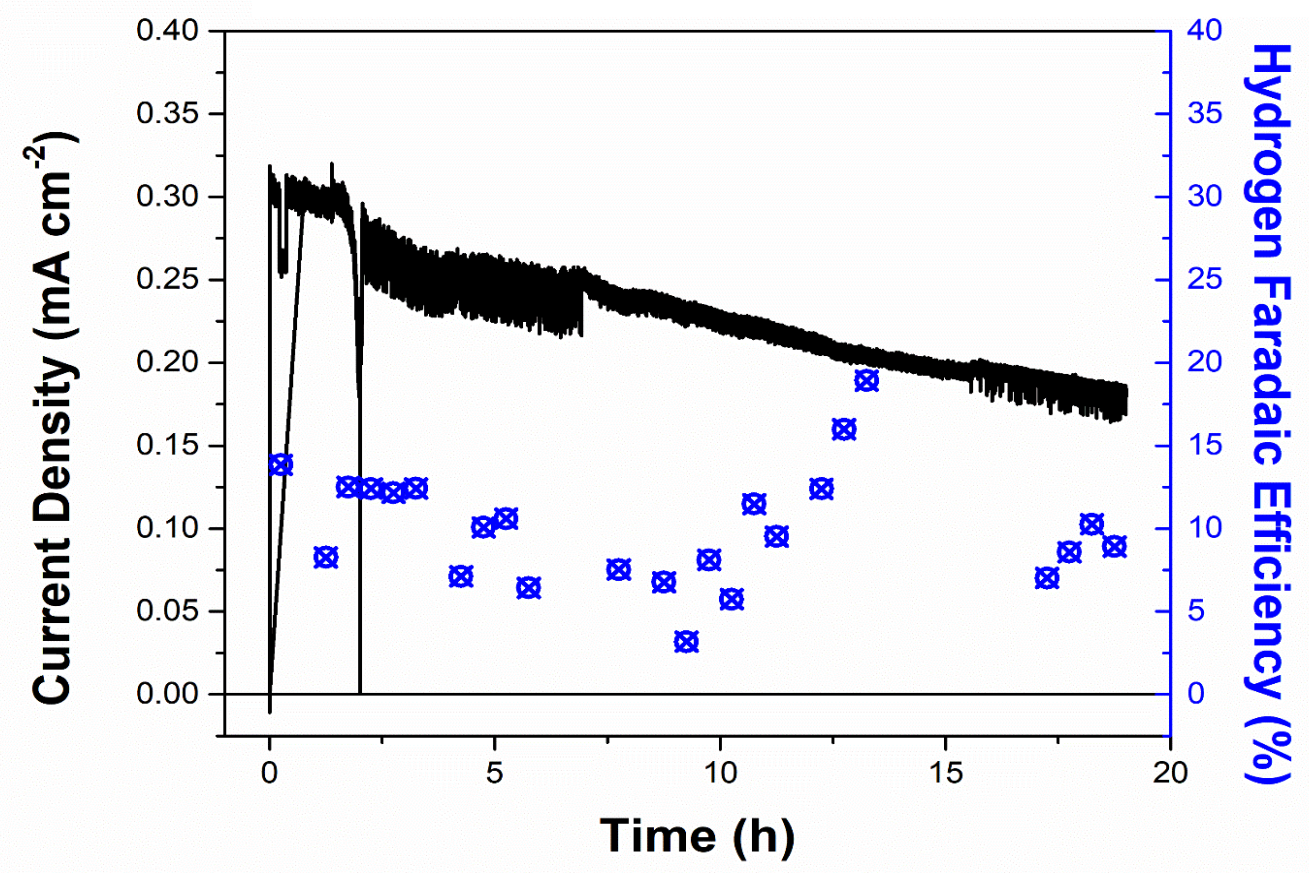

Figure 5.4 Trial 1: Chronoamperogram and hydrogen FE data for $19 \mathrm{~h}$ unassisted photoelectrolysis. At approximately 2 hours the solar lamp was adjusted to two sun. 
experimental trial 2. The $J$ - $V$ behavior expressed in Figure 5.2 is similar to the $J-V$ behavior in trials 1 and 3. The $J-V$ behavior was measured in a two-electrode setup and the threeelectrode setup where the OD-Cu dark cathode operated as the CE or RE. For the threeelectrode measurements, PEIS was conducted immediately beforehand and the cell was corrected $85 \%$ for uncompensated resistance. The short-circuit current $\left(i_{s c}\right)$ represents the photocurrent at $0.0 \mathrm{~V}$ vs. RHE, or the unbiased photocurrent. The photocurrent generated in the three-electrode $J-V$ curve (Figure $5.2 \mathrm{a}$ ) reached $i_{s c}=0.25 \mathrm{~mA} \mathrm{~cm}{ }^{-2}$. This anodic current generated on the $0.60 \mathrm{~cm}^{-2}$ tandem photoanode would match the cathodic current present at the dark $1.00 \mathrm{~cm}^{-2} \mathrm{OD}-\mathrm{Cu}$ cathode. This current would then be responsible for the CORR and HER occurring at that dark cathode in a three-electrode setup. This is more clearly expressed in Figure 5.3 by overlapping the flipped $J$ - $V$ curve of the dark cathode (OD-Cu) with the $J-V$ curve of the photoanode (from Figure 5.2a). The point at which the currents cross is the operating point of the unassisted PEC device. The photocurrent generated in the two-electrode $J-V$ curve (Figure $5.2 \mathrm{~b}$ ) reaches $i_{s c}=0.40 \mathrm{~mA} \mathrm{~cm}{ }^{-2}$. This difference in $i_{s c}$ may be due to the decrease in collective cell resistance in the two-electrode setup in contrast to the three-electrode setup. This initial $i_{s c}$ drops in the first hours of electrolysis (Figure 5.4), possibly due to some stabilization of the PEC setup occurring. This behavior is also seen in trials 2 and 3 (Figure 5.5), although in less time. Due to this decrease in photocurrent (approaching less than $0.10 \mathrm{~mA}$ ) the power of the solar lamp was increased to 2 suns for trial 1. Experiments with a current of around $0.10 \mathrm{~mA}(0.17 \mathrm{~mA}$ $\mathrm{cm}^{-2}$ on the photoanode) would result in too high a chance of product quantification issues with the present experimental setup. Such small currents would inevitably produce too small quantities of product and not pass the detection limits of the product quantification 
methods used. The remaining several hours of photoelectrolysis for trial 1 remained in an adequate steady-state operation. The HER measured via GC maintained a general FE of $\sim 10 \%$. The liquid products measured at the end resulted in FE values of $0.73 \%$ for 1propanol, $0.66 \%$ for acetate, $0 \%$ for ethanol, and $2.22 \%$ for formate. The second trial of

Table 5.1 Faradaic Efficiencies and related data for the three trials of unassisted PEC CORR.

\begin{tabular}{|cccccccc|}
\cline { 4 - 8 } & & & \multicolumn{5}{c|}{ Faradaic Efficiency (\%) } \\
\hline Trial & Suns & $J_{\text {ave }}$ & Propanol & Acetate & Formate & $\mathrm{H}_{2}$ & Total \\
\hline $\mathbf{1}$ & $1-2$ & 0.25 & 0.73 & 0.36 & 2.22 & 10 & 13.31 \\
\hline $\mathbf{2}$ & 2 & 0.15 & 0.66 & 0.40 & 2.06 & 10 & 13.12 \\
\hline $\mathbf{3}$ & 5 & 0.30 & 0.98 & 1.19 & 1.45 & 49 & 52.62 \\
\hline
\end{tabular}

unassisted photoelectrolysis (Figure 5.5a) was completed at a continuous 2 sun condition resulted in similar product distribution (Table 5.1). The absence of ethanol as a reduction product at the end of these long-term electrolyses may mean that the ethanol is reacted further to propanol due to the small photobias applied allowing more residence time of the ethanol intermediate. One more trial was completed at 5 suns (Figure 5.5b). These trials resulted in only slightly different product distribution (Table 5.1).

These pilot experimental trial results obtained so far in this work represent that unassisted PEC CORR has been achieved, yet there are aspects of this PEC experimental configuration that have to be addressed in order to obtain statistically significant results. First, the FE result for formate isn't yet corrected for any non-electrochemical formate production since the control for this specific cell has not been conducted yet as was done 
in our lab's previous CORR study. This control experiment will be conducted in the PTFE cell constructed for these experiments. Secondly, the measured product distributions are no where near a $100 \%$ total. It is vital to account for $~ 100 \%$ of the electron destinations. There are a few factors that are contributing to this deficit. The product quantification of gas products suffers from the low photocurrent generated. The GC used in these experiments has certain product detection limits. These product detection limits are dictated by the flow of the gas travelling through the dynamic mode component of the GC.
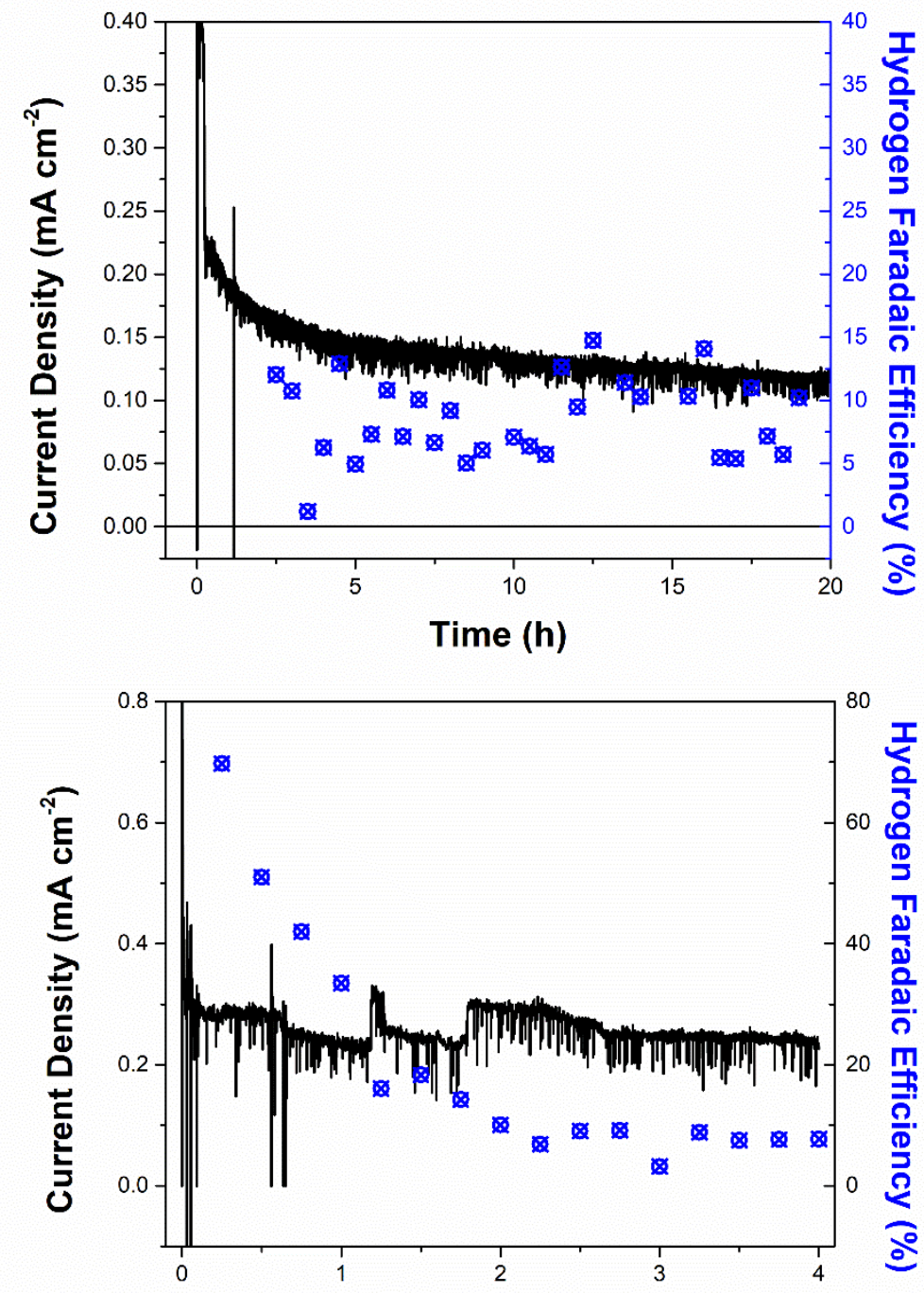

Time (h)

Figure 5.5 Chronoamperograms for Trial 2 (a) at 2 suns. Trial 3 (b) at 5 suns. 
This fact brings into question the overall accuracy of the obtained $\mathrm{H}_{2}$ measurements since that are at or below this detection limit. Also, any gaseous hydrocarbon product may be drowned out by the $\mathrm{CO}$ response on the FID. The mass flow controller in charge of regulating the flow of $\mathrm{CO}$ itself has a lower limit of approximately $5 \mathrm{sccm}$. Future experiments will be using a low flow mass flow controller (ranges of 0.1-7 sccm) that will greatly lower the product detection limit. Also contributing to the unbalanced FE measurements is the fact that several of the reduction products may be travelling across the anion exchange membrane and are being oxidized on the anode. This is generally not an issue in short-term experiments, but for long-term experiments this can mean that measuring all the CORR products becomes nearly impossible. This concept of electromigration of reduction products over time is thoroughly discussed by Krodel et al. ${ }^{315}$

The measurement for efficiency of this PEC device setup can be described by the solar-to-fuel (STF) efficiency. ${ }^{304}$ In the following table the product distribution FE for each trial has been used to calculate the corresponding STF values for each product via the following equation:

$$
\eta_{\text {STF }}=\frac{F E \cdot J_{\text {ave }} \cdot \Delta E}{P_{\text {solar }}}
$$

where $J_{\text {ave }}\left(\mathrm{mA} \mathrm{cm}^{-2}\right)$ is the average current over the period of photoelectrolysis, $\Delta E(\mathrm{~V}$ vs. RHE) is the potential difference corresponding to the Gibbs free-energy difference between the two half-reactions for the fuels being produced at the cathode and for water oxidation at the anode, and $P_{\text {solar }}\left(\mathrm{mW} \mathrm{cm}^{-2}\right)$ is the illumination power from the solar simulator. The $\eta_{S T F}(\%)$ values calculated based of the results listed in Table 5.1 are listed in Table 5.2. 
Table 5.2 Solar-to-fuel efficiency data for propanol and acetate based off of results listed in table 5.1.

\begin{tabular}{|c|c|c|c|c|} 
& & \multicolumn{3}{c|}{$J_{\text {ave }}\left(\mathrm{mA} \mathrm{cm}^{-2}\right) / \mathrm{FE}(\%) / \mathrm{STF}(\%)$} \\
Product & $\Delta \mathrm{E}$ vs. RHE & Trial 1 $\left(0.2 \mathrm{~W} \mathrm{~cm}^{-2}\right)$ & Trial $2\left(0.2 \mathrm{~W} \mathrm{~cm}^{-2}\right)$ & Trial $3\left(0.5 \mathrm{~W} \mathrm{~cm}^{-2}\right)$ \\
\hline Propanol & 0.87 & $0.25 / 0.73 / 0.079$ & $0.15 / 0.66 / 0.043$ & $0.30 / 0.98 / 0.128$ \\
\hline Acetate & 0.73 & $0.25 / 0.36 / 0.033$ & $0.15 / 0.40 / 0.022$ & $0.30 / 1.19 / 0.130$ \\
\hline
\end{tabular}

\subsection{Conclusion}

Although the STF values calculated from the experimental data is $<1 \%$, it shows that unassisted PEC CORR is possible. To our knowledge this reaction has yet to be reported for an unassisted photoelectrochemical cell system. So far, STF values of $0.128 \%$ for propanol and $0.130 \%$ for acetate at 5 suns via unassisted photoelectrochemical carbon monoxide reduction and represents a lower limit of the real production rates due to several experimental obstacles that need to be tackled. It will be interesting to see what these results will be in a true artificial leaf device where the OD-Cu is directly contacted to the back of the photoanode. Future work will be pursued to accomplish this goal as well as bias-assisted experiments to explore the product distribution at different photovoltages. 


\section{CHAPTER 6}

\section{FUTURE PROJECTS AND SUMMARY}

\subsection{Introduction}

In this chapter ongoing projects and future goals will be discussed along with the summary of the dissertation. There exists a catalyst system that has relatively been underresearched in the field of $\mathrm{CO}_{2}$ and $\mathrm{CO}$ reduction. Several catalyst systems involving carbonaceous catalysts exist but one system, doped-nanodiamond, has only just begun to be explored as a $\mathrm{CO}_{2}$ catalyst. The second ongoing project involves the use of the bimetallic alloy, $\mathrm{CuNi}$, as a possible catalyst system to open the product space available in $\mathrm{CO}_{2}$ and $\mathrm{CO}$ reduction. A third project that is proposed involves the use of photodifferential electrochemical mass spectrometry (PDEMS) to study $\mathrm{CO}_{2} \mathrm{RR}$ and CORR reactions.

\subsection{Doped-nanodiamond}

Doped-nanodiamond (DND) catalysts consist of a material in which diamond has been synthetically produced and then purposefully doped with $\mathrm{N}$ or B. ${ }^{316-318}$ Several different applications of this material have been explored. ${ }^{319}$ In particular two recent studies that used DND as the catalyst for $\mathrm{CO}_{2}$ electroreduction showed great selectivity towards a certain product. Nitrogen-DND was demonstrated to reach a $91 \%$ FE for acetate 


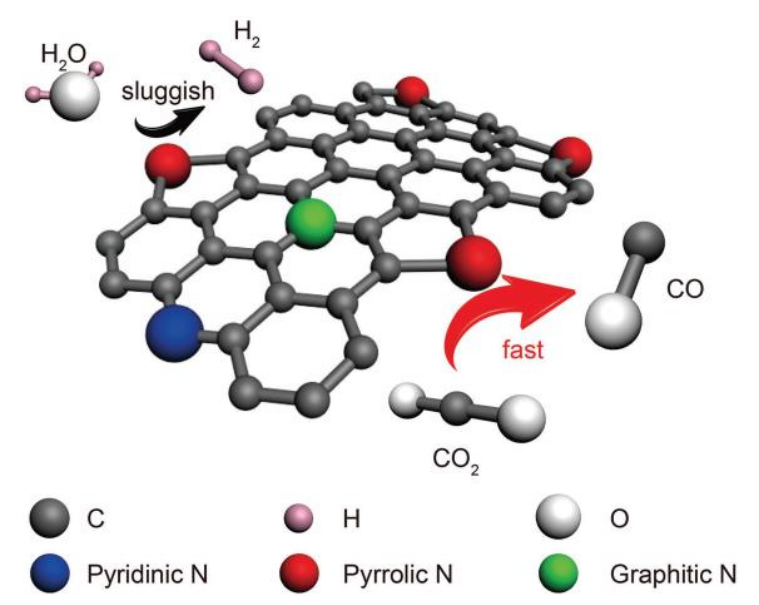

Figure 6.1 Nanodiamond $\mathrm{N}$ groups. ${ }^{322}$

at $\sim-0.9$ V vs. RHE. ${ }^{320}$ Boron and Nitrogen co-doped nanodiamond catalyst demonstrated a selectivity of $93 \% \mathrm{FE}$ for ethanol at $-1.0 \mathrm{~V}$ vs. RHE by the same group. ${ }^{321}$ The activity for this reaction is theorized to stem from the heteroatom groups that are introduced into the nanodiamond's structure. Control over the density of these active sites tunes the catalyst's selectivity. These active sites involving the incorporation of $\mathrm{N}$ are pyridinic, pyrrolic, and graphitic groups (Figure 6.1). The pyridinic and pyrrolic groups are more $\mathrm{CO}_{2}$ active and the graphitic group is more HER active. Reduction of the graphitic groups by steam etching was able to increase the performance of a N-DND catalyst. ${ }^{322}$ More recently, a group who studied their DND material found a high selectivity for CO. A selectivity of $82 \%$ for $\mathrm{CO}$ at $-1.1 \mathrm{~V}$ vs. RHE was achieved. ${ }^{323}$

The author has some limited preliminary results from DND catalysts that has been fabricated here at University of Louisville by Alex Bates and Hank Paxton. In brief, the experimental setup entails a glass $\mathrm{H}$-cell designed by the author, $0.1 \mathrm{M} \mathrm{KHCO}_{3}$ as the electrolyte, $10 \mathrm{sccm}$ flow rate of $\mathrm{CO}_{2}$, and a potential of $-1.05 \mathrm{~V}$ vs. RHE to screen for initial activity of $\mathrm{CO}_{2} \mathrm{RR}$. The results that were gathered are summarized in Table 6.1. 
Table 6.1 DND catalyst preliminary results.

\begin{tabular}{|c|c|c|}
\hline Electrode Designation & Type & Product FE \\
\hline BS22 & Boron-doped & $9.61 \%$ Formic Acid \\
\hline BS58 & Boron-doped & $\begin{array}{c}20.95 \% \text { Formic Acid, } 9.70 \% \text { Methanol, } \\
2.21 \% \text { Acetaldehyde }\end{array}$ \\
\hline BNS13 & Boron, Nitrogen co-doped & $2.86 \%$ Acetone, 3.44\% Acetic Acid \\
\hline
\end{tabular}

These preliminary results may indicate some dependence on N-doping to produce $\mathrm{C}_{2}$ products. B-doping seems to have more selectivity for formic acid. The extent that $\mathrm{B}$ and $\mathrm{N}$ doping has on the catalytic activity of this DND system needs to be explored. It is possible that cooperation of $\mathrm{B}$ and $\mathrm{N}$ heteroatom active sites may reveal unknown catalytic pathways for $\mathrm{CO}_{2} \mathrm{RR}$ and CORR. Control of the density of $\mathrm{B}$ and $\mathrm{N}$ sites in the DND lattice and ratio of $\mathrm{B}$ to $\mathrm{N}$ will most likely influence the product distribution heavily.

\subsection{Bimetallic Catalysts: CuNi}

In the field of $\mathrm{CO}_{2} \mathrm{RR}$, it is theorized that there are two main mechanistic pathways. ${ }^{324}$ Once $\mathrm{CO}_{2}$ is reduced to $\mathrm{CO}$, further reduction leads to hydrocarbon products such as methane, methanol, ethylene, ethane, ethanol, acetic acid, and propanol. If $\mathrm{CO}_{2}$ is reduced to formic acid, it is thought that this is a dead-end product. Recent discoveries have shown otherwise. One study of major significance was able to provide details elucidating the mechanism of the formation of $\mathrm{C}_{3}$ and $\mathrm{C}_{4}$ reduction products from the intermediate of formic acid. ${ }^{92}$ In this study they were able to produce 2,3 -furandiol at a very low overpotential of $0.0 \mathrm{~V}$ vs. $\mathrm{RHE}$ on $\mathrm{Ni}_{2} \mathrm{P}$ with $71 \% \mathrm{FE}$. The reason for these new products is theorized to be due to the presence of hydrides on the catalyst surface that end up not reacting to make $\mathrm{H}_{2}$ but rather incorporate themselves into the reduction products. Metals like Ni are known to mainly be HER catalysts, but in different forms may prove to 
be the key to opening an entirely new product space in the field of $\mathrm{CO}_{2} \mathrm{RR}$. Main group catalysts for $\mathrm{CO}_{2} \mathrm{RR}$ have been predicted to have excellent activity for formic acid. ${ }^{89}$

\subsection{Differential Photoelectrochemical Mass Spectroscopy}

\subsubsection{Introduction}

PEC electrodes for $\mathrm{CO}_{2}$ reduction have typically been studied in static conditions that only give snapshots of the time-averaged behavior, providing limited insight into the nature of these reactions. Studying PEC $\mathrm{CO}_{2} \mathrm{RR}$ behavior in operando via real-time product detection provides the opportunity to develop greater understanding of the fundamental processes by observing the evolution of product formation including certain intermediate species. One technique that allows this real-time product detection is differential electrochemical mass spectrometry (DEMS). ${ }^{325,326}$ DEMS provides real-time information on product identity and formation rates at variable electrochemical conditions, and the popularity of the method for characterization has been growing in recent years. The primary goal of this project will be to innovate upon the DEMS approach by designing an effective system to study a photoelectrochemical $\mathrm{CO}_{2} \mathrm{RR}$ reaction in real time. This differential photoelectrochemical mass spectrometry (DPEMS) will provide real-time product information based on differing photoelectrochemical conditions for the $\mathrm{CO}_{2} \mathrm{RR}$, including $\mathrm{pH}$, electrolyte, light intensity, and illumination wavelength. The DPEMS system will be able to simultaneously measure and correlate current density, overpotential, product identity, relative product concentrations, and faradaic efficiencies as well as the timedependent evolution of these properties. Moreover, the method is amenable to isotopic labelling studies to trace atoms through the reaction and unravel mechanistic routes. A simple version of illuminated DEMS was once reported to study semiconductor 


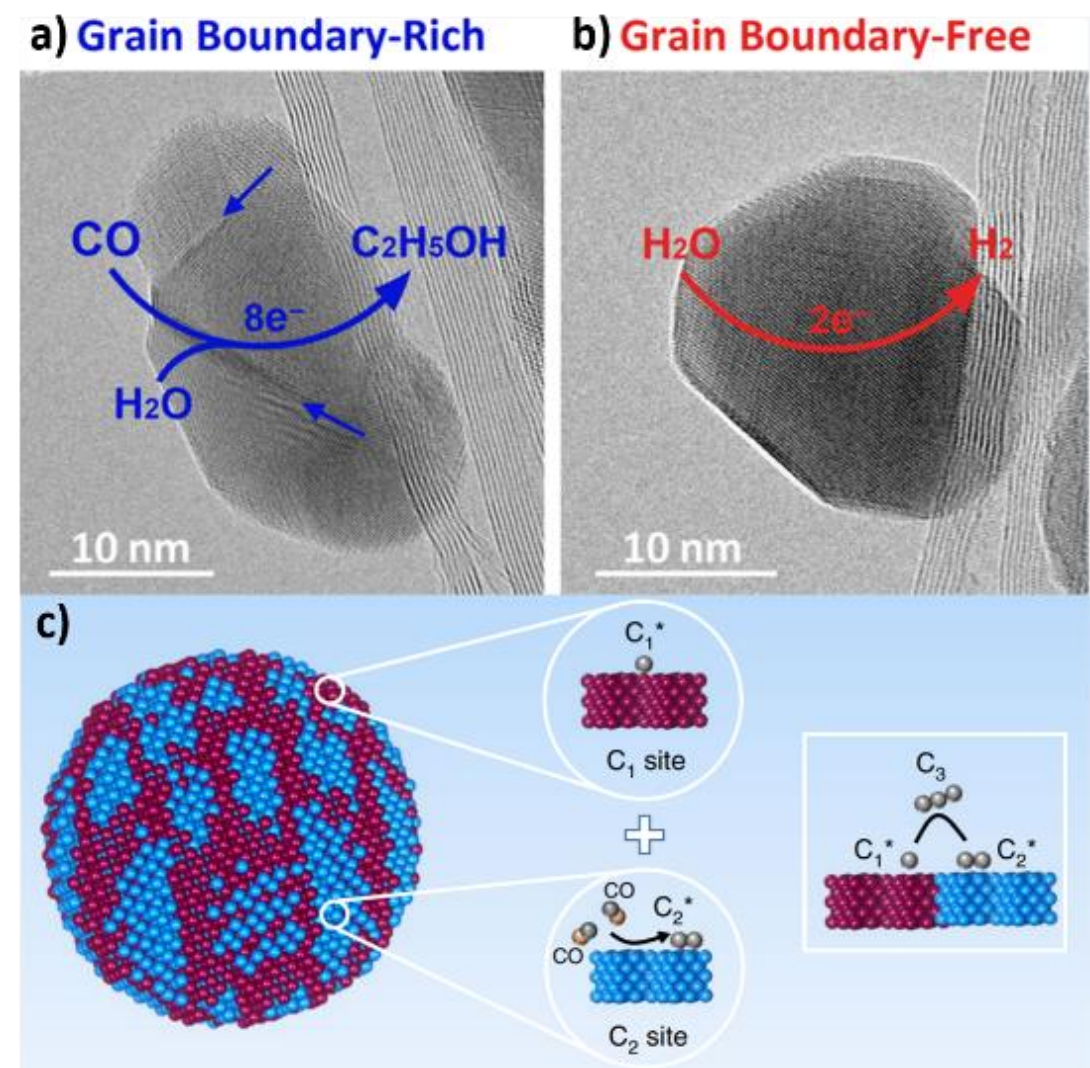

Figure 6.2. a) $\mathrm{Cu}$ nanoparticle with high density of grain boundaries. b) $\mathrm{Cu}$ nanoparticle with no grain boundaries favoring HER. $\left.{ }^{96} \mathbf{c}\right) \mathrm{Cu}$ nanoparticle with fragmented binding sites promoting $\mathrm{C}_{3}$ selectivity. ${ }^{99}$

photocorrosion, but integration of controlled illumination with quantitative product detection has been elusive. ${ }^{327}$ A system will be created for the rapid real-time characterization of $\mathrm{PEC} \mathrm{CO}_{2} \mathrm{RR}$ which will be the cutting-edge characterization method for artificial photosynthesis research. In the development of this DPEMS system, the target $\mathrm{CO}_{2} \mathrm{RR}$ photocatalyst that will be pursued is a p-type copper oxide $\left(\mathrm{p}-\mathrm{Cu}_{2} \mathrm{O}\right)$ semiconductor with incorporated copper oxide based $\mathrm{CO}_{2} \mathrm{RR}$ catalysts along with specific nanostructured morphologies known for active site specific activities and hydrogen evolution reaction (HER) suppression, HER being a reaction in constant competition with $\mathrm{CO}_{2} \mathrm{RR}^{100,328}$ Such $\mathrm{p}-\mathrm{Cu}_{2} \mathrm{O} / \mathrm{Cu}$ heterojunctions have not significantly been explored for $\mathrm{CO}_{2} \mathrm{RR}$ photocatalysis. ${ }^{329}$ These copper oxide catalysts contain advantageous features for 
$\mathrm{C}_{2+}$ products such as high density grain boundaries ${ }^{96}$ and fragmented facets. ${ }^{99}$ The high density of grain boundaries greatly decreases the selectivity for the parasitic HER (Figure 6.1a and 6.1b). Such fragmented facets provide a morphology where $C_{1}$ and $C_{2}$ binding sites, $\mathrm{Cu}(111)$ and $\mathrm{Cu}(100)$ respectively, into close proximity to each other to allow the production of a $\mathrm{C}_{3}$ product (Figure 6.2c). The most recent report for copper's $\mathrm{CO}_{2} \mathrm{RR}$ catalyst activity has demonstrated a $80 \% \mathrm{FE}$ at $-0.4 \mathrm{~V}$ vs. reversible hydrogen electrode (RHE) for $\mathrm{C}_{2+}$ products on a 3D dendritic $\mathrm{Cu} / \mathrm{CuO}$ structure. ${ }^{330}$ Recent efforts in our lab have demonstrated a cascade reactor scheme to take a known Ag catalyst structure known for near $100 \% \mathrm{FE}$ for $\mathrm{CO}$ and directly coupling the produced $\mathrm{CO}$ to a $\mathrm{Cu}$ based reactor consisting of an in-series two step reactor setup, where other attempts at a similar cascade style catalyst system have also been pursued. ${ }^{263,306,331}$ Because of this, specific carbon monoxide reduction reaction (CORR) studies have been pursued. ${ }^{95,97,98,265}$ A modeling study also expressed that such a cascade system would inherently be more efficient. ${ }^{308}$ In a recent study from Jaramillo's group, near full selectivity ( $>99 \%$ FE for CORR products at a low overpotential of $-0.23 \mathrm{~V}$ vs RHE) was provided by greatly enhancing the electrochemically active surface area on $\mathrm{Cu}$ by fabricating a nanoflower structure. ${ }^{100}$ This accomplishment of CORR at low overpotential can lead one to reason that we are close to unassisted PEC CORR, if not $\mathrm{CO}_{2} \mathrm{RR}$ PEC devices. Desirable product selectivity and higher reaction rates at unassisted photovoltages is therefore an achievable goal for PEC $\mathrm{CO}_{2} \mathrm{RR} / \mathrm{CORR}$ in a $\mathrm{Cu}$-based system involving a $\mathrm{p}-\mathrm{Cu}_{2} \mathrm{O} / \mathrm{Cu}$ photocathode. One major condition to test these systems is the specific spectrum of light that excites the catalyst in the PEC device. Copper based photocatalysts have also been shown to have significant activity for photoelectrochemical $\mathrm{CO}_{2} \mathrm{RR}^{332} \mathrm{p}-\mathrm{Cu}_{2} \mathrm{O}$ has been used as a semiconductor in 
several applications. ${ }^{333}$ In previous PEC $\mathrm{CO}_{2} \mathrm{RR}$ p- $\mathrm{Cu}_{2} \mathrm{O}$ structures a $32.69 \% \mathrm{FE}$ for ethylene was achieved on a p- $\mathrm{Cu}_{2} \mathrm{O} /$ nanobelt $\mathrm{Cu}$ photocathode. ${ }^{334}$ Recently gold nanoparticles have shown controllable product selectivity depending on blue or red light excitation, selectively exciting Au's plasmon band. ${ }^{335}$ Also, the same group found significant improvement to selectivity with the aid of an ionic liquid, which led to the formation of propane from $\mathrm{Au}$, known mainly to produce $\mathrm{CO}$, albeit at $\sim 6 \% \mathrm{FE} .{ }^{336}$ This demonstrates a clear motivation to investigate semiconductor/catalyst heterojunctions involved in $\mathrm{CO}_{2} \mathrm{RR}$ photocatalysis and their performance under different light intensity and excitations. Therefore, the core aim for this research is the investigation of a highly nanostructured $\mathrm{p}-\mathrm{Cu}_{2} \mathrm{O} / \mathrm{Cu} \mathrm{CO}_{2} \mathrm{RR}$ photocathode that will be thoroughly understood via in operando techniques including the development of DPEMS by varying the following photoelectrochemical conditions: bias, illumination intensity, and illumination wavelength.

\subsubsection{Semiconductor/Cu Photocathode Fabrication}

The fabrication of the $\mathrm{p}-\mathrm{Cu}_{2} \mathrm{O} / \mathrm{Cu}$ photocathode will be performed alongside similar FTO/Cu, p-Si/Cu, and $\mathrm{n}^{+} \mathrm{p}-\mathrm{Si} / \mathrm{Cu}$ photocathodes. Deposition of catalysts on $\mathrm{p}-\mathrm{Cu}_{2} \mathrm{O}$ will be performed following literature methods, ${ }^{333}$ as well as the silicon based photocathodes. ${ }^{236}$ Our lab has extensive experience manufacturing $\mathrm{n}^{+} \mathrm{p}-\mathrm{Si}$ and $\mathrm{p}-\mathrm{Si}$ electrodes and also manufacture our own $\mathrm{n}^{+} \mathrm{p}-\mathrm{Si}$ material in house. These photoelectrodes will first be investigated by simple photoelectrochemistry to benchmark photoelectrode performance. Matching the current between a typical PEC setup and the DPEMS cell will be necessary to adequately perform experiments at the same illumination intensities based upon the use of a one sun intensity calibrated silicon photoelectrode. Material characterization of these 
photocathodes will be conducted with XPS, XRD, SEM, and TEM to ensure their quality and desired morphologies.

\subsubsection{DPEMS Experimental Setup}

DEMS provides real-time product analysis capable of correlating current density vs. voltage $(J V)$ curves to volatile product formation rates. ${ }^{325,326}$ Figure 6.3 shows the rapid DEMS-measured behavior compared directly to conventional static GC measurements. PEC $\mathrm{CO}_{2} \mathrm{RR}$ studies aim to characterize $\mathrm{CO}_{2} \mathrm{RR}$ activity with and without incident illumination. Figure 6.4 shows an example from our previous work using conventional product analysis methods (i.e., NMR, GC) on $\mathrm{a} \mathrm{n}^{+} \mathrm{p}-\mathrm{Si} / \mathrm{Sn}$ photocathode $\mathrm{CO}_{2} \mathrm{RR}$ system, demonstrating a $\sim 400 \mathrm{mV}$ photo-driven decrease in the overpotential. ${ }^{301}$ Using the

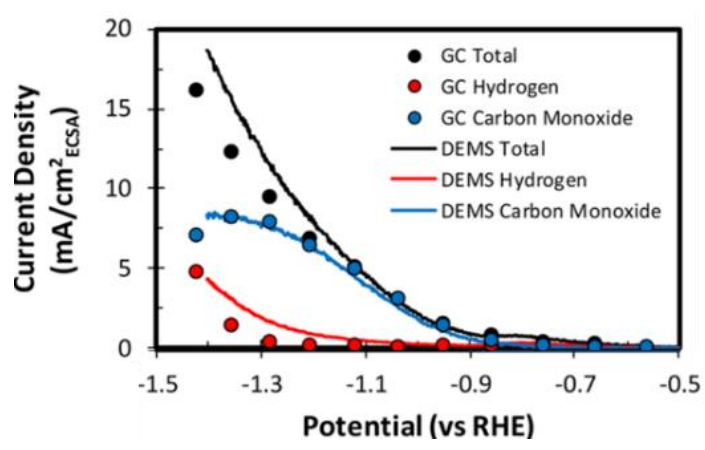

Figure 6.3. Comparison of conventional GC product quantification and DEMS results. ${ }^{324}$

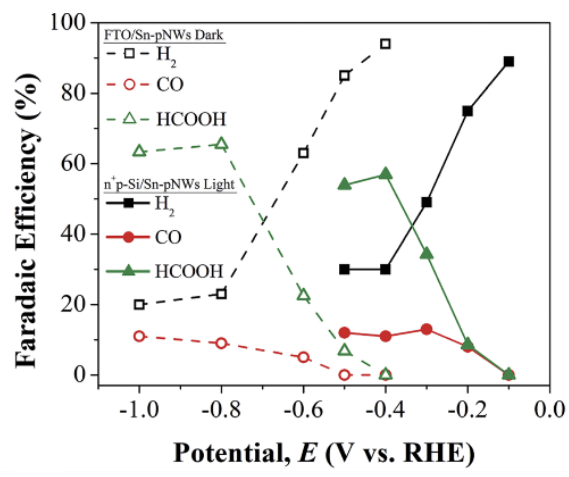

Figure 6.4. FE for products produced on Sn-porous nanowires deposited on FTO without light and on $\mathrm{n}^{+} \mathrm{p}-\mathrm{Si}$ with light. ${ }^{301}$

envisioned DPEMS instrumentation, the data in Figure 6.3 could be generated on the order of minutes rather than days/weeks, with the added benefit of time-dependent information as a function of scan rate. It functions like a normal DEMS setup in that a porous PTFE membrane separates the working electrode from the high vacuum paths that lead to the mass spectrometer (MS). The alteration in setup being that light is oriented into the system in a way to be incident upon the working electrode by the PTFE membrane encircling the 
working electrode, allowing unimpeded incident light upon the electrode. The light would enter the electrochemical cell via a quartz window fitting to make the cell airtight but still allow near $100 \%$ non-diffuse and collimated light to hit the working photoelectrode. This will be difficult to achieve due to the cell geometry. The DPEMS schematic is illustrated in figure 6.5. This design will have a fundamental limitation that a normal DEMS setup does not necessarily possess. The distance the reactants and products need to travel from the entire working electrode (WE) surface will on average have longer lengths to travel to reach the PTFE membrane and be pervaporated into the vacuum. Simple experiments varying the dimensions of the PTFE encirclement membrane will be tested for optimum detection conditions where this mass transfer issue is minimized. Verifications of these optimum conditions will be performed by Ag based HER and $\mathrm{CO}_{2} \mathrm{RR}$ reaction conditions with known outcomes, followed by $\mathrm{p}$-Si photocathodes to benchmark photocatalytic methods. The dimensions of this PTFE membrane will depend on the area of the working photoelectrode. Measures will be taken to ensure the WE area is as large as possible to increase the detection sensitivity of the cell. Another component of the DPEMS cell that will need to be optimized is the volume and shape of the electrolyte chamber. The fluid dynamics of the electrolyte cycling through the cell may need to be modulated via precision peristaltic pumps to prevent any unwanted light diffraction. The distance and position of the reference electrode (RE) will be paramount to the performance of the DPEMS cell. Decreasing the distance between the RE and WE will greatly reduce solution resistance, which would impede the available range of bias that could be applied to the cell. Calibration curves of the products detected in the MS will be conducted following and building upon the work accomplished by Clark and Bell for quantification of analytes and 
deconvolution of mixed $\mathrm{m} / \mathrm{z}$ product signals detected in DEMS. ${ }^{326}$ The next innovative facet to this cell design will be the incorporation of a separated counter electrode (CE) chamber. The design of the CE chamber will include a "sheath" space for which anolyte may flow in and out of the chamber with ease while being separated from the CE back contact along the outside of the fiber optic light connection (Figure 6.5). The CE material can either be a platinum mesh or flexible carbon affixed within the sheath chamber and the catholyte-facing portion of the sheath chamber will comprise of a ring of Selemion anionexchange membrane. The anolyte fluid channels will be incorporated into the fiber optic connection along with the CE back contact wiring. The DPEMS cell itself will be machined out of PEEK and incorporated into an existing mass spec system. On top of this the fiber optic solar input setup will require certain implements for providing monochromatic, modulated, and chopped light. 


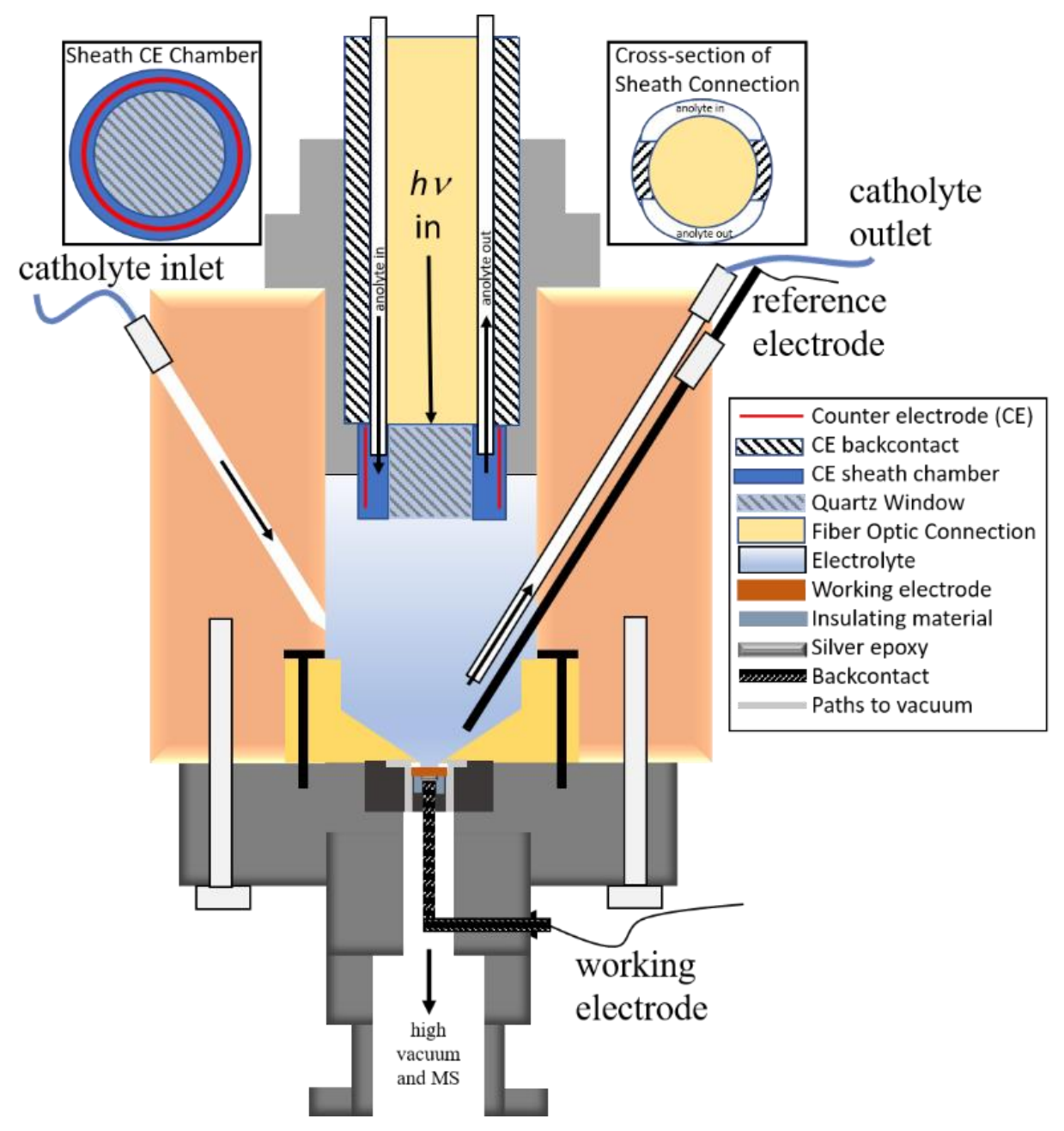

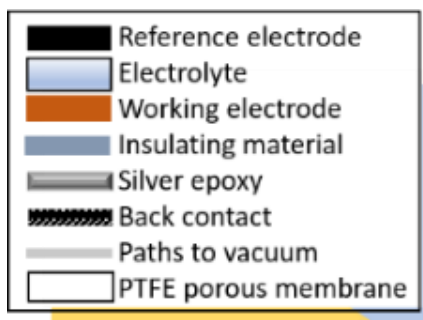

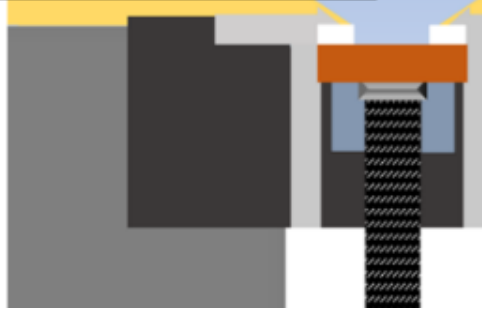

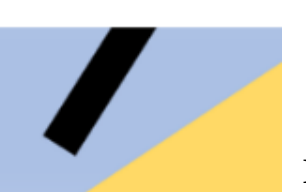

Figure 6.5

Above: Schematic of the DPEMS cell. Left: Close up of the DPEMS WE environment. 


\subsection{Dissertation Summary}

This dissertation has summarized the progress the author has achieved in the efforts of electrochemical reduction of $\mathrm{CO}_{2}$ and $\mathrm{CO}$ among other electrochemical investigations. The significant original contributions to this field of literature that were presented will aid in the efforts of other research endeavors in years to come. In chapter two, several coauthored works were presented and the importance of measuring faradaic efficiency, current density, and overpotential in order to understand catalytic activity is demonstrated. In chapter three, the author established the importance of accurate product quantification and identification methods by assessing the possible contaminants from the membrane component of the typical electrochemical cell utilized in this field. In chapter four, the author demonstrated the control over product selectivity of CORR by pulsing the electrochemical bias showing $\mathrm{C}_{\underline{\underline{1}}}$ products are produced at higher pulse frequencies. In chapter five, the efforts towards unassisted PEC CORR were detailed. In this concluding

chapter future directions of research involving the development of DPEMS instrumentation, a CuNi bimetallic catalyst system, and a DND catalyst system were discussed.

This dissertation has demonstrated the importance of appropriate techniques for the study of $\mathrm{CO}_{2} \mathrm{RR}$ and CORR catalyst system as well as control over these catalyst systems. Further understanding of the catalyst systems for $\mathrm{CO}_{2} \mathrm{RR}$ and CORR in the effort to efficiently produce value-added products will aid in improving our economies relationship to the global carbon cycle. 


\section{REFERENCES}

1. Goodwin, P.; Katavouta, A.; Roussenov, V. M.; Foster, G. L.; Rohling, E. J.; Williams, R. G., Pathways to 1.5 degrees $C$ and 2 degrees $C$ warming based on observational and geological constraints. Nature Geoscience 2018, 11 (2), 102-+.

2. Peter, S. C., Reduction of $\mathrm{CO} 2$ to Chemicals and Fuels: A Solution to Global Warming and Energy Crisis. Acs Energy Letters 2018, 3 (7), 1557-1561.

3. Reisinger, A.; Clark, H., How much do direct livestock emissions actually contribute to global warming? Global Change Biology 2018, 24 (4), 1749-1761.

4. Wigley, T. M. L., The Paris warming targets: emissions requirements and sea level consequences. Climatic Change 2018, 147 (1-2), 31-45.

5. Falkowski, P.; Scholes, R. J.; Boyle, E.; Canadell, J.; Canfield, D.; Elser, J.; Gruber, N.; Hibbard, K.; Hogberg, P.; Linder, S.; Mackenzie, F. T.; Moore, B.; Pedersen, T.; Rosenthal, Y.; Seitzinger, S.; Smetacek, V.; Steffen, W., The global carbon cycle: A test of our knowledge of earth as a system. Science 2000, 290 (5490), 291-296.

6. Wu, H.-L.; Li, X.-B.; Tung, C.-H.; Wu, L.-Z., Semiconductor Quantum Dots: An Emerging Candidate for $\mathrm{CO} 2$ Photoreduction. Advanced Materials 2019, 31 (36).

7. Zachos, J. C.; Dickens, G. R.; Zeebe, R. E., An early Cenozoic perspective on greenhouse warming and carbon-cycle dynamics. Nature 2008, 451 (7176), 279-283.

8. Dong, F.; Wang, Y.; Su, B.; Hua, Y.; Zhang, Y., The process of peak $\mathrm{CO} 2$ emissions in developed economies: A perspective of industrialization and urbanization. Resources Conservation and Recycling 2019, 141, 61-75.

9. Huang, C.-H.; Tan, C.-S., A Review: CO2 Utilization. Aerosol and Air Quality Research 2014, 14 (2), 480-499.

10. Mardani, A.; Streimikiene, D.; Cavallaro, F.; Loganathan, N.; Khoshnoudi, M., Carbon dioxide (CO2) emissions and economic growth: A systematic review of two decades of research from 1995 to 2017. Science of the Total Environment 2019, 649, 31-49.

11. Detz, R. J.; van der Zwaan, B., Transitioning towards negative $\mathrm{CO} 2$ emissions. Energy Policy 2019, 133.

12. Kaya, Y.; Yamaguchi, M.; Geden, O., Towards net zero $\mathrm{CO} 2$ emissions without relying on massive carbon dioxide removal. Sustainability Science 2019, 14 (6), 1739-1743.

13. Wei, Y.; Li, Y.; Wu, M.; Li, Y., The decomposition of total-factor CO2 emission efficiency of 97 contracting countries in Paris Agreement. Energy Economics 2019, 78, 365-378.

14. Arellano-Trevino, M. A.; Kanani, N.; Jeong-Potter, C. W.; Farrauto, R. J., Bimetallic catalysts for $\mathrm{CO} 2$ capture and hydrogenation at simulated flue gas conditions. Chemical Engineering Journal 2019, 375. 
15. Kar, S.; Goeppert, A.; Prakash, G. K. S., Combined CO2 Capture and Hydrogenation to Methanol: Amine Immobilization Enables Easy Recycling of Active Elements.

Chemsuschem 2019, 12 (13), 3172-3177.

16. Li, L.; Zhao, N.; Wei, W.; Sun, Y., A review of research progress on CO2 capture, storage, and utilization in Chinese Academy of Sciences. Fuel 2013, 108, 112-130.

17. Pelletier, C.; Rogaume, Y.; Dieckhoff, L.; Bardeau, G.; Pons, M.-N.; Dufour, A., Effect of combustion technology and biogenic $\mathrm{CO} 2$ impact factor on global warming potential of wood-to-heat chains. Applied Energy 2019, 235, 1381-1388.

18. Pipes, R.; Bhargav, A.; Manthiram, A., Phenyl Disulfide Additive for Solution-Mediated Carbon Dioxide Utilization in Li-CO2 Batteries. Advanced Energy Materials 2019, 9 (21).

19. Song, C.; Liu, Q.; Deng, S.; Li, H.; Kitamura, Y., Cryogenic-based CO2 capture technologies: State-of-the-art developments and current challenges. Renewable \& Sustainable Energy Reviews 2019, 101, 265-278.

20. Yu, K. M. K.; Curcic, I.; Gabriel, J.; Tsang, S. C. E., Recent Advances in CO2 Capture and Utilization. Chemsuschem 2008, 1 (11), 893-899.

21. Jung, S.; Park, Y.-K.; Kwon, E. E., Strategic use of biochar for $\mathrm{CO} 2$ capture and sequestration. Journal of Co2 Utilization 2019, 32, 128-139.

22. Pastero, L.; Curetti, N.; Ortenzi, M. A.; Schiavoni, M.; Destefanis, E.; Pavese, A., CO2 capture and sequestration in stable Ca-oxalate, via Ca-ascorbate promoted green reaction. Science of the Total Environment 2019, 666, 1232-1244.

23. Yang, H.-J.; Yang, H.; Hong, Y.-H.; Zhang, P.-Y.; Wang, T.; Chen, L.-N.; Zhang, F.-Y.; $\mathrm{Wu}$, Q.-H.; Tian, N.; Zhou, Z.-Y.; Sun, S.-G., Promoting Ethylene Selectivity from CO2 Electroreduction on CuO Supported onto CO2 Capture Materials. Chemsuschem 2018, 11 (5), 881-887.

24. Aljabour, A.; Coskun, H.; Apaydin, D. H.; Ozel, F.; Hassel, A. W.; Stadler, P.; Sariciftci, N. S.; Kus, M., Nanofibrous cobalt oxide for electrocatalysis of $\mathrm{CO} 2$ reduction to carbon monoxide and formate in an acetonitrile-water electrolyte solution. Applied Catalysis BEnvironmental 2018, 229, 163-170.

25. Duan, Y.-X.; Meng, F.-L.; Liu, K.-H.; Yi, S.-S.; Li, S.-J.; Yan, J.-M.; Jiang, Q., Amorphizing of Cu Nanoparticles toward Highly Efficient and Robust Electrocatalyst for $\mathrm{CO} 2$ Reduction to Liquid Fuels with High Faradaic Efficiencies. Advanced Materials 2018, 30 (14).

26. Kar, S.; Goeppert, A.; Galvan, V.; Chowdhury, R.; Olah, J.; Prakash, G. K. S., A CarbonNeutral CO2 Capture, Conversion, and Utilization Cycle with Low-Temperature Regeneration of Sodium Hydroxide. Journal of the American Chemical Society 2018, 140 (49), 16873-16876.

27. Krieg, T.; Sydow, A.; Faust, S.; Huth, I.; Holtmann, D., CO2 to Terpenes: Autotrophic and Electroautotrophic alpha-Humulene Production with Cupriavidus necator. Angewandte Chemie-International Edition 2018, 57 (7), 1879-1882.

28. Kumar, A.; Semwal, S.; Choudhury, J., Catalytic Conversion of $\mathrm{CO} 2$ to Formate with Renewable Hydrogen Donors: An Ambient-Pressure and H-2-Independent Strategy. Acs Catalysis 2019, 9 (3), 2164-2168.

29. Ma, W.; Wang, H.; Yu, W.; Wang, X.; Xu, Z.; Zong, X.; Li, C., Achieving Simultaneous $\mathrm{CO} 2$ and H2S Conversion via a Coupled Solar-Driven Electrochemical Approach on NonPrecious-Metal Catalysts. Angewandte Chemie-International Edition 2018, 57 (13), 34733477. 
30. Moioli, E.; Mutschler, R.; Zuettel, A., Renewable energy storage via CO2 and H-2 conversion to methane and methanol: Assessment for small scale applications.

Renewable \& Sustainable Energy Reviews 2019, 107, 497-506.

31. Shi, Z.; Yang, H.; Gao, P.; Li, X.; Zhong, L.; Wang, H.; Liu, H.; Wei, W.; Sun, Y., Direct conversion of $\mathrm{CO} 2$ to long-chain hydrocarbon fuels over K-promoted $\mathrm{CoCu} / \mathrm{TiO} 2$ catalysts. Catalysis Today 2018, 311, 65-73.

32. Trickett, C. A.; Helal, A.; Al-Maythalony, B. A.; Yamani, Z. H.; Cordova, K. E.; Yaghi, O. M., The chemistry of metal-organic frameworks for $\mathrm{CO} 2$ capture, regeneration and conversion. Nature Reviews Materials 2017, 2 (8).

33. Wu, X.; Li, Y.; Zhang, G.; Chen, H.; Li, J.; Wang, K.; Pan, Y.; Zhao, Y.; Sun, Y.; Xie, Y., Photocatalytic $\mathrm{CO} 2$ Conversion of M0.33WO3 Directly from the Air with High Selectivity: Insight into Full Spectrum-Induced Reaction Mechanism. Journal of the American Chemical Society 2019, 141 (13), 5267-5274.

34. Zain, M. M.; Mohamed, A. R., An overview on conversion technologies to produce value added products from $\mathrm{CH} 4$ and $\mathrm{CO} 2$ as major biogas constituents. Renewable \& Sustainable Energy Reviews 2018, 98, 56-63.

35. Zheng, T.; Jiang, K.; Wang, H., Recent Advances in Electrochemical CO2-to-CO Conversion on Heterogeneous Catalysts. Advanced Materials 2018, 30 (48).

36. Cardias, B. B.; de Morais, M. G.; Vieira Costa, J. A., CO2 conversion by the integration of biological and chemical methods: Spirulina sp LEB 18 cultivation with diethanolamine and potassium carbonate addition. Bioresource Technology 2018, 267, 77-83.

37. Efrati, A.; Lu, C.-H.; Michaeli, D.; Nechushtai, R.; Alsaoub, S.; Schuhmann, W.; Willner, I., Assembly of photo-bioelectrochemical cells using photosystem I-functionalized electrodes. Nature Energy 2016, 1.

38. Liu, X.; Kang, F.; Hu, C.; Wang, L.; Xu, Z.; Zheng, D.; Gong, W.; Lu, Y.; Ma, Y.; Wang, J., A genetically encoded photosensitizer protein facilitates the rational design of a miniature photocatalytic CO2-reducing enzyme. Nature Chemistry 2018, 10 (12), 12011206.

39. Rittmann, S. K. M. R.; Seifert, A. H.; Bernacchi, S., Kinetics, multivariate statistical modelling, and physiology of $\mathrm{CO} 2$-based biological methane production. Applied Energy 2018, 216, 751-760.

40. Savvas, S.; Donnelly, J.; Patterson, T.; Chong, Z. S.; Esteves, S. R., Biological methanation of $\mathrm{CO} 2$ in a novel biofilm plug-flow reactor: $\mathrm{A}$ high rate and low parasitic energy process. Applied Energy 2017, 202, 238-247.

41. Singh, R. K.; Singh, R.; Sivakumar, D.; Kondaveeti, S.; Kim, T.; Li, J.; Sung, B. H.; Cho, B.-K.; Kim, D. R.; Kim, S. C.; Kalia, V. C.; Zhang, Y.-H. P. J.; Zhao, H.; Kang, Y. C.; Lee, J.$\mathrm{K}$. Insights into Cell-Free Conversion of $\mathrm{CO} 2$ to Chemicals by a Multienzyme Cascade Reaction. Acs Catalysis 2018, 8 (12), 11085-11093.

42. Yang, H.-Y.; Bao, B.-L.; Liu, J.; Qin, Y.; Wang, Y.-R.; Su, K.-Z.; Han, J.-C.; Mu, Y., Temperature dependence of bioelectrochemical $\mathrm{CO} 2$ conversion and methane production with a mixed-culture biocathode. Bioelectrochemistry 2018, 119, 180-188.

43. Grills, D. C.; Farrington, J. A.; Layne, B. H.; Lymar, S. V.; Mello, B. A.; Preses, J. M.; Wishart, J. F., Mechanism of the Formation of a Mn-Based CO2 Reduction Catalyst Revealed by Pulse Radiolysis with Time-Resolved Infrared Detection. Journal of the American Chemical Society 2014, 136 (15), 5563-5566.

44. Grodkowski, J.; Neta, P., Copper-catalyzed radiolytic reduction of $\mathrm{CO} 2$ to $\mathrm{CO}$ in aqueous solutions. Journal of Physical Chemistry B 2001, 105 (21), 4967-4972. 
45. Lisovskaya, A.; Bartels, D. M., Reduction of $\mathrm{CO} 2$ by hydrated electrons in high temperature water. Radiation Physics and Chemistry 2019, 158, 61-63.

46. Currie, R.; Mottaghi-Tabar, S.; Zhuang, Y.; Simakov, D. S. A., Design of an Air-Cooled Sabatier Reactor for Thermocatalytic Hydrogenation of CO2: Experimental Proof-ofConcept and Model-Based Feasibility Analysis. Industrial \& Engineering Chemistry Research 2019, 58 (29), 12964-12980.

47. Bai, Y.; Zhao, J.; Feng, S.; Liang, X.; Wang, C., Light-driven thermocatalytic $\mathrm{CO} 2$ reduction over surface-passivated $-\mathrm{Mo} 2 \mathrm{C}$ nanowires: enhanced catalytic stability by light. Chemical Communications 2019, 55 (32), 4651-4654.

48. Tackett, B. M.; Gomez, E.; Chen, J. G., Net reduction of $\mathrm{CO} 2$ via its thermocatalytic and electrocatalytic transformation reactions in standard and hybrid processes. Nature Catalysis 2019, 2 (5), 381-386.

49. Takalkar, G.; Bhosale, R. R.; AlMomani, F.; Khraisheh, M., Thermocatalytic splitting of CO2 using sol-gel synthesized Co-ferrite redox materials. Fuel 2019, 257.

50. Ferrah, D.; Haines, A. R.; Galhenage, R. P.; Bruce, J. P.; Babore, A. D.; Hunt, A.; Waluyo, I.; Hemminger, J. C., Wet Chemical Growth and Thermocatalytic Activity of CuBased Nanoparticles Supported on TiO2 Nanoparticles/HOPG: In Situ Ambient Pressure XPS Study of the CO2 Hydrogenation Reaction. Acs Catalysis 2019, 9 (8), 6783-6802.

51. Cometto, C.; Kuriki, R.; Chen, L.; Maeda, K.; Lau, T.-C.; Ishitani, O.; Robert, M., A Carbon Nitride/Fe Quaterpyridine Catalytic System for Photostimulated CO2-to-CO Conversion with Visible Light. Journal of the American Chemical Society 2018, 140 (24), 7437-7440.

52. Kim, C.; Cho, K. M.; Al-Saggaf, A.; Gereige, I.; Jung, H.-T., Z-scheme Photocatalytic CO2 Conversion on Three-Dimensional BiVO4/Carbon-Coated Cu2O Nanowire Arrays under Visible Light. Acs Catalysis 2018, 8 (5), 4170-4177.

53. Meng, A.; Zhang, L.; Cheng, B.; Yu, J., TiO2-MnOx-Pt Hybrid Multiheterojunction Film Photocatalyst with Enhanced Photocatalytic CO2-Reduction Activity. Acs Applied Materials \& Interfaces 2019, 11 (6), 5581-5589.

54. Ran, J.; Jaroniec, M.; Qiao, S.-Z., Cocatalysts in Semiconductor-based Photocatalytic CO2 Reduction: Achievements, Challenges, and Opportunities. Advanced Materials 2018, 30 (7).

55. Wang, S.; Xu, M.; Peng, T.; Zhang, C.; Li, T.; Hussain, I.; Wang, J.; Tan, B., Porous hypercrosslinked polymer-TiO2-graphene composite photocatalysts for visible-lightdriven CO2 conversion. Nature Communications 2019, 10.

56. Xia, T.; Long, R.; Gao, C.; Xiong, Y., Design of atomically dispersed catalytic sites for photocatalytic CO2 reduction. Nanoscale 2019, 11 (23), 11064-11070.

57. Diercks, C. S.; Liu, Y.; Cordova, K. E.; Yaghi, O. M., The role of reticular chemistry in the design of CO2 reduction catalysts. Nature Materials 2018, 17 (4), 301-307.

58. Guntern, Y. T.; Pankhurst, J. R.; Vavra, J.; Mensi, M.; Mantella, V.; Schouwink, P.; Buonsanti, R., Nanocrystal/Metal-Organic Framework Hybrids as Electrocatalytic Platforms for $\mathrm{CO} 2$ Conversion. Angewandte Chemie-International Edition 2019, 58 (36), 12632-12639.

59. Huang, J.; Buonsanti, R., Colloidal Nanocrystals as Heterogeneous Catalysts for Electrochemical CO2 Conversions. Chemistry of Materials 2019, 31 (1), 13-25.

60. Ma, M.; Liu, K.; Shen, J.; Kas, R.; Smith, W. A., In Situ Fabrication and Reactivation of Highly Selective and Stable Ag Catalysts for Electrochemical CO2 Conversion. Acs Energy Letters 2018, 3 (6), 1301-1306. 
61. Nesbitt, N. T.; Ma, M.; Trzesniewski, B. J.; Jaszewski, S.; Tafti, F.; Burns, M. J.; Smith, W. A.; Naughton, M. J., Au Dendrite Electrocatalysts for CO2 Electrolysis. Journal of Physical Chemistry C 2018, 122 (18), 10006-10016.

62. Wang, J.; Ji, Y.; Shao, Q.; Yin, R.; Guo, J.; Li, Y.; Huang, X., Phase and structure modulating of bimetallic CUSn nanowires boosts electrocatalytic conversion of $\mathrm{CO} 2$. Nano Energy 2019, 59, 138-145.

63. Wang, Y.-R.; Huang, Q.; He, C.-T.; Chen, Y.; Liu, J.; Shen, F.-C.; Lan, Y.-Q., Oriented electron transmission in polyoxometalate-metalloporphyrin organic framework for highly selective electroreduction of CO2. Nature Communications 2018, 9.

64. Chen, J.; Yin, J.; Zheng, X.; Ahsaine, H. A.; Zhou, Y.; Dong, C.; Mohammed, O. F.; Takanabe, K.; Bakr, O. M., Compositionally Screened Eutectic Catalytic Coatings on Halide Perovskite Photocathodes for Photoassisted Selective CO2 Reduction. Acs Energy Letters 2019, 4 (6), 1279-1286.

65. Deng, X.; Li, R.; Wu, S.; Wang, L.; Hu, J.; Ma, J.; Jiang, W.; Zhang, N.; Zheng, X.; Gao, C.; Wang, L.; Zhang, Q.; Zhu, J.; Xiong, Y., Metal-Organic Framework Coating Enhances the Performance of Cu2O in Photoelectrochemical CO2 Reduction. Journal of the American Chemical Society 2019, 141 (27), 10924-10929.

66. Kang, H.-Y.; Nam, D.-H.; Yang, K. D.; Joo, W.; Kwak, H.; Kim, H.-H.; Hong, S.-H.; Nam, K. T.; Joo, Y.-C., Synthetic Mechanism Discovery of Monophase Cuprous Oxide for Record High Photoelectrochemical Conversion of $\mathrm{CO} 2$ to Methanol in Water. Acs Nano 2018, 12 (8), 8187-8196.

67. Leung, J. J.; Warnan, J.; Ly, K. H.; Heidary, N.; Dong Heon, N.; Kuehneh, M. F.; Reisner, E., Solar-driven reduction of aqueous $\mathrm{CO} 2$ with a cobalt bis(terpyridine)-based photocathode. Nature Catalysis 2019, 2 (4), 354-365.

68. Ajmal, S.; Yang, Y.; Li, K.; Tahir, M. A.; Liu, Y.; Wang, T.; Bacha, A.-U.-R.; Feng, Y.; Deng, Y.; Zhang, L., Zinc-Modified Copper Catalyst for Efficient (Photo-)Electrochemical $\mathrm{CO} 2$ Reduction with High Selectivity of $\mathrm{HCOOH}$ Production. Journal of Physical Chemistry C 2019, 123 (18), 11555-11563.

69. Chu, S.; Fan, S.; Wang, Y.; Rossouw, D.; Wang, Y.; Botton, G. A.; Mi, Z., Tunable Syngas Production from $\mathrm{CO} 2$ and $\mathrm{H} 2 \mathrm{O}$ in an Aqueous Photoelectrochemical Cell. Angewandte Chemie-International Edition 2016, 55 (46), 14260-14264.

70. DuChene, J. S.; Tagliabue, G.; Welch, A. J.; Cheng, W.-H.; Atwater, H. A., Hot Hole Collection and Photoelectrochemical CO2 Reduction with Plasmonic Au/p-GaN Photocathodes. Nano Letters 2018, 18 (4), 2545-2550.

71. Kang, M. J.; Kim, C. W.; Pawar, A. U.; Cha, H. G.; Ji, S.; Cai, W.-B.; Kang, Y. S., Selective Alcohol on Dark Cathodes by Photoelectrochemical CO2 Valorization and Their In Situ Characterization. Acs Energy Letters 2019, 4 (7), 1549-1555.

72. Kang, U.; Yoon, S. H.; Hang, D. S.; Park, H., Synthesis of Aliphatic Acids from CO2 and Water at Efficiencies Close to the Photosynthesis Limit Using Mixed Copper and Iron Oxide Films. Acs Energy Letters 2019, 4 (9), 2075-2080.

73. Kuk, S. K.; Singh, R. K.; Nam, D. H.; Singh, R.; Lee, J.-K.; Park, C. B., Photoelectrochemical Reduction of Carbon Dioxide to Methanol through a Highly Efficient Enzyme Cascade. Angewandte Chemie-International Edition 2017, 56 (14), 3827-3832.

74. Sahara, G.; Kumagai, H.; Maeda, K.; Kaeffer, N.; Artero, V.; Higashi, M.; Abe, R.; Ishitani, O., Photoelectrochemical Reduction of $\mathrm{CO} 2$ Coupled to Water Oxidation Using a Photocathode with a Ru(II)-Re(I) Complex Photocatalyst and a CoOx/TaON Photoanode. Journal of the American Chemical Society 2016, 138 (42), 14152-14158. 
75. Song, J. T.; Ryoo, H.; Cho, M.; Kim, J.; Kim, J.-G.; Chung, S.-Y.; Oh, J., Nanoporous Au Thin Films on Si Photoelectrodes for Selective and Efficient Photoelectrochemical CO2 Reduction. Advanced Energy Materials 2017, 7 (3).

76. Wang, P.; Wang, S.; Wang, H.; Wu, Z.; Wang, L., Recent Progress on PhotoElectrocatalytic Reduction of Carbon Dioxide. Particle \& Particle Systems Characterization 2018, 35 (1).

77. Jang, Y. J.; Jeong, I.; Lee, J.; Lee, J.; Ko, M. J.; Lee, J. S., Unbiased Sunlight-Driven Artificial Photosynthesis of Carbon Monoxide from CO2 Using a ZnTe-Based Photocathode and a Perovskite Solar Cell in Tandem. Acs Nano 2016, 10 (7), 6980-6987.

78. Ji, Y.; Luo, Y., Direct Donation of Protons from $\mathrm{H} 2 \mathrm{O}$ to $\mathrm{CO} 2$ in Artificial Photosynthesis on the Anatase TiO2(101) Surface. Journal of Physical Chemistry C 2019, 123 (5), 30193023.

79. Kim, D.; Sakimoto, K. K.; Hong, D.; Yang, P., Artificial Photosynthesis for Sustainable Fuel and Chemical Production. Angewandte Chemie-International Edition 2015, 54 (11), 3259-3266.

80. Liu, C.; Colon, B. C.; Ziesack, M.; Silver, P. A.; Nocera, D. G., Water splitting-biosynthetic system with $\mathrm{CO} 2$ reduction efficiencies exceeding photosynthesis. Science 2016, 352 (6290), 1210-1213.

81. Yadav, R. K.; Baeg, J.-O.; Oh, G. H.; Park, N.-J.; Kong, K.-j.; Kim, J.; Hwang, D. W.; Biswas, S. K., A Photocatalyst-Enzyme Coupled Artificial Photosynthesis System for Solar Energy in Production of Formic Acid from CO2. Journal of the American Chemical Society 2012, 134 (28), 11455-11461.

82. Yang, C.-C.; Yu, Y.-H.; van der Linden, B.; Wu, J. C. S.; Mul, G., Artificial Photosynthesis over Crystalline TiO2-Based Catalysts: Fact or Fiction? Journal of the American Chemical Society 2010, 132 (24), 8398-8406.

83. Sun, Z.; Ma, T.; Tao, H.; Fan, Q.; Han, B., Fundamentals and Challenges of Electrochemical CO2 Reduction Using Two-Dimensional Materials. Chem 2017, 3 (4), 560-587.

84. Zhang, N.; Long, R.; Gao, C.; Xiong, Y., Recent progress on advanced design for photoelectrochemical reduction of $\mathrm{CO} 2$ to fuels. Science China-Materials 2018, 61 (6), 771-805.

85. Liu, X.; Xiao, J.; Peng, H.; Hong, X.; Chan, K.; Norskov, J. K., Understanding trends in electrochemical carbon dioxide reduction rates. Nature Communications 2017, 8.

86. Cave, E. R.; Montoya, J. H.; Kuhl, K. P.; Abram, D. N.; Hatsukade, T.; Shi, C.; Hahn, C.; Norskov, J. K.; Jaramillo, T. F., Electrochemical CO2 reduction on Au surfaces: mechanistic aspects regarding the formation of major and minor products. Physical Chemistry Chemical Physics 2017, 19 (24), 15856-15863.

87. Rosen, B. A.; Salehi-Khojin, A.; Thorson, M. R.; Zhu, W.; Whipple, D. T.; Kenis, P. J. A.; Masel, R. I., Ionic Liquid-Mediated Selective Conversion of CO2 to $\mathrm{CO}$ at Low Overpotentials. Science 2011, 334 (6056), 643-644.

88. Mahyoub, S. A.; Qaraah, F. A.; Chen, C. Z.; Zhang, F. H.; Yan, S. L.; Cheng, Z. M., An overview on the recent developments of Ag-based electrodes in the electrochemical reduction of CO2 to CO. Sustainable Energy \& Fuels 2020, 4 (1), 50-67.

89. Han, N.; Ding, P.; He, L.; Li, Y.; Li, Y., Promises of Main Group Metal-Based Nanostructured Materials for Electrochemical CO2 Reduction to Formate. Advanced Energy Materials 2020, 10 (11), 1902338. 
90. Zhao, J.; Xue, S.; Barber, J.; Zhou, Y.; Meng, J.; Ke, X., An overview of Cu-based heterogeneous electrocatalysts for $\mathrm{CO} 2$ reduction. J. Mater. Chem. A 2020, 8 (9), 47004734.

91. Kuhl, K. P.; Cave, E. R.; Abram, D. N.; Jaramillo, T. F., New insights into the electrochemical reduction of carbon dioxide on metallic copper surfaces. Energy Environ. Sci. 2012, 5 (5), 7050-7059.

92. Calvinho, K. U. D.; Laursen, A. B.; Yap, K. M. K.; Goetjen, T. A.; Hwang, S.; Murali, N.; Mejia-Sosa, B.; Lubarski, A.; Teeluck, K. M.; Hall, E. S.; Garfunkel, E.; Greenblatt, M.; Dismukes, G. C., Selective CO2 reduction to C-3 and C-4 oxyhydrocarbons on nickel phosphides at overpotentials as low as $10 \mathrm{mV}$. Energy \& Environmental Science 2018, 11 (9), 2550-2559.

93. Francis, S. A.; Velazquez, J. M.; Ferrer, I. M.; Torelli, D. A.; Guevarra, D.; McDowell, M. T.; Sun, K.; Zhou, X.; Saadi, F. H.; John, J.; Richter, M. H.; Hyler, F. P.; Papadantonakis, K. M.; Brunschwig, B. S.; Lewis, N. S., Reduction of Aqueous CO2 to 1-Propanol at MoS2 Electrodes. Chemistry of Materials 2018, 30 (15), 4902-4908.

94. Wang, L.; Nitopi, S. A.; Bertheussen, E.; Orazov, M.; Morales-Guio, C. G.; Liu, X.; Higgins, D. C.; Chan, K.; Norskov, J. K.; Hahn, C.; Jaramillo, T. F., Electrochemical Carbon Monoxide Reduction on Polycrystalline Copper: Effects of Potential, Pressure, and pH on Selectivity toward Multicarbon and Oxygenated Products. Acs Catalysis 2018, 8 (8), 7445-7454.

95. Li, C. W.; Ciston, J.; Kanan, M. W., Electroreduction of carbon monoxide to liquid fuel on oxide-derived nanocrystalline copper. Nature 2014, 508, 504.

96. Feng, X. F.; Jiang, K. L.; Fan, S. S.; Kanan, M. W., A Direct Grain-Boundary-Activity Correlation for CO Electroreduction on Cu Nanoparticles. Acs Central Science 2016, 2 (3), 169-174.

97. Li, J.; Che, F.; Pang, Y.; Zou, C.; Howe, J. Y.; Burdyny, T.; Edwards, J. P.; Wang, Y.; Li, F.; Wang, Z.; De Luna, P.; Dinh, C.-T.; Zhuang, T.-T.; Saidaminov, M. I.; Cheng, S.; Wu, T.; Finfrock, Y. Z.; Ma, L.; Hsieh, S.-H.; Liu, Y.-S.; Botton, G. A.; Pong, W.-F.; Du, X.; Guo, J.; Sham, T.-K.; Sargent, E. H.; Sinton, D., Copper adparticle enabled selective electrosynthesis of n-propanol. Nature Communications 2018, 9 (1), 4614.

98. Zhuang, T.-T.; Pang, Y.; Liang, Z.-Q.; Wang, Z.; Li, Y.; Tan, C.-S.; Li, J.; Dinh, C. T.; De Luna, P.; Hsieh, P.-L.; Burdyny, T.; Li, H.-H.; Liu, M.; Wang, Y.; Li, F.; Proppe, A.; Johnston, A.; Nam, D.-H.; Wu, Z.-Y.; Zheng, Y.-R.; Ip, A. H.; Tan, H.; Chen, L.-J.; Yu, S.H.; Kelley, S. O.; Sinton, D.; Sargent, E. H., Copper nanocavities confine intermediates for efficient electrosynthesis of C3 alcohol fuels from carbon monoxide. Nature Catalysis 2018, 1 (12), 946-951.

99. Pang, Y. J.; Li, J.; Wang, Z. Y.; Tang, C. S.; Hsieh, P. L.; Zhuang, T. T.; Liang, Z. Q.; Zou, C. Q.; Wang, X.; De Luna, P.; Edwards, J. P.; Xu, Y.; Li, F. W.; Dinh, C. T.; Zhong, M.; Lou, Y. H.; Wu, D.; Chen, L. J.; Sargent, E. H.; Sinton, D., Efficient electrocatalytic conversion of carbon monoxide to propanol using fragmented copper. Nature Catalysis 2019, 2 (3), 251-258.

100. Wang, L.; Nitopi, S.; Wong, A. B.; Snider, J. L.; Nielander, A. C.; Morales-Guio, C. G.; Orazov, M.; Higgins, D. C.; Hahn, C.; Jaramillo, T. F., Electrochemically converting carbon monoxide to liquid fuels by directing selectivity with electrode surface area. Nature Catalysis 2019, 2 (8), 702-708.

101. Wang, L.; Higgins, D. C.; Ji, Y.; Morales-Guio, C. G.; Chan, K.; Hahn, C.; Jaramillo, T. F., Selective reduction of $\mathrm{CO}$ to acetaldehyde with $\mathrm{CuAg}$ electrocatalysts. Proceedings of the National Academy of Sciences 2020, 201821683. 
102. Niu, S.; Li, S.; Du, Y.; Han, X.; Xu, P., How to Reliably Report the Overpotential of an Electrocatalyst. ACS Energy Letters 2020, 1083-1087.

103. Grim, R. G.; Huang, Z.; Guarnieri, M. T.; Ferrell, J. R., III; Tao, L.; Schaidle, J. A., Transforming the carbon economy: challenges and opportunities in the convergence of low-cost electricity and reductive CO2 utilization. Energy \& Environmental Science 2020, 13 (2), 472-494.

104. García de Arquer, F. P.; Dinh, C.-T.; Ozden, A.; Wicks, J.; McCallum, C.; Kirmani, A. R.; Nam, D.-H.; Gabardo, C.; Seifitokaldani, A.; Wang, X.; Li, Y. C.; Li, F.; Edwards, J.; Richter, L. J.; Thorpe, S. J.; Sinton, D.; Sargent, E. H., CO2 electrolysis to multicarbon products at activities greater than $1 \mathrm{~A} \mathrm{~cm}-2$. Science 2020, 367 (6478), 661-666.

105. Straistari, T.; Fize, J.; Shova, S.; Reglier, M.; Artero, V.; Orio, M., A ThiosemicarbazoneNickel(II) Complex as Efficient Electrocatalyst for Hydrogen Evolution. Chemcatchem 2017, 9 (12), 2262-2268.

106. Dubois, M. R.; Dubois, D. L., Development of Molecular Electrocatalysts for $\mathrm{CO} 2$ Reduction and H-2 Production/Oxidation. Accounts of Chemical Research 2009, 42 (12), 1974-1982.

107. Ford, P. C., THE WATER GAS SHIFT REACTION - HOMOGENEOUS CATALYSIS BY RUTHENIUM AND OTHER METAL-CARBONYLS. Accounts of Chemical Research 1981, 14 (2), 31-37.

108. Fukuzumi, S.; Yamada, Y.; Suenobu, T.; Ohkubo, K.; Kotani, H., Catalytic mechanisms of hydrogen evolution with homogeneous and heterogeneous catalysts. Energy \& Environmental Science 2011, 4 (8), 2754-2766.

109. Lazarides, T.; McCormick, T.; Du, P.; Luo, G.; Lindley, B.; Eisenberg, R., Making Hydrogen from Water Using a Homogeneous System Without Noble Metals. Journal of the American Chemical Society 2009, 131 (26), 9192-+.

110. Wiese, S.; Kilgore, U. J.; DuBois, D. L.; Bullock, R. M., Ni((P2N2Ph)-N-Me)(2) (BF4)(2) as an Electrocatalyst for H-2 Production. Acs Catalysis 2012, 2 (5), 720-727.

111. Blakemore, J. D.; Gupta, A.; Warren, J. J.; Brunschwig, B. S.; Gray, H. B., Noncovalent Immobilization of Electrocatalysts on Carbon Electrodes for Fuel Production. Journal of the American Chemical Society 2013, 135 (49), 18288-18291.

112. Brown, A. P.; Anson, F. C., MOLECULAR ANCHORS FOR ATTACHMENT OF METALCOMPLEXES TO GRAPHITE ELECTRODE SURFACES. Journal of Electroanalytical Chemistry 1977, 83 (1), 203-206.

113. Bullock, R. M.; Das, A. K.; Appel, A. M., Surface Immobilization of Molecular Electrocatalysts for Energy Conversion. Chemistry-a European Journal 2017, 23 (32), 7626-7641.

114. Mann, J. A.; Rodriguez-Lopez, J.; Abruna, H. D.; Dichtel, W. R., Multivalent Binding Motifs for the Noncovalent Functionalization of Graphene. Journal of the American Chemical Society 2011, 133 (44), 17614-17617.

115. Berben, L. A.; Peters, J. C., Hydrogen evolution by cobalt tetraimine catalysts adsorbed on electrode surfaces. Chemical Communications 2010, 46 (3), 398-400.

116. Le Goff, A.; Artero, V.; Jousselme, B.; Tran, P. D.; Guillet, N.; Metaye, R.; Fihri, A.; Palacin, S.; Fontecave, M., From Hydrogenases to Noble Metal-Free Catalytic Nanomaterials for H-2 Production and Uptake. Science 2009, 326 (5958), 1384-1387.

117. Lei, H.; Han, A.; Li, F.; Zhang, M.; Han, Y.; Du, P.; Lai, W.; Cao, R., Electrochemical, spectroscopic and theoretical studies of a simple bifunctional cobalt corrole catalyst for oxygen evolution and hydrogen production. Physical Chemistry Chemical Physics 2014, 16 (5), 1883-1893. 
118. Mondal, B.; Sengupta, K.; Rana, A.; Mahammed, A.; Botoshansky, M.; Dey, S. G.; Gross, Z.; Dey, A., Cobalt Corrole Catalyst for Efficient Hydrogen Evolution Reaction from H2O under Ambient Conditions: Reactivity, Spectroscopy, and Density Functional Theory Calculations. Inorganic Chemistry 2013, 52 (6), 3381-3387.

119. Oughli, A. A.; Ruff, A.; Boralugodage, N. P.; Rodriguez-Macia, P.; Plumere, N.; Lubitz, W.; Shaw, W. J.; Schuhmann, W.; Ruediger, O., Dual properties of a hydrogen oxidation $\mathrm{Ni}$-catalyst entrapped within a polymer promote self-defense against oxygen. Nature Communications 2018, 9.

120. Pantani, O.; Anxolabehere-Mallart, E.; Aukauloo, A.; Millet, P., Electroactivity of cobalt and nickel glyoximes with regard to the electro-reduction of protons into molecular hydrogen in acidic media. Electrochemistry Communications 2007, 9 (1), 54-58.

121. Rodriguez-Macia, P.; Priyadarshani, N.; Dutta, A.; Weidenthaler, C.; Lubitz, W.; Shaw, W. J.; Ruediger, O., Covalent Attachment of the Water-insoluble Ni((P2N2Phe)-N-Cy)(2) Electrocatalyst to Electrodes Showing Reversible Catalysis in Aqueous Solution. Electroanalysis 2016, 28 (10), 2452-2458.

122. Tran, P. D.; Le Goff, A.; Heidkamp, J.; Jousselme, B.; Guillet, N.; Palacin, S.; Dau, H.; Fontecave, M.; Artero, V., Noncovalent Modification of Carbon Nanotubes with PyreneFunctionalized Nickel Complexes: Carbon Monoxide Tolerant Catalysts for Hydrogen Evolution and Uptake. Angewandte Chemie-International Edition 2011, 50 (6), 13711374.

123. Zhang, W.; Haddad, A. Z.; Garabato, B. D.; Kozowski, P. M.; Buchanan, R. M.; Grapperhaus, C. A., Translation of Ligand-Centered Hydrogen Evolution Reaction Activity and Mechanism of a Rhenium-Thiolate from Solution to Modified Electrodes: A Combined Experimental and Density Functional Theory Study. Inorganic Chemistry 2017, 56 (4), 2177-2187.

124. Abe, T.; Taguchi, F.; Imaya, H.; Zhao, F.; Zhang, J.; Kaneko, M., Highly active electrocatalysis by cobalt tetraphenylporphyrin incorporated in a nafion membrane for proton reduction. Polymers for Advanced Technologies 1998, 9 (9), 559-562.

125. Koca, A., Copper phthalocyanine complex as electrocatalyst for hydrogen evolution reaction. Electrochemistry Communications 2009, 11 (4), 838-841.

126. Koca, A., Hydrogen evolution reaction on glassy carbon electrode modified with titanyl phthalocyanines. International Journal of Hydrogen Energy 2009, 34 (5), 2107-2112.

127. Koca, A.; Kalkan, A.; Bayir, Z. A., Electrochemical, In Situ Spectroelectrochemical, In Situ Electrocolorimetric and Electrocatalytic Characterization of Metallophthalocyanines Bearing Four Dioctylaminocarbonyl Biphenyloxy Substituents. Electroanalysis 2010, 22 (3), 310-319.

128. Koca, A.; Kalkan, A.; Bayir, Z. A., Electrocatalytic oxygen reduction and hydrogen evolution reactions on phthalocyanine modified electrodes: Electrochemical, in situ spectroelectrochemical, and in situ electrocolorimetric monitoring. Electrochimica Acta 2011, 56 (16), 5513-5525.

129. Grass, V.; Lexa, D.; Saveant, J. M., Electrochemical generation of rhodium porphyrin hydrides. Catalysis of hydrogen evolution. Journal of the American Chemical Society 1997, 119 (32), 7526-7532.

130. Haddad, A. Z.; Cronin, S. P.; Mashuta, M. S.; Buchanan, R. M.; Grapperhaus, C. A., Metal-Assisted Ligand-Centered Electrocatalytic Hydrogen Evolution upon Reduction of a Bis(thiosemicarbazonato)Cu(II) Complex. Inorganic Chemistry 2017, 56 (18), 1125411265. 
131. Haddad, A. Z.; Garabato, B. D.; Kozlowski, P. M.; Buchanan, R. M.; Grapperhaus, C. A., Beyond Metal-Hydrides: Non-Transition-Metal and Metal-Free Ligand-Centered Electrocatalytic Hydrogen Evolution and Hydrogen Oxidation. Journal of the American Chemical Society 2016, 138 (25), 7844-7847.

132. Jain, R.; Al Mamun, A.; Buchanan, R. M.; Kozlowski, P. M.; Grapperhaus, C. A., LigandAssisted Metal-Centered Electrocatalytic Hydrogen Evolution upon Reduction of a Bis(thiosemicarbazonato)Ni(II) Complex. Inorganic Chemistry 2018, 57 (21), 1348613493.

133. Jing, X.; Wu, P.; Liu, X.; Yang, L.; He, C.; Duan, C., Light-driven hydrogen evolution with a nickel thiosemicarbazone redox catalyst featuring $\mathrm{Ni}$ center dot center dot center dot $\mathrm{H}$ interactions under basic conditions. New Journal of Chemistry 2015, 39 (2), 10511059.

134. Straistari, T.; Hardre, R.; Fize, J.; Shova, S.; Giorgi, M.; Reglier, M.; Artero, V.; Orio, M., Hydrogen Evolution Reactions Catalyzed by a Bis(thiosemicarbazone) Cobalt Complex: An Experimental and Theoretical Study. Chemistry-a European Journal 2018, 24 (35), 8779-+.

135. Betts, H. M.; Barnard, P. J.; Bayly, S. R.; Dilworth, J. R.; Gee, A. D.; Holland, J. P., Controlled Axial Coordination: Solid-Phase Synthesis and Purification of MetalloRadiopharmaceuticals. Angewandte Chemie-International Edition 2008, 47 (44), 84168419.

136. Cornish, A. J.; Gaertner, K.; Yang, H.; Peters, J. W.; Hegg, E. L., Mechanism of Proton Transfer in FeFe -Hydrogenase from Clostridium pasteurianum. Journal of Biological Chemistry 2011, 286 (44), 38341-38347.

137. Goldman, C. M.; Mascharak, P. K., Reactions of H-2 with the nickel site(s) of the FeNi and FeNiSe hydrogenases: What do the model complexes suggest? Comments on Inorganic Chemistry 1995, 18 (1), 1-25.

138. Teixeira, V. H.; Baptista, A. M.; Soares, C. M., Pathways of $\mathrm{H}-2$ toward the active site of NiFe -hydrogenase. Biophysical Journal 2006, 91 (6), 2035-2045.

139. Ulloa, O. A.; Huynh, M. T.; Richers, C. P.; Bertke, J. A.; Nilges, M. J.; Hammes-Schiffer, S.; Rauchfuss, T. B., Mechanism of H-2 Production by Models for the NiFe Hydrogenases: Role of Reduced Hydrides. Journal of the American Chemical Society 2016, 138 (29), 9234-9245.

140. Wombwell, C.; Caputo, C. A.; Reisner, E., NiFeSe -Hydrogenase Chemistry. Accounts of Chemical Research 2015, 48 (11), 2858-2865.

141. Rauchfuss, T. B., Diiron Azadithiolates as Models for the FeFe -Hydrogenase Active Site and Paradigm for the Role of the Second Coordination Sphere. Accounts of Chemical Research 2015, 48 (7), 2107-2116.

142. Simmons, T. R.; Berggren, G.; Bacchi, M.; Fontecave, M.; Artero, V., Mimicking hydrogenases: From biomimetics to artificial enzymes. Coordination Chemistry Reviews 2014, 270, 127-150.

143. Weber, K.; Kraemer, T.; Shafaat, H. S.; Weyhermueller, T.; Bill, E.; van Gastel, M.; Neese, F.; Lubitz, W., A Functional NiFe -Hydrogenase Model Compound That Undergoes Biologically Relevant Reversible Thiolate Protonation. Journal of the American Chemical Society 2012, 134 (51), 20745-20755.

144. Wodrich, M. D.; Hu, X., Natural inspirations for metal-ligand cooperative catalysis. Nature Reviews Chemistry 2018, 2 (1). 
145. DuBois, D. L.; Bullock, R. M., Molecular Electrocatalysts for the Oxidation of Hydrogen and the Production of Hydrogen - The Role of Pendant Amines as Proton Relays.

European Journal of Inorganic Chemistry 2011, (7), 1017-1027.

146. Henry, R. M.; Shoemaker, R. K.; DuBois, D. L.; DuBois, M. R., Pendant bases as proton relays in iron hydride and dihydrogen complexes. Journal of the American Chemical Society 2006, 128 (9), 3002-3010.

147. Bediako, D. K.; Solis, B. H.; Dogutan, D. K.; Roubelakis, M. M.; Maher, A. G.; Lee, C. H.; Chambers, M. B.; Hammes-Schiffer, S.; Nocera, D. G., Role of pendant proton relays and proton-coupled electron transfer on the hydrogen evolution reaction by nickel hangman porphyrins. Proceedings of the National Academy of Sciences of the United States of America 2014, 111 (42), 15001-15006.

148. Reath, A. H.; Ziller, J. W.; Tsay, C.; Ryan, A. J.; Yang, J. Y., Redox Potential and Electronic Structure Effects of Proximal Nonredox Active Cations in Cobalt Schiff Base Complexes. Inorganic Chemistry 2017, 56 (6), 3713-3718.

149. Hartley, C. L.; DiRisio, R. J.; Screen, M. E.; Mayer, K. J.; McNamara, W. R., Iron Polypyridyl Complexes for Photocatalytic Hydrogen Generation. Inorganic Chemistry 2016, 55 (17), 8865-8870.

150. McNamara, W. R.; Han, Z.; Yin, C.-J.; Brennessel, W. W.; Holland, P. L.; Eisenberg, R., Cobalt-dithiolene complexes for the photocatalytic and electrocatalytic reduction of protons in aqueous solutions. Proceedings of the National Academy of Sciences of the United States of America 2012, 109 (39), 15594-15599.

151. Queyriaux, N.; Kaeffer, N.; Morozan, A.; Chavarot-Kerlidou, M.; Artero, V., Molecular cathode and photocathode materials for hydrogen evolution in photoelectrochemical devices. Journal of Photochemistry and Photobiology C-Photochemistry Reviews 2015, 25, 90-105.

152. Krawicz, A.; Yang, J.; Anzenberg, E.; Yano, J.; Sharp, I. D.; Moore, G. F., Photofunctional Construct That Interfaces Molecular Cobalt-Based Catalysts for H-2 Production to a Visible-Light-Absorbing Semiconductor. Journal of the American Chemical Society 2013, 135 (32), 11861-11868.

153. Seo, J.; Pekarek, R. T.; Rose, M. J., Photoelectrochemical operation of a surface-bound, nickel-phosphine $\mathrm{H}-2$ evolution catalyst on $\mathrm{p}-\mathrm{Si}(111)$ : a molecular semiconductor \catalyst construct. Chemical Communications 2015, 51 (68), 1326413267.

154. Jiang, W.-X.; Xie, Z.-L.; Zhan, S.-Z., A photocatalytic system with a bis(thiosemicarbazonato)-nickel over CdS nanorods for hydrogen evolution from water under visible light. Inorganic Chemistry Communications 2019, 102, 5-9.

155. Lewis, N. S.; Nocera, D. G., Powering the planet: Chemical challenges in solar energy utilization. Proceedings of the National Academy of Sciences of the United States of America 2006, 103 (43), 15729-15735.

156. Ager, J. W.; Shaner, M. R.; Walczak, K. A.; Sharp, I. D.; Ardo, S., Experimental demonstrations of spontaneous, solar-driven photoelectrochemical water splitting. Energy \& Environmental Science 2015, 8 (10), 2811-2824.

157. Hu, S.; Xiang, C.; Haussener, S.; Berger, A. D.; Lewis, N. S., An analysis of the optimal band gaps of light absorbers in integrated tandem photoelectrochemical water-splitting systems. Energy \& Environmental Science 2013, 6 (10), 2984-2993.

158. Khaselev, O.; Turner, J. A., A monolithic photovoltaic-photoelectrochemical device for hydrogen production via water splitting. Science 1998, 280 (5362), 425-427. 
159. Verlage, E.; Hu, S.; Liu, R.; Jones, R. J. R.; Sun, K.; Xiang, C.; Lewis, N. S.; Atwater, H. A., A monolithically integrated, intrinsically safe, $10 \%$ efficient, solar-driven watersplitting system based on active, stable earth-abundant electrocatalysts in conjunction with tandem III-V light absorbers protected by amorphous TiO2 films. Energy \& Environmental Science 2015, 8 (11), 3166-3172.

160. Alqahtani, M.; Ben-Jabar, S.; Ebaid, M.; Sathasivam, S.; Jurczak, P.; Xia, X.; Alromaeh, A.; Blackman, C.; Qin, Y.; Zhang, B.; Ooi, B. S.; Liu, H.; Parkin, P.; Wu, J., Gallium Phosphide photoanode coated with $\mathrm{TiO} 2$ and $\mathrm{CoOx}$ for stable photoelectrochemical water oxidation. Optics Express 2019, 27 (8), A364-A371.

161. Hu, S.; Shaner, M. R.; Beardslee, J. A.; Lichterman, M.; Brunschwig, B. S.; Lewis, N. S., Amorphous TiO2 coatings stabilize $\mathrm{Si}, \mathrm{GaAs}$, and $\mathrm{GaP}$ photoanodes for efficient water oxidation. Science 2014, 344 (6187), 1005-1009.

162. Kargar, A.; Sukrittanon, S.; Zhou, C.; Ro, Y. G.; Pan, X.; Dayeh, S. A.; Tu, C. W.; Jin, S., GaP/GaNP Heterojunctions for Efficient Solar-Driven Water Oxidation. Small 2017, 13 (21).

163. Price, M. J.; Maldonado, S., Macroporous n-GaP in Nonaqueous Regenerative Photoelectrochemical Cells. Journal of Physical Chemistry C 2009, 113 (28), 1198811994.

164. Zhu, C.; Zheng, M.; Xiong, Z.; Li, H.; Shen, W., Electrochemically etched triangular pore arrays on $\mathrm{GaP}$ and their photoelectrochemical properties from water oxidation. International Journal of Hydrogen Energy 2014, 39 (21), 10861-10869.

165. Martinez-Garcia, A.; Russell, H. B.; Paxton, W.; Ravipati, S.; Calero-Barney, S.; Menon, M.; Richter, E.; Young, J.; Deutsch, T.; Sunkara, M. K., Unassisted Water Splitting Using a GaSbxP(1-x) Photoanode. Advanced Energy Materials 2018, 8 (16).

166. Russell, H. B.; Andriotis, A. N.; Menon, M.; Jasinski, J. B.; Martinez-Garcia, A.; Sunkara, M. K., Direct Band Gap Gallium Antimony Phosphide (GaSbxP1-x) Alloys. Scientific Reports 2016, 6.

167. Pourbaix, M., Atlas of Electrochemical Equilibria in Aqueous Solution. Pergamon Press, Oxford: 1966.

168. Chen, S.; Wang, L.-W., Thermodynamic Oxidation and Reduction Potentials of Photocatalytic Semiconductors in Aqueous Solution. Chemistry of Materials 2012, 24 (18), 3659-3666.

169. Britto, R. J.; Benck, J. D.; Young, J. L.; Hahn, C.; Deutsch, T. G.; Jaramillo, T. F., Molybdenum Disulfide as a Protection Layer and Catalyst for Gallium Indium Phosphide Solar Water Splitting Photocathodes. Journal of Physical Chemistry Letters 2016, 7 (11), 2044-2049.

170. Chen, Y. W.; Prange, J. D.; Duehnen, S.; Park, Y.; Gunji, M.; Chidsey, C. E. D.; Mclntyre, P. C., Atomic layer-deposited tunnel oxide stabilizes silicon photoanodes for water oxidation. Nature Materials 2011, 10 (7), 539-544.

171. Hendricks, O. L.; Tang-Kong, R.; Babadi, A. S.; Mclntyre, P. C.; Chidsey, C. E. D., Atomic Layer Deposited TiO2-IrOx Alloys Enable Corrosion Resistant Water Oxidation on Silicon at High Photovoltage. Chemistry of Materials 2019, 31 (1), 90-100.

172. Hu, S.; Lewis, N. S.; Ager, J. W.; Yang, J.; McKone, J. R.; Strandwitz, N. C., Thin-Film Materials for the Protection of Semiconducting Photoelectrodes in Solar-Fuel Generators. Journal of Physical Chemistry C 2015, 119 (43), 24201-24228.

173. Lichterman, M. F.; Shaner, M. R.; Handler, S. G.; Brunschwig, B. S.; Gray, H. B.; Lewis, N. S.; Spurgeon, J. M., Enhanced Stability and Activity for Water Oxidation in Alkaline Media with Bismuth Vanadate Photoelectrodes Modified with a Cobalt Oxide Catalytic 
Layer Produced by Atomic Layer Deposition. Journal of Physical Chemistry Letters 2013, 4 (23), 4188-4191.

174. Liu, R.; Zheng, Z.; Spurgeon, J.; Yang, X., Enhanced photoelectrochemical water-splitting performance of semiconductors by surface passivation layers. Energy \& Environmental Science 2014, 7 (8), 2504-2517.

175. Erne, B. H.; Vanmaekelbergh, D.; Kelly, J. J., Morphology and strongly enhanced photoresponse of GaP electrodes made porous by anodic etching. Journal of the Electrochemical Society 1996, 143 (1), 305-314.

176. Tjerkstra, R. W.; Rivas, J. G.; Vanmaekelbergh, D.; Kelly, J. J., Porous GaP multilayers formed by electrochemical etching. Electrochemical and Solid State Letters 2002, 5 (5), G32-G35.

177. Memming, R. S., G., Electrochemical Properties of Gallium Phosphide in Aqueopus Solutions. Electrochimica Acta 1968, 13 (6), 1299.

178. Kumar, B.; Llorente, M.; Froehlich, J.; Dang, T.; Sathrum, A.; Kubiak, C. P., Photochemical and Photoelectrochemical Reduction of CO2. In Annual Review of Physical Chemistry, Vol 63, Johnson, M. A.; Martinez, T. J., Eds. 2012; Vol. 63, pp 541-+.

179. Qiao, J.; Liu, Y.; Hong, F.; Zhang, J., A review of catalysts for the electroreduction of carbon dioxide to produce low-carbon fuels. Chemical Society Reviews 2014, 43 (2), 631675.

180. Roy, S. C.; Varghese, O. K.; Paulose, M.; Grimes, C. A., Toward Solar Fuels: Photocatalytic Conversion of Carbon Dioxide to Hydrocarbons. Acs Nano 2010, 4 (3), 1259-1278.

181. Hori, Y.; Kikuchi, K.; Suzuki, S., PRODUCTION OF CO AND CH4 IN ELECTROCHEMICAL REDUCTION OF CO2 AT METAL-ELECTRODES IN AQUEOUS HYDROGENCARBONATE SOLUTION. Chemistry Letters 1985, (11), 1695-1698.

182. Noda, H.; Ikeda, S.; Oda, Y.; Imai, K.; Maeda, M.; Ito, K., ELECTROCHEMICAL REDUCTION OF CARBON-DIOXIDE AT VARIOUS METAL-ELECTRODES IN AQUEOUS POTASSIUM HYDROGEN CARBONATE SOLUTION. Bulletin of the Chemical Society of Japan 1990, 63 (9), 2459-2462.

183. Gattrell, M.; Gupta, N.; Co, A., A review of the aqueous electrochemical reduction of CO2 to hydrocarbons at copper. Journal of Electroanalytical Chemistry 2006, 594 (1), 119.

184. Hori, Y.; Kikuchi, K.; Murata, A.; Suzuki, S., PRODUCTION OF METHANE AND ETHYLENE IN ELECTROCHEMICAL REDUCTION OF CARBON-DIOXIDE AT COPPER ELECTRODE IN AQUEOUS HYDROGENCARBONATE SOLUTION. Chemistry Letters 1986, (6), 897-898.

185. Hori, Y.; Murata, A.; Takahashi, R., FORMATION OF HYDROCARBONS IN THE ELECTROCHEMICAL REDUCTION OF CARBON-DIOXIDE AT A COPPER ELECTRODE IN AQUEOUS-SOLUTION. Journal of the Chemical Society-Faraday Transactions / 1989, 85, 2309-2326.

186. Peterson, A. A.; Abild-Pedersen, F.; Studt, F.; Rossmeisl, J.; Norskov, J. K., How copper catalyzes the electroreduction of carbon dioxide into hydrocarbon fuels. Energy \& Environmental Science 2010, 3 (9), 1311-1315.

187. Asadi, M.; Kumar, B.; Behranginia, A.; Rosen, B. A.; Baskin, A.; Repnin, N.; Pisasale, D.; Phillips, P.; Zhu, W.; Haasch, R.; Klie, R. F.; Kral, P.; Abiade, J.; Salehi-Khojin, A., Robust carbon dioxide reduction on molybdenum disulphide edges. Nature Communications 2014, 5 . 
188. Chen, Y.; Li, C. W.; Kanan, M. W., Aqueous CO2 Reduction at Very Low Overpotential on Oxide-Derived Au Nanoparticles. Journal of the American Chemical Society 2012, 134 (49), 19969-19972.

189. Delacourt, C.; Ridgway, P. L.; Kerr, J. B.; Newman, J., Design of an electrochemical cell making syngas $(\mathrm{CO}+\mathrm{H}-2)$ from $\mathrm{CO} 2$ and $\mathrm{H} 2 \mathrm{O}$ reduction at room temperature. Journal of the Electrochemical Society 2008, 155 (1), B42-B49.

190. Hatsukade, T.; Kuhl, K. P.; Cave, E. R.; Abram, D. N.; Jaramillo, T. F., Insights into the electrocatalytic reduction of $\mathrm{CO} 2$ on metallic silver surfaces. Physical Chemistry Chemical Physics 2014, 16 (27), 13814-13819.

191. Agarwal, A. S.; Zhai, Y.; Hill, D.; Sridhar, N., The Electrochemical Reduction of Carbon Dioxide to Formate/Formic Acid: Engineering and Economic Feasibility. Chemsuschem 2011, 4 (9), 1301-1310.

192. Koleli, F.; Balun, D. B., Reduction of $\mathrm{CO} 2$ under high pressure and high temperature on $\mathrm{Pb}$-granule electrodes in a fixed-bed reactor in aqueous medium. Applied Catalysis aGeneral 2004, 274 (1-2), 237-242.

193. Kumar, B.; Atla, V.; Brian, J. P.; Kumari, S.; Tu Quang, N.; Sunkara, M.; Spurgeon, J. M., Reduced SnO2 Porous Nanowires with a High Density of Grain Boundaries as Catalysts for Efficient Electrochemical $\mathrm{CO} 2$-into-HCOOH Conversion. Angewandte ChemieInternational Edition 2017, 56 (13), 3645-3649.

194. Li, C. W.; Kanan, M. W., CO2 Reduction at Low Overpotential on Cu Electrodes Resulting from the Reduction of Thick Cu2O Films. Journal of the American Chemical Society 2012, 134 (17), 7231-7234.

195. Qiao, J.; Jiang, P.; Liu, J.; Zhang, J., Formation of Cu nanostructured electrode surfaces by an annealing-electroreduction procedure to achieve high-efficiency $\mathrm{CO} 2$ electroreduction. Electrochemistry Communications 2014, 38, 8-11.

196. Sekimoto, T.; Deguchi, M.; Yotsuhashi, S.; Yamada, Y.; Masui, T.; Kuramata, A.; Yamakoshi, S., Highly selective electrochemical reduction of $\mathrm{CO} 2$ to $\mathrm{HCOOH}$ on a gallium oxide cathode. Electrochemistry Communications 2014, 43, 95-97.

197. Wu, J.; Risalvato, F. G.; Ke, F.-S.; Pellechia, P. J.; Zhou, X.-D., Electrochemical Reduction of Carbon Dioxide I. Effects of the Electrolyte on the Selectivity and Activity with Sn Electrode. Journal of the Electrochemical Society 2012, 159 (7), F353-F359.

198. Handoko, A. D.; Ong, C. W.; Huang, Y.; Lee, Z. G.; Lin, L.; Panetti, G. B.; Yeo, B. S., Mechanistic Insights into the Selective Electroreduction of Carbon Dioxide to Ethylene on Cu2O-Derived Copper Catalysts. Journal of Physical Chemistry C 2016, 120 (36), 20058-20067.

199. Hoang, T. T. H.; Ma, S.; Gold, J. I.; Kenis, P. J. A.; Gewirth, A. A., Nanoporous Copper Films by Additive-Controlled Electrodeposition: $\mathrm{CO} 2$ Reduction Catalysis. Acs Catalysis 2017, 7 (5), 3313-3321.

200. Hori, Y.; Takahashi, I.; Koga, O.; Hoshi, N., Electrochemical reduction of carbon dioxide at various series of copper single crystal electrodes. Journal of Molecular Catalysis aChemical 2003, 199 (1-2), 39-47.

201. Ma, S.; Sadakiyo, M.; Luo, R.; Heima, M.; Yamauchi, M.; Kenis, P. J. A., One-step electrosynthesis of ethylene and ethanol from $\mathrm{CO} 2$ in an alkaline electrolyzer. Journal of Power Sources 2016, 301, 219-228.

202. Ren, D.; Ang, B. S.-H.; Yeo, B. S., Tuning the Selectivity of Carbon Dioxide Electroreduction toward Ethanol on Oxide-Derived CuxZn Catalysts. Acs Catalysis 2016, $6(12), 8239-8247$. 
203. Ren, D.; Deng, Y.; Handoko, A. D.; Chen, C. S.; Malkhandi, S.; Yeo, B. S., Selective Electrochemical Reduction of Carbon Dioxide to Ethylene and Ethanol on Copper(I) Oxide Catalysts. Acs Catalysis 2015, 5 (5), 2814-2821.

204. Song, Y.; Peng, R.; Hensley, D. K.; Bonnesen, P. V.; Liang, L.; Wu, Z.; Meyer, H. M., III; Chi, M.; Ma, C.; Sumpter, B. G.; Rondinone, A. J., High-Selectivity Electrochemical Conversion of $\mathrm{CO} 2$ to Ethanol using a Copper Nanoparticle/N-Doped Graphene Electrode. Chemistryselect 2016, 1 (19), 6055-6061.

205. Kim, Y.-G.; Javier, A.; Baricuatro, J. H.; Torelli, D.; Cummins, K. D.; Tsang, C. F.; Hemminger, J. C.; Soriaga, M. P., Surface reconstruction of pure-Cu single-crystal electrodes under CO-reduction potentials in alkaline solutions: A study by seriatim ECSTM-DEMS. Journal of Electroanalytical Chemistry 2016, 780, 290-295.

206. Seh, Z. W.; Kibsgaard, J.; Dickens, C. F.; Chorkendorff, I. B.; Norskov, J. K.; Jaramillo, T. F., Combining theory and experiment in electrocatalysis: Insights into materials design. Science 2017, 355 (6321).

207. Huff, C. A.; Sanford, M. S., Cascade Catalysis for the Homogeneous Hydrogenation of CO2 to Methanol. Journal of the American Chemical Society 2011, 133 (45), 1812218125.

208. Chen, Y.; Choi, S.; Thompson, L. T., Low-Temperature CO2 Hydrogenation to Liquid Products via a Heterogeneous Cascade Catalytic System. Acs Catalysis 2015, 5 (3), 17171725.

209. Kumar, B.; Brian, J. P.; Atla, V.; Kumari, S.; Bertram, K. A.; White, R. T.; Spurgeon, J. $M .$, New trends in the development of heterogeneous catalysts for electrochemical $\mathrm{CO} 2$ reduction. Catalysis Today 2016, 270, 19-30.

210. Hsieh, Y.-C.; Senanayake, S. D.; Zhang, Y.; Xu, W.; Polyansky, D. E., Effect of Chloride Anions on the Synthesis and Enhanced Catalytic Activity of Silver Nanocoral Electrodes for CO2 Electroreduction. Acs Catalysis 2015, 5 (9), 5349-5356.

211. Li, C. W.; Ciston, J.; Kanan, M. W., Electroreduction of carbon monoxide to liquid fuel on oxide-derived nanocrystalline copper. Nature 2014, 508 (7497), 504-+.

212. Kumar, B.; Brian, J. P.; Atla, V.; Kumari, S.; Bertram, K. A.; White, R. T.; Spurgeon, J. M., Controlling the Product Syngas H-2:CO Ratio through Pulsed-Bias Electrochemical Reduction of $\mathrm{CO} 2$ on Copper. Acs Catalysis 2016, 6 (7), 4739-4745.

213. Bard, A. J.; Faulkner, L. R., Electrochemical Methods: Fundamentals and Applications. Second ed.; John Wiley \& Sons: 2001.

214. McCrory, C. C. L.; Jung, S.; Peters, J. C.; Jaramillo, T. F., Benchmarking Heterogeneous Electrocatalysts for the Oxygen Evolution Reaction. Journal of the American Chemical Society 2013, 135 (45), 16977-16987.

215. Lum, Y.; Yue, B.; Lobaccaro, P.; Bell, A. T.; Ager, J. W., Optimizing C-C Coupling on Oxide-Derived Copper Catalysts for Electrochemical CO2 Reduction. Journal of Physical Chemistry C 2017, 121 (26), 14191-14203.

216. Baruch, M. F.; Pander, J. E., III; White, J. L.; Bocarsly, A. B., Mechanistic Insights into the Reduction of $\mathrm{CO} 2$ on Tin Electrodes using in Situ ATR-IR Spectroscopy. Acs Catalysis 2015, 5 (5), 3148-3156.

217. Chen, Y.; Kanan, M. W., Tin Oxide Dependence of the CO2 Reduction Efficiency on Tin Electrodes and Enhanced Activity for Tin/Tin Oxide Thin-Film Catalysts. Journal of the American Chemical Society 2012, 134 (4), 1986-1989.

218. Zhang, S.; Kang, P.; Meyer, T. J., Nanostructured Tin Catalysts for Selective Electrochemical Reduction of Carbon Dioxide to Formate. Journal of the American Chemical Society 2014, 136 (5), 1734-1737. 
219. Mellmann, D.; Sponholz, P.; Junge, H.; Beller, M., Formic acid as a hydrogen storage material - development of homogeneous catalysts for selective hydrogen release. Chemical Society Reviews 2016, 45 (14), 3954-3988.

220. Singh, A. K.; Singh, S.; Kumar, A., Hydrogen energy future with formic acid: a renewable chemical hydrogen storage system. Catalysis Science \& Technology 2016, 6 (1), 12-40.

221. Verma, S.; Kim, B.; Jhong, H.-R. M.; Ma, S.; Kenis, P. J. A., A Gross-Margin Model for Defining Technoeconomic Benchmarks in the Electroreduction of CO2. Chemsuschem 2016, 9 (15), 1972-1979.

222. Das, S.; Daud, W. M. A. W., A review on advances in photocatalysts towards $\mathrm{CO} 2$ conversion. Rsc Advances 2014, 4 (40), 20856-20893.

223. Lu, W.; Jia, B.; Cui, B.; Zhang, Y.; Yao, K.; Zhao, Y.; Wang, J., Efficient Photoelectrochemical Reduction of Carbon Dioxide to Formic Acid: A Functionalized Ionic Liquid as an Absorbent and Electrolyte. Angewandte Chemie-International Edition 2017, 56 (39), 11851-11854.

224. Sheu, J. K.; Liao, P. H.; Huang, T. C.; Chiang, K. J.; Lai, W. C.; Lee, M. L., InGaN-based epitaxial films as photoelectrodes for hydrogen generation through water photoelectrolysis and $\mathrm{CO} 2$ reduction to formic acid. Solar Energy Materials and Solar Cells 2017, 166, 86-90.

225. Wang, Y.; AlOtaibi, B.; Chowdhury, F. A.; Fan, S.; Kibria, M. G.; Li, L.; Li, C.-J.; Mi, Z., Photoelectrochemical reduction of carbon dioxide using Ge doped GaN nanowire photoanodes. Apl Materials 2015, 3 (11).

226. Yang, Y.; Zhan, F.; Li, H.; Liu, W.; Yu, S., In situ Sn-doped WO3 films with enhanced photoelectrochemical performance for reducing $\mathrm{CO} 2$ into formic acid. Journal of Solid State Electrochemistry 2017, 21 (8), 2231-2240.

227. Yang, Y.-h.; Xie, R.-r.; Li, H.; Liu, C.-j.; Liu, W.-h.; Zhan, F.-q., Photoelectrocatalytic reduction of $\mathrm{CO} 2$ into formic acid using WO3-x/TiO2 film as novel photoanode. Transactions of Nonferrous Metals Society of China 2016, 26 (9), 2390-2396.

228. Yin, G.; Abe, H.; Kodiyath, R.; Ueda, S.; Srinivasan, N.; Yamaguchi, A.; Miyauchi, M., Selective electro- or photo-reduction of carbon dioxide to formic acid using a $\mathrm{Cu}-\mathrm{Zn}$ alloy catalyst. J. Mater. Chem. A 2017, 5 (24), 12113-12119.

229. Arai, T.; Tajima, S.; Sato, S.; Uemura, K.; Morikawa, T.; Kajino, T., Selective CO2 conversion to formate in water using a CZTS photocathode modified with a ruthenium complex polymer. Chemical Communications 2011, 47 (47), 12664-12666.

230. Choi, S. K.; Kang, U.; Lee, S.; Ham, D. J.; Ji, S. M.; Park, H., Sn-Coupled p-Si Nanowire Arrays for Solar Formate Production from CO2. Advanced Energy Materials 2014, 4 (11).

231. Huang, X.; Cao, T.; Liu, M.; Zhao, G., Synergistic Photoelectrochemical Synthesis of Formate from $\mathrm{CO} 2$ on $\{12(1)$ over-bar\} Hierarchical Co304. Journal of Physical Chemistry C 2013, 117 (50), 26432-26440.

232. Kang, U.; Choi, S. K.; Ham, D. J.; Ji, S. M.; Choi, W.; Han, D. S.; Abdel-Wahabe, A.; Park, H., Photosynthesis of formate from $\mathrm{CO} 2$ and water at $1 \%$ energy efficiency via copper iron oxide catalysis. Energy \& Environmental Science 2015, 8 (9), 2638-2643.

233. Won, D. H.; Choi, C. H.; Chung, J.; Woo, S. I., Photoelectrochemical production of formic acid and methanol from carbon dioxide on metal-decorated $\mathrm{CuO} / \mathrm{Cu} 2 \mathrm{O}-l a y e r e d$ thin films under visible light irradiation. Applied Catalysis B-Environmental 2014, 158, 217 223.

234. Won, D. H.; Chung, J.; Park, S. H.; Kim, E.-H.; Woo, S. I., Photoelectrochemical production of useful fuels from carbon dioxide on a polypyrrole-coated p-ZnTe photocathode under visible light irradiation. J. Mater. Chem. A 2015, 3 (3), 1089-1095. 
235. Zhou, X.; Liu, R.; Sun, K.; Chen, Y.; Verlage, E.; Francis, S. A.; Lewis, N. S.; Xiang, C., Solar-Driven Reduction of 1 atm of $\mathrm{CO} 2$ to Formate at 10\% Energy-Conversion Efficiency by Use of a TiO2-Protected III-V Tandem Photoanode in Conjunction with a Bipolar Membrane and a Pd/C Cathode. Acs Energy Letters 2016, 1 (4), 764-770.

236. Hinogami, R.; Nakamura, Y.; Yae, S.; Nakato, Y., An approach to ideal semiconductor electrodes for efficient photoelectrochemical reduction of carbon dioxide by modification with small metal particles. Journal of Physical Chemistry B 1998, 102 (6), 974-980.

237. Tu Quang, N.; Atla, V.; Vendra, V. K.; Thapa, A. K.; Jasinski, J. B.; Druffel, T. L.; Sunkara, M. K., Scalable solvo-plasma production of porous tin oxide nanowires. Chemical Engineering Science 2016, 154, 20-26.

238. Boettcher, S. W.; Warren, E. L.; Putnam, M. C.; Santori, E. A.; Turner-Evans, D.; Kelzenberg, M. D.; Walter, M. G.; McKone, J. R.; Brunschwig, B. S.; Atwater, H. A.; Lewis, N. S., Photoelectrochemical Hydrogen Evolution Using Si Microwire Arrays. Journal of the American Chemical Society 2011, 133 (5), 1216-1219.

239. Strandwitz, N. C.; Comstock, D. J.; Grimm, R. L.; Nichols-Nielander, A. C.; Elam, J.; Lewis, N. S., Photoelectrochemical Behavior of n-type Si(100) Electrodes Coated with Thin Films of Manganese Oxide Grown by Atomic Layer Deposition. Journal of Physical Chemistry C 2013, 117 (10), 4931-4936.

240. Tan, M. X.; Laibinis, P. E.; Nguyen, S. T.; Kesselman, J. M.; Stanton, C. E.; Lewis, N. S., PRINCIPLES AND APPLICATIONS OF SEMICONDUCTOR PHOTOELECTROCHEMISTRY. Progress in Inorganic Chemistry, Vol 41 1994, 41, 21-144.

241. Rossi, R. C.; Tan, M. X.; Lewis, N. S., Size-dependent electrical behavior of spatially inhomogeneous barrier height regions on silicon. Applied Physics Letters 2000, 77 (17), 2698-2700.

242. Walter, M. G.; Warren, E. L.; McKone, J. R.; Boettcher, S. W.; Mi, Q.; Santori, E. A.; Lewis, N. S., Solar Water Splitting Cells. Chemical Reviews 2010, 110 (11), 6446-6473.

243. Li, F.; Chen, L.; Knowles, G. P.; MacFarlane, D. R.; Zhang, J., Hierarchical Mesoporous $\mathrm{SnO} 2$ Nanosheets on Carbon Cloth: A Robust and Flexible Electrocatalyst for $\mathrm{CO} 2$ Reduction with High Efficiency and Selectivity. Angewandte Chemie-International Edition 2017, 56 (2), 505-509.

244. Coridan, R. H.; Nielander, A. C.; Francis, S. A.; McDowell, M. T.; Dix, V.; Chatman, S. M.; Lewis, N. S., Methods for comparing the performance of energy-conversion systems for use in solar fuels and solar electricity generation. Energy \& Environmental Science 2015, 8 (10), 2886-2901.

245. Francke, R.; Schille, B.; Roemelt, M., Homogeneously Catalyzed Electroreduction of Carbon Dioxide-Methods, Mechanisms, and Catalysts. Chemical Reviews 2018, 118 (9), 4631-4701.

246. Last, G. V.; Schmick, M. T., A review of major non-power-related carbon dioxide stream compositions. Environmental Earth Sciences 2015, 74 (2), 1189-1198.

247. Ngo, K. T.; McKinnon, M.; Mahanti, B.; Narayanan, R.; Grills, D. C.; Ertem, M. Z.; Rochford, J., Turning on the Protonation-First Pathway for Electrocatalytic $\mathrm{CO} 2$ Reduction by Manganese Bipyridyl Tricarbonyl Complexes. Journal of the American Chemical Society 2017, 139 (7), 2604-2618.

248. Morimoto, T.; Nakajima, T.; Sawa, S.; Nakanishi, R.; Imori, D.; Ishitani, O., CO2 Capture by a Rhenium(I) Complex with the Aid of Triethanolamine. Journal of the American Chemical Society 2013, 135 (45), 16825-16828. 
249. Arikawa, Y.; Nakamura, T.; Ogushi, S.; Eguchi, K.; Umakoshi, K., Fixation of atmospheric carbon dioxide by ruthenium complexes bearing an NHC-based pincer ligand: formation of a methylcarbonato complex and its methylation. Dalton Transactions 2015, 44 (12), 5303-5305.

250. Mandal, S. K.; Ho, D. M.; Orchin, M., Reaction of electrophiles with manganese(I) and rhenium(I) alkoxide complexes: reversible absorption of atmospheric carbon dioxide. Organometallics 1993, 12 (5), 1714-1719.

251. Kumagai, H.; Nishikawa, T.; Koizumi, H.; Yatsu, T.; Sahara, G.; Yamazaki, Y.; Tamaki, Y.; Ishitani, O., Electrocatalytic reduction of low concentration $\mathrm{CO}$. Chemical Science 2019, 10 (6), 1597-1606.

252. Kato, M.; Ito, T., Facile carbon dioxide uptake by zinc(II)-tetraazacycloalkane complexes. 1. Syntheses, characterizations, and chemical properties of (monoalkyl carbonato)(tetraazacycloalkane)zinc(II) complexes. Inorganic Chemistry 1985, 24 (4), 504-508.

253. Franco, F.; Cometto, C.; Nencini, L.; Barolo, C.; Sordello, F.; Minero, C.; Fiedler, J.; Robert, M.; Gobetto, R.; Nervi, C., Local Proton Source in Electrocatalytic CO2 Reduction with [Mn(bpy-R)(CO)3Br] Complexes. Chemistry - A European Journal 2017, 23 (20), $4782-4793$.

254. Larrazabal, G. O.; Martin, A. J.; Perez-Ramirez, J., Building Blocks for High Performance in Electrocatalytic CO2 Reduction: Materials, Optimization Strategies, and Device Engineering. Journal of Physical Chemistry Letters 2017, 8 (16), 3933-3944.

255. Montoya, J. H.; Seitz, L. C.; Chakthranont, P.; Vojvodic, A.; Jaramillo, T. F.; Norskov, J. K., Materials for solar fuels and chemicals. Nature Materials 2017, 16 (1), 70-81.

256. Ma, S.; Luo, R.; Gold, J. I.; Yu, A. Z.; Kim, B.; Kenis, P. J. A., Carbon nanotube containing $\mathrm{Ag}$ catalyst layers for efficient and selective reduction of carbon dioxide. J. Mater. Chem. A 2016, 4 (22), 8573-8578.

257. Verma, S.; Hamasaki, Y.; Kim, C.; Huang, W.; Lu, S.; Jhong, H.-R. M.; Gewirth, A. A.; Fujigaya, T.; Nakashima, N.; Kenis, P. J. A., Insights into the Low Overpotential Electroreduction of $\mathrm{CO} 2$ to $\mathrm{CO}$ on a Supported Gold Catalyst in an Alkaline Flow Electrolyzer. Acs Energy Letters 2018, 3 (1), 193-198.

258. Yang, H.; Kaczur, J. J.; Sajjad, S. D.; Masel, R. I., CO2 Conversion to Formic Acid in a Three Compartment Cell with Sustainion (TM) Membranes. In Selected Proceedings from the 231st Ecs Meeting, Manivannan, M.; Narayan, S.; Kostecki, R.; Johnson, C.; Atanassov, P. B., Eds. 2017; Vol. 77, pp 1425-1431.

259. Dinh, C.-T.; Burdyny, T.; Kibria, M. G.; Seifitokaldani, A.; Gabardo, C. M.; de Arquer, F. P. G.; Kiani, A.; Edwards, J. P.; De Luna, P.; Bushuyev, O. S.; Zou, C.; QuinteroBermudez, R.; Pang, Y.; Sinton, D.; Sargent, E. H., CO2 electroreduction to ethylene via hydroxide-mediated copper catalysis at an abrupt interface. Science 2018, 360 (6390), 783-787.

260. Jouny, M.; Luc, W.; Jiao, F., General Techno-Economic Analysis of CO2 Electrolysis Systems. Industrial \& Engineering Chemistry Research 2018, 57 (6), 2165-2177.

261. Spurgeon, J. M.; Kumar, B., A comparative technoeconomic analysis of pathways for commercial electrochemical CO2 reduction to liquid products. Energy \& Environmental Science 2018, 11 (6), 1536-1551.

262. Lum, Y.; Ager, J. W., Sequential catalysis controls selectivity in electrochemical CO2 reduction on Cu. Energy \& Environmental Science 2018, 11 (10), 2935-2944. 
263. Theaker, N.; Strain, J. M.; Kumar, B.; Brian, J. P.; Kumari, S.; Spurgeon, J. M., Heterogeneously catalyzed two-step cascade electrochemical reduction of $\mathrm{CO} 2$ to ethanol. Electrochimica Acta 2018, 274, 1-8.

264. Zhang, H.; Li, J.; Cheng, M.-J.; Lu, Q., CO Electroreduction: Current Development and Understanding of Cu-Based Catalysts. Acs Catalysis 2019, 9 (1), 49-65.

265. Jouny, M.; Luc, W.; Jiao, F., High-rate electroreduction of carbon monoxide to multicarbon products. Nature Catalysis 2018, 1 (10), 748-755.

266. Giffin, G. A.; Lavina, S.; Pace, G.; Di Noto, V., Interplay between the Structure and Relaxations in Selemion AMV Hydroxide Conducting Membranes for AEMFC Applications. Journal of Physical Chemistry C 2012, 116 (45), 23965-23973.

267. Kutz, R. B.; Chen, Q.; Yang, H.; Sajjad, S. D.; Liu, Z.; Masel, I. R., Sustainion ImidazoliumFunctionalized Polymers for Carbon Dioxide Electrolysis. Energy Technology 2017, 5 (6), 929-936.

268. GmbH, F. B. www.fumatech.com.

269. Membranes International, I. www.ionexchangemembranes.com.

270. HeitnerWirguin, C., Recent advances in perfluorinated ionomer membranes: Structure, properties and applications. Journal of Membrane Science 1996, 120 (1), 1-33.

271. Marcincin, A., Modification of fiber-forming polymers by additives. Progress in Polymer Science 2002, 27 (5), 853-913.

272. Elangovan, M.; Dharmalingam, S., A facile modification of a polysulphone based anti biofouling anion exchange membrane for microbial fuel cell application. Rsc Advances 2016, 6 (25), 20571-20581.

273. DeFrancesco, J. V.; Witkowski, M. R.; Ciolino, L. A., GHB free acid: I. Solution formation studies and spectroscopic characterization by (HNMR)-H-1 and FT-IR. Journal of Forensic Sciences 2006, 51 (2), 321-329.

274. Grootveld, M.; Algeo, D.; Silwood, C. J. L.; Blackburn, J. C.; Clark, A. D., Determination of the illicit drug gamma-hydroxybutyrate $(\mathrm{GHB})$ in human saliva and beverages by $\mathrm{H}-1$ NMR analysis. Biofactors 2006, 27 (1-4), 121-136.

275. Palomino-Schatzlein, M.; Wang, Y.; Brailsford, A. D.; Parella, T.; Cowan, D. A.; LegidoQuigley, C.; Perez-Trujillo, M., Direct Monitoring of Exogenous gamma-Hydroxybutyric Acid in Body Fluids by NMR Spectroscopy. Analytical Chemistry 2017, 89 (16), 83438350.

276. Hu, B. R.; Yue, Y. Q.; Zhu, Y.; Wen, W.; Zhang, F. M.; Hardie, J. W., Proton nuclear magnetic resonance-spectroscopic discrimination of wines reflects genetic homoly of several different grape (V. vinifer L.) Cultivars. PLoS One 2015, 10.

277. Bushuyev, O.; De Luna, P.; Dinh, C. T.; Tao, L.; Saur, G.; van de Lagemaat, J.; Kelly, S. O.; Sargent, E. H., What Should We Make with $\mathrm{CO}_{2}$ and How Can We Make It? Joule 2018, 2, 825-832.

278. Spurgeon, J. M.; Kumar, B., A comparative technoeconomic analysis of pathways for commercial electrochemical $\mathrm{CO}_{2}$ reduction to liquid products Energy Environ. Sci. 2018, 11, 1536-1551.

279. Jouny, M.; Luc, W.; Jiao, F., General Techno-Economic Analysis of $\mathrm{CO}_{2}$ Electrolysis Systems. Ind. Eng. Chem. Res. 2018, 57 (6), 2165-2177.

280. Lum, Y. W.; Yue, B. B.; Lobaccaro, P.; Bell, A. T.; Ager, J. W., Optimizing C-C Coupling on Oxide-Derived Copper Catalysts for Electrochemical $\mathrm{CO}_{2}$ Reduction. J. Phys. Chem. $\mathrm{C}$ 2017, 121 (26), 14191-14203.

281. Perez-Ramirez, J.; Lopez, N., Strategies to break linear scaling relationships. Nature Catalysis 2019, 2 (11), 971-976. 
282. Theaker, N.; Strain, J.; Kumar, B.; Brian, J. P.; Kumari, S.; Spurgeon, J. M., Heterogeneously catalyzed two-step cascade electrochemical reduction of $\mathrm{CO} 2$ to ethanol. Electrochim. Acta 2018, 274, 1-8.

283. Gurudayal; Perone, D.; Malani, S.; Lum, Y.; Haussener, S.; Ager, J. W., Sequential Cascade Electrocatalytic Conversion of Carbon Dioxide to C-C Coupled Products. ACS Appl. Energy Mater. 2019, 2 (6), 4551-4559.

284. Kumar, B.; Brian, J. P.; Atla, V.; Kumari, S.; Bertram, K. A.; White, R. T.; Spurgeon, J. M., Controlling the Product Syngas $\mathrm{H}_{2}$ : $\mathrm{CO}$ Ratio through Pulsed-Bias Electrochemical Reduction of $\mathrm{CO}_{2}$ on Copper. ACS Catal. 2016, 6 (7), 4739-4745.

285. Yano, J.; Morita, T.; Shimano, K.; Nagami, Y.; Yamasaki, S., Selective ethylene formation by pulse-mode electrochemical reduction of carbon dioxide using copper and copperoxide electrodes. J. Solid State Electrochem. 2007, 11 (4), 554-557.

286. Yano, J.; Yamasaki, S., Pulse-mode electrochemical reduction of carbon dioxide using copper and copper oxide electrodes for selective ethylene formation. J. Appl. Electrochem. 2008, 38 (12), 1721-1726.

287. Ishimaru, S.; Shiratsuchi, R.; Nogami, G., Pulsed electroreduction of CO2 on Cu-Ag alloy electrodes. J. Electrochem. Soc. 2000, 147 (5), 1864-1867.

288. Kimura, K. W.; Fritz, K. E.; Kim, J.; Suntivich, J.; Abruna, H. D.; Hanrath, T., Controlled Selectivity of $\mathrm{CO} 2$ Reduction on Copper by Pulsing the Electrochemical Potential. Chemsuschem 2018, 11 (11), 1781-1786.

289. Nogami, G.; Itagaki, H.; Shiratsuchi, R., Pulsed Electroreduction of CO2 on Copper Electrodes II. J. Electrochem. Soc. 1994, 141 (5), 1138-1142.

290. Engelbrecht, A.; Uhlig, C.; Stark, O.; Hammerle, M.; Schmid, G.; Magori, E.; WiesnerFleischer, K.; Fleischer, M.; Moos, R., On the Electrochemical CO2 Reduction at Copper Sheet Electrodes with Enhanced Long-Term Stability by Pulsed Electrolysis. J. Electrochem. Soc. 2018, 165 (15), J3059-J3068.

291. Bertheussen, E.; Verdaguer-Casadevall, A.; Ravasio, D.; Montoya, J. H.; Trimarco, D. B.; Roy, C.; Meier, S.; Wendland, J.; Norskov, J. K.; Stephens, I. E. L.; Chorkendorff, I., Acetaldehyde as an Intermediate in the Electroreduction of Carbon Monoxide to Ethanol on Oxide-Derived Copper. Angew. Chem.-Int. Edit. 2016, 55 (4), 1450-1454.

292. Li, C. W.; Ciston, J.; Kanan, M. W., Electroreduction of carbon monoxide to liquid fuel on oxide-derived nanocrystalline copper. Nature 2014, 508 (7497), 504-507.

293. Gurudayal; Bullock, J.; Sranko, D. F.; Towle, C. M.; Lum, Y.; Hettick, M.; Scott, M. C.; Javey, A.; Ager, J., Efficient solar-driven electrochemical $\mathrm{CO} 2$ reduction to hydrocarbons and oxygenates. Energy \& Environmental Science 2017, 10 (10), 2222-2230.

294. Magesh, G.; Kim, E. S.; Kang, H. J.; Banu, M.; Kim, J. Y.; Kim, J. H.; Lee, J. S., A versatile photoanode-driven photoelectrochemical system for conversion of $\mathrm{CO} 2$ to fuels with high faradaic efficiencies at low bias potentials. J. Mater. Chem. A 2014, 2 (7), 20442049.

295. Schreier, M.; Luo, J.; Gao, P.; Moehl, T.; Mayer, M. T.; Graetzel, M., Covalent Immobilization of a Molecular Catalyst on Cu2O Photocathodes for $\mathrm{CO} 2$ Reduction. Journal of the American Chemical Society 2016, 138 (6), 1938-1946.

296. Zhang, M.; Cheng, J.; Xuan, X.; Zhou, J.; Cen, K., CO2 Synergistic Reduction in a Photoanode-Driven Photoelectrochemical Cell with a Pt-Modified TiO2 Nanotube Photoanode and a Pt Reduced Graphene Oxide Electrocathode. Acs Sustainable Chemistry \& Engineering 2016, 4 (12), 6344-6354. 
297. Halmann, M., PHOTOELECTROCHEMICAL REDUCTION OF AQUEOUS CARBON-DIOXIDE ON P-TYPE GALLIUM-PHOSPHIDE IN LIQUID JUNCTION SOLAR-CELLS. Nature 1978, 275 (5676), 115-116.

298. Xia, S.; Meng, Y.; Zhou, X.; Xue, J.; Pan, G.; Ni, Z., Ti/ZnO-Fe2O3 composite: Synthesis, characterization and application as a highly efficient photoelectrocatalyst for methanol from CO2 reduction. Applied Catalysis B-Environmental 2016, 187, 122-133.

299. Wood, C. J.; Summers, G. H.; Clark, C. A.; Kaeffer, N.; Braeutigam, M.; Carbone, L. R.; D'Amario, L.; Fan, K.; Farre, Y.; Narbey, S.; Oswald, F.; Stevens, L. A.; Parmenter, C. D. J.; Fay, M. W.; La Torre, A.; Snape, C. E.; Dietzek, B.; Dini, D.; Hammarstrom, L.; Pellegrin, Y.; Odobel, F.; Sun, L.; Artero, V.; Gibson, E. A., A comprehensive comparison of dye-sensitized NiO photocathodes for solar energy conversion. Physical Chemistry Chemical Physics 2016, 18 (16), 10727-10738.

300. LaTempa, T. J.; Rani, S.; Bao, N.; Grimes, C. A., Generation of fuel from CO2 saturated liquids using a $\mathrm{p}$-Si nanowire parallel to $\mathrm{n}-\mathrm{TiO} 2$ nanotube array photoelectrochemical cell. Nanoscale 2012, 4 (7), 2245-2250.

301. Rao, K. R.; Pishgar, S.; Strain, J.; Kumar, B.; Atla, V.; Kumari, S.; Spurgeon, J. M., Photoelectrochemical reduction of $\mathrm{CO} 2$ to $\mathrm{HCOOH}$ on silicon photocathodes with reduced SnO2 porous nanowire catalysts. J. Mater. Chem. A 2018, 6 (4), 1736-1742.

302. Cheng, W.-H.; Richter, M. H.; Sullivan, I.; Larson, D. M.; Xiang, C.; Brunschwig, B. S.; Atwater, H. A., CO2 Reduction to CO with 19\% Efficiency in a Solar-Driven Gas Diffusion Electrode Flow Cell under Outdoor Solar Illumination. ACS Energy Letters 2020, 5 (2), 470-476.

303. Chang, X.; Wang, T.; Zhang, P.; Wei, Y.; Zhao, J.; Gong, J., Stable Aqueous Photoelectrochemical CO2 Reduction by a Cu2O Dark Cathode with Improved Selectivity for Carbonaceous Products. Angewandte Chemie International Edition 2016, 55 (31), 8840-8845.

304. Kumaravel, V.; Bartlett, J.; Pillai, S. C., Photoelectrochemical Conversion of Carbon Dioxide (CO2) into Fuels and Value-Added Products. Acs Energy Letters 2020, 5 (2), 486 519.

305. Andrei, V.; Reuillard, B.; Reisner, E., Bias-free solar syngas production by integrating a molecular cobalt catalyst with perovskite-BiVO4 tandems. Nature Materials 2020, 19 (2), 189-+.

306. Clark, E. L.; Hahn, C.; Jaramillo, T. F.; Bell, A. T., Electrochemical CO2 Reduction over Compressively Strained CuAg Surface Alloys with Enhanced Multi-Carbon Oxygenate Selectivity. Journal of the American Chemical Society 2017, 139 (44), 15848-15857.

307. Wang, L.; Nitopi, S. A.; Bertheussen, E.; Orazov, M.; Morales-Guio, C. G.; Liu, X.; Higgins, D. C.; Chan, K.; Nørskov, J. K.; Hahn, C.; Jaramillo, T. F., Electrochemical Carbon Monoxide Reduction on Polycrystalline Copper: Effects of Potential, Pressure, and $\mathrm{pH}$ on Selectivity toward Multicarbon and Oxygenated Products. ACS Catalysis 2018, 8 (8), 7445-7454.

308. Zhou, X.; Xiang, C., Comparative Analysis of Solar-to-Fuel Conversion Efficiency: A Direct, One-Step Electrochemical CO2 Reduction Reactor versus a Two-Step, Cascade Electrochemical CO2 Reduction Reactor. Acs Energy Letters 2018, 3 (8), 1892-1897.

309. Strain, J. M.; Spurgeon, J. M., Assessing contaminants from ion-exchange membranes in the evaluation of aqueous electrochemical carbon dioxide reduction. Journal of $\mathrm{CO} 2$ Utilization 2020, 35, e298-e302. 
310. Hu, S.; Shaner, M. R.; Beardslee, J. A.; Lichterman, M.; Brunschwig, B. S.; Lewis, N. S., Amorphous TiO2 coatings stabilize $\mathrm{Si}, \mathrm{GaAs}$, and $\mathrm{GaP}$ photoanodes for efficient water oxidation. Science 2014, 344 (6187), 1005-1009.

311. Zhao, Y.; Westerik, P.; Santbergen, R.; Zoethout, E.; Gardeniers, H.; Bieberle-Hütter, A., From Geometry to Activity: A Quantitative Analysis of WO3/Si Micropillar Arrays for Photoelectrochemical Water Splitting. Advanced Functional Materials 2020, 1909157.

312. Liu, B.; Aydil, E. S., Growth of Oriented Single-Crystalline Rutile TiO2 Nanorods on Transparent Conducting Substrates for Dye-Sensitized Solar Cells. Journal of the American Chemical Society 2009, 131 (11), 3985-3990.

313. Shaner, M. R.; McDowell, M. T.; Pien, A.; Atwater, H. A.; Lewis, N. S., Si/TiO2 tandemjunction microwire arrays for unassisted solar-driven water splitting. Journal of The Electrochemical Society 2016, 163 (5), H261.

314. Corson, E. R.; Creel, E. B.; Kim, Y.; Urban, J. J.; Kostecki, R.; McCloskey, B. D., A temperature-controlled photoelectrochemical cell for quantitative product analysis. Review of Scientific Instruments 2018, 89 (5).

315. Krodel, M.; Carter, B. M.; Rall, D.; Lohaus, J.; Wessling, M.; Miller, D. J., Rational Design of Ion Exchange Membrane Material Properties Limits the Crossover of $\mathrm{CO} 2$ Reduction Products in Artificial Photosynthesis Devices. ACS applied materials \& interfaces 2020, 12 (10), 12030-12042.

316. Tzeng, Y.; Yeh, S.; Fang, W. C.; Chu, Y., Nitrogen-incorporated ultrananocrystalline diamond and multi-layer-graphene-like hybrid carbon films. Scientific Reports 2014, 4.

317. Kumar, A.; Lin, P. A.; Xue, A.; Hao, B.; Yap, Y. K.; Sankaran, R. M., Formation of nanodiamonds at near-ambient conditions via microplasma dissociation of ethanol vapour. Nature Communications 2013, 4.

318. Cheng, C. Y.; Teii, K., Control of the Growth Regimes of Nanodiamond and Nanographite in Microwave Plasmas. leee Transactions on Plasma Science 2012, 40 (7), 1783-1788.

319. Duan, X.; Xu, J.; Wei, Z.; Ma, J.; Guo, S.; Wang, S.; Liu, H.; Dou, S., Metal-Free Carbon Materials for CO2 Electrochemical Reduction. Advanced Materials 2017, 29 (41).

320. Liu, Y.; Chen, S.; Quan, X.; Yu, H., Efficient Electrochemical Reduction of Carbon Dioxide to Acetate on Nitrogen-Doped Nanodiamond. Journal of the American Chemical Society 2015, 137 (36), 11631-11636.

321. Liu, Y.; Zhang, Y.; Cheng, K.; Quan, X.; Fan, X.; Su, Y.; Chen, S.; Zhao, H.; Zhang, Y.; $\mathrm{Yu}, \mathrm{H}$.; Hoffmann, M. R., Selective Electrochemical Reduction of Carbon Dioxide to Ethanol on a Boron- and Nitrogen-Co-doped Nanodiamond. Angewandte ChemieInternational Edition 2017, 56 (49), 15607-15611.

322. Cui, X.; Pan, Z.; Zhang, L.; Peng, H.; Zheng, G., Selective Etching of Nitrogen-Doped Carbon by Steam for Enhanced Electrochemical CO2 Reduction. Advanced Energy Materials 2017, 7 (22), 1701456.

323. Wanninayake, N.; Ai, Q.; Zhou, R.; Hoque, M. A.; Herrell, S.; Guzman, M. I.; Risko, C.; Kim, D. Y., Understanding the effect of host structure of nitrogen doped ultrananocrystalline diamond electrode on electrochemical carbon dioxide reduction. Carbon 2020, 157, 408-419.

324. Garza, A. J.; Bell, A. T.; Head-Gordon, M., Mechanism of CO2 Reduction at Copper Surfaces: Pathways to C2 Products. ACS Catalysis 2018, 8 (2), 1490-1499.

325. Clark, E. L.; Singh, M. R.; Kwon, Y.; Bell, A. T., Differential Electrochemical Mass Spectrometer Cell Design for Online Quantification of Products Produced during Electrochemical Reduction of CO2. Analytical Chemistry 2015, 87 (15), 8013-8020. 
326. Clark, E. L.; Bell, A. T., Direct Observation of the Local Reaction Environment during the Electrochemical Reduction of CO2. Journal of the American Chemical Society 2018, 140 (22), 7012-7020.

327. Bogdanoff, P.; Friebe, P.; Alonso-Vante, N., A new inlet system for differential electrochemical mass spectroscopy applied to the photocorrosion of $\mathrm{p}-\ln \mathrm{P}(111)$ single crystals. Journal of the Electrochemical Society 1998, 145 (2), 576-582.

328. Lum, Y.; Ager, J. W., Evidence for product-specific active sites on oxide-derived Cu catalysts for electrochemical CO2 reduction. Nature Catalysis 2018.

329. Li, J. Y.; Yuan, L.; Li, S. H.; Tang, Z. R.; Xu, Y. J., One-dimensional copper-based heterostructures toward photo-driven reduction of $\mathrm{CO} 2$ to sustainable fuels and feedstocks. J. Mater. Chem. A 2019, 7 (15), 8676-8689.

330. Zhu, Q.; Sun, X.; Yang, D.; Ma, J.; Kang, X.; Zheng, L.; Zhang, J.; Wu, Z.; Han, B., Carbon dioxide electroreduction to $\mathrm{C} 2$ products over copper-cuprous oxide derived from electrosynthesized copper complex. Nature Communications 2019, 10 (1), 3851.

331. Gurudayal; Perone, D.; Malani, S.; Lum, Y.; Haussener, S.; Ager, J. W., Sequential Cascade Electrocatalytic Conversion of Carbon Dioxide to C-C Coupled Products. Acs Applied Energy Materials 2019, 2 (6), 4551-4559.

332. Christoforidis, K. C.; Fornasiero, P., Photocatalysis for Hydrogen Production and $\mathrm{CO} 2$ Reduction: The Case of Copper-Catalysts. ChemCatChem 2019, 11 (1), 368-382.

333. Sun, S. D.; Zhang, X. J.; Yang, Q.; Liang, S. H.; Zhang, X. Z.; Yang, Z. M., Cuprous oxide (Cu2O) crystals with tailored architectures: A comprehensive review on synthesis, fundamental properties, functional modifications and applications. Prog. Mater. Sci. 2018, 96, 111-173.

334. Ba, X.; Yan, L.-L.; Huang, S.; Yu, J.; Xia, X.-J.; Yu, Y., New Way for CO2 Reduction under Visible Light by a Combination of a Cu Electrode and Semiconductor Thin Film: Cu2O Conduction Type and Morphology Effect. Journal of Physical Chemistry C 2014, 118 (42), 24467-24478.

335. Yu, S.; Wilson, A. J.; Heo, J.; Jain, P. K., Plasmonic Control of Multi-Electron Transfer and C-C Coupling in Visible-Light-Driven CO2 Reduction on Au Nanoparticles. Nano Letters 2018, 18 (4), 2189-2194.

336. Yu, S.; Jain, P. K., Plasmonic photosynthesis of C1-C3 hydrocarbons from carbon dioxide assisted by an ionic liquid. Nature Communications 2019, 10 (1), 2022. 


\section{APPENDIX}

\section{List of Publications:}

Portions of this dissertation were taken from the following publications:

1. Pulsed electrochemical carbon monoxide reduction on thick oxide-derived copper. Jacob M. Strain, Saumya Gulati, Sahar Pishgar, Joshua M. Spurgeon. ChemSusChem 2020, Just Accepted.

2. Exploiting Metal-Ligand Cooperativity to Sequester, Activate, and Reduce Atmospheric Carbon Dioxide with a Neutral Zinc Complex. Steve P. Cronin, Jacob M. Strain, Mark S. Mashuta, Joshua M. Spurgeon, Robert M. Buchanon and Craig A. Grapperhaus. Inorganic Chemistry 2020, Just Accepted.

3. Assessing contaminants from ion-exchange membranes in the evaluation of aqueous electrochemical carbon dioxide reduction. Jacob M. Strain, Joshua M. Spurgeon. Journal of CO2 Utilization 2020, 35, e298-e302.

4. Investigation of the photocorrosion of n-GaP photoanodes in acid with in-situ UVVis spectroscopy. Sahar Pishgar, Jacob Strain, Saumya Gulati, Gamini Sumanasekera, Gautam Gupta, Joshua Spurgeon. Journal of Materials Chemistry A 2019, 7, 2537725388.

5. Synthesis, Characterization, and HER Activity of Pendant Diamine Derivatives of NiATSM. Caleb A. Calvary, Oleksandr Hietsoi, Jacob M. Strain, Mark S. Mashuta, Joshua M. Spurgeon, Robert M. Buchanan, Craig Alan Grapperhaus. European Journal of Inorganic Chemistry 2019, 33. 157

6. Effect of Stacking Interactions on the Translation of Structurally Related Bisthiosemicarbazone Ni(II) HER Catalysts to Modified Electrode Surfaces. Nicholas Vishnosky, Alexander Gupta, Rahul Jain, Jacob Strain, Joshua Spurgeon, Yaroslaw Losovyj, Mark Mashuta, Robert Buchanan, Gautum Gupta, Craig Grapperhaus, Inorganic Chemistry 2019, 58, 18.

7. Photocatalytic hydrogen evolution on Si photocathodes modified with bis(thiosemicarbazonato)nickel(II)/Nafion. Saumya Gulati, Olexsandr Hietsoi, Caleb A. Calvary, Jacob M. Strain, Sahar Pishgar, Henry C. Brun, Craig A. Grappherhaus, Robert M. Buchanan, Joshua M. Spurgeon. Chemical Communications 2019, 55, 94409443. 
8. Heterogeneously catalyzed two-step cascade electrochemical reduction of $\mathrm{CO} 2$ to ethanol. Nolan Theaker, Jacob M. Strain, Bijandra Kumar, Joseph P. Brian, Sudesh Kumari, Joshua M. Spurgeon. Electrochimica Acta 2018, 274, 1-8.

9. Photoelectrochemical Reduction of $\mathrm{CO} 2$ to $\mathrm{HCOOH}$ on Silicon Photocathodes with Reduced SnO2 Porous Nanowire Catalysts. K. Ramachandra Rao, Sahar Pishgar, Jacob M. Strain, Bijandra Kumar, Veerendra Atla, Sudesh Kumari, Joshua Spurgeon Journal of Materials Chemistry A 2018, 6, 1736-1742. 


\section{Chapter 3 Supplementary Information}

\section{Membrane Soak NMR Spectra}

The following figures show example ${ }^{1} \mathrm{H}-\mathrm{NMR}$ spectra from untreated membrane soaks in $0.1 \mathrm{M} \mathrm{KOH}$. The contaminants present are listed in the caption of each figure. DMSO standard is located at $\delta=2.55 \mathrm{ppm}$. Acetone $(\delta=2.06 \mathrm{ppm})$, methanol $(\delta=3.20 \mathrm{ppm})$, and stearic acid $(\delta=1.07 \mathrm{ppm})$ may be present as well in small quantities. Water-saturated baseline correction leads to the observed data from $\delta=4.2-5.4$

Selemion AMV

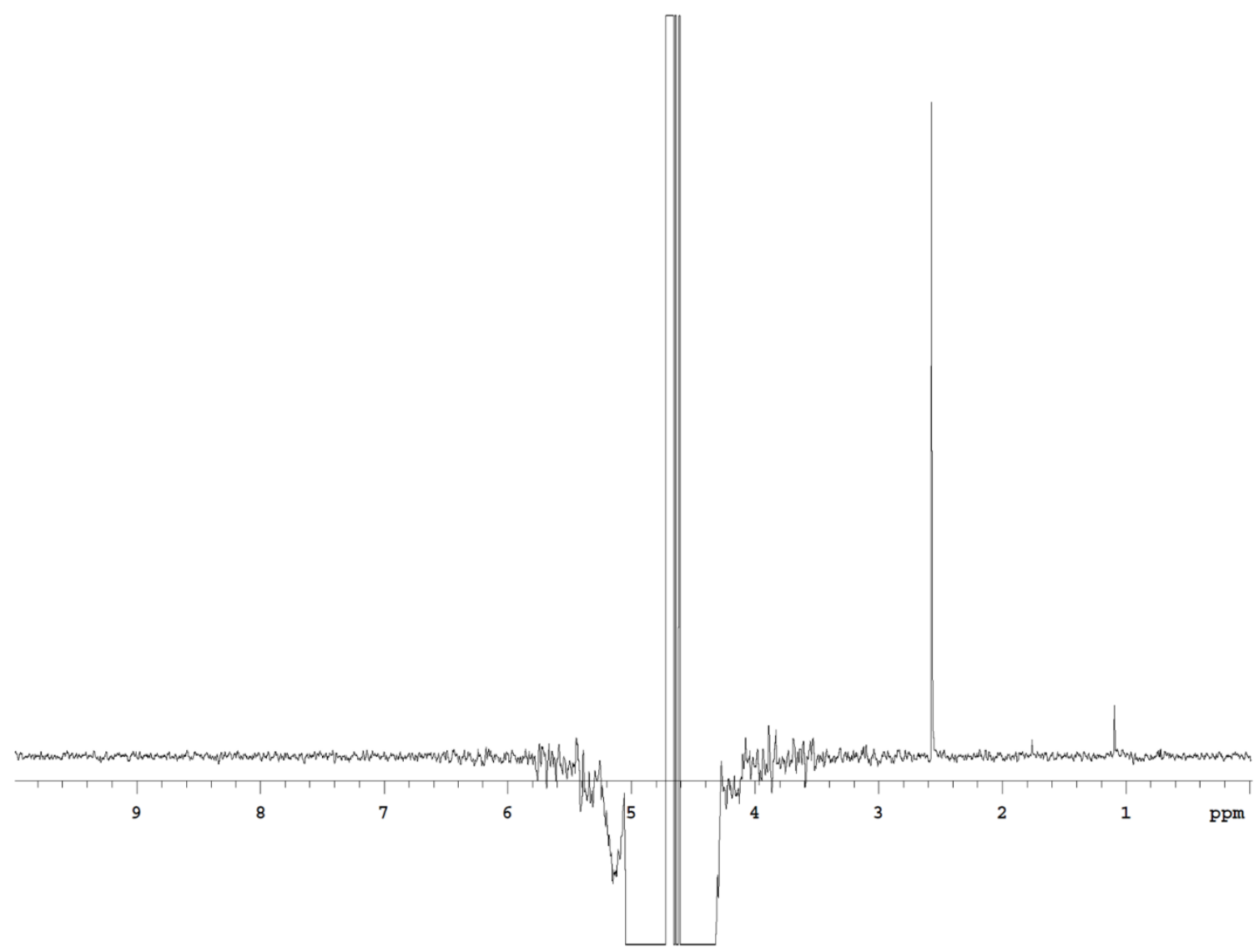

Figure A.2. Example ${ }^{1} \mathrm{H}-\mathrm{NMR}$ spectra for an aliquot of $0.1 \mathrm{M} \mathrm{KOH}$ after soaking untreated Selemion AMV for $2 \mathrm{~h}$. There were few contaminants. Stearic acid at $\delta=1.07 \mathrm{ppm}$ was present in all samples, even blank controls. 
Sustainion

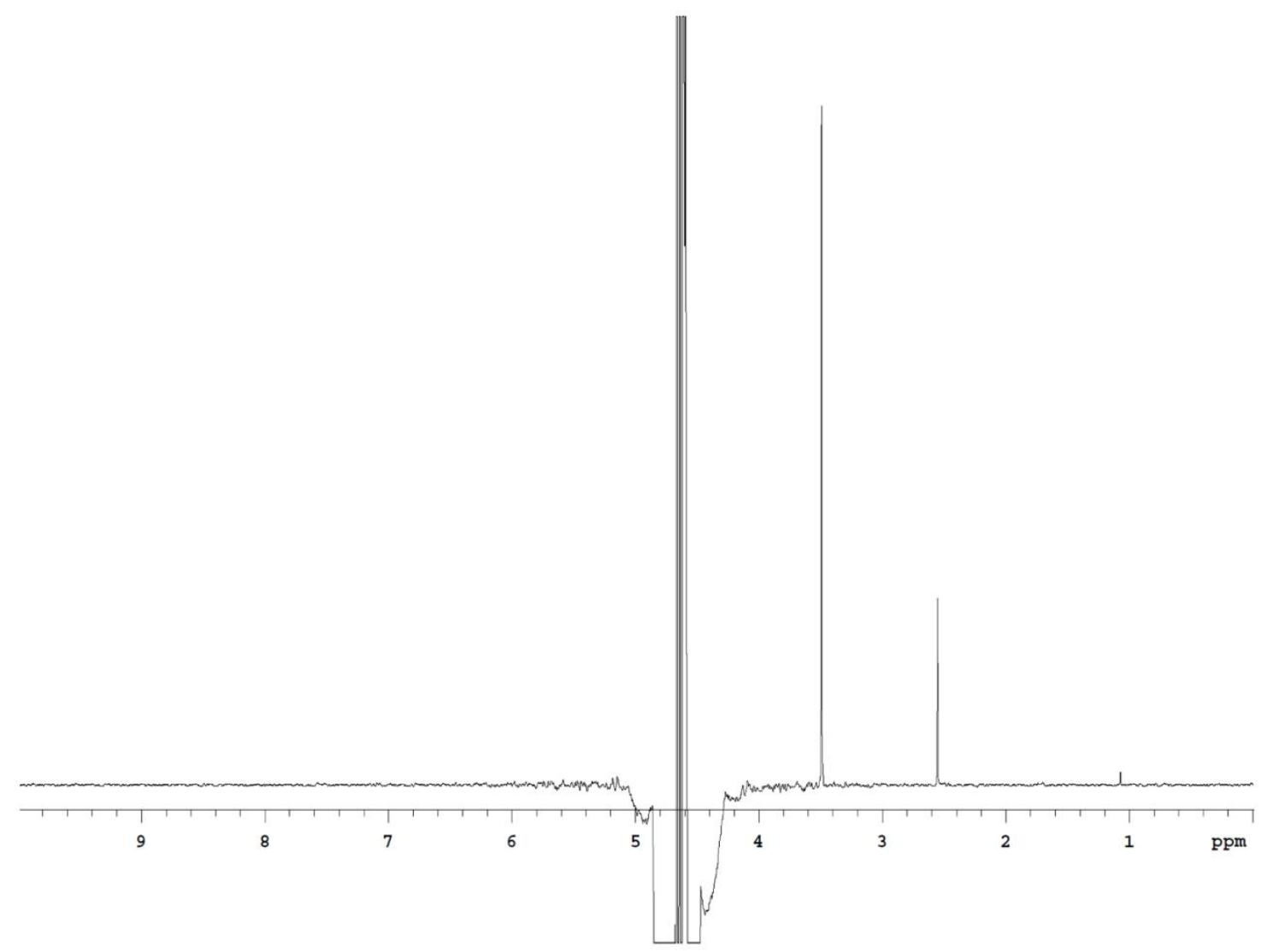

Figure A.2. Example ${ }^{1} \mathrm{H}-\mathrm{NMR}$ spectra for an aliquot of $0.1 \mathrm{M} \mathrm{KOH}$ after soaking untreated Sustainion for $2 \mathrm{~h}$. The primary contaminant was ethylene glycol at $\delta=3.52 \mathrm{ppm}$. Stearic acid at $\delta=1.07 \mathrm{ppm}$ was present in all samples, even blank controls. 


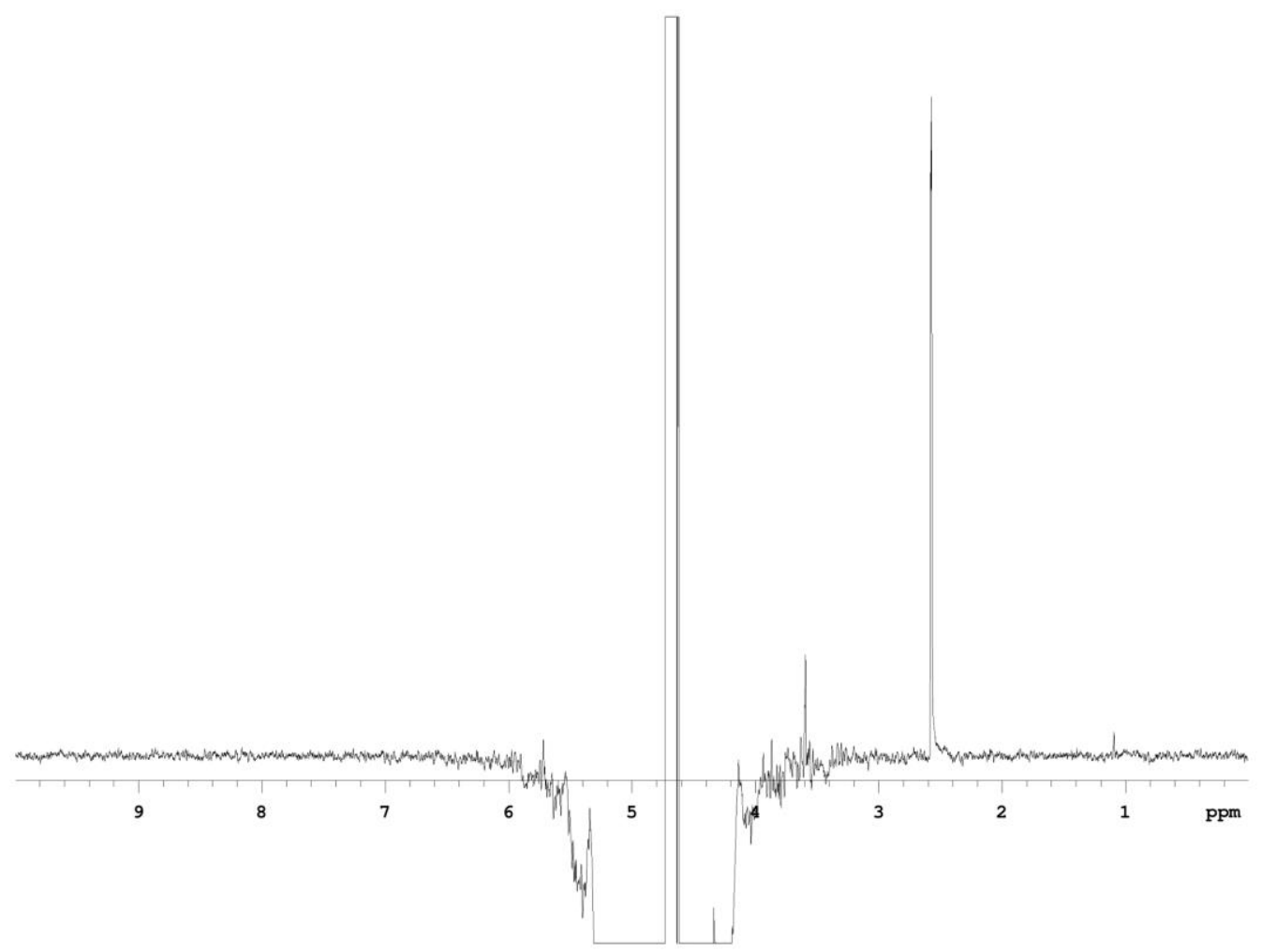

Figure A.3. Example ${ }^{1} \mathrm{H}-\mathrm{NMR}$ spectra for an aliquot of $0.1 \mathrm{M} \mathrm{KOH}$ after soaking untreated FumaSep FAPQ-375-PP for $2 \mathrm{~h}$. The primary contaminant was polyethylene glycol (PEG) at $\delta=$ $3.60 \mathrm{ppm}$. Stearic acid at $\delta=1.07 \mathrm{ppm}$ was present in all samples, even blank controls. 


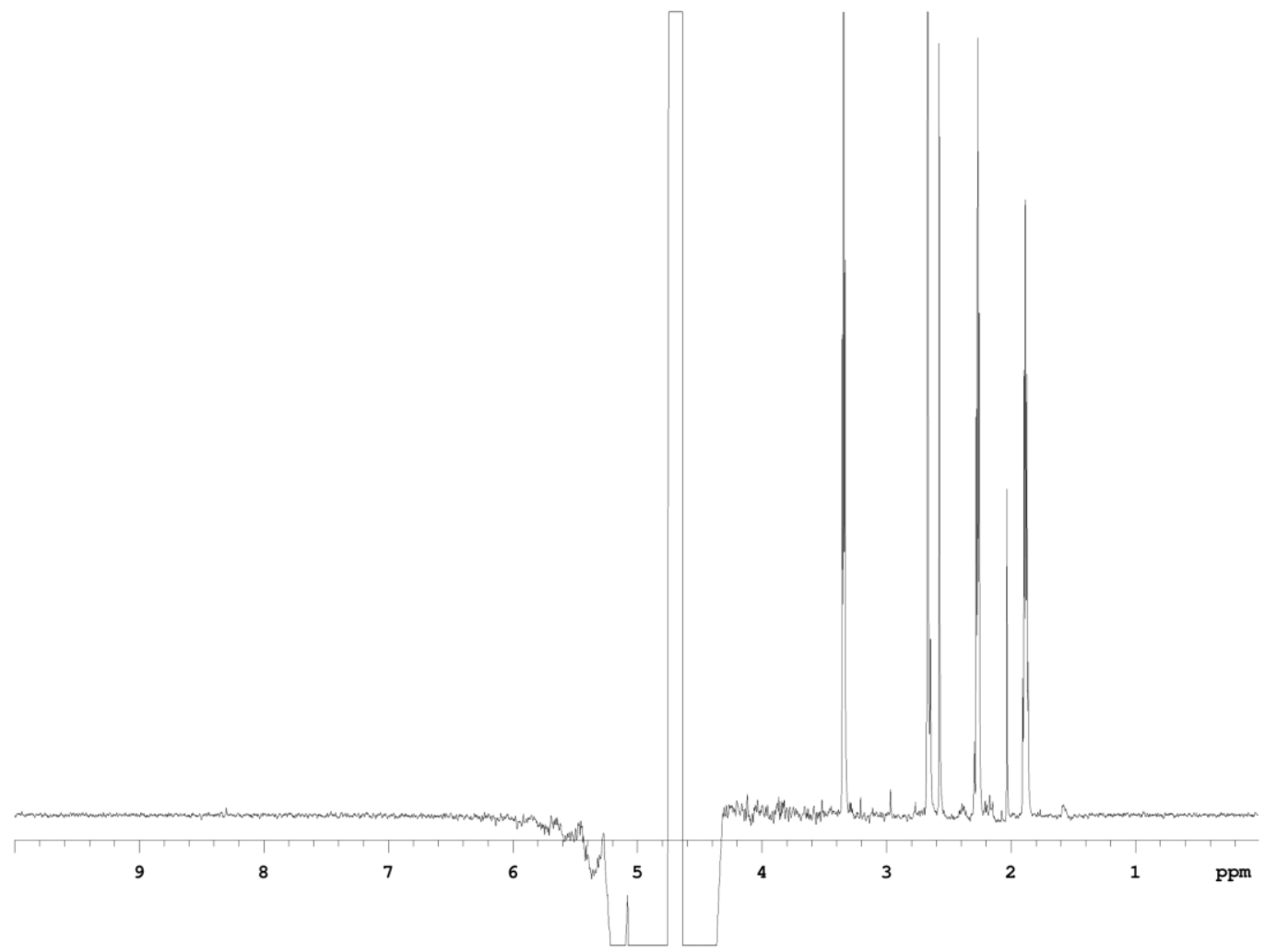

Figure A.4. Example ${ }^{1} \mathrm{H}-\mathrm{NMR}$ spectra for an aliquot of $0.1 \mathrm{M} \mathrm{KOH}$ after soaking untreated AMI7001 for $2 \mathrm{~h}$. The primary contaminant was $\mathrm{N}$-methyl-2-pyrollidinone (NMP) with peaks in chemical shift at $\delta=1.87,2.22,2.65$, and $3.30 \mathrm{ppm}$. 
CMI-7000

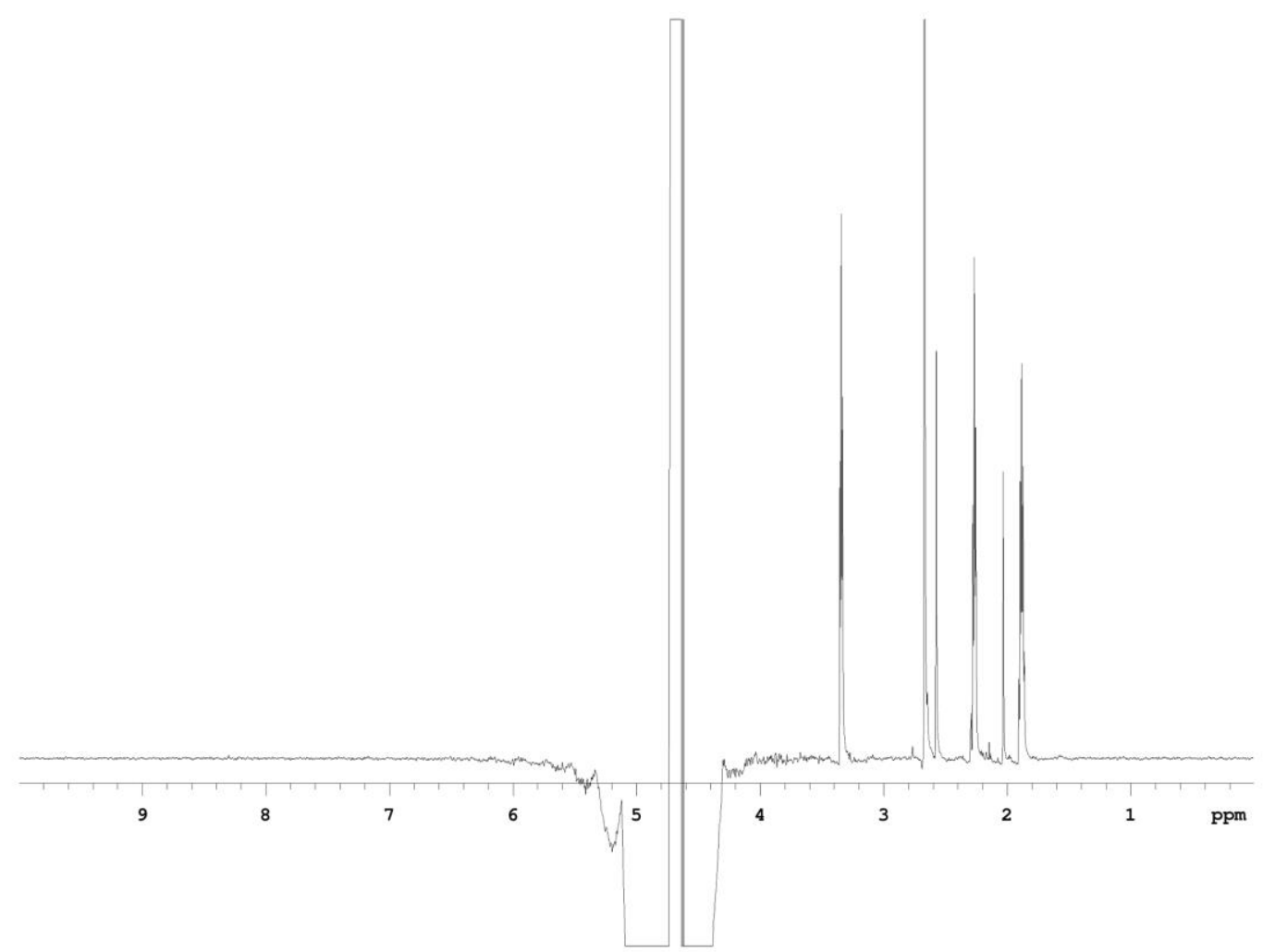

Figure. A.5. Example ${ }^{1} \mathrm{H}-\mathrm{NMR}$ spectra for an aliquot of $0.1 \mathrm{M} \mathrm{KOH}$ after soaking untreated CMI-7000 for $2 \mathrm{~h}$. The primary contaminant was N-methyl-2-pyrollidinone (NMP) with peaks in chemical shift at $\delta=1.87,2.22,2.65$, and $3.30 \mathrm{ppm}$. 
Nafion-117

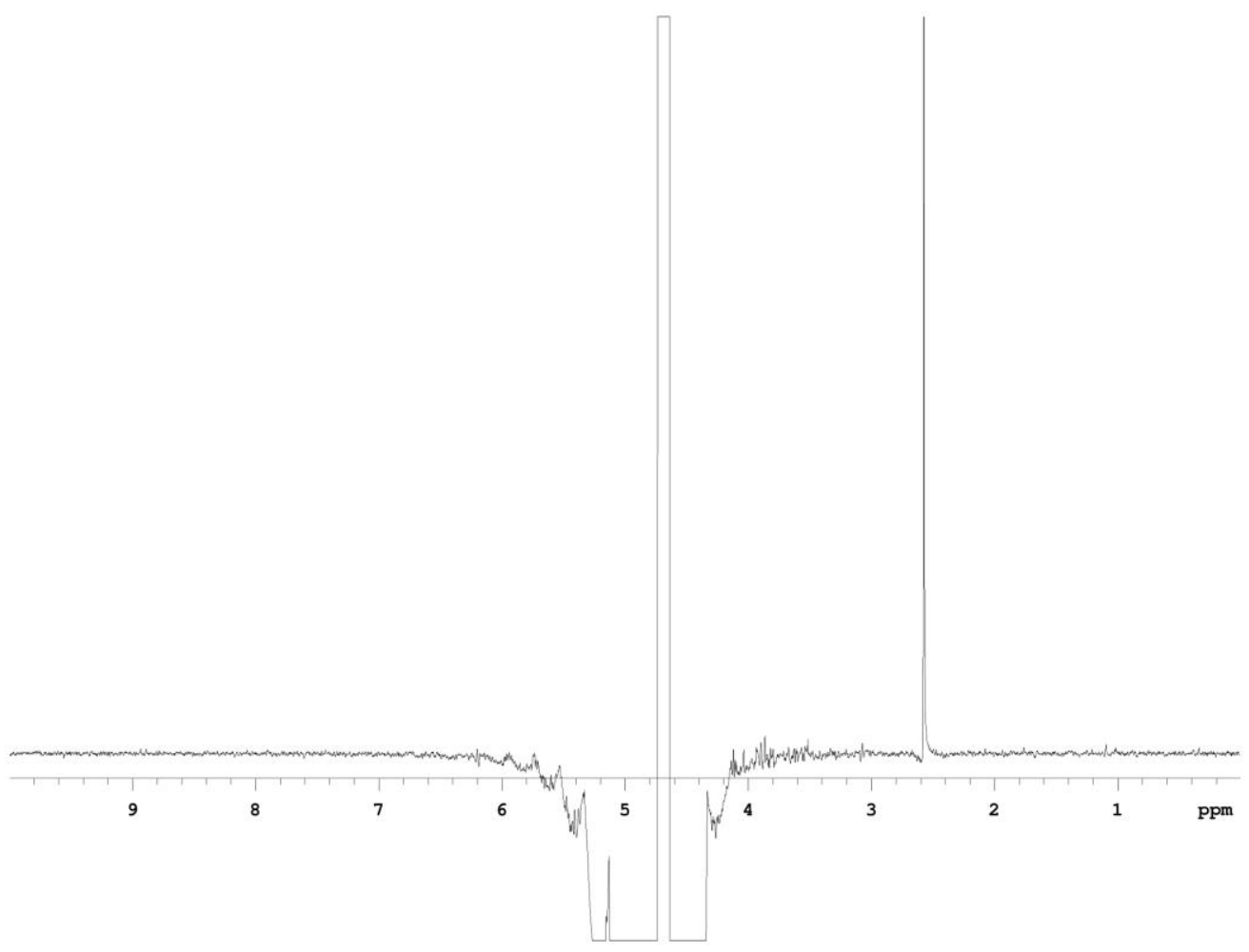

Figure A.6. Example ${ }^{1} \mathrm{H}-\mathrm{NMR}$ spectra for an aliquot of $0.1 \mathrm{M} \mathrm{KOH}$ after soaking untreated Nafion-117 for $2 \mathrm{~h}$. 
Nafion-115

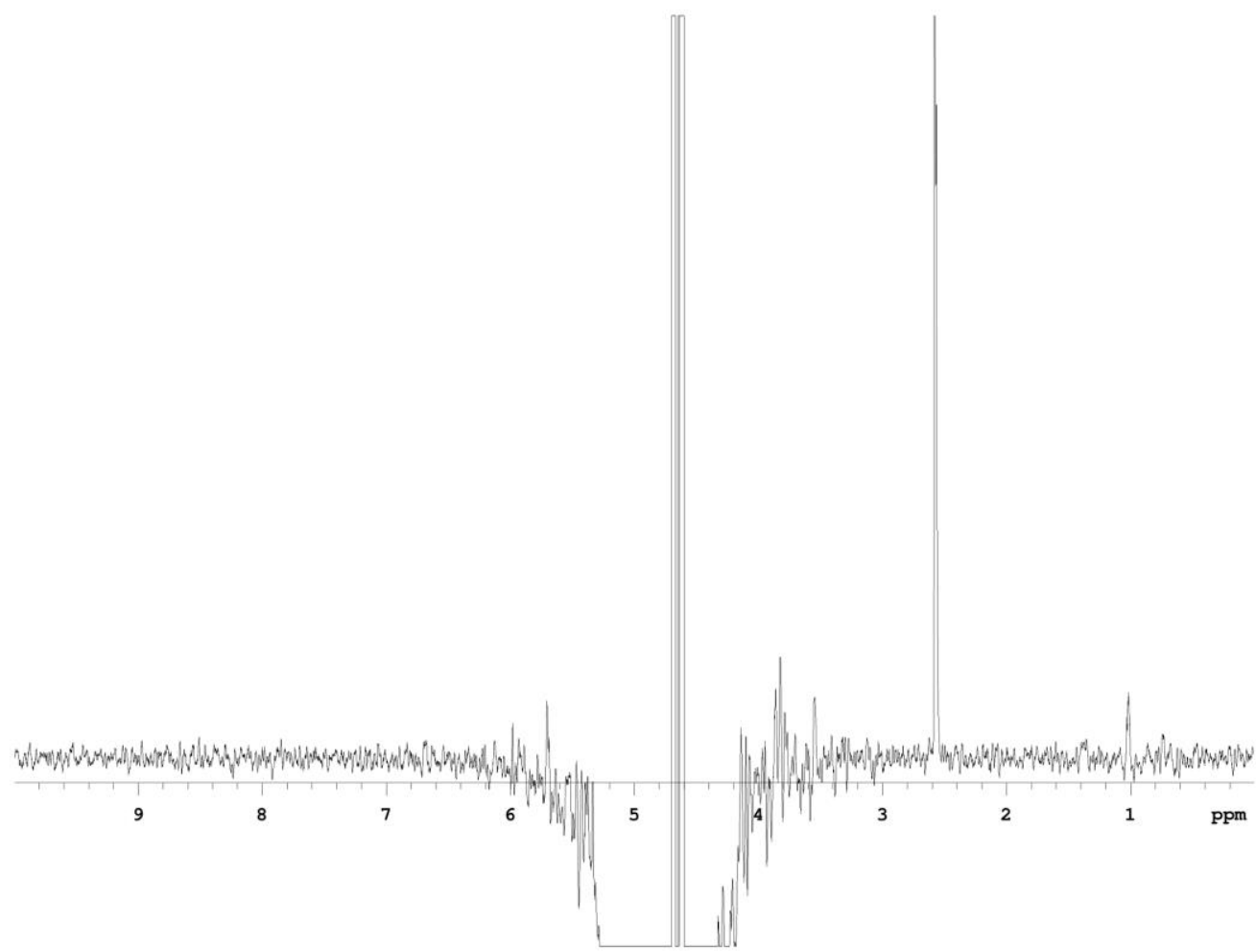

Figure A.7. Example ${ }^{1} \mathrm{H}-\mathrm{NMR}$ spectra for an aliquot of $0.1 \mathrm{M} \mathrm{KOH}$ after soaking untreated Nafion115 for $2 \mathrm{~h}$. Stearic acid at $\delta=1.07 \mathrm{ppm}$ was present in all samples, even blank controls. 


\section{Chapter 4 Supplementary Information}

\section{Electrochemical effect on formate production during CORR}

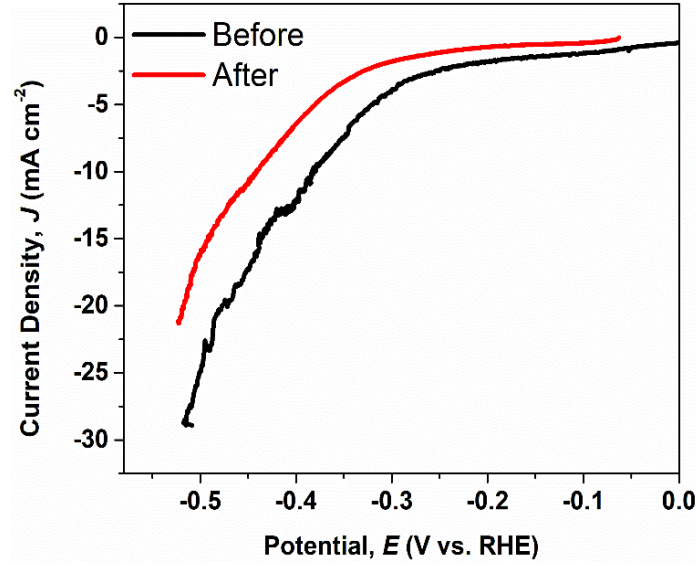

Fig. A.8. Example current density vs. potential behavior for $\mathrm{OD}-\mathrm{Cu}$ in $\mathrm{CO}$-saturated aqueous $0.1 \mathrm{M} \mathrm{KOH}$ before (black) and after (red) a 60 min measurement at $-0.25 \mathrm{~V}$ vs. RHE without pulsed bias.

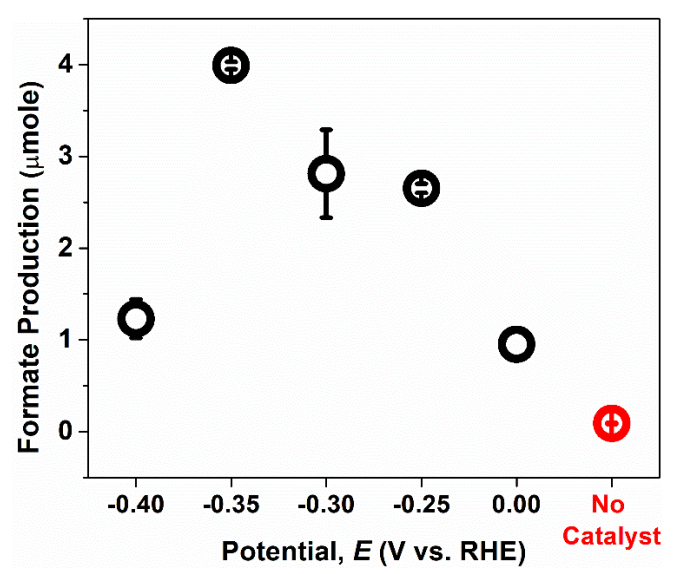

Fig. A.9. Production of formate detected with an OD-Cu electrode after potentiostatic operation for $60 \mathrm{~min}$ under active $\mathrm{CO}$ bubbling in $0.1 \mathrm{M}$ $\mathrm{KOH}$. The No Catalyst condition refers to the formate detected in the electrolyte in the absence of an OD-Cu electrode.

As described in the main manuscript, some researchers have attributed the presence of formate $\left(\mathrm{HCOO}^{-}\right)$during $\mathrm{CO}$ reduction to a purely non-electrochemical route involving hydration of the $\mathrm{CO}$ in alkaline electrolyte. As shown in Fig. A.9, however, the concentration of formate displayed a clear dependence on the applied potential during reactions, as well as the pulsed-bias condition as shown in Fig. 4.4. It has been known for many decades that carbon monoxide can combine with hydroxide to form formate, which is kinetically increased at higher temperature. The formate production observed in the absence of applied bias or faradaic current is attributed to slow rates of this reaction at room temperature:

$$
\mathrm{CO}+\mathrm{OH}^{-} \rightarrow \mathrm{HCOO}^{-}
$$

Under alkaline conditions such as the $0.1 \mathrm{M} \mathrm{KOH}$ electrolyte used herein, the hydrogen evolution reaction (HER) proceeds by: 


$$
2 \mathrm{H}_{2} \mathrm{O}+2 e^{-} \rightarrow 2 \mathrm{OH}^{-}+\mathrm{H}_{2}
$$

We thus propose that the observed dependence of the formate production on applied bias is attributable to locally generated $\mathrm{OH}^{-}$at the surface of the electrode in the vicinity of adsorbed $\mathrm{CO}$, leading to faster rates of reaction (1). The overall reaction is:

$$
2 \mathrm{H}_{2} \mathrm{O}+2 \mathrm{CO}+2 e^{-} \rightarrow 2 \mathrm{HCOO}^{-}+\mathrm{H}_{2}
$$

\section{Additional data for CORR on OD-Cu without pulsed-bias}

Table A.1. Data for CORR on OD-Cu without pulsed-bias, including applied potential (E), current density

\begin{tabular}{|c|c|c|c|c|c|c|c|c|c|}
\hline$E$ (V vs. RHE) & $\begin{array}{c}J \\
(\mathrm{~mA} \mathrm{~cm}) \\
\end{array}$ & Methane (\%) & Formate (\%) & $\begin{array}{c}\text { Ethanol } \\
(\%)\end{array}$ & $\begin{array}{c}\text { Acetate } \\
(\%)\end{array}$ & Propanol (\%) & Ethylene (\%) & $\begin{array}{c}\text { Ethane } \\
(\%)\end{array}$ & Hydrogen (\%) \\
\hline-0.25 & $0.79 \pm 0.12$ & 0 & $1.66 \pm 0.28$ & $6.41 \pm 0.75$ & $4.18 \pm 0.51$ & 0 & 0 & 0 & $48.5 \pm 9.4$ \\
\hline-0.30 & $1.48 \pm 0.32$ & 0 & $1.25 \pm 0.22$ & $12.2 \pm 1.7$ & $5.12 \pm 0.49$ & $0.09 \pm 0.02$ & 0 & 0 & $43.1 \pm 7.1$ \\
\hline-0.35 & $3.42 \pm 0.39$ & $3.14 \pm 0.06$ & $0.96 \pm 0.21$ & $20.7 \pm 1.2$ & $4.61 \pm 0.60$ & $0.35 \pm 0.12$ & 0 & 0 & $73.2 \pm 4.9$ \\
\hline-0.40 & $5.91 \pm 2.25$ & 0 & $0.60 \pm 0.24$ & $6.34 \pm 2.6$ & $0.86 \pm 0.34$ & 0 & $4.73 \pm 2.40$ & $3.29 \pm 1.19$ & $84.3 \pm 3.4$ \\
\hline
\end{tabular}
$(\mathrm{J})$, and the measured product faradaic efficiencies $(\%)$.

\section{Surface roughness effects due to pulsed-bias electrolysis}

The effect of the pulsed-bias conditions on the OD-Cu catalyst morphology was investigated. Representative SEM images of some of the catalyst surfaces after $1 \mathrm{~h}$ $\mathrm{CO}$ reduction measurements are shown in Fig. A.10, with more pulse-timedependent images in Figs. A.11-12. Although some additional nanoscopic roughness and surface bump formations appear to arise when the applied potential was pulsed rather than continuous, no conclusive trend in morphology with pulse time was immediately evident.

For a more quantitative comparison of surface morphology, scan-dependent measurements were made of the surface roughness as determined by double-layer 
capacitance compared to the approximate capacitance of an atomically smooth $\mathrm{Cu}$ foil. Fig. A.13 shows data for an example double-layer capacitance measurement. Though quantitative, the accuracy of this measurement is limited. Significant variability arises from error inherent in the technique as well as variation in the initial OD-Cu oxide thickness, which subsequently affects the depth of the $\mathrm{Cu}$ nanostructures and corresponding roughness. Table A.2 shows the average measured capacitance and roughness values before and after $1 \mathrm{~h}$ pulsed-bias electrolysis measurements for a range of pulse times. Although no trend in roughness with pulse time is evident, all samples displayed an overall decrease in surface roughness after electrolysis ranging from $8-47 \%$. Reduced surface roughness for OD-Cu over extended electrolysis has been previously reported. The reduced surface roughness is consistent with some $\mathrm{Cu}$ nanostructures breaking off during electrolysis and correlates to the gradual decrease in current density observed during a potentiostatic measurement. However, the lack of a clear pulse-timedependent effect on the roughness indicates that the product variability with pulse time is more strongly dependent on dynamic electrochemical and mass transport behavior than on in situ changes in surface area and catalyst sites. 


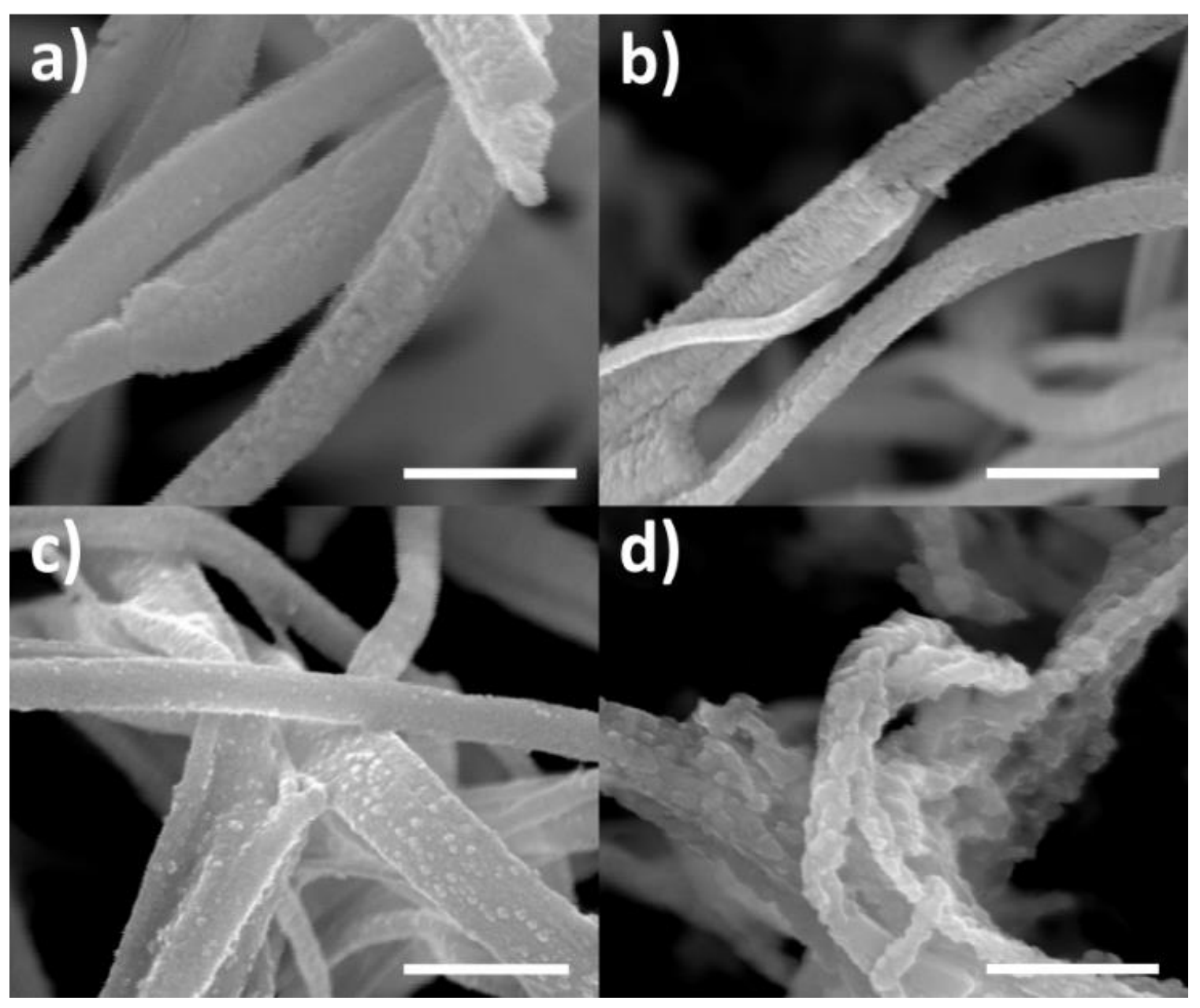

Fig. A.10. SEM images of the OD-Cu surface nanostructure after a $1 \mathrm{~h}$ of electrolysis at (a) continuous potentiostatic conditions, and pulsed-bias conditions of (b) $25 \mathrm{~s}$, (c) $1 \mathrm{~s}$, and (d) $50 \mathrm{~ms}$ pulse times. The scale bar is $500 \mathrm{~nm}$. 


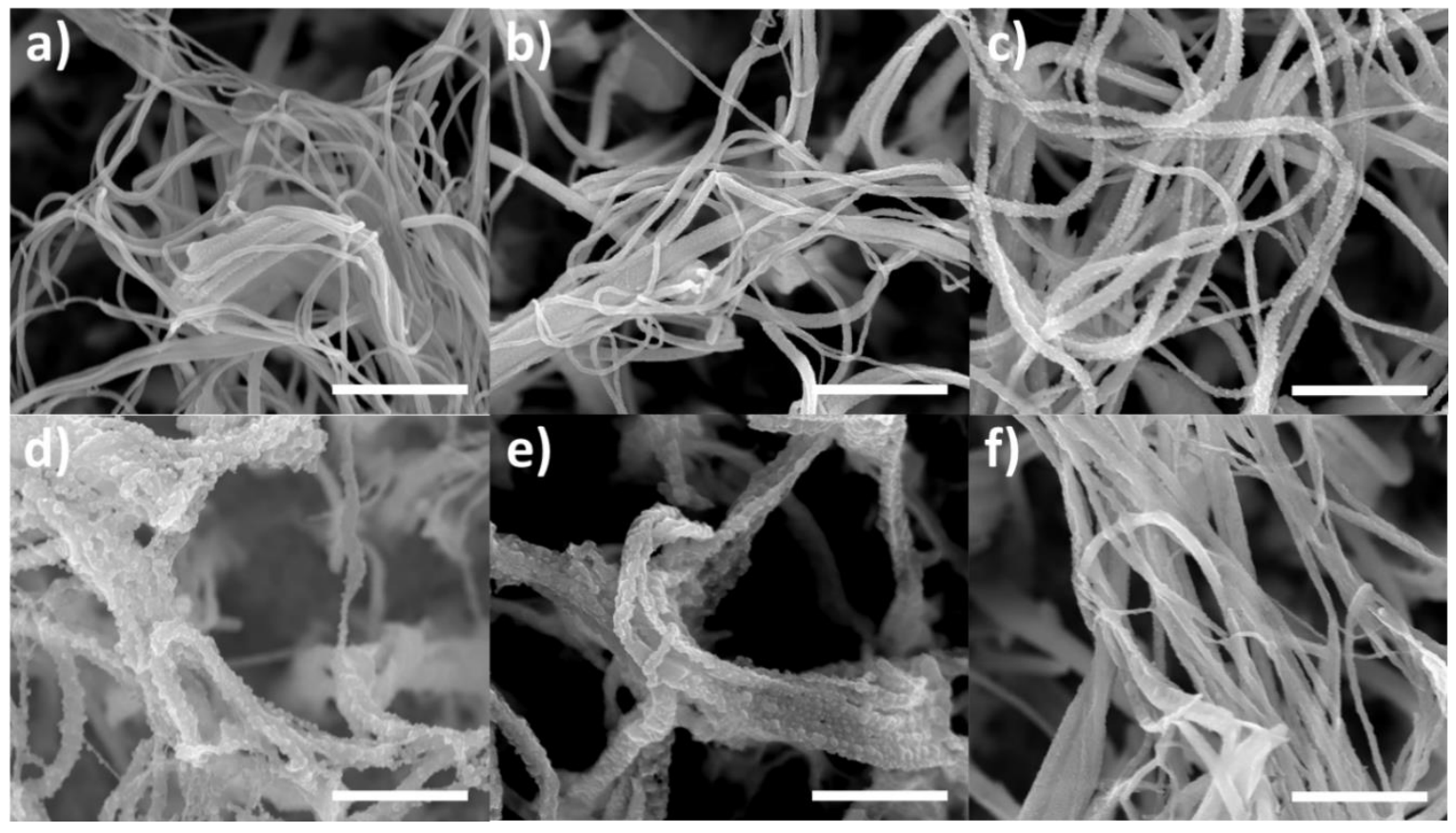

Fig. A.11. SEM images of the OD-Cu surface nanostructure after a $1 \mathrm{~h}$ electrolysis at pulsed-bias conditions of (a) $25 \mathrm{~s}$, (b) $5 \mathrm{~s}$, (c) $1 \mathrm{~s}$, (d) $100 \mathrm{~ms}$, (e) $50 \mathrm{~ms}$, and (f) $10 \mathrm{~ms}$. The scale bar is $1 \mu \mathrm{m}$.

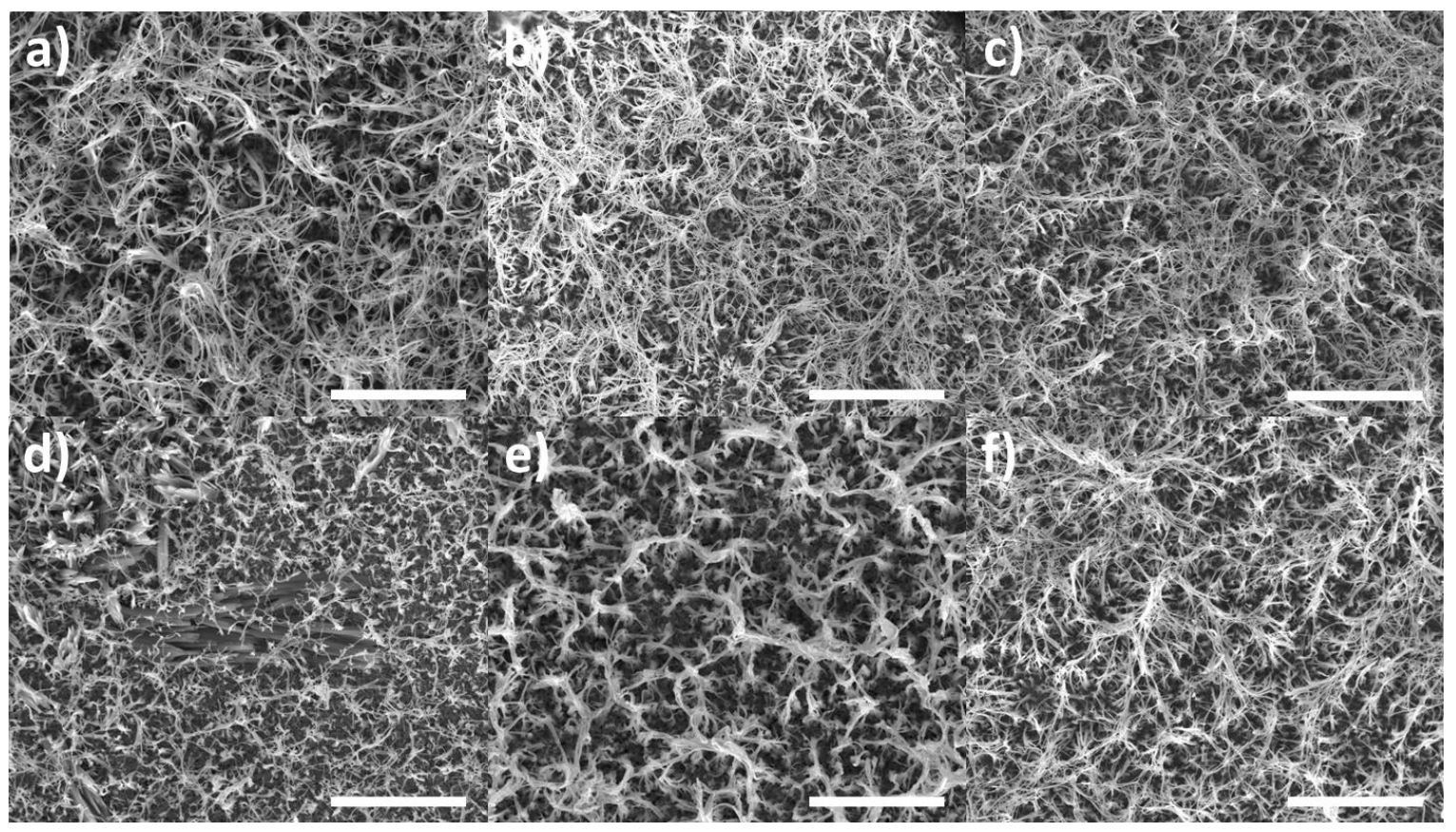

Fig. A.12. SEM images of the OD-Cu surface nanostructure after a $1 \mathrm{~h}$ electrolysis at pulsed-bias conditions of (a) $25 \mathrm{~s}$, (b) $5 \mathrm{~s}$, (c) $1 \mathrm{~s}$, (d) $100 \mathrm{~ms}$, (e) $50 \mathrm{~ms}$, and (f) $10 \mathrm{~ms}$. The scale bar is $10 \mu \mathrm{m}$. 

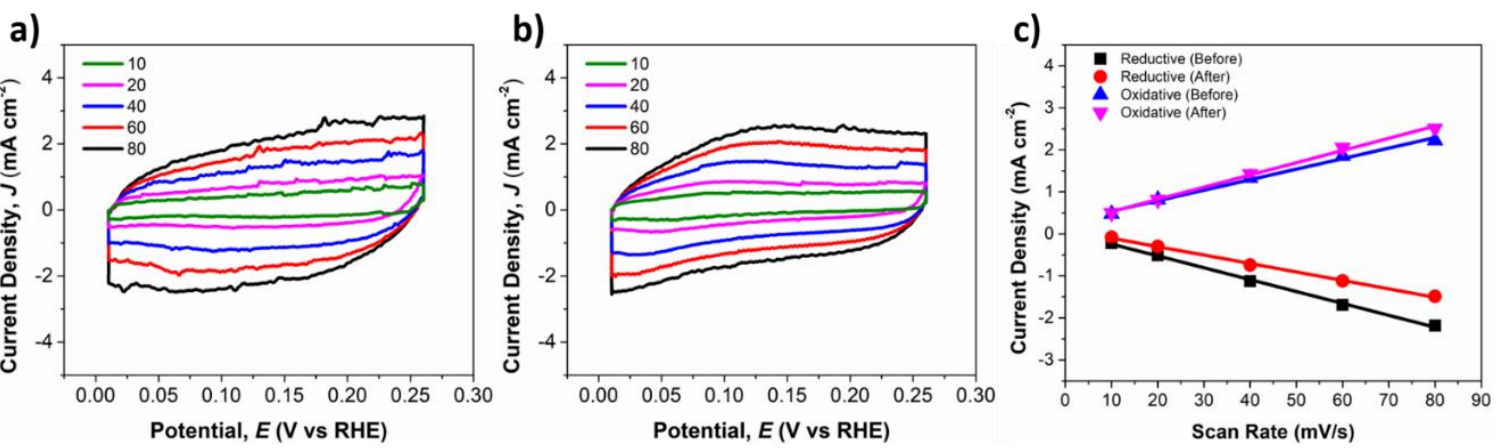

Fig. A.13. Example data for scan-rate dependent measurement of double-layer capacitance, for $50 \mathrm{~ms}$ pulse time conditions. Current density vs. potential with varying scan rate (a) before and (b) after $1 \mathrm{~h}$ pulsed-bias electrolysis. (c) Current density vs. scan rate for the oxidative (top) and reductive (bottom) sweeps before and after electrolysis.

Table A.2. Double-layer capacitance measurement data with varying pulse time, before and after $1 \mathrm{~h}$ electrolysis measurements.

\begin{tabular}{|c|c|c|c|c|c|c|c|c|c|c|c|c|}
\hline \multirow[t]{2}{*}{ Pulse Time } & \multicolumn{2}{|c|}{$10 \mathrm{~ms}$} & \multicolumn{2}{|c|}{$50 \mathrm{~ms}$} & \multicolumn{2}{|c|}{$100 \mathrm{~ms}$} & \multicolumn{2}{|c|}{$1 \mathrm{~s}$} & \multicolumn{2}{|c|}{$5 \mathrm{~s}$} & \multicolumn{2}{|c|}{$25 \mathrm{~s}$} \\
\hline & Before & After & Before & After & Before & After & Before & After & Before & After & Before & After \\
\hline $\begin{array}{l}\text { Reductive } \\
\text { (mF) }\end{array}$ & 39.3 & 22.0 & 28.3 & 20.1 & 20.1 & 11.8 & 36.0 & 27.0 & 44.6 & 32.7 & 43.3 & 21.4 \\
\hline $\begin{array}{c}\text { Oxidative } \\
(\mathrm{mF})\end{array}$ & 48.7 & 27.1 & 25.0 & 29.0 & 24.1 & 12.6 & 34.5 & 24.4 & 44.4 & 33.9 & 40.7 & 22.8 \\
\hline $\begin{array}{c}\text { Average } \\
(\mathrm{mF})\end{array}$ & 44.0 & 24.6 & 26.7 & 24.6 & 22.1 & 12.2 & 35.2 & 25.7 & 44.5 & 33.3 & 42.0 & 22.1 \\
\hline $\begin{array}{l}\text { Roughness } \\
\text { Factor }\end{array}$ & 1517 & 848 & 919 & 847 & 762 & 419 & 1215 & 886 & 1536 & 1146 & 1449 & 762 \\
\hline
\end{tabular}




\section{Additional data for CORR on OD-Cu with pulsed-bias}

Table A.3. Product distribution by charge (\%) data for CORR on $\mathrm{OD}-\mathrm{Cu}$ in $0.1 \mathrm{M} \mathrm{KOH}$ with pulsed-bias conditions between $\mathrm{E}_{\mathrm{c}}=$ $-0.35 \mathrm{~V}$ vs. RHE and $\mathrm{E}_{\mathrm{r}}=0 \mathrm{~V}$ vs. RHE.

\begin{tabular}{cccccc}
\hline Pulse (s) & $\begin{array}{c}\text { Ethanol } \\
\text { (\%) }\end{array}$ & $\begin{array}{c}\text { Acetate } \\
\text { (\%) }\end{array}$ & $\begin{array}{c}\text { Methane } \\
\text { (\%) }\end{array}$ & $\begin{array}{c}\text { Formate } \\
\text { (\%) }\end{array}$ & $\begin{array}{c}\text { Hydrogen } \\
(\%)\end{array}$ \\
\hline 0.01 & 0.06 & 2.05 & 57.78 & 10.69 & 29.32 \\
0.05 & 7.71 & 3.40 & 34.09 & 22.41 & 32.39 \\
0.1 & 0.74 & 4.02 & 34.54 & 31.43 & 29.26 \\
1 & 1.88 & 0.61 & 15.40 & 5.54 & 75.60 \\
5 & 1.38 & 0.74 & 5.79 & 1.41 & 90.44 \\
25 & 2.18 & 0.51 & 4.15 & 0.73 & 92.43 \\
50 & 1.94 & 0.89 & 8.10 & 0.93 & 88.14 \\
1800 & 3.00 & 1.04 & 8.88 & 0.08 & 87 \\
No pulse & 19.7 & 4.61 & 3.14 & 0.96 & 68.20 \\
\hline
\end{tabular}

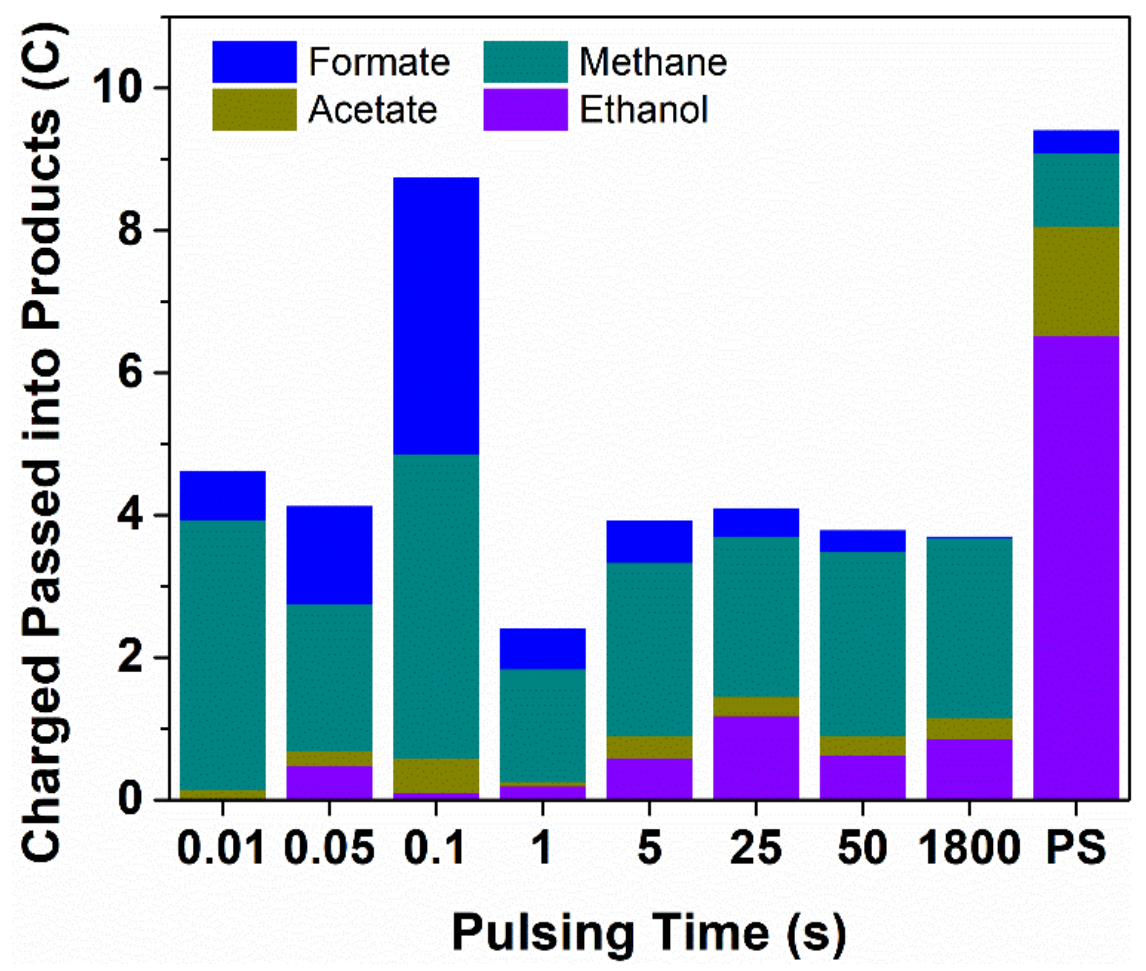

Fig. A.14. The total charge passed only into the detected CORR products. The "PS" condition refers to a potentiostatic measurement at $-0.35 \mathrm{~V}$ vs. RHE for $60 \mathrm{~min}$. 


\section{APPENDIX REFERENCES}

1. Goodwin, P.; Katavouta, A.; Roussenov, V. M.; Foster, G. L.; Rohling, E. J.; Williams, R. G., Pathways to 1.5 degrees $C$ and 2 degrees $C$ warming based on observational and geological constraints. Nature Geoscience 2018, 11 (2), 102-+.

2. Peter, S. C., Reduction of $\mathrm{CO} 2$ to Chemicals and Fuels: A Solution to Global Warming and Energy Crisis. Acs Energy Letters 2018, 3 (7), 1557-1561.

3. Reisinger, A.; Clark, H., How much do direct livestock emissions actually contribute to global warming? Global Change Biology 2018, 24 (4), 1749-1761.

4. Wigley, T. M. L., The Paris warming targets: emissions requirements and sea level consequences. Climatic Change 2018, 147 (1-2), 31-45.

5. $\quad$ Falkowski, P.; Scholes, R. J.; Boyle, E.; Canadell, J.; Canfield, D.; Elser, J.; Gruber, N.; Hibbard, K.; Hogberg, P.; Linder, S.; Mackenzie, F. T.; Moore, B.; Pedersen, T.; Rosenthal, Y.; Seitzinger, S.; Smetacek, V.; Steffen, W., The global carbon cycle: A test of our knowledge of earth as a system. Science 2000, 290 (5490), 291-296.

6. Wu, H.-L.; Li, X.-B.; Tung, C.-H.; Wu, L.-Z., Semiconductor Quantum Dots: An Emerging Candidate for CO2 Photoreduction. Advanced Materials 2019, 31 (36).

7. Zachos, J. C.; Dickens, G. R.; Zeebe, R. E., An early Cenozoic perspective on greenhouse warming and carbon-cycle dynamics. Nature 2008, 451 (7176), 279-283.

8. Dong, F.; Wang, Y.; Su, B.; Hua, Y.; Zhang, Y., The process of peak $\mathrm{CO} 2$ emissions in developed economies: A perspective of industrialization and urbanization. Resources Conservation and Recycling 2019, 141, 61-75.

9. Huang, C.-H.; Tan, C.-S., A Review: $\mathrm{CO} 2$ Utilization. Aerosol and Air Quality Research 2014, 14 (2), 480-499.

10. Mardani, A.; Streimikiene, D.; Cavallaro, F.; Loganathan, N.; Khoshnoudi, M., Carbon dioxide (CO2) emissions and economic growth: A systematic review of two decades of research from 1995 to 2017. Science of the Total Environment 2019, 649, 31-49.

11. Detz, R. J.; van der Zwaan, B., Transitioning towards negative $\mathrm{CO} 2$ emissions. Energy Policy 2019, 133.

12. Kaya, Y.; Yamaguchi, M.; Geden, O., Towards net zero $\mathrm{CO} 2$ emissions without relying on massive carbon dioxide removal. Sustainability Science 2019, 14 (6), 1739-1743.

13. Wei, Y.; Li, Y.; Wu, M.; Li, Y., The decomposition of total-factor CO2 emission efficiency of 97 contracting countries in Paris Agreement. Energy Economics 2019, 78, 365-378.

14. Arellano-Trevino, M. A.; Kanani, N.; Jeong-Potter, C. W.; Farrauto, R. J., Bimetallic catalysts for $\mathrm{CO} 2$ capture and hydrogenation at simulated flue gas conditions. Chemical Engineering Journal 2019, 375.

15. Kar, S.; Goeppert, A.; Prakash, G. K. S., Combined CO2 Capture and Hydrogenation to Methanol: Amine Immobilization Enables Easy Recycling of Active Elements.

Chemsuschem 2019, 12 (13), 3172-3177. 
16. Li, L.; Zhao, N.; Wei, W.; Sun, Y., A review of research progress on CO2 capture, storage, and utilization in Chinese Academy of Sciences. Fuel 2013, 108, 112-130.

17. Pelletier, C.; Rogaume, Y.; Dieckhoff, L.; Bardeau, G.; Pons, M.-N.; Dufour, A., Effect of combustion technology and biogenic $\mathrm{CO} 2$ impact factor on global warming potential of wood-to-heat chains. Applied Energy 2019, 235, 1381-1388.

18. Pipes, R.; Bhargav, A.; Manthiram, A., Phenyl Disulfide Additive for Solution-Mediated Carbon Dioxide Utilization in Li-CO2 Batteries. Advanced Energy Materials 2019, 9 (21).

19. Song, C.; Liu, Q.; Deng, S.; Li, H.; Kitamura, Y., Cryogenic-based CO2 capture technologies: State-of-the-art developments and current challenges. Renewable \& Sustainable Energy Reviews 2019, 101, 265-278.

20. Yu, K. M. K.; Curcic, I.; Gabriel, J.; Tsang, S. C. E., Recent Advances in CO2 Capture and Utilization. Chemsuschem 2008, 1 (11), 893-899.

21. Jung, S.; Park, Y.-K.; Kwon, E. E., Strategic use of biochar for $\mathrm{CO} 2$ capture and sequestration. Journal of Co2 Utilization 2019, 32, 128-139.

22. Pastero, L.; Curetti, N.; Ortenzi, M. A.; Schiavoni, M.; Destefanis, E.; Pavese, A., CO2 capture and sequestration in stable $\mathrm{Ca}$-oxalate, via $\mathrm{Ca}$-ascorbate promoted green reaction. Science of the Total Environment 2019, 666, 1232-1244.

23. Yang, H.-J.; Yang, H.; Hong, Y.-H.; Zhang, P.-Y.; Wang, T.; Chen, L.-N.; Zhang, F.-Y.; Wu, Q.-H.; Tian, N.; Zhou, Z.-Y.; Sun, S.-G., Promoting Ethylene Selectivity from CO2 Electroreduction on CuO Supported onto CO2 Capture Materials. Chemsuschem 2018, 11 (5), 881-887.

24. Aljabour, A.; Coskun, H.; Apaydin, D. H.; Ozel, F.; Hassel, A. W.; Stadler, P.; Sariciftci, N. S.; Kus, M., Nanofibrous cobalt oxide for electrocatalysis of $\mathrm{CO} 2$ reduction to carbon monoxide and formate in an acetonitrile-water electrolyte solution. Applied Catalysis BEnvironmental 2018, 229, 163-170.

25. Duan, Y.-X.; Meng, F.-L.; Liu, K.-H.; Yi, S.-S.; Li, S.-J.; Yan, J.-M.; Jiang, Q., Amorphizing of $\mathrm{Cu}$ Nanoparticles toward Highly Efficient and Robust Electrocatalyst for $\mathrm{CO} 2$ Reduction to Liquid Fuels with High Faradaic Efficiencies. Advanced Materials 2018, 30 (14).

26. Kar, S.; Goeppert, A.; Galvan, V.; Chowdhury, R.; Olah, J.; Prakash, G. K. S., A CarbonNeutral CO2 Capture, Conversion, and Utilization Cycle with Low-Temperature Regeneration of Sodium Hydroxide. Journal of the American Chemical Society 2018, 140 (49), 16873-16876.

27. Krieg, T.; Sydow, A.; Faust, S.; Huth, I.; Holtmann, D., CO2 to Terpenes: Autotrophic and Electroautotrophic alpha-Humulene Production with Cupriavidus necator.

Angewandte Chemie-International Edition 2018, 57 (7), 1879-1882.

28. Kumar, A.; Semwal, S.; Choudhury, J., Catalytic Conversion of $\mathrm{CO} 2$ to Formate with Renewable Hydrogen Donors: An Ambient-Pressure and H-2-Independent Strategy. Acs Catalysis 2019, 9 (3), 2164-2168.

29. Ma, W.; Wang, H.; Yu, W.; Wang, X.; Xu, Z.; Zong, X.; Li, C., Achieving Simultaneous $\mathrm{CO} 2$ and H2S Conversion via a Coupled Solar-Driven Electrochemical Approach on NonPrecious-Metal Catalysts. Angewandte Chemie-International Edition 2018, 57 (13), 34733477.

30. Moioli, E.; Mutschler, R.; Zuettel, A., Renewable energy storage via CO2 and H-2 conversion to methane and methanol: Assessment for small scale applications. Renewable \& Sustainable Energy Reviews 2019, 107, 497-506. 
31. Shi, Z.; Yang, H.; Gao, P.; Li, X.; Zhong, L.; Wang, H.; Liu, H.; Wei, W.; Sun, Y., Direct conversion of $\mathrm{CO} 2$ to long-chain hydrocarbon fuels over K-promoted $\mathrm{CoCu} / \mathrm{TiO} 2$ catalysts. Catalysis Today 2018, 311, 65-73.

32. Trickett, C. A.; Helal, A.; Al-Maythalony, B. A.; Yamani, Z. H.; Cordova, K. E.; Yaghi, O. M., The chemistry of metal-organic frameworks for $\mathrm{CO} 2$ capture, regeneration and conversion. Nature Reviews Materials 2017, 2 (8).

33. Wu, X.; Li, Y.; Zhang, G.; Chen, H.; Li, J.; Wang, K.; Pan, Y.; Zhao, Y.; Sun, Y.; Xie, Y., Photocatalytic CO2 Conversion of M0.33WO3 Directly from the Air with High Selectivity: Insight into Full Spectrum-Induced Reaction Mechanism. Journal of the American Chemical Society 2019, 141 (13), 5267-5274.

34. Zain, M. M.; Mohamed, A. R., An overview on conversion technologies to produce value added products from $\mathrm{CH} 4$ and $\mathrm{CO} 2$ as major biogas constituents. Renewable \& Sustainable Energy Reviews 2018, 98, 56-63.

35. Zheng, T.; Jiang, K.; Wang, H., Recent Advances in Electrochemical CO2-to-CO Conversion on Heterogeneous Catalysts. Advanced Materials 2018, 30 (48).

36. Cardias, B. B.; de Morais, M. G.; Vieira Costa, J. A., CO2 conversion by the integration of biological and chemical methods: Spirulina sp LEB 18 cultivation with diethanolamine and potassium carbonate addition. Bioresource Technology 2018, 267, 77-83.

37. Efrati, A.; Lu, C.-H.; Michaeli, D.; Nechushtai, R.; Alsaoub, S.; Schuhmann, W.; Willner, I., Assembly of photo-bioelectrochemical cells using photosystem I-functionalized electrodes. Nature Energy 2016, 1.

38. Liu, X.; Kang, F.; Hu, C.; Wang, L.; Xu, Z.; Zheng, D.; Gong, W.; Lu, Y.; Ma, Y.; Wang, J., A genetically encoded photosensitizer protein facilitates the rational design of a miniature photocatalytic CO2-reducing enzyme. Nature Chemistry 2018, 10 (12), 12011206.

39. Rittmann, S. K. M. R.; Seifert, A. H.; Bernacchi, S., Kinetics, multivariate statistical modelling, and physiology of $\mathrm{CO}$-based biological methane production. Applied Energy 2018, 216, 751-760.

40. Savvas, S.; Donnelly, J.; Patterson, T.; Chong, Z. S.; Esteves, S. R., Biological methanation of $\mathrm{CO} 2$ in a novel biofilm plug-flow reactor: $\mathrm{A}$ high rate and low parasitic energy process. Applied Energy 2017, 202, 238-247.

41. Singh, R. K.; Singh, R.; Sivakumar, D.; Kondaveeti, S.; Kim, T.; Li, J.; Sung, B. H.; Cho, B.-K.; Kim, D. R.; Kim, S. C.; Kalia, V. C.; Zhang, Y.-H. P. J.; Zhao, H.; Kang, Y. C.; Lee, J.K., Insights into Cell-Free Conversion of $\mathrm{CO} 2$ to Chemicals by a Multienzyme Cascade Reaction. Acs Catalysis 2018, 8 (12), 11085-11093.

42. Yang, H.-Y.; Bao, B.-L.; Liu, J.; Qin, Y.; Wang, Y.-R.; Su, K.-Z.; Han, J.-C.; Mu, Y., Temperature dependence of bioelectrochemical $\mathrm{CO} 2$ conversion and methane production with a mixed-culture biocathode. Bioelectrochemistry 2018, 119, 180-188.

43. Grills, D. C.; Farrington, J. A.; Layne, B. H.; Lymar, S. V.; Mello, B. A.; Preses, J. M.; Wishart, J. F., Mechanism of the Formation of a Mn-Based CO2 Reduction Catalyst Revealed by Pulse Radiolysis with Time-Resolved Infrared Detection. Journal of the American Chemical Society 2014, 136 (15), 5563-5566.

44. Grodkowski, J.; Neta, P., Copper-catalyzed radiolytic reduction of $\mathrm{CO} 2$ to $\mathrm{CO}$ in aqueous solutions. Journal of Physical Chemistry B 2001, 105 (21), 4967-4972.

45. Lisovskaya, A.; Bartels, D. M., Reduction of $\mathrm{CO} 2$ by hydrated electrons in high temperature water. Radiation Physics and Chemistry 2019, 158, 61-63.

46. Currie, R.; Mottaghi-Tabar, S.; Zhuang, Y.; Simakov, D. S. A., Design of an Air-Cooled Sabatier Reactor for Thermocatalytic Hydrogenation of CO2: Experimental Proof-of- 
Concept and Model-Based Feasibility Analysis. Industrial \& Engineering Chemistry Research 2019, 58 (29), 12964-12980.

47. Bai, Y.; Zhao, J.; Feng, S.; Liang, X.; Wang, C., Light-driven thermocatalytic $\mathrm{CO} 2$ reduction over surface-passivated $-\mathrm{Mo} 2 \mathrm{C}$ nanowires: enhanced catalytic stability by light. Chemical Communications 2019, 55 (32), 4651-4654.

48. Tackett, B. M.; Gomez, E.; Chen, J. G., Net reduction of $\mathrm{CO} 2$ via its thermocatalytic and electrocatalytic transformation reactions in standard and hybrid processes. Nature Catalysis 2019, 2 (5), 381-386.

49. Takalkar, G.; Bhosale, R. R.; AlMomani, F.; Khraisheh, M., Thermocatalytic splitting of CO2 using sol-gel synthesized Co-ferrite redox materials. Fuel 2019, 257.

50. Ferrah, D.; Haines, A. R.; Galhenage, R. P.; Bruce, J. P.; Babore, A. D.; Hunt, A.; Waluyo, I.; Hemminger, J. C., Wet Chemical Growth and Thermocatalytic Activity of CuBased Nanoparticles Supported on TiO2 Nanoparticles/HOPG: In Situ Ambient Pressure XPS Study of the CO2 Hydrogenation Reaction. Acs Catalysis 2019, 9 (8), 6783-6802.

51. Cometto, C.; Kuriki, R.; Chen, L.; Maeda, K.; Lau, T.-C.; Ishitani, O.; Robert, M., A Carbon Nitride/Fe Quaterpyridine Catalytic System for Photostimulated CO2-to-CO Conversion with Visible Light. Journal of the American Chemical Society 2018, 140 (24), 7437-7440.

52. Kim, C.; Cho, K. M.; Al-Saggaf, A.; Gereige, I.; Jung, H.-T., Z-scheme Photocatalytic CO2 Conversion on Three-Dimensional BiVO4/Carbon-Coated Cu2O Nanowire Arrays under Visible Light. Acs Catalysis 2018, 8 (5), 4170-4177.

53. Meng, A.; Zhang, L.; Cheng, B.; Yu, J., TiO2-MnOx-Pt Hybrid Multiheterojunction Film Photocatalyst with Enhanced Photocatalytic CO2-Reduction Activity. Acs Applied Materials \& Interfaces 2019, 11 (6), 5581-5589.

54. Ran, J.; Jaroniec, M.; Qiao, S.-Z., Cocatalysts in Semiconductor-based Photocatalytic CO2 Reduction: Achievements, Challenges, and Opportunities. Advanced Materials 2018, 30 (7).

55. Wang, S.; Xu, M.; Peng, T.; Zhang, C.; Li, T.; Hussain, I.; Wang, J.; Tan, B., Porous hypercrosslinked polymer-TiO2-graphene composite photocatalysts for visible-lightdriven CO2 conversion. Nature Communications 2019, 10.

56. Xia, T.; Long, R.; Gao, C.; Xiong, Y., Design of atomically dispersed catalytic sites for photocatalytic CO2 reduction. Nanoscale 2019, 11 (23), 11064-11070.

57. Diercks, C. S.; Liu, Y.; Cordova, K. E.; Yaghi, O. M., The role of reticular chemistry in the design of CO2 reduction catalysts. Nature Materials 2018, 17 (4), 301-307.

58. Guntern, Y. T.; Pankhurst, J. R.; Vavra, J.; Mensi, M.; Mantella, V.; Schouwink, P.; Buonsanti, R., Nanocrystal/Metal-Organic Framework Hybrids as Electrocatalytic Platforms for $\mathrm{CO} 2$ Conversion. Angewandte Chemie-International Edition 2019, 58 (36), 12632-12639.

59. Huang, J.; Buonsanti, R., Colloidal Nanocrystals as Heterogeneous Catalysts for Electrochemical CO2 Conversions. Chemistry of Materials 2019, 31 (1), 13-25.

60. Ma, M.; Liu, K.; Shen, J.; Kas, R.; Smith, W. A., In Situ Fabrication and Reactivation of Highly Selective and Stable Ag Catalysts for Electrochemical CO2 Conversion. Acs Energy Letters 2018, 3 (6), 1301-1306.

61. Nesbitt, N. T.; Ma, M.; Trzesniewski, B. J.; Jaszewski, S.; Tafti, F.; Burns, M. J.; Smith, W. A.; Naughton, M. J., Au Dendrite Electrocatalysts for CO2 Electrolysis. Journal of Physical Chemistry C 2018, 122 (18), 10006-10016. 
62. Wang, J.; Ji, Y.; Shao, Q.; Yin, R.; Guo, J.; Li, Y.; Huang, X., Phase and structure modulating of bimetallic CuSn nanowires boosts electrocatalytic conversion of $\mathrm{CO} 2$. Nano Energy 2019, 59, 138-145.

63. Wang, Y.-R.; Huang, Q.; He, C.-T.; Chen, Y.; Liu, J.; Shen, F.-C.; Lan, Y.-Q., Oriented electron transmission in polyoxometalate-metalloporphyrin organic framework for highly selective electroreduction of CO2. Nature Communications 2018, 9.

64. Chen, J.; Yin, J.; Zheng, X.; Ahsaine, H. A.; Zhou, Y.; Dong, C.; Mohammed, O. F.; Takanabe, K.; Bakr, O. M., Compositionally Screened Eutectic Catalytic Coatings on Halide Perovskite Photocathodes for Photoassisted Selective CO2 Reduction. Acs Energy Letters 2019, 4 (6), 1279-1286.

65. Deng, X.; Li, R.; Wu, S.; Wang, L.; Hu, J.; Ma, J.; Jiang, W.; Zhang, N.; Zheng, X.; Gao, C.; Wang, L.; Zhang, Q.; Zhu, J.; Xiong, Y., Metal-Organic Framework Coating Enhances the Performance of Cu2O in Photoelectrochemical CO2 Reduction. Journal of the American Chemical Society 2019, 141 (27), 10924-10929.

66. Kang, H.-Y.; Nam, D.-H.; Yang, K. D.; Joo, W.; Kwak, H.; Kim, H.-H.; Hong, S.-H.; Nam, K. T.; Joo, Y.-C., Synthetic Mechanism Discovery of Monophase Cuprous Oxide for Record High Photoelectrochemical Conversion of $\mathrm{CO} 2$ to Methanol in Water. Acs Nano 2018, 12 (8), 8187-8196.

67. Leung, J. J.; Warnan, J.; Ly, K. H.; Heidary, N.; Dong Heon, N.; Kuehneh, M. F.; Reisner, E., Solar-driven reduction of aqueous $\mathrm{CO} 2$ with a cobalt bis(terpyridine)-based photocathode. Nature Catalysis 2019, 2 (4), 354-365.

68. Ajmal, S.; Yang, Y.; Li, K.; Tahir, M. A.; Liu, Y.; Wang, T.; Bacha, A.-U.-R.; Feng, Y.; Deng, Y.; Zhang, L., Zinc-Modified Copper Catalyst for Efficient (Photo-)Electrochemical $\mathrm{CO} 2$ Reduction with High Selectivity of $\mathrm{HCOOH}$ Production. Journal of Physical Chemistry C 2019, 123 (18), 11555-11563.

69. Chu, S.; Fan, S.; Wang, Y.; Rossouw, D.; Wang, Y.; Botton, G. A.; Mi, Z., Tunable Syngas Production from $\mathrm{CO} 2$ and $\mathrm{H} 2 \mathrm{O}$ in an Aqueous Photoelectrochemical Cell. Angewandte Chemie-International Edition 2016, 55 (46), 14260-14264.

70. DuChene, J. S.; Tagliabue, G.; Welch, A. J.; Cheng, W.-H.; Atwater, H. A., Hot Hole Collection and Photoelectrochemical CO2 Reduction with Plasmonic Au/p-GaN Photocathodes. Nano Letters 2018, 18 (4), 2545-2550.

71. Kang, M. J.; Kim, C. W.; Pawar, A. U.; Cha, H. G.; Ji, S.; Cai, W.-B.; Kang, Y. S., Selective Alcohol on Dark Cathodes by Photoelectrochemical CO2 Valorization and Their In Situ Characterization. Acs Energy Letters 2019, 4 (7), 1549-1555.

72. Kang, U.; Yoon, S. H.; Hang, D. S.; Park, H., Synthesis of Aliphatic Acids from $\mathrm{CO} 2$ and Water at Efficiencies Close to the Photosynthesis Limit Using Mixed Copper and Iron Oxide Films. Acs Energy Letters 2019, 4 (9), 2075-2080.

73. Kuk, S. K.; Singh, R. K.; Nam, D. H.; Singh, R.; Lee, J.-K.; Park, C. B., Photoelectrochemical Reduction of Carbon Dioxide to Methanol through a Highly Efficient Enzyme Cascade. Angewandte Chemie-International Edition 2017, 56 (14), 3827-3832.

74. Sahara, G.; Kumagai, H.; Maeda, K.; Kaeffer, N.; Artero, V.; Higashi, M.; Abe, R.; Ishitani, O., Photoelectrochemical Reduction of $\mathrm{CO} 2$ Coupled to Water Oxidation Using a Photocathode with a Ru(II)-Re(I) Complex Photocatalyst and a CoOx/TaON Photoanode. Journal of the American Chemical Society 2016, 138 (42), 14152-14158.

75. Song, J. T.; Ryoo, H.; Cho, M.; Kim, J.; Kim, J.-G.; Chung, S.-Y.; Oh, J., Nanoporous Au Thin Films on Si Photoelectrodes for Selective and Efficient Photoelectrochemical CO2 Reduction. Advanced Energy Materials 2017, 7 (3). 
76. Wang, P.; Wang, S.; Wang, H.; Wu, Z.; Wang, L., Recent Progress on PhotoElectrocatalytic Reduction of Carbon Dioxide. Particle \& Particle Systems Characterization 2018, 35 (1).

77. Jang, Y. J.; Jeong, I.; Lee, J.; Lee, J.; Ko, M. J.; Lee, J. S., Unbiased Sunlight-Driven Artificial Photosynthesis of Carbon Monoxide from CO2 Using a ZnTe-Based Photocathode and a Perovskite Solar Cell in Tandem. Acs Nano 2016, 10 (7), 6980-6987.

78. Ji, Y.; Luo, Y., Direct Donation of Protons from $\mathrm{H} 2 \mathrm{O}$ to $\mathrm{CO} 2$ in Artificial Photosynthesis on the Anatase TiO2(101) Surface. Journal of Physical Chemistry C 2019, 123 (5), 30193023.

79. Kim, D.; Sakimoto, K. K.; Hong, D.; Yang, P., Artificial Photosynthesis for Sustainable Fuel and Chemical Production. Angewandte Chemie-International Edition 2015, 54 (11), 3259-3266.

80. Liu, C.; Colon, B. C.; Ziesack, M.; Silver, P. A.; Nocera, D. G., Water splitting-biosynthetic system with $\mathrm{CO} 2$ reduction efficiencies exceeding photosynthesis. Science 2016, 352 (6290), 1210-1213.

81. Yadav, R. K.; Baeg, J.-O.; Oh, G. H.; Park, N.-J.; Kong, K.-j.; Kim, J.; Hwang, D. W.; Biswas, S. K., A Photocatalyst-Enzyme Coupled Artificial Photosynthesis System for Solar Energy in Production of Formic Acid from CO2. Journal of the American Chemical Society 2012, 134 (28), 11455-11461.

82. Yang, C.-C.; Yu, Y.-H.; van der Linden, B.; Wu, J. C. S.; Mul, G., Artificial Photosynthesis over Crystalline TiO2-Based Catalysts: Fact or Fiction? Journal of the American Chemical Society 2010, 132 (24), 8398-8406.

83. Sun, Z.; Ma, T.; Tao, H.; Fan, Q.; Han, B., Fundamentals and Challenges of Electrochemical CO2 Reduction Using Two-Dimensional Materials. Chem 2017, 3 (4), 560-587.

84. Zhang, N.; Long, R.; Gao, C.; Xiong, Y., Recent progress on advanced design for photoelectrochemical reduction of CO2 to fuels. Science China-Materials 2018, 61 (6), 771-805.

85. Liu, X.; Xiao, J.; Peng, H.; Hong, X.; Chan, K.; Norskov, J. K., Understanding trends in electrochemical carbon dioxide reduction rates. Nature Communications 2017, 8.

86. Cave, E. R.; Montoya, J. H.; Kuhl, K. P.; Abram, D. N.; Hatsukade, T.; Shi, C.; Hahn, C.; Norskov, J. K.; Jaramillo, T. F., Electrochemical $\mathrm{CO} 2$ reduction on Au surfaces: mechanistic aspects regarding the formation of major and minor products. Physical Chemistry Chemical Physics 2017, 19 (24), 15856-15863.

87. Rosen, B. A.; Salehi-Khojin, A.; Thorson, M. R.; Zhu, W.; Whipple, D. T.; Kenis, P. J. A.; Masel, R. I., Ionic Liquid-Mediated Selective Conversion of CO2 to $\mathrm{CO}$ at Low Overpotentials. Science 2011, 334 (6056), 643-644.

88. Mahyoub, S. A.; Qaraah, F. A.; Chen, C. Z.; Zhang, F. H.; Yan, S. L.; Cheng, Z. M., An overview on the recent developments of Ag-based electrodes in the electrochemical reduction of CO2 to CO. Sustainable Energy \& Fuels 2020, 4 (1), 50-67.

89. Han, N.; Ding, P.; He, L.; Li, Y.; Li, Y., Promises of Main Group Metal-Based Nanostructured Materials for Electrochemical CO2 Reduction to Formate. Advanced Energy Materials 2020, 10 (11), 1902338.

90. Zhao, J.; Xue, S.; Barber, J.; Zhou, Y.; Meng, J.; Ke, X., An overview of Cu-based heterogeneous electrocatalysts for $\mathrm{CO} 2$ reduction. J. Mater. Chem. A 2020, 8 (9), 47004734. 
91. Kuhl, K. P.; Cave, E. R.; Abram, D. N.; Jaramillo, T. F., New insights into the electrochemical reduction of carbon dioxide on metallic copper surfaces. Energy \& Environmental Science 2012, 5 (5), 7050-7059.

92. Calvinho, K. U. D.; Laursen, A. B.; Yap, K. M. K.; Goetjen, T. A.; Hwang, S.; Murali, N.; Mejia-Sosa, B.; Lubarski, A.; Teeluck, K. M.; Hall, E. S.; Garfunkel, E.; Greenblatt, M.; Dismukes, G. C., Selective $\mathrm{CO} 2$ reduction to $\mathrm{C}-3$ and $\mathrm{C}-4$ oxyhydrocarbons on nickel phosphides at overpotentials as low as $10 \mathrm{mV}$. Energy \& Environmental Science 2018, 11 (9), 2550-2559.

93. Francis, S. A.; Velazquez, J. M.; Ferrer, I. M.; Torelli, D. A.; Guevarra, D.; McDowell, M. T.; Sun, K.; Zhou, X.; Saadi, F. H.; John, J.; Richter, M. H.; Hyler, F. P.; Papadantonakis, K. M.; Brunschwig, B. S.; Lewis, N. S., Reduction of Aqueous CO2 to 1-Propanol at MoS2 Electrodes. Chemistry of Materials 2018, 30 (15), 4902-4908.

94. Wang, L.; Nitopi, S. A.; Bertheussen, E.; Orazov, M.; Morales-Guio, C. G.; Liu, X.; Higgins, D. C.; Chan, K.; Norskov, J. K.; Hahn, C.; Jaramillo, T. F., Electrochemical Carbon Monoxide Reduction on Polycrystalline Copper: Effects of Potential, Pressure, and pH on Selectivity toward Multicarbon and Oxygenated Products. Acs Catalysis 2018, 8 (8), 7445-7454.

95. Li, C. W.; Ciston, J.; Kanan, M. W., Electroreduction of carbon monoxide to liquid fuel on oxide-derived nanocrystalline copper. Nature 2014, 508, 504.

96. Feng, X. F.; Jiang, K. L.; Fan, S. S.; Kanan, M. W., A Direct Grain-Boundary-Activity Correlation for CO Electroreduction on Cu Nanoparticles. Acs Central Science 2016, 2 (3), 169-174.

97. Li, J.; Che, F.; Pang, Y.; Zou, C.; Howe, J. Y.; Burdyny, T.; Edwards, J. P.; Wang, Y.; Li, F.; Wang, Z.; De Luna, P.; Dinh, C.-T.; Zhuang, T.-T.; Saidaminov, M. I.; Cheng, S.; Wu, T.; Finfrock, Y. Z.; Ma, L.; Hsieh, S.-H.; Liu, Y.-S.; Botton, G. A.; Pong, W.-F.; Du, X.; Guo, J.; Sham, T.-K.; Sargent, E. H.; Sinton, D., Copper adparticle enabled selective electrosynthesis of n-propanol. Nature Communications 2018, 9 (1), 4614.

98. Zhuang, T.-T.; Pang, Y.; Liang, Z.-Q.; Wang, Z.; Li, Y.; Tan, C.-S.; Li, J.; Dinh, C. T.; De Luna, P.; Hsieh, P.-L.; Burdyny, T.; Li, H.-H.; Liu, M.; Wang, Y.; Li, F.; Proppe, A.; Johnston, A.; Nam, D.-H.; Wu, Z.-Y.; Zheng, Y.-R.; Ip, A. H.; Tan, H.; Chen, L.-J.; Yu, S.H.; Kelley, S. O.; Sinton, D.; Sargent, E. H., Copper nanocavities confine intermediates for efficient electrosynthesis of C3 alcohol fuels from carbon monoxide. Nature Catalysis 2018, 1 (12), 946-951.

99. Pang, Y. J.; Li, J.; Wang, Z. Y.; Tang, C. S.; Hsieh, P. L.; Zhuang, T. T.; Liang, Z. Q.; Zou, C. Q.; Wang, X.; De Luna, P.; Edwards, J. P.; Xu, Y.; Li, F. W.; Dinh, C. T.; Zhong, M.; Lou, Y. H.; Wu, D.; Chen, L. J.; Sargent, E. H.; Sinton, D., Efficient electrocatalytic conversion of carbon monoxide to propanol using fragmented copper. Nature Catalysis 2019, 2 (3), 251-258.

100. Wang, L.; Nitopi, S.; Wong, A. B.; Snider, J. L.; Nielander, A. C.; Morales-Guio, C. G.; Orazov, M.; Higgins, D. C.; Hahn, C.; Jaramillo, T. F., Electrochemically converting carbon monoxide to liquid fuels by directing selectivity with electrode surface area. Nature Catalysis 2019, 2 (8), 702-708.

101. Wang, L.; Higgins, D. C.; Ji, Y.; Morales-Guio, C. G.; Chan, K.; Hahn, C.; Jaramillo, T. F., Selective reduction of $\mathrm{CO}$ to acetaldehyde with $\mathrm{CuAg}$ electrocatalysts. Proceedings of the National Academy of Sciences 2020, 201821683.

102. Niu, S.; Li, S.; Du, Y.; Han, X.; Xu, P., How to Reliably Report the Overpotential of an Electrocatalyst. ACS Energy Letters 2020, 1083-1087. 
103. Grim, R. G.; Huang, Z.; Guarnieri, M. T.; Ferrell, J. R., III; Tao, L.; Schaidle, J. A., Transforming the carbon economy: challenges and opportunities in the convergence of low-cost electricity and reductive CO2 utilization. Energy \& Environmental Science 2020, 13 (2), 472-494.

104. García de Arquer, F. P.; Dinh, C.-T.; Ozden, A.; Wicks, J.; McCallum, C.; Kirmani, A. R.; Nam, D.-H.; Gabardo, C.; Seifitokaldani, A.; Wang, X.; Li, Y. C.; Li, F.; Edwards, J.; Richter, L. J.; Thorpe, S. J.; Sinton, D.; Sargent, E. H., CO<sub $>2</ s u b>$ electrolysis to multicarbon products at activities greater than $1 \mathrm{~A} c \mathrm{~cm}\langle$ sup $>-2</$ sup $>$. Science 2020, 367 (6478), 661-666.

105. Straistari, T.; Fize, J.; Shova, S.; Reglier, M.; Artero, V.; Orio, M., A ThiosemicarbazoneNickel(II) Complex as Efficient Electrocatalyst for Hydrogen Evolution. Chemcatchem 2017, 9 (12), 2262-2268.

106. Dubois, M. R.; Dubois, D. L., Development of Molecular Electrocatalysts for $\mathrm{CO} 2$ Reduction and H-2 Production/Oxidation. Accounts of Chemical Research 2009, 42 (12), 1974-1982.

107. Ford, P. C., THE WATER GAS SHIFT REACTION - HOMOGENEOUS CATALYSIS BY RUTHENIUM AND OTHER METAL-CARBONYLS. Accounts of Chemical Research 1981, 14 (2), 31-37.

108. Fukuzumi, S.; Yamada, Y.; Suenobu, T.; Ohkubo, K.; Kotani, H., Catalytic mechanisms of hydrogen evolution with homogeneous and heterogeneous catalysts. Energy \& Environmental Science 2011, 4 (8), 2754-2766.

109. Lazarides, T.; McCormick, T.; Du, P.; Luo, G.; Lindley, B.; Eisenberg, R., Making Hydrogen from Water Using a Homogeneous System Without Noble Metals. Journal of the American Chemical Society 2009, 131 (26), 9192-+.

110. Wiese, S.; Kilgore, U. J.; DuBois, D. L.; Bullock, R. M., Ni((P2N2Ph)-N-Me)(2) (BF4)(2) as an Electrocatalyst for H-2 Production. Acs Catalysis 2012, 2 (5), 720-727.

111. Blakemore, J. D.; Gupta, A.; Warren, J. J.; Brunschwig, B. S.; Gray, H. B., Noncovalent Immobilization of Electrocatalysts on Carbon Electrodes for Fuel Production. Journal of the American Chemical Society 2013, 135 (49), 18288-18291.

112. Brown, A. P.; Anson, F. C., MOLECULAR ANCHORS FOR ATTACHMENT OF METALCOMPLEXES TO GRAPHITE ELECTRODE SURFACES. Journal of Electroanalytical Chemistry 1977, 83 (1), 203-206.

113. Bullock, R. M.; Das, A. K.; Appel, A. M., Surface Immobilization of Molecular Electrocatalysts for Energy Conversion. Chemistry-a European Journal 2017, 23 (32), 7626-7641.

114. Mann, J. A.; Rodriguez-Lopez, J.; Abruna, H. D.; Dichtel, W. R., Multivalent Binding Motifs for the Noncovalent Functionalization of Graphene. Journal of the American Chemical Society 2011, 133 (44), 17614-17617.

115. Berben, L. A.; Peters, J. C., Hydrogen evolution by cobalt tetraimine catalysts adsorbed on electrode surfaces. Chemical Communications 2010, 46 (3), 398-400.

116. Le Goff, A.; Artero, V.; Jousselme, B.; Tran, P. D.; Guillet, N.; Metaye, R.; Fihri, A.; Palacin, S.; Fontecave, M., From Hydrogenases to Noble Metal-Free Catalytic Nanomaterials for H-2 Production and Uptake. Science 2009, 326 (5958), 1384-1387.

117. Lei, H.; Han, A.; Li, F.; Zhang, M.; Han, Y.; Du, P.; Lai, W.; Cao, R., Electrochemical, spectroscopic and theoretical studies of a simple bifunctional cobalt corrole catalyst for oxygen evolution and hydrogen production. Physical Chemistry Chemical Physics 2014, 16 (5), 1883-1893. 
118. Mondal, B.; Sengupta, K.; Rana, A.; Mahammed, A.; Botoshansky, M.; Dey, S. G.; Gross, Z.; Dey, A., Cobalt Corrole Catalyst for Efficient Hydrogen Evolution Reaction from H2O under Ambient Conditions: Reactivity, Spectroscopy, and Density Functional Theory Calculations. Inorganic Chemistry 2013, 52 (6), 3381-3387.

119. Oughli, A. A.; Ruff, A.; Boralugodage, N. P.; Rodriguez-Macia, P.; Plumere, N.; Lubitz, W.; Shaw, W. J.; Schuhmann, W.; Ruediger, O., Dual properties of a hydrogen oxidation $\mathrm{Ni}$-catalyst entrapped within a polymer promote self-defense against oxygen. Nature Communications 2018, 9.

120. Pantani, O.; Anxolabehere-Mallart, E.; Aukauloo, A.; Millet, P., Electroactivity of cobalt and nickel glyoximes with regard to the electro-reduction of protons into molecular hydrogen in acidic media. Electrochemistry Communications 2007, 9 (1), 54-58.

121. Rodriguez-Macia, P.; Priyadarshani, N.; Dutta, A.; Weidenthaler, C.; Lubitz, W.; Shaw, W. J.; Ruediger, O., Covalent Attachment of the Water-insoluble Ni((P2N2Phe)-N-Cy)(2) Electrocatalyst to Electrodes Showing Reversible Catalysis in Aqueous Solution. Electroanalysis 2016, 28 (10), 2452-2458.

122. Tran, P. D.; Le Goff, A.; Heidkamp, J.; Jousselme, B.; Guillet, N.; Palacin, S.; Dau, H.; Fontecave, M.; Artero, V., Noncovalent Modification of Carbon Nanotubes with PyreneFunctionalized Nickel Complexes: Carbon Monoxide Tolerant Catalysts for Hydrogen Evolution and Uptake. Angewandte Chemie-International Edition 2011, 50 (6), 13711374.

123. Zhang, W.; Haddad, A. Z.; Garabato, B. D.; Kozowski, P. M.; Buchanan, R. M.; Grapperhaus, C. A., Translation of Ligand-Centered Hydrogen Evolution Reaction Activity and Mechanism of a Rhenium-Thiolate from Solution to Modified Electrodes: A Combined Experimental and Density Functional Theory Study. Inorganic Chemistry 2017, 56 (4), 2177-2187.

124. Abe, T.; Taguchi, F.; Imaya, H.; Zhao, F.; Zhang, J.; Kaneko, M., Highly active electrocatalysis by cobalt tetraphenylporphyrin incorporated in a nafion membrane for proton reduction. Polymers for Advanced Technologies 1998, 9 (9), 559-562.

125. Koca, A., Copper phthalocyanine complex as electrocatalyst for hydrogen evolution reaction. Electrochemistry Communications 2009, 11 (4), 838-841.

126. Koca, A., Hydrogen evolution reaction on glassy carbon electrode modified with titanyl phthalocyanines. International Journal of Hydrogen Energy 2009, 34 (5), 2107-2112.

127. Koca, A.; Kalkan, A.; Bayir, Z. A., Electrochemical, In Situ Spectroelectrochemical, In Situ Electrocolorimetric and Electrocatalytic Characterization of Metallophthalocyanines Bearing Four Dioctylaminocarbonyl Biphenyloxy Substituents. Electroanalysis 2010, 22 (3), 310-319.

128. Koca, A.; Kalkan, A.; Bayir, Z. A., Electrocatalytic oxygen reduction and hydrogen evolution reactions on phthalocyanine modified electrodes: Electrochemical, in situ spectroelectrochemical, and in situ electrocolorimetric monitoring. Electrochimica Acta 2011, 56 (16), 5513-5525.

129. Grass, V.; Lexa, D.; Saveant, J. M., Electrochemical generation of rhodium porphyrin hydrides. Catalysis of hydrogen evolution. Journal of the American Chemical Society 1997, 119 (32), 7526-7532.

130. Haddad, A. Z.; Cronin, S. P.; Mashuta, M. S.; Buchanan, R. M.; Grapperhaus, C. A., Metal-Assisted Ligand-Centered Electrocatalytic Hydrogen Evolution upon Reduction of a Bis(thiosemicarbazonato)Cu(II) Complex. Inorganic Chemistry 2017, 56 (18), 1125411265. 
131. Haddad, A. Z.; Garabato, B. D.; Kozlowski, P. M.; Buchanan, R. M.; Grapperhaus, C. A., Beyond Metal-Hydrides: Non-Transition-Metal and Metal-Free Ligand-Centered Electrocatalytic Hydrogen Evolution and Hydrogen Oxidation. Journal of the American Chemical Society 2016, 138 (25), 7844-7847.

132. Jain, R.; Al Mamun, A.; Buchanan, R. M.; Kozlowski, P. M.; Grapperhaus, C. A., LigandAssisted Metal-Centered Electrocatalytic Hydrogen Evolution upon Reduction of a Bis(thiosemicarbazonato)Ni(II) Complex. Inorganic Chemistry 2018, 57 (21), 1348613493.

133. Jing, X.; Wu, P.; Liu, X.; Yang, L.; He, C.; Duan, C., Light-driven hydrogen evolution with a nickel thiosemicarbazone redox catalyst featuring $\mathrm{Ni}$ center dot center dot center dot $\mathrm{H}$ interactions under basic conditions. New Journal of Chemistry 2015, 39 (2), 10511059.

134. Straistari, T.; Hardre, R.; Fize, J.; Shova, S.; Giorgi, M.; Reglier, M.; Artero, V.; Orio, M., Hydrogen Evolution Reactions Catalyzed by a Bis(thiosemicarbazone) Cobalt Complex: An Experimental and Theoretical Study. Chemistry-a European Journal 2018, 24 (35), 8779-+.

135. Betts, H. M.; Barnard, P. J.; Bayly, S. R.; Dilworth, J. R.; Gee, A. D.; Holland, J. P., Controlled Axial Coordination: Solid-Phase Synthesis and Purification of MetalloRadiopharmaceuticals. Angewandte Chemie-International Edition 2008, 47 (44), 84168419.

136. Cornish, A. J.; Gaertner, K.; Yang, H.; Peters, J. W.; Hegg, E. L., Mechanism of Proton Transfer in FeFe -Hydrogenase from Clostridium pasteurianum. Journal of Biological Chemistry 2011, 286 (44), 38341-38347.

137. Goldman, C. M.; Mascharak, P. K., Reactions of H-2 with the nickel site(s) of the FeNi and FeNiSe hydrogenases: What do the model complexes suggest? Comments on Inorganic Chemistry 1995, 18 (1), 1-25.

138. Teixeira, V. H.; Baptista, A. M.; Soares, C. M., Pathways of $\mathrm{H}-2$ toward the active site of NiFe -hydrogenase. Biophysical Journal 2006, 91 (6), 2035-2045.

139. Ulloa, O. A.; Huynh, M. T.; Richers, C. P.; Bertke, J. A.; Nilges, M. J.; Hammes-Schiffer, S.; Rauchfuss, T. B., Mechanism of H-2 Production by Models for the NiFe Hydrogenases: Role of Reduced Hydrides. Journal of the American Chemical Society 2016, 138 (29), 9234-9245.

140. Wombwell, C.; Caputo, C. A.; Reisner, E., NiFeSe -Hydrogenase Chemistry. Accounts of Chemical Research 2015, 48 (11), 2858-2865.

141. Rauchfuss, T. B., Diiron Azadithiolates as Models for the FeFe -Hydrogenase Active Site and Paradigm for the Role of the Second Coordination Sphere. Accounts of Chemical Research 2015, 48 (7), 2107-2116.

142. Simmons, T. R.; Berggren, G.; Bacchi, M.; Fontecave, M.; Artero, V., Mimicking hydrogenases: From biomimetics to artificial enzymes. Coordination Chemistry Reviews 2014, 270, 127-150.

143. Weber, K.; Kraemer, T.; Shafaat, H. S.; Weyhermueller, T.; Bill, E.; van Gastel, M.; Neese, F.; Lubitz, W., A Functional NiFe -Hydrogenase Model Compound That Undergoes Biologically Relevant Reversible Thiolate Protonation. Journal of the American Chemical Society 2012, 134 (51), 20745-20755.

144. Wodrich, M. D.; Hu, X., Natural inspirations for metal-ligand cooperative catalysis. Nature Reviews Chemistry 2018, 2 (1). 
145. DuBois, D. L.; Bullock, R. M., Molecular Electrocatalysts for the Oxidation of Hydrogen and the Production of Hydrogen - The Role of Pendant Amines as Proton Relays.

European Journal of Inorganic Chemistry 2011, (7), 1017-1027.

146. Henry, R. M.; Shoemaker, R. K.; DuBois, D. L.; DuBois, M. R., Pendant bases as proton relays in iron hydride and dihydrogen complexes. Journal of the American Chemical Society 2006, 128 (9), 3002-3010.

147. Bediako, D. K.; Solis, B. H.; Dogutan, D. K.; Roubelakis, M. M.; Maher, A. G.; Lee, C. H.; Chambers, M. B.; Hammes-Schiffer, S.; Nocera, D. G., Role of pendant proton relays and proton-coupled electron transfer on the hydrogen evolution reaction by nickel hangman porphyrins. Proceedings of the National Academy of Sciences of the United States of America 2014, 111 (42), 15001-15006.

148. Reath, A. H.; Ziller, J. W.; Tsay, C.; Ryan, A. J.; Yang, J. Y., Redox Potential and Electronic Structure Effects of Proximal Nonredox Active Cations in Cobalt Schiff Base Complexes. Inorganic Chemistry 2017, 56 (6), 3713-3718.

149. Hartley, C. L.; DiRisio, R. J.; Screen, M. E.; Mayer, K. J.; McNamara, W. R., Iron Polypyridyl Complexes for Photocatalytic Hydrogen Generation. Inorganic Chemistry 2016, 55 (17), 8865-8870.

150. McNamara, W. R.; Han, Z.; Yin, C.-J.; Brennessel, W. W.; Holland, P. L.; Eisenberg, R., Cobalt-dithiolene complexes for the photocatalytic and electrocatalytic reduction of protons in aqueous solutions. Proceedings of the National Academy of Sciences of the United States of America 2012, 109 (39), 15594-15599.

151. Queyriaux, N.; Kaeffer, N.; Morozan, A.; Chavarot-Kerlidou, M.; Artero, V., Molecular cathode and photocathode materials for hydrogen evolution in photoelectrochemical devices. Journal of Photochemistry and Photobiology C-Photochemistry Reviews 2015, 25, 90-105.

152. Krawicz, A.; Yang, J.; Anzenberg, E.; Yano, J.; Sharp, I. D.; Moore, G. F., Photofunctional Construct That Interfaces Molecular Cobalt-Based Catalysts for H-2 Production to a Visible-Light-Absorbing Semiconductor. Journal of the American Chemical Society 2013, 135 (32), 11861-11868.

153. Seo, J.; Pekarek, R. T.; Rose, M. J., Photoelectrochemical operation of a surface-bound, nickel-phosphine $\mathrm{H}-2$ evolution catalyst on $\mathrm{p}-\mathrm{Si}(111)$ : a molecular semiconductor\catalyst construct. Chemical Communications 2015, 51 (68), 1326413267.

154. Jiang, W.-X.; Xie, Z.-L.; Zhan, S.-Z., A photocatalytic system with a bis(thiosemicarbazonato)-nickel over CdS nanorods for hydrogen evolution from water under visible light. Inorganic Chemistry Communications 2019, 102, 5-9.

155. Lewis, N. S.; Nocera, D. G., Powering the planet: Chemical challenges in solar energy utilization. Proceedings of the National Academy of Sciences of the United States of America 2006, 103 (43), 15729-15735.

156. Ager, J. W.; Shaner, M. R.; Walczak, K. A.; Sharp, I. D.; Ardo, S., Experimental demonstrations of spontaneous, solar-driven photoelectrochemical water splitting. Energy \& Environmental Science 2015, 8 (10), 2811-2824.

157. Hu, S.; Xiang, C.; Haussener, S.; Berger, A. D.; Lewis, N. S., An analysis of the optimal band gaps of light absorbers in integrated tandem photoelectrochemical water-splitting systems. Energy \& Environmental Science 2013, 6 (10), 2984-2993.

158. Khaselev, O.; Turner, J. A., A monolithic photovoltaic-photoelectrochemical device for hydrogen production via water splitting. Science 1998, 280 (5362), 425-427. 
159. Verlage, E.; Hu, S.; Liu, R.; Jones, R. J. R.; Sun, K.; Xiang, C.; Lewis, N. S.; Atwater, H. A., A monolithically integrated, intrinsically safe, $10 \%$ efficient, solar-driven watersplitting system based on active, stable earth-abundant electrocatalysts in conjunction with tandem III-V light absorbers protected by amorphous TiO2 films. Energy \& Environmental Science 2015, 8 (11), 3166-3172.

160. Alqahtani, M.; Ben-Jabar, S.; Ebaid, M.; Sathasivam, S.; Jurczak, P.; Xia, X.; Alromaeh, A.; Blackman, C.; Qin, Y.; Zhang, B.; Ooi, B. S.; Liu, H.; Parkin, P.; Wu, J., Gallium Phosphide photoanode coated with $\mathrm{TiO} 2$ and $\mathrm{CoOx}$ for stable photoelectrochemical water oxidation. Optics Express 2019, 27 (8), A364-A371.

161. Hu, S.; Shaner, M. R.; Beardslee, J. A.; Lichterman, M.; Brunschwig, B. S.; Lewis, N. S., Amorphous TiO2 coatings stabilize $\mathrm{Si}, \mathrm{GaAs}$, and $\mathrm{GaP}$ photoanodes for efficient water oxidation. Science 2014, 344 (6187), 1005-1009.

162. Kargar, A.; Sukrittanon, S.; Zhou, C.; Ro, Y. G.; Pan, X.; Dayeh, S. A.; Tu, C. W.; Jin, S., GaP/GaNP Heterojunctions for Efficient Solar-Driven Water Oxidation. Small 2017, 13 (21).

163. Price, M. J.; Maldonado, S., Macroporous n-GaP in Nonaqueous Regenerative Photoelectrochemical Cells. Journal of Physical Chemistry C 2009, 113 (28), 1198811994.

164. Zhu, C.; Zheng, M.; Xiong, Z.; Li, H.; Shen, W., Electrochemically etched triangular pore arrays on GaP and their photoelectrochemical properties from water oxidation. International Journal of Hydrogen Energy 2014, 39 (21), 10861-10869.

165. Martinez-Garcia, A.; Russell, H. B.; Paxton, W.; Ravipati, S.; Calero-Barney, S.; Menon, M.; Richter, E.; Young, J.; Deutsch, T.; Sunkara, M. K., Unassisted Water Splitting Using a GaSbxP(1-x) Photoanode. Advanced Energy Materials 2018, 8 (16).

166. Russell, H. B.; Andriotis, A. N.; Menon, M.; Jasinski, J. B.; Martinez-Garcia, A.; Sunkara, M. K., Direct Band Gap Gallium Antimony Phosphide (GaSbxP1-x) Alloys. Scientific Reports 2016, 6.

167. Pourbaix, M., Atlas of Electrochemical Equilibria in Aqueous Solution. Pergamon Press, Oxford: 1966.

168. Chen, S.; Wang, L.-W., Thermodynamic Oxidation and Reduction Potentials of Photocatalytic Semiconductors in Aqueous Solution. Chemistry of Materials 2012, 24 (18), 3659-3666.

169. Britto, R. J.; Benck, J. D.; Young, J. L.; Hahn, C.; Deutsch, T. G.; Jaramillo, T. F., Molybdenum Disulfide as a Protection Layer and Catalyst for Gallium Indium Phosphide Solar Water Splitting Photocathodes. Journal of Physical Chemistry Letters 2016, 7 (11), 2044-2049.

170. Chen, Y. W.; Prange, J. D.; Duehnen, S.; Park, Y.; Gunji, M.; Chidsey, C. E. D.; Mclntyre, P. C., Atomic layer-deposited tunnel oxide stabilizes silicon photoanodes for water oxidation. Nature Materials 2011, 10 (7), 539-544.

171. Hendricks, O. L.; Tang-Kong, R.; Babadi, A. S.; Mclntyre, P. C.; Chidsey, C. E. D., Atomic Layer Deposited TiO2-IrOx Alloys Enable Corrosion Resistant Water Oxidation on Silicon at High Photovoltage. Chemistry of Materials 2019, 31 (1), 90-100.

172. Hu, S.; Lewis, N. S.; Ager, J. W.; Yang, J.; McKone, J. R.; Strandwitz, N. C., Thin-Film Materials for the Protection of Semiconducting Photoelectrodes in Solar-Fuel Generators. Journal of Physical Chemistry C 2015, 119 (43), 24201-24228.

173. Lichterman, M. F.; Shaner, M. R.; Handler, S. G.; Brunschwig, B. S.; Gray, H. B.; Lewis, N. S.; Spurgeon, J. M., Enhanced Stability and Activity for Water Oxidation in Alkaline Media with Bismuth Vanadate Photoelectrodes Modified with a Cobalt Oxide Catalytic 
Layer Produced by Atomic Layer Deposition. Journal of Physical Chemistry Letters 2013, 4 (23), 4188-4191.

174. Liu, R.; Zheng, Z.; Spurgeon, J.; Yang, X., Enhanced photoelectrochemical water-splitting performance of semiconductors by surface passivation layers. Energy \& Environmental Science 2014, 7 (8), 2504-2517.

175. Erne, B. H.; Vanmaekelbergh, D.; Kelly, J. J., Morphology and strongly enhanced photoresponse of GaP electrodes made porous by anodic etching. Journal of the Electrochemical Society 1996, 143 (1), 305-314.

176. Tjerkstra, R. W.; Rivas, J. G.; Vanmaekelbergh, D.; Kelly, J. J., Porous GaP multilayers formed by electrochemical etching. Electrochemical and Solid State Letters 2002, 5 (5), G32-G35.

177. Memming, R. S., G., Electrochemical Properties of Gallium Phosphide in Aqueopus Solutions. Electrochimica Acta 1968, 13 (6), 1299.

178. Kumar, B.; Llorente, M.; Froehlich, J.; Dang, T.; Sathrum, A.; Kubiak, C. P., Photochemical and Photoelectrochemical Reduction of CO2. In Annual Review of Physical Chemistry, Vol 63, Johnson, M. A.; Martinez, T. J., Eds. 2012; Vol. 63, pp 541-+.

179. Qiao, J.; Liu, Y.; Hong, F.; Zhang, J., A review of catalysts for the electroreduction of carbon dioxide to produce low-carbon fuels. Chemical Society Reviews 2014, 43 (2), 631675.

180. Roy, S. C.; Varghese, O. K.; Paulose, M.; Grimes, C. A., Toward Solar Fuels: Photocatalytic Conversion of Carbon Dioxide to Hydrocarbons. Acs Nano 2010, 4 (3), 1259-1278.

181. Hori, Y.; Kikuchi, K.; Suzuki, S., PRODUCTION OF CO AND CH4 IN ELECTROCHEMICAL REDUCTION OF CO2 AT METAL-ELECTRODES IN AQUEOUS HYDROGENCARBONATE SOLUTION. Chemistry Letters 1985, (11), 1695-1698.

182. Noda, H.; Ikeda, S.; Oda, Y.; Imai, K.; Maeda, M.; Ito, K., ELECTROCHEMICAL REDUCTION OF CARBON-DIOXIDE AT VARIOUS METAL-ELECTRODES IN AQUEOUS POTASSIUM HYDROGEN CARBONATE SOLUTION. Bulletin of the Chemical Society of Japan 1990, 63 (9), 2459-2462.

183. Gattrell, M.; Gupta, N.; Co, A., A review of the aqueous electrochemical reduction of CO2 to hydrocarbons at copper. Journal of Electroanalytical Chemistry 2006, 594 (1), 119.

184. Hori, Y.; Kikuchi, K.; Murata, A.; Suzuki, S., PRODUCTION OF METHANE AND ETHYLENE IN ELECTROCHEMICAL REDUCTION OF CARBON-DIOXIDE AT COPPER ELECTRODE IN AQUEOUS HYDROGENCARBONATE SOLUTION. Chemistry Letters 1986, (6), 897-898.

185. Hori, Y.; Murata, A.; Takahashi, R., FORMATION OF HYDROCARBONS IN THE ELECTROCHEMICAL REDUCTION OF CARBON-DIOXIDE AT A COPPER ELECTRODE IN AQUEOUS-SOLUTION. Journal of the Chemical Society-Faraday Transactions / 1989, 85, 2309-2326.

186. Peterson, A. A.; Abild-Pedersen, F.; Studt, F.; Rossmeisl, J.; Norskov, J. K., How copper catalyzes the electroreduction of carbon dioxide into hydrocarbon fuels. Energy \& Environmental Science 2010, 3 (9), 1311-1315.

187. Asadi, M.; Kumar, B.; Behranginia, A.; Rosen, B. A.; Baskin, A.; Repnin, N.; Pisasale, D.; Phillips, P.; Zhu, W.; Haasch, R.; Klie, R. F.; Kral, P.; Abiade, J.; Salehi-Khojin, A., Robust carbon dioxide reduction on molybdenum disulphide edges. Nature Communications 2014, 5 . 
188. Chen, Y.; Li, C. W.; Kanan, M. W., Aqueous CO2 Reduction at Very Low Overpotential on Oxide-Derived Au Nanoparticles. Journal of the American Chemical Society 2012, 134 (49), 19969-19972.

189. Delacourt, C.; Ridgway, P. L.; Kerr, J. B.; Newman, J., Design of an electrochemical cell making syngas $(\mathrm{CO}+\mathrm{H}-2)$ from $\mathrm{CO} 2$ and $\mathrm{H} 2 \mathrm{O}$ reduction at room temperature. Journal of the Electrochemical Society 2008, 155 (1), B42-B49.

190. Hatsukade, T.; Kuhl, K. P.; Cave, E. R.; Abram, D. N.; Jaramillo, T. F., Insights into the electrocatalytic reduction of $\mathrm{CO} 2$ on metallic silver surfaces. Physical Chemistry Chemical Physics 2014, 16 (27), 13814-13819.

191. Agarwal, A. S.; Zhai, Y.; Hill, D.; Sridhar, N., The Electrochemical Reduction of Carbon Dioxide to Formate/Formic Acid: Engineering and Economic Feasibility. Chemsuschem 2011, 4 (9), 1301-1310.

192. Koleli, F.; Balun, D. B., Reduction of $\mathrm{CO} 2$ under high pressure and high temperature on $\mathrm{Pb}$-granule electrodes in a fixed-bed reactor in aqueous medium. Applied Catalysis aGeneral 2004, 274 (1-2), 237-242.

193. Kumar, B.; Atla, V.; Brian, J. P.; Kumari, S.; Tu Quang, N.; Sunkara, M.; Spurgeon, J. M., Reduced SnO2 Porous Nanowires with a High Density of Grain Boundaries as Catalysts for Efficient Electrochemical $\mathrm{CO} 2$-into-HCOOH Conversion. Angewandte ChemieInternational Edition 2017, 56 (13), 3645-3649.

194. Li, C. W.; Kanan, M. W., CO2 Reduction at Low Overpotential on Cu Electrodes Resulting from the Reduction of Thick Cu2O Films. J. Am. Chem. Soc. 2012, 134 (17), 7231-7234.

195. Qiao, J.; Jiang, P.; Liu, J.; Zhang, J., Formation of Cu nanostructured electrode surfaces by an annealing-electroreduction procedure to achieve high-efficiency $\mathrm{CO} 2$ electroreduction. Electrochemistry Communications 2014, 38, 8-11.

196. Sekimoto, T.; Deguchi, M.; Yotsuhashi, S.; Yamada, Y.; Masui, T.; Kuramata, A.; Yamakoshi, S., Highly selective electrochemical reduction of $\mathrm{CO} 2$ to $\mathrm{HCOOH}$ on a gallium oxide cathode. Electrochemistry Communications 2014, 43, 95-97.

197. Wu, J.; Risalvato, F. G.; Ke, F.-S.; Pellechia, P. J.; Zhou, X.-D., Electrochemical Reduction of Carbon Dioxide I. Effects of the Electrolyte on the Selectivity and Activity with Sn Electrode. Journal of the Electrochemical Society 2012, 159 (7), F353-F359.

198. Handoko, A. D.; Ong, C. W.; Huang, Y.; Lee, Z. G.; Lin, L.; Panetti, G. B.; Yeo, B. S., Mechanistic Insights into the Selective Electroreduction of Carbon Dioxide to Ethylene on Cu2O-Derived Copper Catalysts. Journal of Physical Chemistry C 2016, 120 (36), 20058-20067.

199. Hoang, T. T. H.; Ma, S.; Gold, J. I.; Kenis, P. J. A.; Gewirth, A. A., Nanoporous Copper Films by Additive-Controlled Electrodeposition: $\mathrm{CO} 2$ Reduction Catalysis. Acs Catalysis 2017, 7 (5), 3313-3321.

200. Hori, Y.; Takahashi, I.; Koga, O.; Hoshi, N., Electrochemical reduction of carbon dioxide at various series of copper single crystal electrodes. Journal of Molecular Catalysis aChemical 2003, 199 (1-2), 39-47.

201. Ma, S.; Sadakiyo, M.; Luo, R.; Heima, M.; Yamauchi, M.; Kenis, P. J. A., One-step electrosynthesis of ethylene and ethanol from $\mathrm{CO} 2$ in an alkaline electrolyzer. Journal of Power Sources 2016, 301, 219-228.

202. Ren, D.; Ang, B. S.-H.; Yeo, B. S., Tuning the Selectivity of Carbon Dioxide Electroreduction toward Ethanol on Oxide-Derived CuxZn Catalysts. Acs Catalysis 2016, 6 (12), 8239-8247. 
203. Ren, D.; Deng, Y.; Handoko, A. D.; Chen, C. S.; Malkhandi, S.; Yeo, B. S., Selective Electrochemical Reduction of Carbon Dioxide to Ethylene and Ethanol on Copper(I) Oxide Catalysts. Acs Catalysis 2015, 5 (5), 2814-2821.

204. Song, Y.; Peng, R.; Hensley, D. K.; Bonnesen, P. V.; Liang, L.; Wu, Z.; Meyer, H. M., III; Chi, M.; Ma, C.; Sumpter, B. G.; Rondinone, A. J., High-Selectivity Electrochemical Conversion of $\mathrm{CO} 2$ to Ethanol using a Copper Nanoparticle/N-Doped Graphene Electrode. Chemistryselect 2016, 1 (19), 6055-6061.

205. Kim, Y.-G.; Javier, A.; Baricuatro, J. H.; Torelli, D.; Cummins, K. D.; Tsang, C. F.; Hemminger, J. C.; Soriaga, M. P., Surface reconstruction of pure-Cu single-crystal electrodes under CO-reduction potentials in alkaline solutions: A study by seriatim ECSTM-DEMS. Journal of Electroanalytical Chemistry 2016, 780, 290-295.

206. Seh, Z. W.; Kibsgaard, J.; Dickens, C. F.; Chorkendorff, I. B.; Norskov, J. K.; Jaramillo, T. F., Combining theory and experiment in electrocatalysis: Insights into materials design. Science 2017, 355 (6321).

207. Huff, C. A.; Sanford, M. S., Cascade Catalysis for the Homogeneous Hydrogenation of CO2 to Methanol. Journal of the American Chemical Society 2011, 133 (45), 1812218125.

208. Chen, Y.; Choi, S.; Thompson, L. T., Low-Temperature CO2 Hydrogenation to Liquid Products via a Heterogeneous Cascade Catalytic System. Acs Catalysis 2015, 5 (3), 17171725.

209. Kumar, B.; Brian, J. P.; Atla, V.; Kumari, S.; Bertram, K. A.; White, R. T.; Spurgeon, J. $M .$, New trends in the development of heterogeneous catalysts for electrochemical $\mathrm{CO} 2$ reduction. Catalysis Today 2016, 270, 19-30.

210. Hsieh, Y.-C.; Senanayake, S. D.; Zhang, Y.; Xu, W.; Polyansky, D. E., Effect of Chloride Anions on the Synthesis and Enhanced Catalytic Activity of Silver Nanocoral Electrodes for CO2 Electroreduction. Acs Catalysis 2015, 5 (9), 5349-5356.

211. Li, C. W.; Ciston, J.; Kanan, M. W., Electroreduction of carbon monoxide to liquid fuel on oxide-derived nanocrystalline copper. Nature 2014, 508 (7497), 504-+.

212. Kumar, B.; Brian, J. P.; Atla, V.; Kumari, S.; Bertram, K. A.; White, R. T.; Spurgeon, J. M., Controlling the Product Syngas H-2:CO Ratio through Pulsed-Bias Electrochemical Reduction of $\mathrm{CO} 2$ on Copper. Acs Catalysis 2016, 6 (7), 4739-4745.

213. Bard, A. J.; Faulkner, L. R., Electrochemical Methods: Fundamentals and Applications. Second ed.; John Wiley \& Sons: 2001.

214. McCrory, C. C. L.; Jung, S.; Peters, J. C.; Jaramillo, T. F., Benchmarking Heterogeneous Electrocatalysts for the Oxygen Evolution Reaction. Journal of the American Chemical Society 2013, 135 (45), 16977-16987.

215. Lum, Y.; Yue, B.; Lobaccaro, P.; Bell, A. T.; Ager, J. W., Optimizing C-C Coupling on Oxide-Derived Copper Catalysts for Electrochemical CO2 Reduction. Journal of Physical Chemistry C 2017, 121 (26), 14191-14203.

216. Baruch, M. F.; Pander, J. E., III; White, J. L.; Bocarsly, A. B., Mechanistic Insights into the Reduction of $\mathrm{CO} 2$ on Tin Electrodes using in Situ ATR-IR Spectroscopy. Acs Catalysis 2015, 5 (5), 3148-3156.

217. Chen, Y.; Kanan, M. W., Tin Oxide Dependence of the CO2 Reduction Efficiency on Tin Electrodes and Enhanced Activity for Tin/Tin Oxide Thin-Film Catalysts. Journal of the American Chemical Society 2012, 134 (4), 1986-1989.

218. Zhang, S.; Kang, P.; Meyer, T. J., Nanostructured Tin Catalysts for Selective Electrochemical Reduction of Carbon Dioxide to Formate. Journal of the American Chemical Society 2014, 136 (5), 1734-1737. 
219. Mellmann, D.; Sponholz, P.; Junge, H.; Beller, M., Formic acid as a hydrogen storage material - development of homogeneous catalysts for selective hydrogen release. Chemical Society Reviews 2016, 45 (14), 3954-3988.

220. Singh, A. K.; Singh, S.; Kumar, A., Hydrogen energy future with formic acid: a renewable chemical hydrogen storage system. Catalysis Science \& Technology 2016, 6 (1), 12-40.

221. Verma, S.; Kim, B.; Jhong, H.-R. M.; Ma, S.; Kenis, P. J. A., A Gross-Margin Model for Defining Technoeconomic Benchmarks in the Electroreduction of CO2. Chemsuschem 2016, 9 (15), 1972-1979.

222. Das, S.; Daud, W. M. A. W., A review on advances in photocatalysts towards $\mathrm{CO} 2$ conversion. Rsc Advances 2014, 4 (40), 20856-20893.

223. Lu, W.; Jia, B.; Cui, B.; Zhang, Y.; Yao, K.; Zhao, Y.; Wang, J., Efficient Photoelectrochemical Reduction of Carbon Dioxide to Formic Acid: A Functionalized Ionic Liquid as an Absorbent and Electrolyte. Angewandte Chemie-International Edition 2017, 56 (39), 11851-11854.

224. Sheu, J. K.; Liao, P. H.; Huang, T. C.; Chiang, K. J.; Lai, W. C.; Lee, M. L., InGaN-based epitaxial films as photoelectrodes for hydrogen generation through water photoelectrolysis and $\mathrm{CO} 2$ reduction to formic acid. Solar Energy Materials and Solar Cells 2017, 166, 86-90.

225. Wang, Y.; AlOtaibi, B.; Chowdhury, F. A.; Fan, S.; Kibria, M. G.; Li, L.; Li, C.-J.; Mi, Z., Photoelectrochemical reduction of carbon dioxide using Ge doped GaN nanowire photoanodes. Apl Materials 2015, 3 (11).

226. Yang, Y.; Zhan, F.; Li, H.; Liu, W.; Yu, S., In situ Sn-doped WO3 films with enhanced photoelectrochemical performance for reducing $\mathrm{CO} 2$ into formic acid. Journal of Solid State Electrochemistry 2017, 21 (8), 2231-2240.

227. Yang, Y.-h.; Xie, R.-r.; Li, H.; Liu, C.-j.; Liu, W.-h.; Zhan, F.-q., Photoelectrocatalytic reduction of $\mathrm{CO} 2$ into formic acid using WO3-x/TiO2 film as novel photoanode. Transactions of Nonferrous Metals Society of China 2016, 26 (9), 2390-2396.

228. Yin, G.; Abe, H.; Kodiyath, R.; Ueda, S.; Srinivasan, N.; Yamaguchi, A.; Miyauchi, M., Selective electro- or photo-reduction of carbon dioxide to formic acid using a $\mathrm{Cu}-\mathrm{Zn}$ alloy catalyst. J. Mater. Chem. A 2017, 5 (24), 12113-12119.

229. Arai, T.; Tajima, S.; Sato, S.; Uemura, K.; Morikawa, T.; Kajino, T., Selective CO2 conversion to formate in water using a CZTS photocathode modified with a ruthenium complex polymer. Chemical Communications 2011, 47 (47), 12664-12666.

230. Choi, S. K.; Kang, U.; Lee, S.; Ham, D. J.; Ji, S. M.; Park, H., Sn-Coupled p-Si Nanowire Arrays for Solar Formate Production from CO2. Advanced Energy Materials 2014, 4 (11).

231. Huang, X.; Cao, T.; Liu, M.; Zhao, G., Synergistic Photoelectrochemical Synthesis of Formate from $\mathrm{CO} 2$ on $\{12(1)$ over-bar\} Hierarchical Co304. Journal of Physical Chemistry C 2013, 117 (50), 26432-26440.

232. Kang, U.; Choi, S. K.; Ham, D. J.; Ji, S. M.; Choi, W.; Han, D. S.; Abdel-Wahabe, A.; Park, H., Photosynthesis of formate from $\mathrm{CO} 2$ and water at $1 \%$ energy efficiency via copper iron oxide catalysis. Energy \& Environmental Science 2015, 8 (9), 2638-2643.

233. Won, D. H.; Choi, C. H.; Chung, J.; Woo, S. I., Photoelectrochemical production of formic acid and methanol from carbon dioxide on metal-decorated $\mathrm{CuO} / \mathrm{Cu} 2 \mathrm{O}-l a y e r e d$ thin films under visible light irradiation. Applied Catalysis B-Environmental 2014, 158, 217 223.

234. Won, D. H.; Chung, J.; Park, S. H.; Kim, E.-H.; Woo, S. I., Photoelectrochemical production of useful fuels from carbon dioxide on a polypyrrole-coated p-ZnTe photocathode under visible light irradiation. J. Mater. Chem. A 2015, 3 (3), 1089-1095. 
235. Zhou, X.; Liu, R.; Sun, K.; Chen, Y.; Verlage, E.; Francis, S. A.; Lewis, N. S.; Xiang, C., Solar-Driven Reduction of 1 atm of $\mathrm{CO} 2$ to Formate at 10\% Energy-Conversion Efficiency by Use of a TiO2-Protected III-V Tandem Photoanode in Conjunction with a Bipolar Membrane and a Pd/C Cathode. Acs Energy Letters 2016, 1 (4), 764-770.

236. Hinogami, R.; Nakamura, Y.; Yae, S.; Nakato, Y., An approach to ideal semiconductor electrodes for efficient photoelectrochemical reduction of carbon dioxide by modification with small metal particles. Journal of Physical Chemistry B 1998, 102 (6), 974-980.

237. Tu Quang, N.; Atla, V.; Vendra, V. K.; Thapa, A. K.; Jasinski, J. B.; Druffel, T. L.; Sunkara, M. K., Scalable solvo-plasma production of porous tin oxide nanowires. Chemical Engineering Science 2016, 154, 20-26.

238. Boettcher, S. W.; Warren, E. L.; Putnam, M. C.; Santori, E. A.; Turner-Evans, D.; Kelzenberg, M. D.; Walter, M. G.; McKone, J. R.; Brunschwig, B. S.; Atwater, H. A.; Lewis, N. S., Photoelectrochemical Hydrogen Evolution Using Si Microwire Arrays. Journal of the American Chemical Society 2011, 133 (5), 1216-1219.

239. Strandwitz, N. C.; Comstock, D. J.; Grimm, R. L.; Nichols-Nielander, A. C.; Elam, J.; Lewis, N. S., Photoelectrochemical Behavior of n-type Si(100) Electrodes Coated with Thin Films of Manganese Oxide Grown by Atomic Layer Deposition. Journal of Physical Chemistry C 2013, 117 (10), 4931-4936.

240. Tan, M. X.; Laibinis, P. E.; Nguyen, S. T.; Kesselman, J. M.; Stanton, C. E.; Lewis, N. S., PRINCIPLES AND APPLICATIONS OF SEMICONDUCTOR PHOTOELECTROCHEMISTRY. Progress in Inorganic Chemistry, Vol 41 1994, 41, 21-144.

241. Rossi, R. C.; Tan, M. X.; Lewis, N. S., Size-dependent electrical behavior of spatially inhomogeneous barrier height regions on silicon. Applied Physics Letters 2000, 77 (17), 2698-2700.

242. Walter, M. G.; Warren, E. L.; McKone, J. R.; Boettcher, S. W.; Mi, Q.; Santori, E. A.; Lewis, N. S., Solar Water Splitting Cells. Chemical Reviews 2010, 110 (11), 6446-6473.

243. Li, F.; Chen, L.; Knowles, G. P.; MacFarlane, D. R.; Zhang, J., Hierarchical Mesoporous $\mathrm{SnO} 2$ Nanosheets on Carbon Cloth: A Robust and Flexible Electrocatalyst for $\mathrm{CO} 2$ Reduction with High Efficiency and Selectivity. Angewandte Chemie-International Edition 2017, 56 (2), 505-509.

244. Coridan, R. H.; Nielander, A. C.; Francis, S. A.; McDowell, M. T.; Dix, V.; Chatman, S. M.; Lewis, N. S., Methods for comparing the performance of energy-conversion systems for use in solar fuels and solar electricity generation. Energy \& Environmental Science 2015, 8 (10), 2886-2901.

245. Francke, R.; Schille, B.; Roemelt, M., Homogeneously Catalyzed Electroreduction of Carbon Dioxide-Methods, Mechanisms, and Catalysts. Chemical Reviews 2018, 118 (9), 4631-4701.

246. Last, G. V.; Schmick, M. T., A review of major non-power-related carbon dioxide stream compositions. Environmental Earth Sciences 2015, 74 (2), 1189-1198.

247. Ngo, K. T.; McKinnon, M.; Mahanti, B.; Narayanan, R.; Grills, D. C.; Ertem, M. Z.; Rochford, J., Turning on the Protonation-First Pathway for Electrocatalytic $\mathrm{CO} 2$ Reduction by Manganese Bipyridyl Tricarbonyl Complexes. Journal of the American Chemical Society 2017, 139 (7), 2604-2618.

248. Morimoto, T.; Nakajima, T.; Sawa, S.; Nakanishi, R.; Imori, D.; Ishitani, O., CO2 Capture by a Rhenium(I) Complex with the Aid of Triethanolamine. Journal of the American Chemical Society 2013, 135 (45), 16825-16828. 
249. Arikawa, Y.; Nakamura, T.; Ogushi, S.; Eguchi, K.; Umakoshi, K., Fixation of atmospheric carbon dioxide by ruthenium complexes bearing an NHC-based pincer ligand: formation of a methylcarbonato complex and its methylation. Dalton Transactions 2015, 44 (12), 5303-5305.

250. Mandal, S. K.; Ho, D. M.; Orchin, M., Reaction of electrophiles with manganese(I) and rhenium(I) alkoxide complexes: reversible absorption of atmospheric carbon dioxide. Organometallics 1993, 12 (5), 1714-1719.

251. Kumagai, H.; Nishikawa, T.; Koizumi, H.; Yatsu, T.; Sahara, G.; Yamazaki, Y.; Tamaki, Y.; Ishitani, O., Electrocatalytic reduction of low concentration CO2. Chemical Science 2019, 10 (6), 1597-1606.

252. Kato, M.; Ito, T., Facile carbon dioxide uptake by zinc(II)-tetraazacycloalkane complexes. 1. Syntheses, characterizations, and chemical properties of (monoalkyl carbonato)(tetraazacycloalkane)zinc(II) complexes. Inorganic Chemistry 1985, 24 (4), 504-508.

253. Franco, F.; Cometto, C.; Nencini, L.; Barolo, C.; Sordello, F.; Minero, C.; Fiedler, J.; Robert, M.; Gobetto, R.; Nervi, C., Local Proton Source in Electrocatalytic CO2 Reduction with [Mn(bpy-R)(CO)3Br] Complexes. Chemistry - A European Journal 2017, 23 (20), $4782-4793$.

254. Larrazabal, G. O.; Martin, A. J.; Perez-Ramirez, J., Building Blocks for High Performance in Electrocatalytic CO2 Reduction: Materials, Optimization Strategies, and Device Engineering. Journal of Physical Chemistry Letters 2017, 8 (16), 3933-3944.

255. Montoya, J. H.; Seitz, L. C.; Chakthranont, P.; Vojvodic, A.; Jaramillo, T. F.; Norskov, J. K., Materials for solar fuels and chemicals. Nature Materials 2017, 16 (1), 70-81.

256. Ma, S.; Luo, R.; Gold, J. I.; Yu, A. Z.; Kim, B.; Kenis, P. J. A., Carbon nanotube containing $\mathrm{Ag}$ catalyst layers for efficient and selective reduction of carbon dioxide. J. Mater. Chem. A 2016, 4 (22), 8573-8578.

257. Verma, S.; Hamasaki, Y.; Kim, C.; Huang, W.; Lu, S.; Jhong, H.-R. M.; Gewirth, A. A.; Fujigaya, T.; Nakashima, N.; Kenis, P. J. A., Insights into the Low Overpotential Electroreduction of $\mathrm{CO} 2$ to $\mathrm{CO}$ on a Supported Gold Catalyst in an Alkaline Flow Electrolyzer. Acs Energy Letters 2018, 3 (1), 193-198.

258. Yang, H.; Kaczur, J. J.; Sajjad, S. D.; Masel, R. I., CO2 Conversion to Formic Acid in a Three Compartment Cell with Sustainion (TM) Membranes. In Selected Proceedings from the 231st Ecs Meeting, Manivannan, M.; Narayan, S.; Kostecki, R.; Johnson, C.; Atanassov, P. B., Eds. 2017; Vol. 77, pp 1425-1431.

259. Dinh, C.-T.; Burdyny, T.; Kibria, M. G.; Seifitokaldani, A.; Gabardo, C. M.; de Arquer, F. P. G.; Kiani, A.; Edwards, J. P.; De Luna, P.; Bushuyev, O. S.; Zou, C.; QuinteroBermudez, R.; Pang, Y.; Sinton, D.; Sargent, E. H., CO2 electroreduction to ethylene via hydroxide-mediated copper catalysis at an abrupt interface. Science 2018, 360 (6390), 783-787.

260. Jouny, M.; Luc, W.; Jiao, F., General Techno-Economic Analysis of CO2 Electrolysis Systems. Industrial \& Engineering Chemistry Research 2018, 57 (6), 2165-2177.

261. Spurgeon, J. M.; Kumar, B., A comparative technoeconomic analysis of pathways for commercial electrochemical CO2 reduction to liquid products. Energy \& Environmental Science 2018, 11 (6), 1536-1551.

262. Lum, Y.; Ager, J. W., Sequential catalysis controls selectivity in electrochemical CO2 reduction on Cu. Energy \& Environmental Science 2018, 11 (10), 2935-2944. 
263. Theaker, N.; Strain, J. M.; Kumar, B.; Brian, J. P.; Kumari, S.; Spurgeon, J. M., Heterogeneously catalyzed two-step cascade electrochemical reduction of $\mathrm{CO} 2$ to ethanol. Electrochimica Acta 2018, 274, 1-8.

264. Zhang, H.; Li, J.; Cheng, M.-J.; Lu, Q., CO Electroreduction: Current Development and Understanding of Cu-Based Catalysts. ACS Catalysis 2019, 9 (1), 49-65.

265. Jouny, M.; Luc, W.; Jiao, F., High-rate electroreduction of carbon monoxide to multicarbon products. Nature Catalysis 2018, 1 (10), 748-755.

266. Giffin, G. A.; Lavina, S.; Pace, G.; Di Noto, V., Interplay between the Structure and Relaxations in Selemion AMV Hydroxide Conducting Membranes for AEMFC Applications. Journal of Physical Chemistry C 2012, 116 (45), 23965-23973.

267. Kutz, R. B.; Chen, Q.; Yang, H.; Sajjad, S. D.; Liu, Z.; Masel, I. R., Sustainion ImidazoliumFunctionalized Polymers for Carbon Dioxide Electrolysis. Energy Technology 2017, 5 (6), 929-936.

268. GmbH, F. B. www.fumatech.com.

269. Membranes International, I. www.ionexchangemembranes.com.

270. HeitnerWirguin, C., Recent advances in perfluorinated ionomer membranes: Structure, properties and applications. Journal of Membrane Science 1996, 120 (1), 1-33.

271. Marcincin, A., Modification of fiber-forming polymers by additives. Progress in Polymer Science 2002, 27 (5), 853-913.

272. Elangovan, M.; Dharmalingam, S., A facile modification of a polysulphone based anti biofouling anion exchange membrane for microbial fuel cell application. Rsc Advances 2016, 6 (25), 20571-20581.

273. DeFrancesco, J. V.; Witkowski, M. R.; Ciolino, L. A., GHB free acid: I. Solution formation studies and spectroscopic characterization by (HNMR)-H-1 and FT-IR. Journal of Forensic Sciences 2006, 51 (2), 321-329.

274. Grootveld, M.; Algeo, D.; Silwood, C. J. L.; Blackburn, J. C.; Clark, A. D., Determination of the illicit drug gamma-hydroxybutyrate $(\mathrm{GHB})$ in human saliva and beverages by $\mathrm{H}-1$ NMR analysis. Biofactors 2006, 27 (1-4), 121-136.

275. Palomino-Schatzlein, M.; Wang, Y.; Brailsford, A. D.; Parella, T.; Cowan, D. A.; LegidoQuigley, C.; Perez-Trujillo, M., Direct Monitoring of Exogenous gamma-Hydroxybutyric Acid in Body Fluids by NMR Spectroscopy. Analytical Chemistry 2017, 89 (16), 83438350.

276. Hu, B. R.; Yue, Y. Q.; Zhu, Y.; Wen, W.; Zhang, F. M.; Hardie, J. W., Proton nuclear magnetic resonance-spectroscopic discrimination of wines reflects genetic homoly of several different grape (V. vinifer L.) Cultivars. PLoS One 2015, 10.

277. Bushuyev, O.; De Luna, P.; Dinh, C. T.; Tao, L.; Saur, G.; van de Lagemaat, J.; Kelly, S. O.; Sargent, E. H., What Should We Make with $\mathrm{CO}_{2}$ and How Can We Make It? Joule 2018, 2, 825-832.

278. Spurgeon, J. M.; Kumar, B., A comparative technoeconomic analysis of pathways for commercial electrochemical $\mathrm{CO}_{2}$ reduction to liquid products Energy Environ. Sci. 2018, 11, 1536-1551.

279. Jouny, M.; Luc, W.; Jiao, F., General Techno-Economic Analysis of $\mathrm{CO}_{2}$ Electrolysis Systems. Ind. Eng. Chem. Res. 2018, 57 (6), 2165-2177.

280. Lum, Y. W.; Yue, B. B.; Lobaccaro, P.; Bell, A. T.; Ager, J. W., Optimizing C-C Coupling on Oxide-Derived Copper Catalysts for Electrochemical $\mathrm{CO}_{2}$ Reduction. J. Phys. Chem. $\mathrm{C}$ 2017, 121 (26), 14191-14203.

281. Perez-Ramirez, J.; Lopez, N., Strategies to break linear scaling relationships. Nature Catalysis 2019, 2 (11), 971-976. 
282. Theaker, N.; Strain, J.; Kumar, B.; Brian, J. P.; Kumari, S.; Spurgeon, J. M., Heterogeneously catalyzed two-step cascade electrochemical reduction of $\mathrm{CO} 2$ to ethanol. Electrochim. Acta 2018, 274, 1-8.

283. Gurudayal; Perone, D.; Malani, S.; Lum, Y.; Haussener, S.; Ager, J. W., Sequential Cascade Electrocatalytic Conversion of Carbon Dioxide to C-C Coupled Products. ACS Appl. Energy Mater. 2019, 2 (6), 4551-4559.

284. Kumar, B.; Brian, J. P.; Atla, V.; Kumari, S.; Bertram, K. A.; White, R. T.; Spurgeon, J. M., Controlling the Product Syngas $\mathrm{H}_{2}$ : $\mathrm{CO}$ Ratio through Pulsed-Bias Electrochemical Reduction of $\mathrm{CO}_{2}$ on Copper. ACS Catal. 2016, 6 (7), 4739-4745.

285. Yano, J.; Morita, T.; Shimano, K.; Nagami, Y.; Yamasaki, S., Selective ethylene formation by pulse-mode electrochemical reduction of carbon dioxide using copper and copperoxide electrodes. J. Solid State Electrochem. 2007, 11 (4), 554-557.

286. Yano, J.; Yamasaki, S., Pulse-mode electrochemical reduction of carbon dioxide using copper and copper oxide electrodes for selective ethylene formation. J. Appl. Electrochem. 2008, 38 (12), 1721-1726.

287. Ishimaru, S.; Shiratsuchi, R.; Nogami, G., Pulsed electroreduction of CO2 on Cu-Ag alloy electrodes. J. Electrochem. Soc. 2000, 147 (5), 1864-1867.

288. Kimura, K. W.; Fritz, K. E.; Kim, J.; Suntivich, J.; Abruna, H. D.; Hanrath, T., Controlled Selectivity of $\mathrm{CO} 2$ Reduction on Copper by Pulsing the Electrochemical Potential. Chemsuschem 2018, 11 (11), 1781-1786.

289. Nogami, G.; Itagaki, H.; Shiratsuchi, R., Pulsed Electroreduction of CO2 on Copper Electrodes II. J. Electrochem. Soc. 1994, 141 (5), 1138-1142.

290. Engelbrecht, A.; Uhlig, C.; Stark, O.; Hammerle, M.; Schmid, G.; Magori, E.; WiesnerFleischer, K.; Fleischer, M.; Moos, R., On the Electrochemical CO2 Reduction at Copper Sheet Electrodes with Enhanced Long-Term Stability by Pulsed Electrolysis. J. Electrochem. Soc. 2018, 165 (15), J3059-J3068.

291. Bertheussen, E.; Verdaguer-Casadevall, A.; Ravasio, D.; Montoya, J. H.; Trimarco, D. B.; Roy, C.; Meier, S.; Wendland, J.; Norskov, J. K.; Stephens, I. E. L.; Chorkendorff, I., Acetaldehyde as an Intermediate in the Electroreduction of Carbon Monoxide to Ethanol on Oxide-Derived Copper. Angew. Chem.-Int. Edit. 2016, 55 (4), 1450-1454.

292. Li, C. W.; Ciston, J.; Kanan, M. W., Electroreduction of carbon monoxide to liquid fuel on oxide-derived nanocrystalline copper. Nature 2014, 508 (7497), 504-507.

293. Gurudayal; Bullock, J.; Sranko, D. F.; Towle, C. M.; Lum, Y.; Hettick, M.; Scott, M. C.; Javey, A.; Ager, J., Efficient solar-driven electrochemical $\mathrm{CO} 2$ reduction to hydrocarbons and oxygenates. Energy \& Environmental Science 2017, 10 (10), 2222-2230.

294. Magesh, G.; Kim, E. S.; Kang, H. J.; Banu, M.; Kim, J. Y.; Kim, J. H.; Lee, J. S., A versatile photoanode-driven photoelectrochemical system for conversion of $\mathrm{CO} 2$ to fuels with high faradaic efficiencies at low bias potentials. J. Mater. Chem. A 2014, 2 (7), 20442049.

295. Schreier, M.; Luo, J.; Gao, P.; Moehl, T.; Mayer, M. T.; Graetzel, M., Covalent Immobilization of a Molecular Catalyst on Cu2O Photocathodes for $\mathrm{CO} 2$ Reduction. Journal of the American Chemical Society 2016, 138 (6), 1938-1946.

296. Zhang, M.; Cheng, J.; Xuan, X.; Zhou, J.; Cen, K., CO2 Synergistic Reduction in a Photoanode-Driven Photoelectrochemical Cell with a Pt-Modified TiO2 Nanotube Photoanode and a Pt Reduced Graphene Oxide Electrocathode. Acs Sustainable Chemistry \& Engineering 2016, 4 (12), 6344-6354. 
297. Halmann, M., PHOTOELECTROCHEMICAL REDUCTION OF AQUEOUS CARBON-DIOXIDE ON P-TYPE GALLIUM-PHOSPHIDE IN LIQUID JUNCTION SOLAR-CELLS. Nature 1978, 275 (5676), 115-116.

298. Xia, S.; Meng, Y.; Zhou, X.; Xue, J.; Pan, G.; Ni, Z., Ti/ZnO-Fe2O3 composite: Synthesis, characterization and application as a highly efficient photoelectrocatalyst for methanol from CO2 reduction. Applied Catalysis B-Environmental 2016, 187, 122-133.

299. Wood, C. J.; Summers, G. H.; Clark, C. A.; Kaeffer, N.; Braeutigam, M.; Carbone, L. R.; D'Amario, L.; Fan, K.; Farre, Y.; Narbey, S.; Oswald, F.; Stevens, L. A.; Parmenter, C. D. J.; Fay, M. W.; La Torre, A.; Snape, C. E.; Dietzek, B.; Dini, D.; Hammarstrom, L.; Pellegrin, Y.; Odobel, F.; Sun, L.; Artero, V.; Gibson, E. A., A comprehensive comparison of dye-sensitized NiO photocathodes for solar energy conversion. Physical Chemistry Chemical Physics 2016, 18 (16), 10727-10738.

300. LaTempa, T. J.; Rani, S.; Bao, N.; Grimes, C. A., Generation of fuel from CO2 saturated liquids using a $\mathrm{p}$-Si nanowire parallel to $\mathrm{n}-\mathrm{TiO} 2$ nanotube array photoelectrochemical cell. Nanoscale 2012, 4 (7), 2245-2250.

301. Rao, K. R.; Pishgar, S.; Strain, J.; Kumar, B.; Atla, V.; Kumari, S.; Spurgeon, J. M., Photoelectrochemical reduction of $\mathrm{CO} 2$ to $\mathrm{HCOOH}$ on silicon photocathodes with reduced SnO2 porous nanowire catalysts. J. Mater. Chem. A 2018, 6 (4), 1736-1742.

302. Cheng, W.-H.; Richter, M. H.; Sullivan, I.; Larson, D. M.; Xiang, C.; Brunschwig, B. S.; Atwater, H. A., CO2 Reduction to CO with 19\% Efficiency in a Solar-Driven Gas Diffusion Electrode Flow Cell under Outdoor Solar Illumination. ACS Energy Letters 2020, 5 (2), 470-476.

303. Chang, X.; Wang, T.; Zhang, P.; Wei, Y.; Zhao, J.; Gong, J., Stable Aqueous Photoelectrochemical CO2 Reduction by a Cu2O Dark Cathode with Improved Selectivity for Carbonaceous Products. Angewandte Chemie International Edition 2016, 55 (31), 8840-8845.

304. Kumaravel, V.; Bartlett, J.; Pillai, S. C., Photoelectrochemical Conversion of Carbon Dioxide (CO2) into Fuels and Value-Added Products. Acs Energy Letters 2020, 5 (2), 486 519.

305. Andrei, V.; Reuillard, B.; Reisner, E., Bias-free solar syngas production by integrating a molecular cobalt catalyst with perovskite-BiVO4 tandems. Nature Materials 2020, 19 (2), 189-+.

306. Clark, E. L.; Hahn, C.; Jaramillo, T. F.; Bell, A. T., Electrochemical CO2 Reduction over Compressively Strained CuAg Surface Alloys with Enhanced Multi-Carbon Oxygenate Selectivity. Journal of the American Chemical Society 2017, 139 (44), 15848-15857.

307. Wang, L.; Nitopi, S. A.; Bertheussen, E.; Orazov, M.; Morales-Guio, C. G.; Liu, X.; Higgins, D. C.; Chan, K.; Nørskov, J. K.; Hahn, C.; Jaramillo, T. F., Electrochemical Carbon Monoxide Reduction on Polycrystalline Copper: Effects of Potential, Pressure, and pH on Selectivity toward Multicarbon and Oxygenated Products. ACS Catalysis 2018, 8 (8), 7445-7454.

308. Zhou, X.; Xiang, C., Comparative Analysis of Solar-to-Fuel Conversion Efficiency: A Direct, One-Step Electrochemical CO2 Reduction Reactor versus a Two-Step, Cascade Electrochemical CO2 Reduction Reactor. ACS Energy Letters 2018, 3 (8), 1892-1897.

309. Strain, J. M.; Spurgeon, J. M., Assessing contaminants from ion-exchange membranes in the evaluation of aqueous electrochemical carbon dioxide reduction. Journal of $\mathrm{CO} 2$ Utilization 2020, 35, e298-e302. 
310. Hu, S.; Shaner, M. R.; Beardslee, J. A.; Lichterman, M.; Brunschwig, B. S.; Lewis, N. S., Amorphous $\mathrm{TiO}<\mathrm{sub}>2</$ sub $>$ coatings stabilize $\mathrm{Si}, \mathrm{GaAs}$, and GaP photoanodes for efficient water oxidation. Science 2014, 344 (6187), 1005-1009.

311. Zhao, Y.; Westerik, P.; Santbergen, R.; Zoethout, E.; Gardeniers, H.; Bieberle-Hütter, A., From Geometry to Activity: A Quantitative Analysis of WO3/Si Micropillar Arrays for Photoelectrochemical Water Splitting. Advanced Functional Materials 2020, 1909157.

312. Liu, B.; Aydil, E. S., Growth of Oriented Single-Crystalline Rutile TiO2 Nanorods on Transparent Conducting Substrates for Dye-Sensitized Solar Cells. Journal of the American Chemical Society 2009, 131 (11), 3985-3990.

313. Shaner, M. R.; McDowell, M. T.; Pien, A.; Atwater, H. A.; Lewis, N. S., Si/TiO2 tandemjunction microwire arrays for unassisted solar-driven water splitting. Journal of The Electrochemical Society 2016, 163 (5), H261.

314. Corson, E. R.; Creel, E. B.; Kim, Y.; Urban, J. J.; Kostecki, R.; McCloskey, B. D., A temperature-controlled photoelectrochemical cell for quantitative product analysis. Review of Scientific Instruments 2018, 89 (5).

315. Krodel, M.; Carter, B. M.; Rall, D.; Lohaus, J.; Wessling, M.; Miller, D. J., Rational Design of Ion Exchange Membrane Material Properties Limits the Crossover of $\mathrm{CO} 2$ Reduction Products in Artificial Photosynthesis Devices. ACS applied materials \& interfaces 2020, 12 (10), 12030-12042.

316. Tzeng, Y.; Yeh, S.; Fang, W. C.; Chu, Y., Nitrogen-incorporated ultrananocrystalline diamond and multi-layer-graphene-like hybrid carbon films. Scientific Reports 2014, 4.

317. Kumar, A.; Lin, P. A.; Xue, A.; Hao, B.; Yap, Y. K.; Sankaran, R. M., Formation of nanodiamonds at near-ambient conditions via microplasma dissociation of ethanol vapour. Nature Communications 2013, 4.

318. Cheng, C. Y.; Teii, K., Control of the Growth Regimes of Nanodiamond and Nanographite in Microwave Plasmas. leee Transactions on Plasma Science 2012, 40 (7), 1783-1788.

319. Duan, X.; Xu, J.; Wei, Z.; Ma, J.; Guo, S.; Wang, S.; Liu, H.; Dou, S., Metal-Free Carbon Materials for CO2 Electrochemical Reduction. Advanced Materials 2017, 29 (41).

320. Liu, Y.; Chen, S.; Quan, X.; Yu, H., Efficient Electrochemical Reduction of Carbon Dioxide to Acetate on Nitrogen-Doped Nanodiamond. Journal of the American Chemical Society 2015, 137 (36), 11631-11636.

321. Liu, Y.; Zhang, Y.; Cheng, K.; Quan, X.; Fan, X.; Su, Y.; Chen, S.; Zhao, H.; Zhang, Y.; $\mathrm{Yu}, \mathrm{H}$.; Hoffmann, M. R., Selective Electrochemical Reduction of Carbon Dioxide to Ethanol on a Boron- and Nitrogen-Co-doped Nanodiamond. Angewandte ChemieInternational Edition 2017, 56 (49), 15607-15611.

322. Cui, X.; Pan, Z.; Zhang, L.; Peng, H.; Zheng, G., Selective Etching of Nitrogen-Doped Carbon by Steam for Enhanced Electrochemical $\mathrm{CO} 2$ Reduction. Advanced Energy Materials 2017, 7 (22), 1701456.

323. Wanninayake, N.; Ai, Q.; Zhou, R.; Hoque, M. A.; Herrell, S.; Guzman, M. I.; Risko, C.; Kim, D. Y., Understanding the effect of host structure of nitrogen doped ultrananocrystalline diamond electrode on electrochemical carbon dioxide reduction. Carbon 2020, 157, 408-419.

324. Garza, A. J.; Bell, A. T.; Head-Gordon, M., Mechanism of CO2 Reduction at Copper Surfaces: Pathways to C2 Products. ACS Catalysis 2018, 8 (2), 1490-1499.

325. Clark, E. L.; Singh, M. R.; Kwon, Y.; Bell, A. T., Differential Electrochemical Mass Spectrometer Cell Design for Online Quantification of Products Produced during Electrochemical Reduction of CO2. Analytical Chemistry 2015, 87 (15), 8013-8020. 
326. Clark, E. L.; Bell, A. T., Direct Observation of the Local Reaction Environment during the Electrochemical Reduction of CO2. Journal of the American Chemical Society 2018, 140 (22), 7012-7020.

327. Bogdanoff, P.; Friebe, P.; Alonso-Vante, N., A new inlet system for differential electrochemical mass spectroscopy applied to the photocorrosion of $\mathrm{p}-\ln \mathrm{P}(111)$ single crystals. Journal of the Electrochemical Society 1998, 145 (2), 576-582.

328. Lum, Y.; Ager, J. W., Evidence for product-specific active sites on oxide-derived Cu catalysts for electrochemical CO2 reduction. Nature Catalysis 2018.

329. Li, J. Y.; Yuan, L.; Li, S. H.; Tang, Z. R.; Xu, Y. J., One-dimensional copper-based heterostructures toward photo-driven reduction of $\mathrm{CO} 2$ to sustainable fuels and feedstocks. J. Mater. Chem. A 2019, 7 (15), 8676-8689.

330. Zhu, Q.; Sun, X.; Yang, D.; Ma, J.; Kang, X.; Zheng, L.; Zhang, J.; Wu, Z.; Han, B., Carbon dioxide electroreduction to $\mathrm{C} 2$ products over copper-cuprous oxide derived from electrosynthesized copper complex. Nature Communications 2019, 10 (1), 3851.

331. Gurudayal; Perone, D.; Malani, S.; Lum, Y.; Haussener, S.; Ager, J. W., Sequential Cascade Electrocatalytic Conversion of Carbon Dioxide to C-C Coupled Products. Acs Applied Energy Materials 2019, 2 (6), 4551-4559.

332. Christoforidis, K. C.; Fornasiero, P., Photocatalysis for Hydrogen Production and $\mathrm{CO} 2$ Reduction: The Case of Copper-Catalysts. ChemCatChem 2019, 11 (1), 368-382.

333. Sun, S. D.; Zhang, X. J.; Yang, Q.; Liang, S. H.; Zhang, X. Z.; Yang, Z. M., Cuprous oxide (Cu2O) crystals with tailored architectures: A comprehensive review on synthesis, fundamental properties, functional modifications and applications. Prog. Mater. Sci. 2018, 96, 111-173.

334. Ba, X.; Yan, L.-L.; Huang, S.; Yu, J.; Xia, X.-J.; Yu, Y., New Way for CO2 Reduction under Visible Light by a Combination of a Cu Electrode and Semiconductor Thin Film: Cu2O Conduction Type and Morphology Effect. Journal of Physical Chemistry C 2014, 118 (42), 24467-24478.

335. Yu, S.; Wilson, A. J.; Heo, J.; Jain, P. K., Plasmonic Control of Multi-Electron Transfer and C-C Coupling in Visible-Light-Driven CO2 Reduction on Au Nanoparticles. Nano Letters 2018, 18 (4), 2189-2194.

336. Yu, S.; Jain, P. K., Plasmonic photosynthesis of C1-C3 hydrocarbons from carbon dioxide assisted by an ionic liquid. Nature Communications 2019, 10 (1), 2022.

337. Boswell, M. C.; Dickson, J. V., THE ACTION OF SODIUM HYDROXIDE ON CARBON MONOXIDE, SODIUM FORMATE AND SODIUM OXALATE. Journal of the American Chemical Society 1918, 40 (12), 1779-1786.

338. McCrory, C. C. L.; Jung, S.; Ferrer, I. M.; Chatman, S. M.; Peters, J. C.; Jaramillo, T. F., Benchmarking Hydrogen Evolving Reaction and Oxygen Evolving Reaction Electrocatalysts for Solar Water Splitting Devices. Journal of the American Chemical Society 2015, 137 (13), 4347-4357. 


\section{CURRICULUM VITA}

NAME:

ADDRESS:

DOB:

EDUCATION

\& TRAINING:

AWARDS:

PROFESSIONAL SOCIETIES:

PUBLICATIONS:
Jacob Michael Strain

332 Kenilworth Rd.

Louisville, KY 40206

Bowling Green, Kentucky - January 6, 1989

B.S., Investigative Biotechnology Minor in Chemistry

Western Kentucky University

2007-2012

Ph.D., Chemistry

University of Louisville, Louisville

2015-2020

First Place Graduate Student Oral Talk in Analytical/Physical

Chemistry Division Kentucky Academy of Sciences 2016 Annual Meeting

Second Place \$150 prize 2019Student Research Exposition Speed Engineering

Society for Electroanalytical Chemistry

Pulsed electrochemical carbon monoxide reduction on thick oxide-derived copper. Jacob M. Strain, Saumya Gulati, Sahar Pishgar, Joshua M. Spurgeon. ChemSusChem 2020, Just Accepted.

Exploiting Metal-Ligand Cooperativity to Sequester, Activate, and Reduce Atmospheric Carbon Dioxide with a Neutral Zinc Complex. Steve P. Cronin, Jacob M. Strain, Mark S. Mashuta, Joshua M. Spurgeon, Robert M. Buchanon and Craig A. Grapperhaus. Inorganic Chemistry 2020, Just Accepted.

Assessing contaminants from ion-exchange membranes in the evaluation of aqueous electrochemical carbon dioxide 
reduction. Jacob M. Strain, Joshua M. Spurgeon. Journal of CO2 Utilization 2020, 35, e298-e302.

Investigation of the photocorrosion of n-GaP photoanodes in acid with in-situ UV-Vis spectroscopy. Sahar Pishgar, Jacob Strain, Saumya Gulati, Gamini Sumanasekera, Gautam Gupta, Joshua Spurgeon. Journal of Materials Chemistry A 2019, 7, 25377-25388.

Synthesis, Characterization, and HER Activity of Pendant Diamine Derivatives of NiATSM. Caleb A. Calvary, Oleksandr Hietsoi, Jacob M. Strain, Mark S. Mashuta, Joshua M. Spurgeon, Robert M. Buchanan, Craig Alan Grapperhaus. European Journal of Inorganic Chemistry 2019, 33. 157

Effect of Stacking Interactions on the Translation of Structurally Related Bis-thiosemicarbazone Ni(II) HER Catalysts to Modified Electrode Surfaces. Nicholas Vishnosky, Alexander Gupta, Rahul Jain, Jacob Strain, Joshua Spurgeon, Yaroslaw Losovyj, Mark Mashuta, Robert Buchanan, Gautum Gupta, Craig Grapperhaus, Inorganic Chemistry 2019, 58, 18.

Photocatalytic hydrogen evolution on Si photocathodes modified with bis(thiosemicarbazonato)nickel(II)/Nafion. Saumya Gulati, Olexsandr Hietsoi, Caleb A. Calvary, Jacob M. Strain, Sahar Pishgar, Henry C. Brun, Craig A. Grappherhaus, Robert M. Buchanan, Joshua M. Spurgeon. Chemical Communications 2019, 55, 9440-9443.

Precise control in photovoltaic response of Poly(3hexylthiophene): Fullerene solar cells via accelerated-solvent vapor annealing. Soundaram J. Ananthakrishnan, Swapnil Sahare, Jacob Strain, Manda Venkataramana, Muhammad Jahan, Hemali Rathnayake. Science Advances Today 2018, 4, 25279.

Heterogeneously catalyzed two-step cascade electrochemical reduction of CO2 to ethanol. Nolan Theaker, Jacob M. Strain, Bijandra Kumar, Joseph P. Brian, Sudesh Kumari, Joshua M. Spurgeon. Electrochimica Acta 2018, 274, 1-8.

Photoelectrochemical Reduction of $\mathrm{CO} 2$ to $\mathrm{HCOOH}$ on Silicon Photocathodes with Reduced SnO2 Porous Nanowire Catalysts. K. Ramachandra Rao, Sahar Pishgar, Jacob M. Strain, Bijandra Kumar, Veerendra Atla, Sudesh Kumari, Joshua Spurgeon. Journal of Materials Chemistry A 2018, 6, 1736-1742. 
A Novel Donor-Donor Polymeric Dyad of Poly(3Hexylthiophene-Block-Oligo(Anthracene-9,10-Diyl): Synthesis, Solid-State Packing, and Electronic Properties. Soundaram J. Ananthakrishnan, Jacob Strain, Niharika Neerudu Sreeramulu, Abu Mitul, Louis E. McNamara, Anastasiia Iefanova, Nathan I. Hammer, Qiquan Qiao, Hemali Rathnayake. Journal of Polymer Science Part A: Polymer Chemistry 2016, 54, 3032-3045.

Synthesis, Characterization, and Structure of Some New Substituted 5, 6-Fused Pyridazines. Chad A. Snyder, Nathan C. Tice, Phenahas G. Sriramula, James L. Neathery, Justin K. Mobley, Chad L. Phillips, Andrew Z. Preston, Jacob M. Strain, Eric S. Vanover, Michael P. Starling, Nilesh V. Sahi. Synthetic Communications 2011, 41, 9.

NATIONAL MEETING PRESENTATIONS:

Pulsed Electrochemical Carbon Monoxide Reduction on OxideDerived Copper Catalyst. January 2020 Gordon Research Conference: Electrochemistry, Ventura, CA. Jacob M. Strain, Saumya Gulati, Sahar Pishgar, Joshua Spurgeon (Poster)

Ultrafast Transient Absorption Spectroscopy Investigation of Photoinduced Dynamics in Poly(3-hexylthiophene)-blockoligo(anthracene-9,10-diyl). Jacob Strain, Hemali Rathnayake, Jinjun Liu. International Symposium of Molecular Spectroscopy 2017. (Talk)

Ultrafast Transient Absorption Spectroscopy Investigation of Photoinduced Dynamics in Novel Donor-Acceptor Core-Shell Nanostructures for Organic Photovoltaics. Jacob Strain, Thulitha M. Abeywickrama, Hemali Rathnayake, Jinjun Liu; 2017 American Chemical Society Annual Meeting San Francisco. (Talk)

REFEREED JOURNALS: Journal of CO2 Utilization Communications Chemistry Chemical Engineering Journal Journal of Materials Chemistry A 